\title{
Blood coagulation and diabetic vascular complications
}

Citation for published version (APA):

Hansen, H. R. (2007). Blood coagulation and diabetic vascular complications. [Doctoral Thesis, Maastricht University]. Maastricht University. https://doi.org/10.26481/dis.20070209hh

Document status and date:

Published: 01/01/2007

DOI:

10.26481/dis.20070209hh

Document Version:

Publisher's PDF, also known as Version of record

\section{Please check the document version of this publication:}

- A submitted manuscript is the version of the article upon submission and before peer-review. There can be important differences between the submitted version and the official published version of record.

People interested in the research are advised to contact the author for the final version of the publication, or visit the DOI to the publisher's website.

- The final author version and the galley proof are versions of the publication after peer review.

- The final published version features the final layout of the paper including the volume, issue and page numbers.

Link to publication

\footnotetext{
General rights rights.

- You may freely distribute the URL identifying the publication in the public portal. please follow below link for the End User Agreement:

www.umlib.nl/taverne-license

Take down policy

If you believe that this document breaches copyright please contact us at:

repository@maastrichtuniversity.nl

providing details and we will investigate your claim.
}

Copyright and moral rights for the publications made accessible in the public portal are retained by the authors and/or other copyright owners and it is a condition of accessing publications that users recognise and abide by the legal requirements associated with these

- Users may download and print one copy of any publication from the public portal for the purpose of private study or research.

- You may not further distribute the material or use it for any profit-making activity or commercial gain

If the publication is distributed under the terms of Article $25 \mathrm{fa}$ of the Dutch Copyright Act, indicated by the "Taverne" license above, 
Blood coagulation

and

diabetic vascular complications 
Hjalmar R. Hansen, Maastricht - Amsterdam 2007

ISBN: $\quad 978-90-9021552-5$

Layout: Hjalmar R. Hansen - Henri M.H. Spronk

Production: Datawyse by / Universitaire Pers Maastricht

All rights reserved. No part of this thesis may be reproduced, stored in a retrieval system or transmitted in any form or by means, without the permission in writing from the author, or, when appropriate, of the publishers of the publications. 
Blood coagulation

and

diabetic vascular complications

\section{PROEFSCHRIFT}

Ter verkrijging van de graad van doctor aan de Universiteit Maastricht

op gezag van de Rector Magnificus, Prof. Mr. G.P.M.F. Mols,

volgens het besluit van het College van Decanen,

in het openbaar te verdedigen

op vrijdag 9 februari 2007 om 12:00 uur

door

Hjalmar R. Hansen

Geboren op 13 februari 1973 te Amsterdam 


\section{Promotor}

Prof. Dr. H. ten Cate

Prof. Dr. P.H. Reitsma (Universiteit van Amsterdam)

\section{Copromotor}

Dr. H.M.H. Spronk

\section{Beoordelingscommissie}

Prof. Dr. C.D.A. Stehouwer (voorzitter)

Prof. Dr. M.P. van Dieijen-Visser

Prof. Dr. M.H. Prins

Prof. Dr. J. Rosing

Prof. Dr. J.L. Waltenberger

Financial support by the Netherlands Heart Foundation for the publication of this thesis is
gratefully acknowledged 
I may not have gone where I intended to go, but I think I have ended up where I needed to be.

Douglas N. Adams

(1952-2001) 


\section{Contents}

1 Introduction

2 Soluble tissue factor is a candidate marker for progression of microvascular disease in patients with type 2 diabetes

3 The prognostic significance of QRS and QTc interval prolongation in a Dutch type-2 diabetes population

4 Detection of advanced glycated end products (AGEs) in urine from patients with type 2 diabetes: a pilot cohort study

5 Circulating Matrix Gla protein: a potential marker for vascular complications of type 2 diabetes mellitus

6 Lessons from mouse models for arterial thrombosis: does clotting make a difference in human cardiovascular disease?

7 Hyperglycemia accelerates arterial thrombus formation in vivo

8 Differential expression of tissue factor mRNA and protein expression in murine sepsis: the role of the granulocyte revisited

9 Prolonged systemic inhibition of thrombin does not diminish nephropathy in diabetic mice

10 General discussion, summary and conclusions 147

Algemene samenvatting

Curriculum vitae 
Chapter 1

Introduction

Hjalmar R. Hansen • Henri M.H. Spronk • Pieter H. Reitsma • Hugo ten Cate 


\section{Epidemiology and clinical aspects}

The discovery of insulin by Banting and Best in the early 1920 s was a milestone of medicine in the $20^{\text {th }}$ century and contributed to two major findings. The first was that the hyperglycemia of diabetes had two distinct origins occurring in the absence or presence of circulating insulin, leading to the postulation of two forms of diabetes. The second major finding was that the response or 'sensitivity' of individuals to the glucose lowering action of insulin could vary greatly, which led to the recognition of insulin resistance. Based on these findings, diabetes can be roughly distinguished in two main types; type-1, or insulin dependent diabetes, and type-2, or insulin independent diabetes. Type-1 diabetes mainly occurs in the young age and is an autoimmune disease which is caused by destruction of the insulin producing $\beta$-cells of the pancreas, resulting in complete insulin deficiency. The absence of insulin in the circulation is responsible for an inadequate transport of glucose from blood to tissues, resulting in high blood glucose levels and diminished glucose reserve in tissue. The treatment of patients with type- 1 diabetes consists of administering exogenous insulin to prevent the development of ketoacidosis.

Type-2 diabetes is a disease which is characterized by the clustering of metabolic abnormalities in the presence of underlying insulin resistance, caused by defects in the uptake, metabolism and /or storage of glucose by the celli. The pancreas will increase its endogenous insulin production to compensate for this relative insulin shortage which results in a state of hyperinsulinemia and relatively normal blood glucose levels. In later stages of the disease pancreatic $\beta$-cells lose their capacity to produce enough insulin to cope with the insulin resistance and blood glucose levels start to increase above normal levels. Early clinical symptoms in type-2 diabetes are mainly caused by this hyperglycaemic state and include polyuria and polydipsia. The therapeutic approach to type-2 diabetes is to encourage weight loss by means of diet and increased physical exercise, in combination with oral medication that reduces insulin resistance. When lowering insulin resistance with medication and physical exercise becomes insufficient, a combination of exogenous insulin and insulin resistance lowering medication is necessary.

Diabetes mellitus was long considered a disease of minor significance to world health, but is now recognized as one of the main threats to human health in the $21^{\text {st }}$ century ${ }^{2}$. Worldwide, over 135 million individuals are affected by any form of diabetes $^{3}$ where type-2 diabetes patients account for about $90 \%$ of the cases. During the past two decades a dramatic increase in the number of people diagnosed with diabetes has occurred world wide ${ }^{4}$. Pronounced changes in the environment and in human behaviour and lifestyle have accompanied globalization, and these have resulted in escalating rates of obesity and diabetes ${ }^{4}$. The prevalence of diabetes (including type- 1 and -2 ) in the Dutch population is estimated at about 500.000 individuals 5,6 . 
The diabetes epidemic relates particularly to type-2 diabetes and is taking place in both developed and developing nations ${ }^{4}$. This epidemic is partly caused by the advances made in modern medicine, with people living longer owing to elimination of many of the communicable diseases ${ }^{4}$.

Metabolic syndrome is a constellation of risk factors of metabolic origin that determine the increased risk for cardiovascular disease and type-2 diabetes. These risk factors are atherogenic dyslipidemia, elevated blood pressure, elevated blood plasma glucose, a prothrombotic state, and a proinflammatory state. The two major underlying risk factors for metabolic syndrome are obesity and insulin resistance; exacerbating factors include physical inactivity, advancing age, and endocrine and genetic factors. In many patients, metabolic syndrome culminates in type- 2 diabetes, which further increases the risk for cardiovascular disease. Epidemiologic studies have shown the importance of metabolic syndrome in type- 2 diabetes. When these conditions co-exist, as is commonly observed, the prevalence of coronary disease reaches about $20 \% 7$.

Besides the short term aspects, like polyuria and polydipsia, type- 2 diabetes is a substantial cardiovascular risk factor causing an increased morbidity and mortality in this population. Vascular disease in diabetes is usually differentiated in microvascular and/or macrovascular disease, where the former is characterized by diabetic retinopathy and nephropathy and the latter by medium-large vessel disease including ischemic coronary, cerebrovascular and peripheral artery disease. The prevalence of diabetic renal disease in the North American and European population surveys is between 6 to $10 \%{ }^{8}$. In about $20-40 \%$ of patients with type-2 diabetes and microalbuminuria, renal impairment was shown to progress to overt nephropathy in the absence of specific interventions. Microalbuminuria approximately doubles the risk of a cardiovascular event in patients with type-2 diabetes after adjusting for other risk factors ${ }^{9} 10$. Elevated rates of urinary albumin excretion also predict the onset of renal disease but have also been related to left ventricular dysfunction of the heart, stroke and myocardial infarction ${ }^{11,12}$. Thus, screening for microalbuminuria is recommended and should be a priority in clinics caring for diabetic patients.

Histological studies of coronary artery atheroma from diabetic subjects report more extensive lesions with a higher prevalence of inflammatory and thrombotic changes compared to specimens from non-diabetic subjects ${ }^{13}$. In general, the risk of incident or fatal coronary heart disease is $2-4$ fold higher in people with diabetes than in those without 14,15. Furthermore, long-term prognosis after a coronary event is significantly worse among people with diabetes than those without ${ }^{16}$. The high risk in these patients is often attributable to the presence of one or more factors comprising the metabolic syndrome17. The fact that patients with type- 2 diabetes and no prior history of coronary disease have an equivalent risk of developing 
myocardial infarction as non-diabetics with a prior myocardial infarction ${ }^{18,19}$ shows that the presence of diabetes itself can be considered an important risk factor.

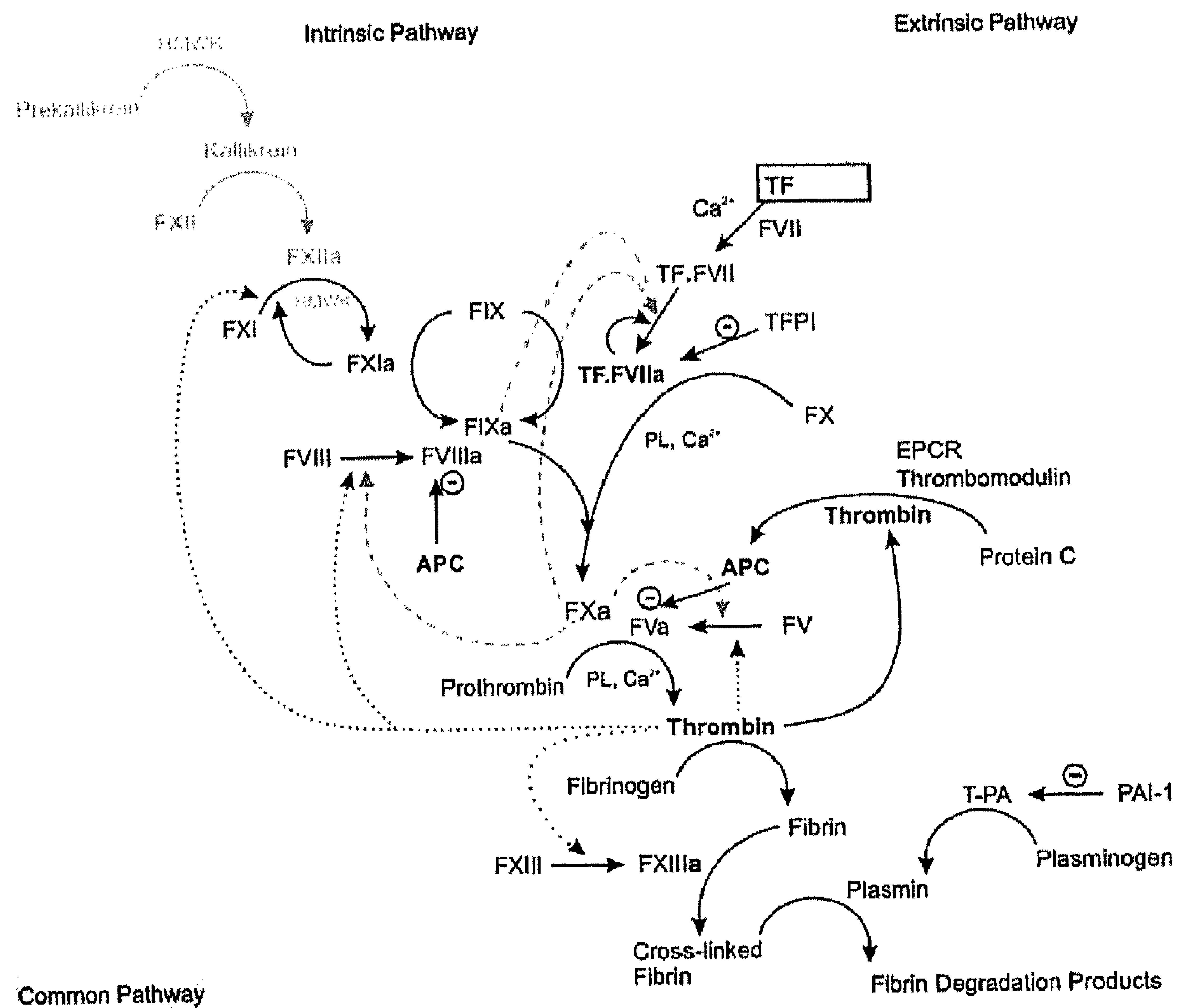

Fibrinolysis

Figure 1

Schematic overview of the blood coagulation cascade. The model is divided in the intrinsic, extrinsic, and common pathway. F\#\#\#: blood coagulation factor denoted in Roman numerals. Active forms are denoted by a small ' $a$ ' added to the Roman number. TF: tissue factor. PL: phospholipid. HMWK: high molecular weight kininogen. Positive feedback loops by thrombin (dotted lines), FIXa (dashed-dotted line), and FXa (dashed line) are indicated in grey. $\Theta$ indicates inhibition by activated protein C (APC) and tissue factor pathway inhibitor (TFPI).

Because of the premature morbidity and mortality associated with diabetes, prevention of complications is a key issue. Interventional studies such as the United Kingdom Prospective Diabetes Study ${ }^{20}$ and the Diabetes Control and Complications Trial21,22 provided scientific evidence that good glycemic control is beneficial for the prevention of diabetes-related complications, as is appropriate therapy for hypertension and dyslipidemia. These studies show the importance of hyperglycemia as a risk factor for thrombogenic complications in diabetes.

To lower the incidence of cardiovascular complications in type- 2 diabetes it is necessary to screen these patients for known risk factors for cardiovascular disease 
and treat them accordingly. A better understanding of the mechanisms that precede or accompany these complications may lead to better treatment and a lowering of cardiovascular mortality and morbidity.

\section{Blood coagulation and diabetic vascular disease}

The enhanced risk of atherothrombotic vascular events in type-2 diabetes is thought to result from accelerated atherosclerosis in combination with a hypercoagulable state (increased clotting, platelet reactivity and reduced fibrinolysis), endothelial dysfunction and abnormal bloodflow ${ }^{23,24}$. These changes reflect the elements of Virchow's triad, formulated more than 150 years ago 25 . The essential components of this triad include abnormalities of the vessel wall, changes in blood constituents and irregularities of blood flow.

Physiologically, a balance between the coagulation and fibrinolytic pathways (Figure 1) is necessary to maintain hemostasis and to protect from excessive bleeding during injury, and at the same time to maintain blood fluidity within the vascular system. Pathophysiological perturbation of this system occurs in many acute and chronic diseases; in type-2 diabetes many of the components of both the coagulation and fibrinolytic systems are altered, although the data from different studies are not consistent.

Increased activation of the plasmatic coagulation mechanism depends on the availability of the procoagulant transmembrane protein tissue factor on a phospholipid membrane. In normal circumstances, very low concentrations of tissue factor are exposed to circulating blood, which is sufficient to generate the low level of thrombim that is normally present 26,27 . In arterial vascular disease tissue factor becomes abundantly expressed in atherosclerotic plaque lesions, where it retains procoagulant activity. Upon rupture of the plaque this tissue factor becomes one of the triggers for acute atherothrombosis ${ }^{28}$. In diabetes mellitus, tissue factor is also found in arterial plaque lesions ${ }^{29}$ but it is uncertain whether the amount or activity is different from arterial plaques in non-diabetic individuals.

In recent years much attention has been given to the identity and putative role of soluble tissue factor. The concentration of tissue factor antigen (defined as soluble molecules detected by a commercial ELISA) is elevated in plasma from patients with type-2 diabetes ${ }^{30,31}$. Elevated soluble tissue factor levels in plasma may be a consequence of increased synthesis of this procoagulant molecule. Indeed, monocytes express tissue factor mRNA upon stimulation with glycated albumin. This form of albumin is a consequence of chronic hyperglycemia ${ }^{32,33}$. Theoretically, other cells, including vascular endothelial cells, may be involved in tissue factor synthesis, but direct evidence is lacking. One of the major debates in coagulation research is the relevance of circulating (soluble) tissue factor for clotting. For efficient catalytic factor VIIa-tissue factor complex formation, the presence of both 
intact tissue factor and phospholipids is essential. Although tissue factor is detectable on phospholipid-rich microparticles in plasma from patients with type 2 diabetes $^{34,35}$ it is questionable whether these particles are sufficient to drive coagulation activity in plasma. Estimations of the concentrations of tissue factor molecules in plasma do not provide support for a significant role of the blood borne soluble tissue factor pool in coagulation, although it remains possible that local conditions where tissue factor rich-microparticles accumulate at site of plaque lesions may be optimal to promote thrombosis in a tissue factor dependent manner ${ }^{36,37}$. For the time being, the role of tissue factor as a circulating procoagulant molecule remains to be established. At the same time, soluble tissue factor appears to be an interesting marker of microvascular disease in type $2^{38}$.

In addition to being initiated, propagation of the plasmatic coagulation system depends on different factors including concentration of clotting proteins (e.g. prothrombin concentration), rate of conversion of zymogen to enzyme (determined by factors such as the availability of a catalytic phospholipid surface) and rate of inactivation of coagulation proteases (dependent on availability of natural anticoagulants).

In type-2 diabetes concentrations of particular coagulation proteins, including fibrinogen ${ }^{39,40}$ factor VII 41,42 and factor VIII activity ${ }^{43}$, may be elevated as compared to non-diabetic individuals. Although these particular proteins may not be major determinants for the rate of thrombin generation, one of the key reactions in the coagulation cascade, a specific contribution to clot stability has been proposed. Upon conversion of fibrinogen to fibrin followed by formation of a polymerized fibrin clot, thrombin diffuses into the $\operatorname{clot}^{44}$ where it binds to fibrin and becomes inaccessible to inhibition by antithrombin 45 . The result is that thrombin remains catalytically active, thereby allowing the clot to grow. In relation to clot stability, fundamental work has been carried out by Peter Grant's laboratory showing that clots, formed in vitro from fibrinogen purified from plasma from type-2 diabetic patients, had a less porous structure than those form control individuals. Importantly, these structural changes were related to the level of glycemic control46. One of the factors that may contribute to clot stability is a more efficient activation of fibrinogen by thrombin indicated by a significant increase in fibrinopeptide $B$ cleavage from fibrinogen 46 . In addition, factors associated with clot lysis are important in clot stability (as outlined below).

Ongoing research from our group confirms that the fibrinogen concentration is one of the main determinants for thrombin generation in plasma47. This effect of fibrinogen may be explained from the interaction between thrombin and fibrin causing alterations in diffusion factors, substrate conversion, or interactions with antithrombin 44 . Structural features of fibrinogen molecules also appear to play a role. Standeven and colleagues ${ }^{48}$ showed that the fibrinogen Aa Thr312Ala polymorphism within the aC domain of fibrinogen, which is important for lateral 
aggregation and factor XIII-induced cross-linking of fibrin fibres, resulted in larger fibre diameters in the Ala312 clots and fewer fibres per square micrometer. Although this particular polymorphism has not been studied in relation to diabetic vascular disease, one might assume that both fibrinogen concentration and composition are important contributors to clot stability in diabetes.

In addition to the concentration of clotting proteins, the rate of conversion determines clot formation. Prothrombin activation fragment $1+2(F 1+2)$ is released when prothrombin is cleaved and the plasma concentrations of this peptide have been reported to be increased in type- 2 diabetes, reflecting accelerated thrombin generation 43,49 . In contrast, in a cohort study (chapter 2) we did not observe any increased rate of thrombin generation with this assay ${ }^{38}$.

Once formed, free thrombin is rapidly inactivated by antithrombin, through formation of thrombin-antithrombin complexes (TAT) which are also indicators of coagulation system activity and appear to be increased in diabetes $50-52$. Overall, a tendency towards increased thrombin generation may be observed in type-2 diabetes, of which the causes are still unknown. One determinant of thrombin generation may be platelet reactivity, contributing to more efficient formation of prothrombinase complex at the platelet surface.

Another factor influencing overall coagulation activity is the natural anticoagulant network. Antithrombin is a broad spectrum serine protease inhibitor that inhibits the activity of multiple serine proteases of the coagulation pathway. Factors XIIa, XIa, IXa, Xa and thrombin are serine proteases that are all inhibited by antithrombin. A number of studies demonstrate normal41 or increased levels of antithrombin ${ }^{39,53}$ in association with diabetes. The significance, if any, of increased concentrations of antithrombin in relation to its inhibitory potential is, however, unknown.

Co-factors Va and VIIIa are not inhibited by antithrombin, but are under control of the protein $\mathrm{C}$ pathway. Protein $\mathrm{C}$ is a vitamin $\mathrm{K}$-dependent protein produced by the liver circulating in an inactive form until it is activated by thrombin in complex with the endothelial cell receptor thrombomodulin. Activated protein C (APC) proteolytically inactivates factors $\mathrm{Va}$ and VIIIa, limiting further generation of thrombin. Besides the direct influence on coagulation, APC appears to regulate inflammatory processes in part by blocking the activity of the transcription factor nuclear factor $(\mathrm{NF})-\mathrm{kB}$, by inhibiting proinflammatory cytokines production and limiting thrombin generation ${ }^{54,55}$, at least in vitro. Whether these anti-inflammatory actions of APC, presumably mediated via protease activated receptor 1 (PAR-1) and endothelial protein $\mathrm{C}$ receptor (EPCR), play any role of significance in vivo remains to be established56.

Several studies of patients with type- 2 diabetes have reported a possible relationship between hyperglycemia and downregulation of the protein $\mathrm{C}$ system ${ }^{57-}$ 59. These observations relate to various aspects of the protein $\mathrm{C}$ system including 
reduced availability of cell associated thrombomodulin, such as has been documented in human atherosclerotic lesions, and which may correspond with increased soluble thrombomodulin in type-2 diabetes, especially in patients with microangiopathy 51,60 . Another aspect is reduced sensitivity to the inhibitory effects of APC, so called APC resistance ${ }^{42}$. Although APC resistance is well known to occur in relation to the factor $\mathrm{V}$ Leiden mutation, it may also have an acquired basis, due to variations in the concentrations of the pro- and anticoagulant proteins involved in the test system. Acquired APC resistance, however, is not a test artefact, but has clinical significance in relation to the risk of for instance venous thrombosis ${ }^{61}$. It is plausible that this phenomenon also entails a risk of arterial thrombotic events in patients with diabetes.

Factor VIIa is a serine protease that is only poorly inactivated by antithrombin 43 . Tissue factor pathway inhibitor (TFPI) serves as the most important inhibitor by forming a quaternary complex with the tissue factor- factor VIIa-factor Xa complex, shutting off the procoagulant activity of the tissue factor- factor VIIa complex towards factors IX and $\mathrm{X}^{62}$. Recent evidence shows that protein $\mathrm{S}$ is a cofactor for the interaction between TFPI and the tissue factor-factor VIIa- factor Xa complex ${ }^{63}$. The regulation of TFPI production, which appears in three different compartments in blood (endothelial cell associated, lipoprotein associated and free forms), is poorly understood. Measured as overall plasma concentration TFPI activity is positively correlated with blood glucose levels and is higher in more severe cases of diabetes and in patients with diabetic complications ${ }^{64,65}$. It is however unknown what the clinical significance of these observations is in terms of the inhibitory potential of TFPI on clotting activity. The fact that TFPI interacts with lipoproteins including very low density lipoproteins may modulate the availability of the inhibitor for attenuating coagulation but the net effect is still unknown.

\section{Fibrinolysis in diabetes mellitus.}

In order to limit fibrin accretion in the vasculature the blood carries several proteins that reduce the size of the polymerized fibrin clot. Hence, vascular endothelial cells release tissue plasminogen activator (tPA) which binds to the fibrin clot via its fibrin binding site. Plasminogen is produced by the liver and circulates in its inactive form until clotting occurs. After formation of fibrin, plasminogen binds via its fibrin receptor and upon binding of plasminogen and tPA to fibrin, conversion of plasminogen to plasmin rapidly occurs. Once activated, plasmin degrades the cross-linked fibrin gradually releasing fibrin degradation products, one of which is the D-dimer fragment.

tPA activity is negatively controlled by plasminogen activator inhibitor type-1 (PAI1). In diabetes plasma antigen levels of tPA have been reported to be normal to high 
$41,51,66$, while tPA activity appears to be attenuated 66 , indicating a state of impaired fibrinolysis. Increased levels of tPA antigen predicted the development of urinary albumin excretion, a strong marker for cardiovascular disease64,67 . Levels of PAI-1 are found to be increased in type-2 diabetes 64,68 , and insulin levels are directly correlated with PAI- 1 and inversely correlated with tPA activity ${ }^{69}$. Together with increased levels of fibrin degradation products like D-dimers in type-2 diabetes 51,70 these shifts in fibrinolysis lead to a state of decreased clot lysis in diabetes. It has been shown that adipocytes and probably also hepatocytes are involved in PAI-1 production under influence of pro-inflammatory cytokines such as tumor necrosis factor $a^{71}$. Reduction of body fat mass by liposuction or bariatric surgery indeed lowers plasma inflammatory markers and PAI-1 concentrations. Thus, PAI- 1 can be considered a marker for metabolic syndrome and it probably also plays a functional role as one of the key inhibitors of fibrinolysis. The latter remains, however, a debated issue from a clinical perspective. Surprisingly, no clinical studies demonstrate a major influence of PAI- 1 concentration or of polymorphisms in the PAI- 1 gene (such as the PAI-1 $-6754 \mathrm{G} / 5 \mathrm{G}$ )in relation to risk of arterial thrombotic events, neither in diabetic patients nor in the general population 72 .

Other features of fibrinolysis may also be of interest in plasma from patients with diabetes. Recent work indicates that lysis of diabetic clots made of plasma from these patients (rather than from purified proteins) is much slower than lysis of clots made of plasma from normal individuals ${ }^{46}$. Added to the aforementioned observations on fibrinogen, thrombin formation and clot stability, it appears that also fibrin clot breakdown may be impaired in diabetes. It now becomes of interest to establish the clinical relevance of these observations in terms of risk factor analysis and predictive value of clot lysis diagnostic tests (such as modern applications of thromboelastography). .

\section{Platelet function in diabetes mellitus}

Platelets form a primary defence mechanism when the integrity of vasculature is lost. Adherence of platelets to the site of injury is triggered by (subendothelial) proteins including collagen and von Willebrand factor (vWF) ${ }^{73}$ (Figure 2). vWF is produced by vascular endothelial cells and stored in Weibel Palade bodies. A fraction of vWF is also stored in platelet organelles and secreted upon activation. In blood, vWF circulates in complex with factor VIII for which it is a carrier protein. The concentration of vWF is often increased in patients with type- 2 diabetes 40,70 and in large studies such as the Hoorn Study, vWF concentration is an independent risk factor for cardiovascular and all cause mortality, in diabetic (and non-diabetic) individuals ${ }^{74}$. It is still unclear how elevated VWF in plasma should be interpreted. Most likely it should primarily be seen as a reflection of endothelial cell activation, similar to soluble thrombomodulin. Whether increased vWF concentrations also 
reflect increased production by the endothelium, which could theoretically have consequences for platelet adhesion and activation, is unknown. A current subject of interest is the role of the VWF cleaving protease ADAMTS 13. Although this protease, that cleaves vWF multimers into single chain proteins, has been particularly associated with thrombotic thrombocytopenic purpura, it is possible that variations in its production or function, have consequences for the concentration of circulating vWF in other conditions like diabetes ${ }^{75}$.

Platelets that adhere to subendothelial proteins become activated by thrombin, tromboxane $\mathrm{A} 2$ and other agonists and express glycoproteins including IIb/IIla that bind fibrinogen, allowing platelets to form aggregates 76 . Diabetes causes a number of structural and functional alterations in platelets 77,78 . One of the first described abnormalities in platelet function was that platelets from diabetic patients appeared to be 'stickier' than platelets from non-diabetic controls79. A second observation that was made is the increase in main platelet volume in patients with type-2 diabetes ${ }^{80}$ as well as the correlation between platelet volume and the number of platelet glycoprotein Ib molecules81, which may have implications for platelet function. Platelet function appears to be altered in diabetes in a number of different ways that have been recently reviewed82,83. Overall, platelets appear to be hyperresponsive to what are normally subthreshold concentrations of agonists. Elevated glucose levels and glycated low density lipoproteins and hyperinsulinemia may impair calcium homeostasis, inhibit platelet membrane ATPase activity, activate protein $\mathrm{C}$ kinase, impair NO production and increase reactive oxygen species production. In concert, these functional changes may explain the increased reactivity of platelets in diabetes. In patients with newly diagnosed insulindependent diabetes mellitus, the expression of activated GPIIa/IIIb was almost 3 times higher when compared to non diabetics ${ }^{84}$. A recent meta-analysis shows that inhibitors of the GPIIa/IIIb receptor significantly lower the mortality in patients with type-2 diabetes after an acute coronary event, while this effect was not seen in nondiabetic subjects ${ }^{85}$, which suggests that this mechanism is of particular importance in diabetic patients.

Platelets synthesise a potent aggregation stimulating factor, thromboxane $A_{2}$. The excretion rate of 11-dehydro- $\mathrm{TxB}_{2}$, its major metabolite, is significantly higher in patients with type-2 diabetes and decreases with insulin therapy ${ }^{86}$. Although no specific studies with acetylsalicylic acid (aspirin), an inhibitor of the production of thromboxane $A_{2}$, have been carried out in diabetics, the beneficial effect of this therapy in reducing cardiovascular complications and death in the general population including those with type-2 diabetes patients, has been shown by several large population studies ${ }^{87-89}$. 


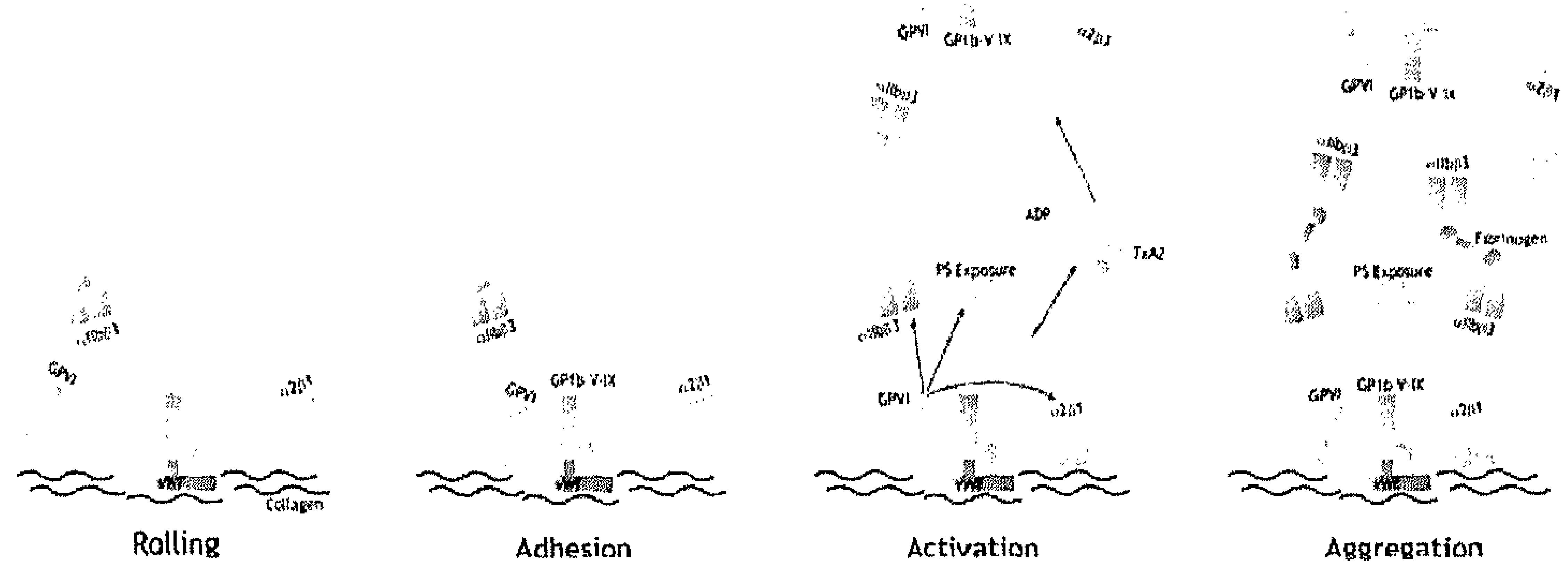

Figure 2

Schematic drawing of platelet collagen interaction, leading to platelet activation and thrombus formation. Upon vessel wall damage, rolling platelets interact with the subendothelial collagen via von Willebrand factor which activates its platelet receptor glycoprotein (GP)Ib-V-IX which initiates platelet rolling. Subsequent stable adhesion of platelets to the vessel wall occurs after binding glycoprotein VI (GPVI) and integrin $\alpha 2 \beta 1$. GPVI binding leads to activation of integrins $\alpha 2 \beta 1$ and $\alpha$ bII $\beta 3$, and phosphatidyl-scrine (PS) exposure on the platelets outer membrane, which forms a catalytic surface for the formation of factor Xa and thrombin. Activated platelets secrete autocrine agents like ADP and thromboxane A2 (TXA2), which together with thrombin leads to the activation of other platelets. Activated platelets form aggregates through cross-linking of fibrinogen bound to integrin $\alpha b l i \beta 3$. This aggregate is stabilized by crosslinking of platelets via fibrine which is formed out of fibrinogen through activity of thrombin.

In summary, blood coagulation appears to be influenced by diabetes type 2 in many different ways. Causal factors may be both related to hyperglycemia, or more precise variations in glucose concentration, as well as a number of metabolic factors that contribute to enhanced ROS activity, AGE formation, endothelial cell perturbation, enhanced PAI-I production etcetera. Basically all three components of blood coagulation, i.e. primary haemostasis, coagulation and fibrinolysis are affected in a direction of increased clot formation and reduced clot breakdown. The net effect probably explains the high risk of atherothrombotic events in diabetes.

\section{Blood coagulation and links to other aspects of pathophysiology of diabetes}

The candidate causal factors of hypercoagulability in diabetes include hyperglycemia, chronic inflammation associated with metabolic syndrome, and advanced glycation endproducts (AGEs). AGEs are formed upon interaction between reducing sugars and biological amines through a series of oxidative and nonoxidative reactions. Glucose in tissue is metabolized to 3-deoxyglucosone (3-DG), methylglyoxal (MG), and $N^{\varepsilon}$-(carboxymethyl)lysine (CML) 90. Because of their stability, glycated proteins accumulate slowly over a person's lifespan and thus can contribute to age-associated structural and physiological changes in the 
cardiovascular system such as increased vascular and myocardial stiffness, endothelial dysfunction, altered vascular injury responses, and atherosclerotic plaque formation. The mechanisms by which AGEs affect the cardiovascular system include collagen cross-linking, alteration of low-density lipoprotein molecules, and impairment of cellular nitric oxide signalling through their interaction with AGE receptors (RAGEs). Thus, the accumulation of AGEs may help to explain the increased risk of cardiovascular disease associated with ageing as well as with diabetes mellitus and hypertension, two conditions that accelerate and enhance AGE formation. It was shown that atherosclerotic plaques from type-2 diabetes patients are characterized by an increased amount of AGEs and an increased expression of the AGE receptor (RAGE) ${ }^{91}$, although a study from our institution showed an approximately equal immunohistochemical signal for AGE in advanced plaques from diabetic and matched non-diabetic individuals, suggesting that ageing and accelerated atherosclerosis as such are related to AGE generation and accumulation $^{29}$. RAGE levels also correlated with higher levels of glycosylated hemoglobin $\left(\mathrm{HbA}_{1 \mathrm{c}}\right)$ and an unstable plaque phenotype ${ }^{91}$.

In vitro studies have shown that AGE-RAGE binding on macrophages and microglia leads to oxidant stress and activation of the transcription factor NF-kB ${ }^{22}$. This activation can promote the generation of pro-inflammatory cytokines like IL-1a, IL-6 and TNFa and promote a procoagulant state by modulating gene transcription for tissue factor and thrombomodulin ${ }^{93}$. The latter interactions may be relevant to activation of the coagulation system in diabetes, as discussed in the previous section.

Recent studies show that AGEs induce chymase via the RAGE-ERK 1/2 MAP kinase pathway 94,95 . Chymase is an alternative pathway for generating angiotensin II, which in turn is a key mediator of diabetic vascular disease 96,97 ,

Diabetic nephropathy is a common and serious complication of diabetes that in the time before the introduction of angiotensin converting enzyme (ACE) inhibitors led to a substantial degree of renal failure. Diabetes is estimated to increase the risk of end-stage renal disease approximately 12-fold98. Epidemiologic studies have demonstrated that the risk for developing diabetic nephropathy is higher in patients with poor metabolic contro199,100. Diabetic nephropathy is characterized by specific histological features, including thickening of the capillary basement membrane of the glomeruli and mesangial matrix increases ${ }^{101}$. The deposition of fibrin in the glomeruli of mice in experimental models of diabetes ${ }^{102,103}$ suggests that the hypercoaguble state as is present in diabetes plays a role in the pathophysiology of diabetic kidney disease. Increased levels of TF mRNA in kidneys of diabetic mice ${ }^{104}$, and locally expressed tissue factor have been demonstrated in different models of experimental kidney disease ${ }^{105,106}$. One of the histological aspects suggesting involvement of coagulation in diabetic kidney disease is locally deposited fibrin in 
glomeruli 103,104 . In comparison with other chronic kidney diseases such as glomerulonephritis, a causal contribution of activated coagulation proteases like thrombin may be expected to play a role in diabetes, but there is as yet no evidence for this assumption. While at the plasma level, elevated levels of soluble tissue factor and fibrinogen are elevated in patients with microvascular disease 31,107 the contribution of local versus plasma factors in the development of diabetic kidney disease is not yet understood.

\section{Contents of the thesis}

The research presented in this thesis focuses on two aspects of diabetes, namely first, clinical elements related to diagnosis and prognosis and second, experimental elements related to the pathophysiology of vascular disease.

In a patient cohort we investigated the relevance of an activated coagulation system for diabetic micro- and macrovascular complications. In contrast to other studies, as outlined above, we did not find convincing evidence of a "hypercoagulable state" in patients with type- 2 diabetes as compared to an apparently healthy control group (chapter 2). One of the factors that stood out was soluble tissue factor, as a marker of microvascular complications, although it remains uncertain whether this molecule has any biological significance. This diabetes cohort was also explored with two novel potential markers of vascular disease, AGEs in urine (chapter 4) and matrix Gla protein in plasma (MGP; chapter 5). Both factors have been associated with specific elements of vascular disease, including vascular wall stiffness, and in fact an interaction between AGE and MGP effects may be of importance in vascular calcification. While our study suggests that AGEs and MGP may have distinct roles in vascular complications of diabetes, further and larger studies are required to verify the diagnostic potential.

One of the tools for screening patients with type 2 diabetes for prevalent macrovascular disease is the electrocardiogram (ECG). As part of the routine workup of our patient cohort a standard 12-lead ECG was performed and we utilized the data of this screening to determine specific abnormalities in relation to vascular complications (chapter 3).

The second part of the thesis consists of a series of studies performed in mice. This animal species is commonly used, also to investigate pathophysiological aspects of complex disease, including sepsis and other inflammatory diseases (also discussed in chapter 8). Arterial thrombosis is one of the processes that are mimicked in mouse models of disease as reviewed in chapter 6 . The other animal experiments focussed again on diabetes and particularly the procoagulant effects of hyperglycemia, induced by streptozotocin injections in mice. Streptozotocin causes, by destructing beta cells in the pancreas, a hyperglycaemic condition due to insulin deficiency. We utilized this model to study the effects of hyperglycaemia on arterial 
thrombus formation in mice, in which we characterized the contributions of platelets and coagulation (chapter 7). Finally, the streptozotocin model was employed to test the effects of pharmacological inhibition of thrombin on diabetic nephropathy. Based on studies by others we assumed that local tissue factor and thrombin generation would contribute to nephropathy due to thrombin mediated PAR-1 signalling effects. Prolonged treatment with the thrombin inhibitor ximelagatran did not, however, diminish nephropathy determined as mild histological abnormalities and increased fibrin staining (chapter 9). Finally, in chapter 10 the main results are summarized and discussed. 


\section{References}

1. Saltiel AR. Series introduction: the molecular and physiological basis of insulin resistance: emerging implications for metabolic and cardiovascular diseases. J Clin Invest. 2000;106:163:164.

2. Zimmet P. Globalization, coca-colonization and the chronic disease epidemic: can the Doomsday scenario be averted? J Intern Med. 2000;247:301-310.

3. Moreno PR, Fuster V. New aspects in the pathogenesis of diabetic atherothrombosis. J Am Coll Cardiol. 2004;44:2293-2300.

4. Zimmet P, Alberti KG, Shaw J. Global and societal implications of the diabetes epidemic. Nature. 2001;414:782-787.

5. Gezondheidsraad. Screening op type 2 diabetes. Den Haag. 2004:Publicatie nr. 2004/2016.

6. Nederlandse Hartstichting Hart- en vaatziekten in Nederland 2005. 2005:33-64.

7. Alexander CM, Landsman PB, Teutsch SM, Haffner SM. NCEP-defined metabolic syndrome, diabetes, and prevalence of coronary heart disease among NHANES III participants age 50 years and older. Diabetes. 2003;52:1210-1214.

8. Jones CA, Francis ME, Eberhardt MS, et al. Microalbuminuria in the US population: third National Health and Nutrition Examination Survey. Am J Kidney Dis. 2002;39:445-459.

9. Hillege HL, Fidler V, Diercks GF, et al. Urinary albumin excretion predicts cardiovascular and noncardiovascular mortality in general population. Circulation. 2002;106:1777-1782.

10. Karalliedde J, Viberti G. Microalbuminuria and cardiovascular risk. Am J Hypertens. 2004;17:986-993.

11. Miettinen $\mathrm{H}$, Haffner $S M$, Lehto $S$, Ronnemaa T, Pyorala K, Laakso M. Proteinuria predicts stroke and other atherosclerotic vascular disease events in nondiabetic and non-insulindependent diabetic subjects. Stroke. 1996;27:2033-2039.

12. Valmadrid CT, Klein R, Moss SE, Klein BE. The risk of cardiovascular disease mortality associated with microalbuminuria and gross proteinuria in persons with older-onset diabetes mellitus. Arch Intern Med. 2000;160:1093-1100.

13. Moreno PR, Murcia AM, Palacios IF, et al. Coronary composition and macrophage infiltration in atherectomy specimens from patients with diabetes mellitus. Circulation. 2000;102:21802184.

14. Laakso M. Cardiovascular disease in type 2 diabetes: challenge for treatment and prevention. J Intern Med. 2001;249:225-235.

15. Almdal $T$, Scharling $H$, Jensen JS, Vestergaard $H$. The independent effect of type 2 diabetes mellitus on ischemic heart disease, stroke, and death: a population-based study of 13,000 men and women with 20 years of follow-up. Arch Intern Med. 2004;164:1422-1426.

16. Mukamal KJ, Nesto RW, Cohen MC, et al. Impact of diabetes on long-term survival after acute myocardial infarction: comparability of risk with prior myocardial infarction. Diabetes Care. 2001;24:1422-1427.

17. Sobel BE. Effects of glycemic control and other determinants on vascular disease in type 2 diabetes. Am J Med. 2002;113 Suppl 6A:12S-22S.

18. Haffner SM, Lehto S, Ronnemaa T, Pyorala K, Laakso M. Mortality from coronary heart disease in subjects with type 2 diabetes and in nondiabetic subjects with and without prior myocardial infarction. N Engl J Med. 1998;339:229-234. 
19. Evans JM, Wang J, Morris AD. Comparison of cardiovascular risk between patients with type 2 diabetes and those who had had a myocardial infarction: cross sectional and cohort studies. Bmj. 2002;324:939-942.

20. Stratton IM, Adler Al, Neil HA, et al. Association of glycaemia with macrovascular and microvascular complications of type 2 diabetes (UKPDS 35): prospective observational study. Bmj. 2000;321:405-412.

21. The effect of intensive treatment of diabetes on the development and progression of longterm complications in insulin-dependent diabetes mellitus. The Diabetes Control and Complications Trial Research Group. N Engl J Med. 1993;329:977-986.

22. Nathan DM, Cleary PA, Backlund JY, et al. Intensive diabetes treatment and cardiovascular disease in patients with type 1 diabetes. N Engl J Med. 2005;353:2643-2653.

23. Varughese GI, Tomson J, Lip GY. Type 2 diabetes mellitus: a cardiovascular perspective. Int $J$ Clin Pract. 2005;59:798-816.

24. Colwell JA, Nesto RW. The platelet in diabetes: focus on prevention of ischemic events. Diabetes Care. 2003;26:2181-2188.

25. Virchow R. Phlogose und Thrombose in Gerassystem. Frankfurt: Von Meidinger Sohn; 1856.

26. Bauer KA, Kass BL, ten Cate H, Hawiger JJ, Rosenberg RD. Factor IX is activated in vivo by the tissue factor mechanism. Blood. 1990;76:731-736.

27. Levi $M$, ten Cate $H$, Bauer KA, et al. Inhibition of endotoxin-induced activation of coagulation and fibrinolysis by pentoxifylline or by a monoclonal anti-tissue factor antibody in chimpanzees. J Clin Invest. 1994;93:114-120.

28. Moreno PR, Bernardi VH, Lopez-Cuellar J, et al. Macrophages, smooth muscle cells, and tissue factor in unstable angina. Implications for cell-mediated thrombogenicity in acute coronary syndromes. Circulation. 1996;94:3090-3097.

29. Sommeijer DW, Beganovic A, Schalkwijk CG, et al. More fibrosis and thrombotic complications but similar expression patterns of markers for coagulation and inflammation in symptomatic plaques from DM2 patients. J Histochem Cytochem. 2004;52:1141-1149.

30. Zumbach $M$, Hofmann $M$, Borcea $V$, et al. Tissue factor antigen is elevated in patients with microvascular complications of diabetes mellitus. Exp Clin Endocrinol Diabetes. 1997; 105:206-212.

31. Song KS, Kim HK. Plasma levels of tissue factor antigen in patients with non-insulindependent diabetes mellitus. Yonsei Med J. 2004;45:38-42.

32. Ichikawa $K$, Yoshinari $M$, Iwase $M$, et al. Advanced glycosylation end products induced tissue factor expression in human monocyte-like U937 cells and increased tissue factor expression in monocytes from diabetic patients. Atherosclerosis. 1998;136:281-287.

33. Khechai $F$, Ollivier V, Bridey F, Amar M, Hakim J, de Prost D. Effect of advanced glycation end product-modified albumin on tissue factor expression by monocytes. Role of oxidant stress and protein tyrosine kinase activation. Arterioscler Thromb Vasc Biol. 1997;17:28852890.

34. Sommeijer DW, Joop K, Leyte A, Reitsma PH, ten Cate H. Pravastatin reduces fibrinogen receptor gpllla on platelet-derived microparticles in patients with type 2 diabetes. $J$ Thromb Haemost. 2005;3:1168-1171.

35. Diamant M, Nieuwland R, Pablo RF, Sturk A, Smit JW, Radder JK. Elevated numbers of tissue-factor exposing microparticles correlate with components of the metabolic syndrome in uncomplicated type 2 diabetes mellitus. Circulation. 2002;106:2442-2447. 
36. Butenas S, Bouchard BA, Brummel-Ziedins KE, Parhami-Seren B, Mann KG. Tissue factor activity in whole blood. Blood. 2005;105:2764-2770.

37. Butenas S, Mann KG. Active tissue factor in blood? Nat Med. 2004;10:1155-1156; author reply 1156.

38. Sommeijer DW, Hansen HR, van Oerle R, et al. Soluble tissue factor is a candidate marker for progression of microvascular disease in patients with Type 2 diabetes. $J$ Thromb Haemost. 2006;4:574-580.

39. Adelstein S, Gomperts ED, Joffe BI, Hockley J, Seftel HC. Haemostatic factors in Black and White diabetics. S Afr Med J. 1979;55:325-328.

40. Collier A, Rumley A, Rumley AG, et al. Free radical activity and hemostatic factors in NIDDM patients with and without microalbuminuria. Diabetes. 1992;41:909-913.

41. Carmassi $F$, Morale $M$, Puccetti $R$, et al. Coagulation and fibrinolytic system impairment in insulin dependent diabetes mellitus. Thromb Res. 1992;67:643-654.

42. Folsom AR, Wu KK, Rasmussen M, Chambless LE, Aleksic N, Nieto FJ. Determinants of population changes in fibrinogen and factor VII over 6 years: the Atherosclerosis Risk in Communities (ARIC) Study. Arterioscler Thromb Vasc Biol. 2000;20:601-606.

43. Carr ME. Diabetes mellitus: a hypercoagulable state. J Diabetes Complications. 2001;15:4454.

44. Hemker HC, de Smedt E, Hemker PW. Mathematical and biological models of blood coagulation. A rebuttal. J Thromb Haemost. 2006;4:710-711.

45. Weitz JI, Leslie $B$, Hudoba $M$. Thrombin binds to soluble fibrin degradation products where it is protected from inhibition by heparin-antithrombin but susceptible to inactivation by antithrombin-independent inhibitors. Circulation. 1998;97:544-552.

46. Dunn EJ, Ariens RA, Grant PJ. The influence of type 2 diabetes on fibrin structure and function. Diabetologia. 2005;48:1198-1206.

47. Hemker HC, Giesen P, AlDieri R, et al. The calibrated automated thrombogram (CAT): a universal routine test for hyper- and hypocoagulability. Pathophysiol Haemost Thromb. 2002;32:249-253.

48. Standeven KF, Grant PJ, Carter AM, Scheiner T, Weisel JW, Ariens RA. Functional analysis of the fibrinogen Aalpha Thr312Ala polymorphism: effects on fibrin structure and function. Circulation. 2003;107:2326-2330.

49. Yamada T, Sato A, Nishimori T, et al. Importance of hypercoagulability over hyperglycemia for vascular complication in type 2 diabetes. Diabetes Res Clin Pract. 2000;49:23-31.

50. Takahashi H, Tsuda A, Tatewaki W, Wada K, Niwano H, Shibata A. Activation of blood coagulation and fibrinolysis in diabetes mellitus: evaluation by plasma levels of thrombinantithrombin III complex and plasmin-alpha 2-plasmin inhibitor complex. Thromb Res. 1989;55:727-735.

51. Reverter $\mathrm{J}$, Reverter JC, Tassies D, et al. Thrombomodulin and induced tissue factor expression on monocytes as markers of diabetic microangiopathy: a prospective study on hemostasis and lipoproteins in insulin-dependent diabetes mellitus. Am J Hematol. 1997;56:93-99.

52. Lopez Y, Paloma MJ, Rifon J, Cuesta B, Paramo JA. Measurement of prethrombotic markers in the assessment of acquired hypercoagulable states. Thromb Res. 1999;93:71-78.

53. Erem C, Hacihasanoglu A, Celik S, et al. Coagulation and fibrinolysis parameters in type 2 diabetic patients with and without diabetic vascular complications. Med Princ Pract. 2005; 14:22-30. 
54. Contreras JL, Eckstein C, Smyth CA, et al. Activated protein C preserves functional islet mass after intraportal transplantation: a novel link between endothelial cell activation, thrombosis, inflammation, and islet cell death. Diabetes. 2004;53:2804-2814.

55. Shibata M, Kumar SR, Amar A, et al. Anti-inflammatory, antithrombotic, and neuroprotective effects of activated protein $C$ in a murine model of focal ischemic stroke. Circulation. 2001;103:1799-1805.

56. Slofstra SH, Ten Cate H, Spek CA. Signal transduction induced by activated protein C: no role in protection against sepsis? Trends Mol Med. 2006.

57. Gabazza EC, Takeya $\mathrm{H}$, Deguchi $\mathrm{H}$, et al. Protein $\mathrm{C}$ activation in NIDDM patients. Diabetologia. 1996;39:1455-1461.

58. Pannacciulli N, De Mitrio V, Sciaraffia M, Giorgino R, De Pergola G. A family history of type 2 diabetes is associated with lower sensitivity to activated protein $C$ in overweight and obese premenopausal women. Thromb Haemost. 2001;86:1593-1594.

59. Hafer-Macko CE, Ivey FM, Gyure KA, Sorkin JD, Macko RF. Thrombomodulin deficiency in human diabetic nerve microvasculature. Diabetes. 2002;51:1957-1963.

60. Fujiwara Y, Tagami S, Kawakami Y. Circulating thrombomodulin and hematological alterations in type 2 diabetic patients with retinopathy. J Atheroscler Thromb. 1998;5:2128.

61. Nojima J, Kuratsune $H$, Suehisa E, Iwatani $Y$, Kanakura $Y$. Acquired activated protein $C$ resistance associated with IgG antibodies against beta2-glycoprotein I and prothrombin as a strong risk factor for venous thromboembolism. Clin Chem. 2005;51:545-552.

62. Lwaleed BA, Bass PS. Tissue factor pathway inhibitor: structure, biology and involvement in disease. J Pathol. 2006;208:327-339.

63. Hackeng TM, Sere KM, Tans G, Rosing J. Protein S stimulates inhibition of the tissue factor pathway by tissue factor pathway inhibitor. Proc Natl Acad Sci U S A. 2006;103:3106-3111.

64. Kario K, Matsuo T, Kobayashi H, Matsuo M, Sakata T, Miyata T. Activation of tissue factorinduced coagulation and endothelial cell dysfunction in non-insulin-dependent diabetic patients with microalbuminuria. Arterioscler Thromb Vasc Biol. 1995;15:1114-1120.

65. Leurs PB, Stolk RP, Hamulyak K, Van Oerle R, Grobbee DE, Wolffenbuttel BH. Tissue factor pathway inhibitor and other endothelium-dependent hemostatic factors in elderly individuals with normal or impaired glucose tolerance and type 2 diabetes. Diabetes Care. 2002;25:1340-1345.

66. Ludwig 5, Dharmalingam S, Erickson-Nesmith S, et al. Impact of simvastatin on hemostatic and fibrinolytic regulators in Type 2 diabetes mellitus. Diabetes Res Clin Pract. 2005;70:110118.

67. Stehouwer CD, Gall MA, Twisk JW, Knudsen E, Emeis JJ, Parving HH. Increased urinary albumin excretion, endothelial dysfunction, and chronic low-grade inflammation in type 2 diabetes: progressive, interrelated, and independently associated with risk of death. Diabetes. 2002;51:1157-1165.

68. Yu Y, Suo L, Yu H, Wang $\mathrm{C}$, Tang $\mathrm{H}$. Insulin resistance and endothelial dysfunction in type 2 diabetes patients with or without microalbuminuria. Diabetes Res Clin Pract. 2004;65:95104.

69. Eliasson M, Asplund K, Evrin PE, Lindahl B, Lundblad D. Hyperinsulinemia predicts low tissue plasminogen activator activity in a healthy population: the Northern Sweden MONICA Study. Metabolism. 1994;43:1579-1586. 
70. Lee AJ, MacGregor AS, Hau CM, et al. The role of haematological factors in diabetic peripheral arterial disease: the Edinburgh artery study. $\mathrm{Br} J$ Haematol. 1999;105:648-654.

71. Chomiki N, Henry M, Alessi MC, Anfosso F, Juhan-Vague I. Plasminogen activator inhibitor-1 expression in human liver and healthy or atherosclerotic vessel walls. Thromb Haemost. 1994; 72:44-53.

72. Lowe GD. Can haematological tests predict cardiovascular risk? The 2005 Kettle Lecture. $\mathrm{Br}$ J Haematol. 2006;133:232-250.

73. Roth GJ. Developing relationships: arterial platelet adhesion, glycoprotein lb, and leucinerich glycoproteins. Blood. 1991;77:5-19.

74. Jager A, van Hinsbergh VW, Kostense PJ, et al. von Willebrand factor, C-reactive protein, and 5-year mortality in diabetic and nondiabetic subjects: the Hoorn Study. Arterioscler Thromb Vasc Biol. 1999;19:3071-3078.

75. Claus RA, Bockmeyer CL, Sossdorf $M$, Losche $W$, Hilberg T. Physical stress as a model to study variations in ADAMTS-13 activity, von Willebrand factor level and platelet activation. $J$ Thromb Haemost. 2006;4:902-905.

76. Furie B, Furie BC. The molecular basis of blood coagulation. Cell. 1988;53:505-518.

77. Sobol $A B$, Watala $C$. The role of platelets in diabetes-related vascular complications. Diabetes Res Clin Pract. 2000;50:1-16.

78. Yazbek N, Bapat A, Kleiman N. Platelet abnormalities in diabetes mellitus. Coron Artery Dis. 2003;14:365-371.

79. Bridges JM, Dalby AM, Millar JH, Weaver JA. An Effect Of D-Glucose On Platelet Stickiness. Lancet. 1965;42:75-77.

80. Sharpe PC, Trinick T. Mean platelet volume in diabetes mellitus. Q J Med. 1993;86:739-742.

81. Tschoepe $D$, Roesen $P$, Kaufmann $L$, et al. Evidence for abnormal platelet glycoprotein expression in diabetes mellitus. Eur J Clin Invest. 1990;20:166-170.

82. Ferroni P, Basili S, Falco A, Davi G. Platelet activation in type 2 diabetes mellitus. J Thromb Haemost. 2004;2:1282-1291.

83. Watala C. Blood platelet reactivity and its pharmacological modulation in (people with) diabetes mellitus. Curr Pharm Des. 2005;11:2331-2365.

84. Tschoepe D, Driesch E, Schwippert B, Nieuwenhuis HK, Gries FA. Exposure of adhesion molecules on activated platelets in patients with newly diagnosed IDDM is not normalized by near-normoglycemia. Diabetes. 1995;44:890-894.

85. Roffi $M$, Chew DP, Mukherjee D, et al. Platelet glycoprotein llb/llla inhibitors reduce mortality in diabetic patients with non-ST-segment-elevation acute coronary syndromes. Circulation. 2001;104:2767-2771.

86. Davi G, Catalano I, Averna M, et al. Thromboxane biosynthesis and platelet function in type II diabetes mellitus. N Engl J Med. 1990;322:1769-1774.

87. Hansson L, Zanchetti A, Carruthers SG, et al. Effects of intensive blood-pressure lowering and low-dose aspirin in patients with hypertension: principal results of the Hypertension Optimal Treatment (HOT) randomised trial. HOT Study Group. Lancet. 1998;351:1755-1762.

88. Final report on the aspirin component of the ongoing Physicians' Health Study. Steering Committee of the Physicians' Health Study Research Group. N Engl J Med. 1989;321:129-135.

89. Rolka DB, Fagot-Campagna A, Narayan KM. Aspirin use among adults with diabetes: estimates from the Third National Health and Nutrition Examination Survey. Diabetes Care. $2001 ; 24: 197-201$. 
90. Wada R, Yagihashi S. Role of advanced glycation end products and their receptors in development of diabetic neuropathy. Ann N Y Acad Sci. 2005;1043:598-604.

91. Cipollone $F$, lezzi A, Fazia $M$, et al. The receptor RAGE as a progression factor amplifying arachidonate-dependent inflammatory and proteolytic response in human atherosclerotic plaques: role of glycemic control. Circulation. 2003;108:1070-1077.

92. Singh R, Barden A, Mori T, Beilin L. Advanced glycation end-products: a review. Diabetologia. 2001;44:129-146.

93. Bierhaus A, Hofmann MA, Ziegler R, Nawroth PP. AGEs and their interaction with AGEreceptors in vascular disease and diabetes mellitus. I. The AGE concept. Cardiovasc Res. 1998;37:586-600.

94. Koka V, Wang W, Huang XR, Kim-Mitsuyama S, Truong LD, Lan HY. Advanced glycation end products activate a chymase-dependent angiotensin II-generating pathway in diabetic complications. Circulation. 2006;113:1353-1360.

95. Takai S, Jin D, Muramatsu M, Okamoto $Y$, Miyazaki $M$. Therapeutic applications of chymase inhibitors in cardiovascular diseases and fibrosis. Eur J Pharmacol. 2004;501:1-8.

96. Cooper ME. The role of the renin-angiotensin-aldosterone system in diabetes and its vascular complications. Am J Hypertens. 2004;17:165-205; quiz A12-14.

97. Unger $\mathrm{T}$. The role of the renin-angiotensin system in the development of cardiovascular disease. Am J Cardiol, 2002;89:3A-9A; discussion 10A.

98. Brancati FL, Whelton PK, Randall BL, Neaton JD, Stamler J, Klag MJ. Risk of end-stage renal disease in diabetes mellitus: a prospective cohort study of men screened for MRFIT. Multiple Risk Factor Intervention Trial. Jama. 1997;278:2069-2074.

99. Pirart J. [Diabetes mellitus and its degenerative complications: a prospective study of 4,400 patients observed between 1947 and 1973 (2nd part) (author's transl)]. Diabete Metab. 1977;3:173-182.

100. Microvascular and acute complications in IDDM patients: the EURODIAB IDDM Complications Study. Diabetologia. 1994;37:278-285.

101. Bakris GL, Bhandaru S, Akerstrom V, Re RN. ACE inhibitor-mediated attenuation of mesangial cell growth. A role for endothelin. Am J Hypertens. 1994;7:583-590.

102. Farquhar A, MacDonald MK, Ireland JT. The role of fibrin deposition in diabetic glomerulosclerosis: a light, electron and immunofluorescence microscopy study. J Clin Pathol. 1972;25:657-667.

103. Herlihy WG, Nordquist JA, Mandal AK, Llach F. Diabetic nephropathy associated with fibrin formation. Hum Pathol. 1981;12:658-660.

104. Sommeijer DW, Florquin S, Hoedemaker I, Timmerman JJ, Reitsma PH, Ten Cate H. Renal tissue factor expression is increased in streptozotocin-induced diabetic mice. Nephron Exp Nephrol. 2005;101:e86-94.

105. Yamamoto K, Loskutoff DJ, Saito H. Renal expression of fibrinolytic genes and tissue factor in a murine model of renal disease as a function of age. Semin Thromb Hemost. 1998;24:261-268.

106. Erlich JH, Holdsworth SR, Tipping PG. Tissue factor initiates glomerular fibrin deposition and promotes major histocompatibility complex class II expression in crescentic glomerulonephritis. Am J Pathol. 1997;150:873-880.

107. Asakawa $H$, Tokunaga $K$, Kawakami F. Elevation of fibrinogen and thrombin-antithrombin III complex levels of type 2 diabetes mellitus patients with retinopathy and nephropathy. $J$ Diabetes Complications. 2000;14:121-126. 
Chapter 2

Soluble tissue factor is a candidate marker for progression of microvascular disease in patients with type 2 diabetes

Hjalmar R. Hansen • Dirkje W. Sommeijer • Rene van Oerle • Karly Hamulyak Anton P. van Zanten • Eelco Meesters • Henri M.H. Spronk $\downarrow$ Hugo ten Cate

J Thromb Haemost. 2006 Mar;4(3):574-80 


\section{Summary}

Objective: To determine the relationship between abnormalities in blood coagulation and prevalent or incident cardiovascular complications in type 2 diabetes. Design and methods: Prospective cohort study of 128 patients with type 2 diabetes in whom blood samples were collected at baseline and after one year of follow-up. All cardiovascular complications at baseline and follow-up were recorded. Forty-three healthy, age matched subjects served as a control group.

Results: Logistic analysis revealed an independent relationship between soluble TF and microvascular disease (per $\mathrm{pg} / \mathrm{mL} \mathrm{TF}: \operatorname{Exp}(\mathrm{B})=1.008 ; \mathrm{CI}(95 \%) 1.002-1.014)$, or neurogenic disease $(\operatorname{Exp}(B)=1.006 ; \mathrm{CI}(95 \%) 1.001-1.011)$. The highest levels of soluble $\mathrm{TF}$ were observed in patients with microvascular and neurogenic disease $(\mathrm{p}<0.001)$. Patients with type 2 diabetes having a soluble $\mathrm{TF}$ concentration $>300$ $\mathrm{pg} / \mathrm{mL}$ are at a 15 -fold higher risk for the presence of microvascular disease and at a 10-fold higher risk for the presence of neurogenic disease compared to patients with concentrations below $100 \mathrm{pg} / \mathrm{mL}$. Soluble TF was correlated with tPA, vWFag, systolic blood pressure and age. Levels of $F 1^{\circ}+2, \mathrm{D}$-dimer, FVIII activity, t-PA and vWFag were not different among patients with micro-, macro- or neurogenic complications compared to patients without those complications. Forty eight new micro,-macro- and/or neurogenic complications were diagnosed after one year follow up. With the exception of higher F1+2 levels after one year all other markers remained unchanged. A trend towards higher soluble TF levels was observed in patients with new microvascular events $(\mathrm{p}=0.056)$. Conclusions: Soluble $\mathrm{TF}$ is associated with existing microvascular and neurogenic complications in patients with type 2 diabetes and is a candidate marker for progression of microvascular disease. 


\section{Introduction}

Type 2 diabetes is a chronic metabolic disorder that is accompanied by considerable cardiovascular mortality due to myocardial infarction, heart failure, stroke, or "sudden death". In addition, chronic morbidity is often seen in the form of major vascular complications including peripheral arterial disease and/or microvascular complications such as retinopathy and nephropathy ${ }^{1-4}$. Acute atherothrombotic complications like myocardial infarction are the consequence of advanced atherosclerotic lesions that rupture or erode, thereby exposing procoagulant proteins that initiate blood coagulation 5. In addition to such local encounters between blood and damaged vessel wall, a systemic prothrombotic state may also increase the risk of thrombosis $6-8$. Numerous, mostly cross-sectional, studies have addressed the question whether type 2 diabetes is associated with increased systemic blood coagulation activity 9,10. However, evidence that activated coagulation or inhibited fibrinolysis has clinical implications in patients with type 2 diabetes remains circumstantial 11,12 , despite the wealth of observational data supporting a hypercoagulable state in blood as well as an activated vascular endothelial surface in type 2 diabetes patients.

The high risk of vascular complications in type 2 diabetes urges for laboratory tests that help to predict such complications, or to identify patients at risk who would benefit of specific antithrombotic protection. In addition, the availability of one or more laboratory tests that distinguish patients with microvascular disease from those with either large vessel or both types of vascular disease would be helpful in the diagnostic workup.

In this report we studied soluble tissue factor (TF) in conjunction with other markers of coagulation, fibrinolysis and endothelial cell activation in relationship to prevalent, new vascular complications in a group of consecutively analyzed patients with type 2 diabetes.

\section{Patients and methods}

\section{Patient population}

Patients were recruited from the outpatient clinic of the Slotervaart hospital, Amsterdam, The Netherlands. Men and women with a minimum age of 25 years with type 2 diabetes mellitus were eligible for the study. Excluded were patients with undetectable C-peptide levels, insulin treatment before puberty, history of ketoacidosis, active chronic inflammatory disease or cancer. Forty-three age and sex matched apparently healthy control persons were recruited from the outpatient eye clinic and from the hospital staff at the Slotervaart hospital. All patients and controls gave informed consent and the study was approved by the institutional Ethical Review Board of the Slotervaart Hospital, Amsterdam. 


\section{Study design}

At inclusion and after one year follow-up, patients were interviewed and given a physical examination. Patients were evaluated with respect to microvascular, macrovascular and neurogenic complications. Microvascular disease included one or more of the following: retinopathy (diagnosed by fundoscopic examination), microalbuminuria (microalbumin $>30 \mathrm{mg} / 24 \mathrm{~h}$ ). Macrovascular disease included: documented myocardial infarction, angina pectoris, cerebrovascular accident or intermittent claudication. Neurogenic disease included: neuropathy (diagnosed by electromyography) and neuropathic ulcera and/or Charcot's foot. Further data were obtained about duration of type 2 diabetes, medication use, body mass index (BMI), blood pressure (high blood pressure was defined as systolic pressure $\geq 140 \mathrm{mmHg}$ and/or diastolic pressure $\geq 85 \mathrm{mmHg}$ ) and lifestyle parameters.

The plasma levels of soluble TF (TF), soluble thrombomodulin (TM), von Willebrand factor antigen (vWFag), prothrombin fragment F1+2, D-dimer, plasminogen activator inhibitor type 1 (PAI-1) and tissue type plasminogen activator (tPA), cholesterol, homocysteine, $\mathrm{HbA}_{\mathbf{l c}}$ and glucose were measured at baseline and after one year follow up.

\section{Blood sampling and laboratory procedures}

Blood samples were obtained by standard venepuncture and collected into $3.2 \%$ trisodium citrate (Beckton Dickinson, San Jose, CA, USA). Citrated plasma was stored at $-70^{\circ} \mathrm{C}$ until use. Plasma triglycerides, total cholesterol and high density lipoprotein (HDL)-cholesterol were measured enzymatically (Synchron LX20/CX7delta $\circledast$, Beckman Coulter, Fullerton, California, USA). Low density lipoprotein (LDL)-cholesterol was calculated by the Friedwald formula ${ }^{13}$. PAI-1 was measured using Biological Immuno-Assay Chromolize(B) PAI-1 from Trinity biotech (Bray, Ireland). In vivo thrombin formation was assessed by determination of prothrombin fragments $\mathrm{F} 1+2$, using a commercial ELISA (Enzygnost; Dade-Behring, Darmstadt, Germany). Soluble TF antigen was measured by ELISA (Imubind®, American diagnostica Inc., Greenwich, Conneticut, USA). Soluble TM antigen levels were analysed by ELISA (Diaclone Research, Besancon, France). vWFag levels were determined by an immunoturbidimetric assay with the Behring Coagulation System (BCS) (vWFAg Dade-Behring). Factor VIII activity was measured using a chromogenic assay with the BCS. t-PA antigen levels were determined using an ELISA (Imulyse ${ }^{\mathrm{TM}}$, Biopool, Bray, Ireland) and D-dimers were quantified by an immunoturbidimetric assay utilizing a BCS (D-dimer plus; Dade-Behring). $\mathrm{Hb}_{1 \mathrm{c}}$ was determined in whole blood by high-performance liquid chromatography using a mono S column (Pharmacia diagnostics, Uppsala, Sweden). Homocysteine levels were measured by high-performance liquid chromatography (Jasco, Tokyo, Japan). All assays were performed according to the instructions of the manufacturer without any modification. 


\section{Statistical analysis}

Data are presented as median (range). Differences between groups (patients with type 2 diabetes vs. controls and patients with cardiovascular complications vs. patients without complications) were assessed using non-paired Student's $t$-test or Mann-Whitney U test when distribution was not normal. For comparison of data from patients with type 2 diabetes at baseline with data after one year follow up a paired $t$-Test or Wilcoxon rank test was used. Logistic regression analysis was performed for each marker associated with existing cardiovascular complications on univariate analysis. Statistical analysis was performed on the complete patient data as well as after separating individuals that used "statins" from "no-statins" users. The same separate data analysis was done for those using oral anticoagulants versus those not using oral anticoagulants.

$\mathrm{P}$ values $<0.05$ were considered statistically significant. Statistical analyses were performed using SPSS version 11.5.

\section{Results}

\section{Patient baseline characteristics}

One hundred and twenty-eight patients with type 2 diabetes $(76$ men and 52 women) were evaluated in this study. The baseline characteristics of the patient group are summarized in table 1 . Twenty nine percent of type 2 diabetes patients had microvascular complications (retinopathy and/or nephropathy), 40\% had macrovascular complications (myocardial infarction, angina pectoris, cerebrovascular event, peripheral artery disease), 23\% suffered from neurogenic complications (neuropathy and/or neuropathic ulcer). Sixty percent of all patients had one or more types of complications at baseline. The study was primarily designed as a prospective cohort investigation. However, to estimate the deviation of laboratory values from normal for comparable age and sex we recruited forty-three apparently healthy subjects without type 2 diabetes ( 27 men, 16 women), with a mean age of 61 years to serve as a comparative group.

Baseline coagulation- and endothelial markers of the patient group are given in table 2 and compared with the values from normal individuals. Plasma levels of soluble TF were significantly higher in patients (154 (32-572) vs. 132 (40-270) $\mathrm{pg} / \mathrm{mL}$ in the control group; $\mathrm{p}=0.015)$. t-PA and PAI- 1 were also elevated in the patients with type 2 diabetes (t-PA: $9.8(2.2-22.5)$ vs. $7.3(2.2-17.6) \mathrm{nmol} / \mathrm{L} ; \mathrm{p}=$ 0.021 and PAI-1: $6.5(0.1-55.0)$ vs. $4,1(0.1-44.4) \mathrm{U} / \mathrm{mL} ; \mathrm{p}=0.035)$.

The median $\mathrm{F} 1+2$ level was $0.71(0.17-1.36) \mathrm{nmol} / \mathrm{L}$ in the patient group and was lower than the median level in the age matched normal persons $(0.97(0.26-3.16)$ $\mathrm{nmol} / \mathrm{L} ; \mathrm{p}<0.001)$. A trend towards higher levels of factor VIII activity $(\mathrm{p}=0.1)$, and of D-dimer $(p=0.3)$ was observed in the patient group compared to the control group. vWFag and soluble TM did not differ between the two groups. 
Table 1.

Characteristics of subjects with type 2 diabetes.

\begin{tabular}{|c|c|}
\hline Baseline characteristics & Type 2 diabetes patients $n=128$ \\
\hline Age (years) & $59.1(30.6-87.5)$ \\
\hline Sex (\% male) & $60 \%$ \\
\hline Duration of diabetes until sample date (years) & $7.2(0.0-32.2)$ \\
\hline Systolic blood pressure $(\mathrm{mmHg})$ & $142(105-210)$ \\
\hline Diastolic blood pressure $(\mathrm{mmHg})$ & $81(50-110)$ \\
\hline$B M I\left(\mathrm{~kg} / \mathrm{m}^{2}\right)$ & $29.6(25.9 \cdot 32.7)$ \\
\hline $\mathrm{Hb}(\mathrm{mmol} / \mathrm{L})$ & $8.8(6.3 \cdot 10.5)$ \\
\hline Leucocytes $\left(10^{9} / \mathrm{L}\right)$ & $7.8(3.1-21.5)$ \\
\hline Platelets $\left(10^{9} / L\right)$ & $250(129-399)$ \\
\hline Glucose (mmol/L) & $9.6(2.9-20.9)$ \\
\hline $\mathrm{HbA}_{1 c}(\%)$ & $7.5(5.2-11.8)$ \\
\hline Creatinine (mmol/24hr) & $82(7-139)$ \\
\hline Total cholesterol (mmol/L) & $5.12(2.56-7.80)$ \\
\hline HDL cholesterol ( $\mathrm{mmol} / \mathrm{L})$ & $1.21(0.68-4.90)$ \\
\hline LDL cholesterol (mmol/L) & $3.13(1.00-5.71)$ \\
\hline Triglycerides (mmol/L) & $1.73(0.47-4.66)$ \\
\hline Homocysteine ( $\mu \mathrm{mol} / \mathrm{l})$ & $10.9(3.9-24.8)$ \\
\hline Microalbumin (mg $/ 24 \mathrm{hr}$ ) & $51(2.826)$ \\
\hline
\end{tabular}

Relationship between markers of coagulation and endothelial dysfunction and prevalent cardiovascular complications

To explore which coagulation or endothelial cell markers are related to prevalent cardiovascular complications, parameters were compared between patients with and without cardiovascular complications. Existence of microvascular disease was associated with significantly higher levels of circulating soluble TF (192 (148-271) vs. $142(105-185) \mathrm{pg} / \mathrm{mL} ; \mathrm{p}<0.001)$. In addition, soluble $\mathrm{TF}$ was increased in patients with neurogenic complications compared to those without these complications (182 (154-235) vs. $145(105-200) \mathrm{pg} / \mathrm{mL} ; \mathrm{p}=0.004)$. Soluble TF correlated to tPA $(\mathrm{r}=0.29 ; \mathrm{p}<0.001)$, vWFag $(\mathrm{r}=0.25 ; \mathrm{p}=0.004)$, systolic blood pressure $(r=0.34 ; p<0.001)$ and age $(r=0.47 ; p<0.001)$. Prothrombin fragment $F 1+2$, D-dimer, FVIII activity, soluble TM, t-PA and vWFag were not significantly different between patients with micro-, macro- or neurogenic complications and patients without those complications. In contrast to our expectations, patients with microvascular complications had significantly lower PAI-1 levels than patients without such complications $(3.7(1.7-8.9)$ vs. $8.7(3.5-19.6) \mathrm{U} / \mathrm{mL} ; \mathrm{p}=0.03)$. To asses the increased risk of having a microvascular or neurogenic complication in relation with TF concentrations we compared four groups of TF concentration (Table 3). 
Patients with $\mathrm{TF}$ concentrations above $300 \mathrm{pg} / \mathrm{mL}$ compared to the reference group of patients with concentrations below $100 \mathrm{pg} / \mathrm{mL}$ are at a 15 -fold higher risk for having microvascular complications and at a 10-fold higher risk of having neurogenic complications.

Table 2.

Plasma levels of coagulation and endothelial activation markers.

\begin{tabular}{lrr}
\hline & Controls & Type 2 Diabetes \\
& $\mathrm{N}=43$ & $\mathrm{~N}=128$ \\
\hline F1+2 (nmol/L) & $0.97(0.26-3.16)$ & $0.71(0.17-1.36)^{*}$ \\
Factor VIII activity $(\%)$ & $157(75-297)$ & $167(53-306)$ \\
Soluble thrombomodulin & $5.4(2.2-22)$ & $5.8(2.8-22)$ \\
Soluble tissue factor $(\mathrm{pg} / \mathrm{mL})$ & $132(40-270)$ & $154(32-572) \dagger$ \\
t.PA $(\mathrm{ng} / \mathrm{mL})$ & $7.3(2.2-17.6)$ & $9.8(2.2-22.5) \dagger$ \\
PAl-1 $(\mathrm{U} / \mathrm{mL})$ & $4.1(0.1-41.4)$ & $6.5(0.1-55) \dagger$ \\
von Willebrand factor $(\%$ d.N.) & $140(65-268)$ & $143(33-337)$ \\
D-Dimer $(\mu g / \mathrm{L})$ & $149(62-1186)$ & $162(50-1614)$ \\
\hline Data are presented as medians (range). * $P<0.001$ vs. Controls, $\dagger \mathrm{P}<0.05$ vs. Controls &
\end{tabular}

To test which factors had an independent relationship with micro-, macrovascular, or neurogenic complications at baseline we performed logistic regression analysis. In addition to soluble TF, univariate analysis selected age, type 2 diabetes duration, homocysteine and systolic blood pressure as variables associated $(P<0.05)$ with microvascular complications. In the multivariate model only soluble TF $(1.008$ (1.002-1.014)) [Exp(B) (95\%Cl)] and duration of type 2 diabetes (1.115 (1.0151.182)) had an independent relation with microvascular disease. An increase of 1 $\mathrm{pg} / \mathrm{mL}$ enhances the risk for existing microvascular disease with $0.8 \%$. Mutivariate analysis selected age $(1.079(1.035-1.124))$, type 2 diabetes duration (1.080 (1.014$1.150)$, and total cholesterol $(0.439(0.277-0.698))$ as variables having an independent relation with macrovascular complications. In contrast to our expectations, a negative relation between total cholesterol with macrovascular complications was observed. To test whether lower cholesterol levels in patients with macrovascular complications could be explained by statin treatment in this group, the number of statin users was evaluated in the patients with and without macrovascular complications. Indeed, significantly more patients with macrovascular complications were treated with statins (with complications 65\% statin user, without complications $18 \%$ statin user; $p<0.0001)$. Neurogenic complications were independently associated with soluble TF (1.006 (1.001-1.011)) and age (1.057 (1.015-1.100)) in multivariate analysis.

The use of medication including statins, aspirin or oral anticoagulants did not influence any of the observed associations between laboratory data and clinical outcomes in the patient group. For soluble TF, this means that the difference between patients with and without microvascular or neurogenic complications 
remains statistically significant in those not using a statin $(n=48 ; p<0.05$ and $p<$ $0.001)$, respectively; for patients not on aspirin $(n=36)$ soluble $T F$ also remained significantly associated with micro- and neurogenic complications ( $p<0.01$ for both). In patients that did not use a statin or did not use aspirin, the association between PAI-1 and microvascular complications remains significant $(p<0.05)$. Only 5 patients used an oral anticoagulant agent, but this did not influence any of the statistical analyses.

Table 3.

Odds ratios ( $95 \%$ confidence interval $[\mathrm{CI}]$ ) for three categories of soluble TF concentrations compared to soluble TF concentrations below $100 \mathrm{pg} / \mathrm{mL}$ in type 2 diabetes with microvascular and neurogenic complications, respectively. ( ${ }^{*}$ indicates reference group)

\begin{tabular}{|c|c|c|c|c|}
\hline soluble TF $(\mathrm{pg} / \mathrm{mL})$ & $<100$ & $100-200$ & $200-300$ & $>300$ \\
\hline $\begin{array}{l}\text { patients without } \\
\text { microvascular } \\
\text { complications }\end{array}$ & 19 & 55 & 14 & 3 \\
\hline $\begin{array}{l}\text { patients with } \\
\text { microvascular } \\
\text { complications }\end{array}$ & 3 & 15 & 11 & 7 \\
\hline $\begin{array}{l}\text { Odds ratio for patients } \\
\text { with microvascular } \\
\text { complications }(95 \% \mathrm{CI})\end{array}$ & * & $1.7(0.5-6.1)$ & $5.0(1.2-19.7)$ & $14.8(2.6-85.9)$ \\
\hline $\begin{array}{l}\text { patients without } \\
\text { neurogenic } \\
\text { complications }\end{array}$ & 20 & 54 & 19 & 5 \\
\hline $\begin{array}{l}\text { patients with neurogenic } \\
\text { complications }\end{array}$ & 2 & 16 & 6 & 5 \\
\hline $\begin{array}{l}\text { Odds ratio for patients } \\
\text { with neurogenic } \\
\text { complications }(95 \% \mathrm{Cl})\end{array}$ & * & $3.0(0.7-12.5)$ & $3.2(0.6-15.3)$ & $10.0(1.6-59.1)$ \\
\hline
\end{tabular}

Relationship between markers of coagulation and incidence

of cardiovascular complications

After one year follow up we obtained clinical data from 117 patients with type 2 diabetes; 8 patients were lost to follow up due to moving to another region and 3 declined follow up assessment. In these 117 patients (91\% of the initial cohort) 48 new cardiovascular complications were diagnosed in a total of 41 patients: two 
cardiovascular deaths, 1 non fatal myocardial infarction, 4 ischemic strokes, 3 new cases of angina pectoris, 2 patients with a presentation of intermittent claudication, 8 newly detected cases of retinopathy, 13 micro-albuminuria, 13 neuropathy and 2 ulcers. Laboratory data after one year follow up were obtained from 87 patients. New cardiovascular complications diagnosed in these patients were: 1 myocardial infarction, 2 ischemic strokes, 1 angina pectoris, 2 intermittent claudication, 6 retinopathy, 9 micro-albuminuria, 12 neuropathy, 1 neurogenic ulcer. The level of soluble TF, vWFag, D-dimer, FVIII activity, t-PA and PAI-1 remained all unchanged after one year follow up compared to baseline levels. The exception was the concentration of $\mathrm{F} 1+2$, which was significantly higher after 1 year as compared to baseline (1.00 (0.77-1.14) vs. $0.72 \mathrm{nmol} / \mathrm{L}(0.59-0.83)$; $\mathrm{p}<0.0001)$.

To investigate the relationship between the different parameters at baseline and incidence of micro-, macro- and neurogenic cardiovascular complications, the parameters were compared between patients with and without new complications. Soluble $\mathrm{TF}$ was higher in patients with a new microvascular event although not statistically significant $(182(155-240)$ vs. $150(109-202) \mathrm{pg} / \mathrm{mL} ; \mathrm{p}=0.056)$. Lower levels of HDL-cholesterol were associated with the incidence of macrovascular disease (1.02 (0.86-1.07) vs. $1.09(0.96-1.41) \mathrm{mmol} / \mathrm{L} ; \mathrm{p}=0.046)$. Levels of vWFag F1+2, D-dimer, FVII activity, t-PA and PAI-1 were not statistically different among patients with and without micro,- macro- and neurogenic complications after one year follow up. In addition, type 2 diabetes duration, $\mathrm{HbA}_{1 \mathrm{c}}$, age, total cholesterol, homocysteine and blood pressure were all similar in the groups with and without new events.

\section{Discussion}

The high rate of thrombotic complications and the observed high levels of coagulation markers in patients with type 2 diabetes suggest that a hypercoagulable state contributes to the increased risk for cardiovascular disease 68. However, whether there is a causal relationship between the procoagulant state in blood and prevalent or new vascular complications remains unclear. In order to address this relationship the present study was undertaken.

The main outcome of this study was the observed independent association between soluble $\mathrm{TF}$, in addition to type 2 diabetes duration and age, and prevalent microvascular and/or neurogenic complications in patients with type 2 diabetes, suggestive for a relation between soluble $\mathrm{TF}$ and microvascular endothelial dysfunction.

At the initiation of this study we considered soluble $\mathrm{TF}$ as a possible source of procoagulant activity that irrespective of the cellular source might be related to the risk of thrombotic complications. Increased TF expression on circulating monocytes 14,15 , a higher percentage of $\mathrm{TF}$ positive microparticles 16 and increased levels of 
circulating TF activity 17 and TF antigen 18,19 have been observed in patients with type 2 diabetes. The intact glycoprotein TF induces coagulation activation upon vascular injury ${ }^{20}$. The circulating form or 'blood-borne' TF has been proposed as a marker of vascular injury $21-23$ and as a source of procoagulant activity, when exposed on the surface of circulating microparticles ${ }^{24-26 . ~ H o w e v e r, ~ a ~ r e c e n t ~ a n a l y s i s ~}$ predicts that it is very unlikely that the fraction of soluble TF detected by commercial assays such as used in our study contains relevant quantities of active TF 27. In fact, when we tested samples from patients with the highest amounts of TF antigen, the relative activity detected by a novel activity assay was negligible [unpublished data; W Hermens, $R$ van Oerle et al, manuscript in preparation]. Our finding that soluble $\mathrm{TF}$ was independently related to existing microvascular disease (microalbuminuria, retinopathy) and neuropathy, suggests that soluble TF reflects endothelial dysfunction, rather than procoagulant activity, which is supported by the significant correlation between soluble TF and vWFag, an established marker of endothelial dysfunction, $(\mathrm{r}=0.25 ; \mathrm{p}=0.004)$ in the present study and in previous reports 23. Nevertheless, our patient population did not have any profound disturbance in endothelial activation considering the lack of a significant difference between vWF and soluble TM levels from patients and age matched controls, which may be attributable to lack of power, or to the fact that on average these patients were not profoundly metabolically deranged.

Patients with type 2 diabetes having soluble TF concentrations above $300 \mathrm{pg} / \mathrm{mL}$ have a 15-fold higher risk for the presence of microvascular disease compared to those with concentrations below $100 \mathrm{pg} / \mathrm{mL}$. Other investigators have also reported a relationship between soluble $\mathrm{TF}$ levels and existing microvascular disease in patients with type 2 diabetes 18,28 . However these studies did not show that soluble TF predicted microvascular disease independent from other risk factors.

Prothrombin fragment F1+2, D-dimer, FVIII activity, soluble TM, t-PA, PAI-1 and vWFag were not related to prevalent or incident micro-, macro- and neurogenic cardiovascular complications in the patients. Our observations confirm a prothrombotic state in type 2 diabetes, but do not provide evidence for a major role of hypercoagulability, defined as increased rate of thrombin and/or fibrin generation. Previous studies have clearly shown an increased clotting activity in type 2 diabetes and the discrepancies among different study populations may be due to various confounding factors, including metabolic control, co morbidity and medication. The increased level of PAI-1 confirms many previous studies in diabetic patients; its source may be primarily abdominal fat cells, but platelets and perivascular adipose tissue should also be taken into account 29,30 . One important modulator of coagulation may have been the use of statins in a substantial proportion of these patients, since we and others have demonstrated that statins may reduce coagulation activity in type 2 diabetes 31,32 . In the present study 
however, we did not detect any anticoagulant influence of concurrent use of a statin.

Markers of coagulation and endothelial activation and incidence of vascular disease Cohort studies showed that vWFag, as marker of endothelial dysfunction, and in addition FVIII activity, which levels are related to vWFag 33 , predicted acute macrovascular events $2,34,35$ and all-cause mortality 36 . Few studies have evaluated the predictive value of other markers of coagulation and endothelial dysfunction for cardiovascular events in patients with type 2 diabetes and the results of these studies are inconclusive. In patients with type 2 diabetes undergoing hemodialysis elevated D-dimer levels were associated with a higher risk for all-cause mortality 37 . In contrast, in 93 patients with type 2 diabetes prothrombin fragment F1+2 was not predictive for micro- and macrovascular complications after a follow period of 2 years ${ }^{38}$. Although our study is limited by its short follow up period, we were able to detect 48 new events in 41 patients.

In the patients tested after one year follow up the laboratory markers remained surprisingly unchanged. This finding supports the idea that the measured circulating proteins reflect the individual's chronic condition and are hardly influenced by relatively short term variations. The finding of a significant increase in $\mathrm{F} 1+2$ in this one year period may theoretically be due to an ageing effect, but in the absence of parallel changes in the fibrin marker $D$-dimer this change should not be interpreted as increased hypercoagulability. In addition, the rise in $\mathrm{F} 1+2$ was not different between patients developing new complications as compared to those not developing complications in the one year follow up period (data not shown).

In the patients with incident microvascular disease a trend towards higher soluble TF levels was observed. This finding supports the concept that markers of vascular cell activation predict cardiovascular events in patients with type 2 diabetes 39 . However, whether these increases have a causal relationship with existing or developing cardiovascular complications is unknown on the basis of available literature data.

In conclusion, whereas a number of proteins reflecting coagulation and fibrinolysis fail to predict a clinically relevant outcome in patients with type 2 diabetes, the present study showed that soluble $T F$ is independently related to presence of microvascular disease. Although our data primarily reflect a pathophysiological process it may be postulated that soluble $\mathrm{TF}$ is a promising marker of microvascular disease. 


\section{Acknowledgements}

We gratefully acknowledge the technical support of Yvonne van der Heide, BSc, and the help in analysis of the data by Vincent Rietveld, MSc. We thank Monique de Rijk and Olga Ternede, research nurses from the Slotervaart Hospital, for their great help in this investigation. We thank APA Groot and EW Vogels from the Laboratory for Experimental Internal Medicine (AMC) for their excellent technical assistance. We thank R Lindeboom from the department of Clinical Epidemiology (AMC) and prof M.H. Prins from the department of Clinical Epidemiology (UM) for statistical advice.

$\mathrm{H}$ ten Cate is a Clinical Established Investigator of and HR Hansen is supported by the Netherlands Heart Foundation (Project grant 2000B062). The study costs were defrayed from the material budget provided by the Netherlands Heart Foundation to DW Sommeijer, HR Hansen and $\mathrm{H}$ ten Cate. 


\section{References}

1. Stamler J, Vaccaro O, Neaton JD, Wentworth D. Diabetes, other risk factors, and 12-yr cardiovascular mortality for men screened in the Multiple Risk Factor Intervention Trial. Diabetes Care. 1993;16:434-444.

2. Standl E, Balletshofer B, Dahl B, et al. Predictors of 10-year macrovascular and overall mortality in patients with NIDDM: the Munich General Practitioner Project. Diabetologia. 1996;39:1540-1545.

3. Juhan-Vague I, Thompson SG, Jespersen J. Involvement of the hemostatic system in the insulin resistance syndrome. A study of 1500 patients with angina pectoris. The ECAT Angina Pectoris Study Group. Arterioscler Thromb. 1993;13:1865-1873.

4. Mogensen CE. Microalbuminuria predicts clinical proteinuria and early mortality in maturityonset diabetes. N Engl J Med. 1984;310:356-360.

5. Gutstein DE, Fuster V. Pathophysiology and clinical significance of atherosclerotic plaque rupture. Cardiovasc Res. 1999;41:323-333.

6. Koenig W. Haemostatic risk factors for cardiovascular diseases. Eur Heart J. 1998;19 Suppl C:C39-43.

7. Moss AJ, Goldstein RE, Marder VJ, et al. Thrombogenic factors and recurrent coronary events. Circulation. 1999;99:2517-2522.

8. Biondi-Zoccai GG, Abbate A, Liuzzo G, Biasucci LM. Atherothrombosis, inflammation, and diabetes. J Am Coll Cardiol. 2003;41:1071-1077.

9. Carr ME. Diabetes mellitus: a hypercoagulable state. J Diabetes Complications. 2001;15:4454.

10. Frohlich J, Steiner G. Dyslipidaemia and coagulation defects of insulin resistance. Int J Clin Pract Suppl. 2000:14-22.

11. Grundy SM, Hansen B, Smith SC, Jr., Cleeman JI, Kahn RA. Clinical management of metabolic syndrome: report of the American Heart Association/National Heart, Lung, and Blood Institute/American Diabetes Association conference on scientific issues related to management. Circulation. 2004;109:551-556.

12. Eckel RH, Wassef M, Chait A, et al. Prevention Conference VI: Diabetes and Cardiovascular Disease: Writing Group H: pathogenesis of atherosclerosis in diabetes. Circulation. 2002;105:e138-143.

13. Friedewald WT, Levy RI, Fredrickson DS. Estimation of the concentration of low-density lipoprotein cholesterol in plasma, without use of the preparative ultracentrifuge. Clin Chem. 1972;18:499-502.

14. Reverter $\mathrm{JL}$, Reverter JC, Tassies $\mathrm{D}$, et al. Thrombomodulin and induced tissue factor expression on monocytes as markers of diabetic microangiopathy: a prospective study on hemostasis and lipoproteins in insulin-dependent diabetes mellitus. Am J Hematol. 1997;56:93-99.

15. Buchs AE, Kornberg A, Zahavi M, Aharoni D, Zarfati C, Rapoport MJ. Increased expression of tissue factor and receptor for advanced glycation end products in peripheral blood mononuclear cells of patients with type 2 diabetes mellitus with vascular complications. Exp Diabesity Res. 2004;5:163-169.

16. Diamant M, Nieuwland R, Pablo RF, Sturk A, Smit JW, Radder JK. Elevated numbers of tissue-factor exposing microparticles correlate with components of the metabolic syndrome in uncomplicated type 2 diabetes mellitus. Circulation. 2002;106:2442-2447. 
17. Sambola A, Osende J, Hathcock J, et al. Role of risk factors in the modulation of tissue factor activity and blood thrombogenicity. Circulation. 2003;107:973-977.

18. Zumbach $M$, Hofmann $M$, Borcea $V$, et al. Tissue factor antigen is elevated in patients with microvascular complications of diabetes mellitus. Exp Clin Endocrinol Diabetes. 1997; 105:206-212.

19. Lim HS, Blann AD, Lip GY. Soluble CD40 ligand, soluble P-selectin, interleukin-6, and tissue factor in diabetes mellitus: relationships to cardiovascular disease and risk factor intervention. Circulation. 2004;109:2524-2528.

20. Doshi SN, Marmur JD. Evolving role of tissue factor and its pathway inhibitor. Crit Care Med. 2002;30:5241-250.

21. Koyama T, Ohdama S, Aoki N. Plasma tissue factor reflects endothelial cell injury rather than upregulation of tissue factor expression. Thromb Haemost. 1997;78:972.

22. Cardigan R, McGloin H, Mackie I, Machin S, Singer M. Endothelial dysfunction in critically ill patients: the effect of haemofiltration. Intensive Care Med. 1998;24:1264-1271.

23. Makin AJ, Blann AD, Chung NA, Silverman SH, Lip GY. Assessment of endothelial damage in atherosclerotic vascular disease by quantification of circulating endothelial cells. Relationship with von Willebrand factor and tissue factor. Eur Heart J. 2004;25:371-376.

24. Mackman N. Role of tissue factor in hemostasis, thrombosis, and vascular development. Arterioscler Thromb Vasc Biol. 2004;24:1015-1022.

25. Muller I, Klocke A, Alex M, et al. Intravascular tissue factor initiates coagulation via circulating microvesicles and platelets. Faseb J. 2003;17:476-478.

26. Falati S, Gross P, Merrill-Skoloff G, Furie BC, Furie B. Real-time in vivo imaging of platelets, tissue factor and fibrin during arterial thrombus formation in the mouse. Nat Med. 2002;8:1175-1181.

27. Butenas S, Bouchard BA, Brummel-Ziedins KE, Parhami-Seren B, Mann KG. Tissue factor activity in whole blood. Blood. 2005;105:2764-2770.

28. Song KS, Kim HK. Plasma levels of tissue factor antigen in patients with non-insulindependent diabetes mellitus. Yonsei Med J. 2004;45:38-42.

29. Mavri A, Alessi MC, Juhan-Vague I. Hypofibrinolysis in the insulin resistance syndrome: implication in cardiovascular diseases. J Intern Med. 2004;255:448-456.

30. Yudkin JS, Eringa E, Stehouwer CD. "Vasocrine" signalling from perivascular fat: a mechanism linking insulin resistance to vascular disease. Lancet. 2005;365:1817-1820.

31. Sommeijer DW, MacGillavry MR, Meijers JC, Van Zanten AP, Reitsma PH, Ten Cate H. Antiinflammatory and anticoagulant effects of pravastatin in patients with type 2 diabetes. Diabetes Care. 2004;27:468-473.

32. Undas A, Brummel-Ziedins KE, Mann KG. Statins and blood coagulation. Arterioscler Thromb Vasc Biol. 2005;25:287-294.

33. Bombeli T, Jutzi M, De Conno E, Seifert B, Fehr J. In patients with deep-vein thrombosis elevated levels of factor VIII correlate only with von Willebrand factor but not other endothelial cell-derived coagulation and fibrinolysis proteins. Blood Coagul Fibrinolysis. 2002;13:577-581.

34. Breddin HK, Krzywanek $\mathrm{HJ}$, Althoff $\mathrm{P}$, et al. Spontaneous platelet aggregation and coagulation parameters as risk factors for arterial occlusions in diabetics. Results of the PARD-study. Int Angiol. 1986;5:181-195. 
35. Saito I, Folsom AR, Brancati FL, Duncan BB, Chambless LE, MCGovern PG. Nontraditional risk factors for coronary heart disease incidence among persons with diabetes: the Atherosclerosis Risk in Communities (ARIC) Study. Ann Intern Med. 2000;133:81-91.

36. Jager A, van Hinsbergh VW, Kostense PJ, et al. von Willebrand factor, C-reactive protein, and 5-year mortality in diabetic and nondiabetic subjects: the Hoorn Study. Arterioscler Thromb Vasc Biol. 1999; 19:3071-3078.

37. Hocher B, Ziebig R, Altermann C, et al. Different impact of biomarkers as mortality predictors among diabetic and nondiabetic patients undergoing hemodialysis. J Am Soc Nephrol. 2003;14:2329.2337.

38. Mascia F, Paoletti P, Mameli G, Mamusa AM, Cirillo R, Marongiu F. Dermatan sulphate, heparin cofactor $I$, and $F 1+2$ peptide in non-insulin-dependent diabetes mellitus. Thromb Res. 2000;97:263-265.

39. Leurs PB, Stolk RP, Hamulyak K, Van Oerle R, Grobbee DE, Wolffenbuttel BH. Tissue factor pathway inhibitor and other endothelium-dependent hemostatic factors in elderly individuals with normal or impaired glucose tolerance and type 2 diabetes. Diabetes Care. 2002;25:1340-1345. 
Chapter 3

The prognostic significance of QRS and QTc interval prolongation in a Dutch type-2 diabetes population

Hjalmar H. Hansen - Wik L. ten Holt • Eelco W. Meesters • Henri M.H. Spronk Pieter H. Reitsma - Hugo ten Cate Diabetic Medicine. 2007 Submitted 


\section{Abstract}

Aims The purpose of this study was to re-evaluate the clinical usefulness of a single screening ECG recording in type-2 diabetes patients attending the diabetes outpatient

clinic.

Methods and results Clinical data concerning diabetic cardiovascular complications were recorded at first visit and after one year follow-up and compared with ECG data including QTc-interval and QRS-duration in a cohort of 128 type-2 diabetes outpatients. Patients with current neurogenic disease had significantly longer duration of QTc-intervals than subjects without such complications (433 $\mathrm{msec}(421-445)$ vs. $420 \mathrm{msec}(415-425) \mathrm{p}=0.02)$. No significant correlations were observed between QTC-intervals or QRS-duration at baseline and other forms of diabetic complications. Patients with new diabetic complications during the one year follow-up $(n=41)$ had a statistically significant prolongation of QRS-duration at baseline compared with patients who did not develop new cardiovascular complications (98 msec (92-104) vs. $93 \mathrm{msec}(89-96) \mathrm{p}=0.0326$ ). Furthermore, QRS-duration at baseline was significantly prolonged in patients with new macrovascular events $(n=13)$ compared to those patients who did not develop a new macrovascular complication (98 $\mathrm{msec}(96-124)$ vs. $93 \mathrm{msec}(90-96) \mathrm{p}=0.0012)$.

Conclusion This study provides new arguments in favor of the clinical relevance of a single ECG recording for assessing the risk of prevalent as well as incident cardiovascular complications in type- 2 diabetes patients. 


\section{Introduction}

Type- 2 diabetes is a common disease with increasing prevalence due to advanced age, little physical activity and more obesity in the general population. Patients with type-2 diabetes have a 2-4 fold increased morbidity from cardiovascular disease in comparison with non-diabetic subjects 1,2 . Around $28 \%$ of men and $18 \%$ of women with type-2 diabetes have some form of ischemic heart disease 3-5. As a consequence, the estimated reduction of life expectancy is 10 years for a person when diagnosed with diabetes at 45 years of age and 5 years when diagnosed at 60 years of age. Because of the substantial risks for cardiovascular disease in the type2 diabetes population, the best approach for risk reduction is by screening for known risk factors including smoking, hypertension, microalbuminuria, and dyslipidemia. Furthermore, upon first assessment in the outpatient clinic, an electrocardiogram $(E C G)$ is taken and several studies have demonstrated that a single ECG recording can show specific abnormalities that translate into an increased risk of (myocardial) morbidity 6-10. In general everyday practice, however, a single ECG recording does not lead to specific adjustments in patient care. In order to reassess the clinical value of the single recording ECG we studied baseline ECG recordings in a cohort of consecutive type-2 diabetes patients who were referred by their general practitioner to the diabetes outpatient clinic of the Slotervaart hospital, the Netherlands.

\section{Methods}

\section{Study Patients}

The patient cohort involved 128 consecutive type- 2 diabetes patients from the outpatient clinic of the Slotervaart hospital, the Netherlands. All patients were referred by the general practitioner, usually because of concern about metabolic control or persistent presence of risk factors, such as hypertension, or dyslipidemia. 76 men and 52 women with a minimum age of 25 years and with type- 2 diabetes participated in this study. The mean age was 59.1 years (range: 30.6-87.5). Excluded from this study were patients with undetectable C-peptide levels, insulin treatment before puberty, history of diabetic ketoacidosis, active chronic inflammatory disease, or cancer. This study was approved by the Medical Ethical Committee, Slotervaart Hospital, Amsterdam, The Netherlands, and all participants
gave written informed consent.

\section{Study design}

At inclusion and after one year follow-up, patients with type-2 diabetes were given a thorough physical examination and medical history was recorded. Special focus was put on the occurrence of any existing cardiovascular complications. Microvascular 
disease included one or more of the following: retinopathy (as diagnosed by fundoscopy by an ophthalmologist through dilated pupils) or microalbuminuria (microalbumin excretion in urine $>30 \mathrm{mg} / 24 \mathrm{~h}$ ). Neuropathy, defined as peripheral sensory neuropathy, was assessed clinically by electromyography or neurogenic ulcers. Macrovascular disease included one or more of the following: documented myocardial infarction or angina pectoris, according to the guidelines of the Dutch Society of Cardiology, cerebrovascular accident or intermittent claudication. Further data were obtained on the duration of type- 2 diabetes, medication use, body mass index, blood pressure (high blood pressure was defined as systolic pressure $>140$ $\mathrm{mmHg}$ and/or diastolic pressure $>85 \mathrm{mmHg}$ ), and lifestyle parameters.

\section{Electrocardiographic variables}

Electrocardiograms where registered at each visit. All electrocardiograms where assessed by a single cardiologist(WLtH ), who was unaware of the status of the patients or of the presence or absence of existing complications. QRS-duration, duration of QT-interval, and heart rate were copied from the electrocardiograms as they were measured by the "Megacart $3 \mathrm{~V} 4$ " assessment program in the ECGrecorders. In case a Megacart evaluation was not present (7 of 128 cases) electrocardiographic intervals were manually measured by the cardiologist, obtaining the QT-interval from the lead with the most clear T-wave ending when assessing leads II, III, V2 or V3. Corrected QT-intervals were calculated from heart rate and duration of QT-interval using the Bazett-formula 11. Electrocardiograms were assessed for pathologic Q-waves, pathologic ST-changes and conductiondisturbances. If present, two electrocardiograms of each patient were assessed, with at least one year interval between the two electrocardiograms.

\section{Blood sampling and laboratory procedures}

Blood sampling consisted of a standard venapuncture at which blood was collected into $3.2 \%$ trisodium citrate (Beckton Dickinson, San Jose, CA, USA) as described previously ${ }^{12}$. Citrated plasma was stored at $-80^{\circ} \mathrm{C}$ until use. Plasma triglycerides, total cholesterol and high density lipoprotein (HDL)-cholesterol were measured enzymatically (Synchron LX20/CX7delta®), Beckman Coulter, Fullerton, California, USA). Low density lipoprotein (LDL)-cholesterol was calculated using the Friedewald formula ${ }^{13}$. $\mathrm{HbA}_{1 \mathrm{c}}$ was determined in whole blood by high-performance liquid chromatography using a mono $\mathrm{S}$ column (Pharmacia diagnostics, Uppsala, Sweden). Homocysteine levels were measured by high-performance liquid chromatography (Jasco, Tokyo, Japan). Soluble tissue factor (sTF) antigen levels were measured by ELISA (Imubind $\otimes$, American diagnostica Inc., Greenwich, Conneticut, USA) and von Willebrand Factor (vWF) antigen levels were determined by an immunoturbidimetric assay with the Behring Coagulation System (BCS) (vWFAg Dade-Behring). 
All assays were performed according the instructions of the manufacturer without any modification.

Statistical analysis

Data are presented as median (inter-quartile range) for non-normal or mean (95\% confidence interval) for normally distributed variables. Differences between groups (patients with cardiovascular complications vs. patients without complications) were assessed using non-paired Student's $t$-test for normally distributed variables or Mann-Whitney $U$ test when the distribution was not normal. For comparison of data from patients with type- 2 diabetes at baseline with data after one year followup a paired $t$-Test or Wilcoxon rank test was used, depending on the normality of the distribution. Corrections for potential confounders were done by ANCOVA analysis (General linear model, univariate). $P$ values $<0.05$ were considered statistically significant. Statistical analyses were performed using SPSS version 12.01 for Microsoft Windows.

Table 1

Characteristics of subjects with type 2 diabetes

\begin{tabular}{|c|c|}
\hline Baseline characteristics & Type 2 diabetes patients $n=128$ \\
\hline Age (years) & $59.1(30.6-87.5)$ \\
\hline Sex $(\%$ male) & $60 \%$ \\
\hline Duration of diabetes until sample date (years) & $7.2(0.0-32.2)$ \\
\hline Systolic blood pressure $(\mathrm{mmHg})$ & $142(105-210)$ \\
\hline Diastolic blood pressure $(\mathrm{mmHg})$ & $81(50-110)$ \\
\hline$B M I\left(\mathrm{~kg} / \mathrm{m}^{2}\right)$ & $29.6(25.9-32.7)$ \\
\hline $\mathrm{Hb}(\mathrm{mmol} / \mathrm{L})$ & $8.8(6.3-10.5)$ \\
\hline Leucocytes $\left(10^{9} / L\right)$ & $7.8(3.1-21.5)$ \\
\hline Platelets $\left(10^{9} / \mathrm{L}\right)$ & $250(129.399)$ \\
\hline Glucose (mmol/L) & $9.6(2.9-20.9)$ \\
\hline $\mathrm{HbA}_{1 \mathrm{c}}(\%)$ & $7.5(5.2-11.8)$ \\
\hline Creatinine (mmol/24hr) & $82(7-139)$ \\
\hline Total cholesterol (mmol/L) & $5.12(2.56-7.80)$ \\
\hline $\mathrm{HDL}$ cholesterol (mmol/L) & $1.21(0.68-4.90)$ \\
\hline LDL cholesterol (mmol/L) & $3.13(1.00-5.71)$ \\
\hline Triglycerides (mmol/L) & $1.73(0.47-4.66)$ \\
\hline Homocysteine ( $\mu$ mol $/ L)$ & $10.9(3.9-24.8)$ \\
\hline Microalbumin (mg $/ 24 \mathrm{hr}$ ) & $51(2-826)$ \\
\hline
\end{tabular}

\section{Results}

\section{Patient baseline characteristics}

The study was primarily designed as a prospective cohort investigation, therefore the comparison with healthy individuals was not considered relevant. One hundred and twenty-eight patients with type-2 diabetes were evaluated in this study, of 
which the baseline characteristics are summarized in Table 1 . Twenty nine percent of the type-2 diabetes patients had current microvascular complications (retinopathy and/or nephropathy), 40\% had current macrovascular complications (myocardial infarction, angina pectoris, cerebrovascular event, or peripheral artery disease), and $23 \%$ suffered from current neurogenic complications (neuropathy, neurogenic ulcer). Sixty percent of all patients had one or more types of complications at inclusion.

Mean QT-interval duration was $377 \mathrm{msec}$. (370-382) and was not significantly different between type-2 diabetic males and females $(377(367-387)$ vs. $375(368-$ 383). The mean heart rate was $78 / \mathrm{min}( \pm 15)(76 / \mathrm{min} \pm 17$ in males vs. $80 / \mathrm{min} \pm$ 10 in females, $p=0.0265)$. Mean QTc-interval was $423 \mathrm{msec}$. (419-428) and significantly different between the sexes: $418(412-424)$ in males vs. $430(425-438)$ in females, $p=0.009$. QRS-duration at baseline was $95 \mathrm{msec}(92-98)$ and was longer in males compared to females $(99(94-103)$ vs. $89(85-92), p=0.009)$. Two patients had a left anterior fascicular block, two patients right axis deviation, but no other conduction defects were noted. Blood pressure and smoking were not associated with the ECG parameters in this study population.

\section{Relationship between ECG parameters and laboratory markers}

To investigate relationships between classic risk factors for cardiovascular disease and the measured and calculated ECG parameters, Spearman-Rho correlations were calculated (Table 2). Total cholesterol, HDL, LDL, triglycerides, homocysteine, and vWF antigen did not correlate with QRS-duration or duration of QTc-interval. sTF antigen levels, however, displayed a weak but significant correlation with QRSduration $(r=0.256, p=0.0055)$.

Table 2

Relationship between ECG parameters and laboratory markers

\begin{tabular}{|c|c|c|}
\hline Labortatory Markers & QTC & QRS \\
\hline \multirow[t]{2}{*}{ Soluble Tissue Factor } & $r=0.008(-0.173-0.190)$ & $(0.077-0.418)$ \\
\hline & & $p=0.0055$ \\
\hline Von Willebrand Factor & $r=0.124(-0.058-0.299)$ & $r=0.109(-0.074-0.287)$ \\
\hline Total cholesterol & $r=-0.010(-0.195-0.176)$ & $r=0.022(-0.160-0.204)$ \\
\hline HDL cholesterol & $r=-0.025(-0.210-0.161)$ & $r=0.008(-0.178-0.195)$ \\
\hline LDL cholesterol & $r=-0.107(-0.287-0.080)$ & $r=-0.060(-0.244-0.128)$ \\
\hline Triglycerides & $r=0.173(-0.013-0.348)$ & $r=0.043(-0.141-0.231)$ \\
\hline Homocysteine & $r=0.131(-0.075-0.326)$ & $r=0.173(-0.033-0.365)$ \\
\hline
\end{tabular}

Data shown is the Spearman correlation coefficient for laboratory markers versus respectively QTc-interval, and QRS-duration (95\% Cl)

Relationship between ECG parameters and current cardiovascular complications In order to investigate the relationship between the different ECG parameters at baseline and the prevalence of cardiovascular complications, ECG parameters were 
compared between patients with and without cardiovascular complications (Figures 1 and 2). The presence of neurogenic disease was associated with a significantly longer duration of QTc-intervals (433 $\mathrm{msec}$ (422-444) vs. $420 \mathrm{msec}$ (416-425) $\mathrm{p}=0.02$ ), whereas the QTc-interval was not different between patients with or without current macrovascular complications (424 msec (417-432) vs. $423 \mathrm{msec}$ (417-429) or microvascular complications (429 msec (421-439) vs. $421 \mathrm{msec}$ (416426). QTc-intervals remained significantly longer in subjects with neurogenic complications at baseline compared to those without such complications when corrections were made for potential confounders such as age, gender, smoking, medication (ß-blockers and calcium antagonists), blood pressure, and glucose levels $(\mathrm{p}=0.02$, Table 3$)$.

The other measured ECG parameters (heart rate frequency and QRS-duration) were not related to the presence of cardiovascular disease, although we observed a trend towards longer QRS-durations in patients with current macro- and microvascular complications.
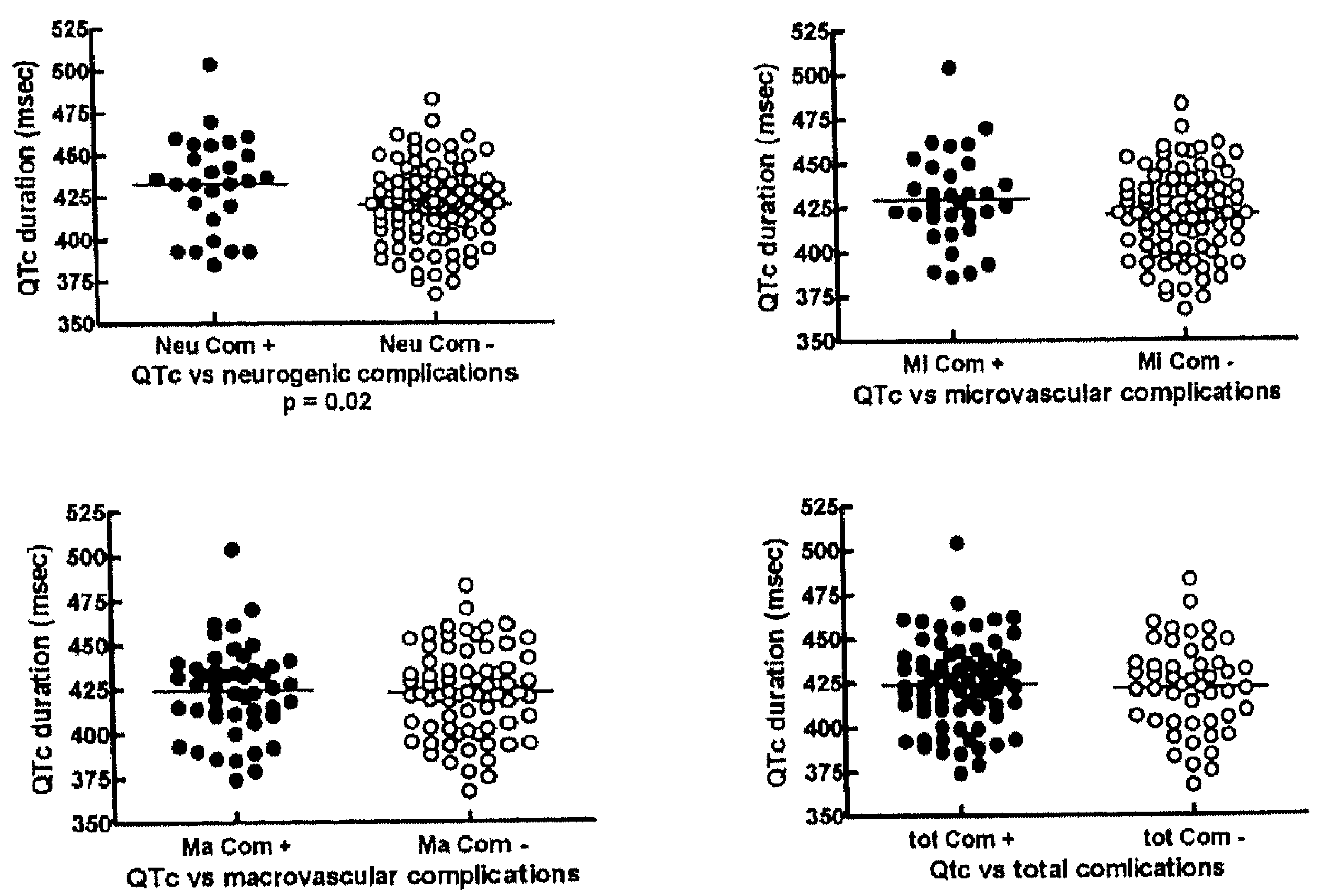

Figure 1:

Duration of QTc-interval in type-2 diabetes patients with or without neurogenic complications (a), microvascular complications (b), macrovascular complications (c) and total complications (d) at baseline. 
Table 3

Differences in potential confounders on ECG-analysis

\begin{tabular}{|c|c|c|c|c|c|c|c|}
\hline \multirow[b]{2}{*}{ Confounder } & \multicolumn{6}{|c|}{$\begin{array}{c}\text { Neurogenic Complications } \\
\text { (At baseline) }\end{array}$} & \multirow[b]{2}{*}{$\mathrm{p}$} \\
\hline & No & & & Yes & & & \\
\hline$n$ & 90 & & & 27 & & & \\
\hline Age & 54.6 & $(48.8-$ & $64.8)$ & 66.7 & $(58.2$ & 73.7) & 0.001 \\
\hline Male/Female & $55 / 35$ & & & $17 / 10$ & & & \\
\hline Systolic BP & 140 & $(124 \cdot$ & 150) & 145 & (131 - & 176) & \\
\hline Diastolic BP & 80 & $(80-$ & 90) & 80 & $(70-$ & 85) & \\
\hline Smoking & 23 & & & 4 & & & \\
\hline B-Blocker & 15 & & & 3 & & & \\
\hline Calcium Antagonist & 13 & & & 4 & & & \\
\hline Glucose & 8.8 & $(7.3$ - & $10.5)$ & 9.6 & $(7.5-$ & 11.3) & \\
\hline $\mathrm{HbA}_{1 c}$ & 7.3 & $(6.5-$ & $8.2)$ & 7.4 & (6.7 - & $8.0)$ & \\
\hline QRS (msec) & 92 & $(84 \cdot$ & $100)$ & 92 & $(88-$ & & \\
\hline \multirow[t]{3}{*}{ QTc (msec) } & 420 & $(416$ - & 415) & 433 & $(422$ - & 444) & $0.02^{*}$ \\
\hline & \multicolumn{6}{|c|}{$\begin{array}{c}\text { Macrovascular Events } \\
\text { (After one year follow-up) }\end{array}$} & \\
\hline & No & & & Yes & & & $\mathrm{p}$ \\
\hline$n$ & 103 & & & 14 & & & \\
\hline Age & 58.2 & $(51.5$ & 68.9) & 57 & $(54.4-$ & $62.5)$ & \\
\hline Male/Female & $59 / 44$ & & & $13 / 1$ & & & \\
\hline Systolic BP & 140 & $(125-$ & 160) & 133 & $(130-$ & 144) & \\
\hline Diastolic BP & 80 & $(76$ & 90) & 80 & $(70-$ & 85) & \\
\hline Smoking & 23 & & & 4 & & & \\
\hline B-Blocker & 14 & & & 4 & & & \\
\hline Calcium Antagonist & 12 & & & 5 & & & 0.033 \\
\hline Glucose & 9.0 & $(7.4$ - & $10.7)$ & 8.0 & (7.0 - & 12.0) & \\
\hline \multirow[t]{2}{*}{$\mathrm{HbA}_{1 \mathrm{c}}$} & 7.0 & $(6.5-$ & $8.2)$ & 7.3 & $(6.7-$ & $8.1)$ & \\
\hline & & & & 93 & $(90$. & 96) & \\
\hline QRS (msec) & 93 & $(90-$ & 96) & 110 & (96- & 125) & $0.009^{*}$ \\
\hline QTc (msec) & 429 & $(416$ - & 442) & 423 & (418 - & 429) & \\
\hline
\end{tabular}

Relationship between ECG parameters and new cardiovascular events

After one year follow-up we obtained clinical data from 117 patients with type-2 diabetes; 8 patients were lost to follow-up due to moving to another region and 3 declined follow-up assessment. In these 117 patients (91\% of the initial cohort) 48 
new cardiovascular complications were diagnosed in a total of 41 patients, including two cardiovascular deaths, 1 non-fatal myocardial infarction, 4 ischemic strokes, 3 new cases of angina pectoris, 2 cases with a presentation of intermittent claudication, 8 newly detected cases of retinopathy, 13 micro-albuminuria, 13 neuropathy and 2 neurogenic ulcers. The relationships between the different ECG parameters at baseline and the incidence of new micro-, macro- and neurogenic complications during follow-up was determined through comparison of the ECG parameters between patients with and without those new complications. When comparing the patients who developed any new diabetic complication $(n=41)$ after 1 year to those who did not, we noticed a significant prolongation of QRS-duration at baseline in those patients with new complications: $98 \mathrm{msec}(92-104) \mathrm{vs} .93 \mathrm{msec}$ (89-96) $\mathrm{p}=0.0326$ (Figure 3).
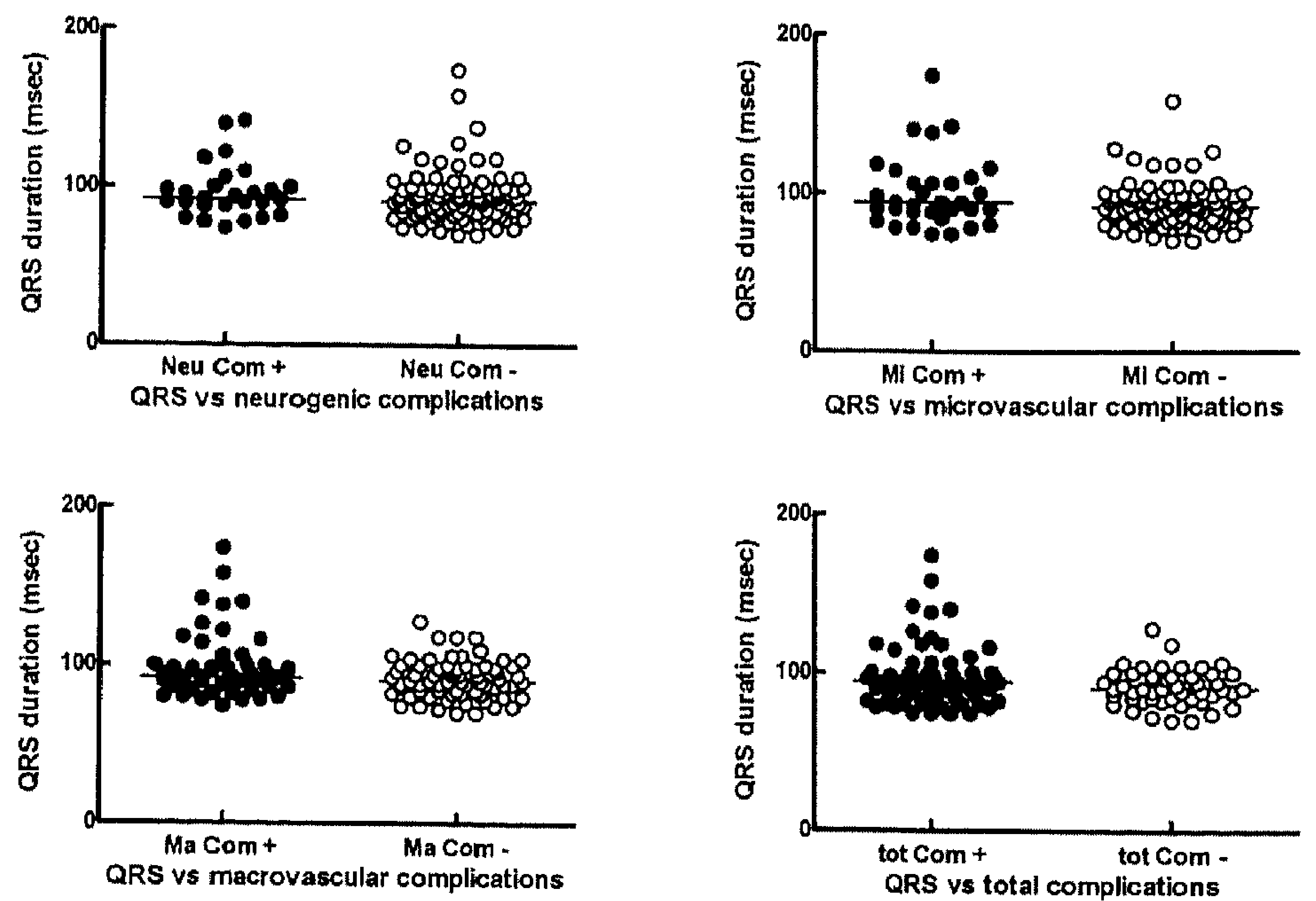

Figure 2:

QRS-duration in type-2 diabetes patients with or without neurogenic complications (a), microvascular complications (b), macrovascular complications (c) and total complications (d) at baseline.

QRS-duration at baseline was significantly prolonged in patients with new macrovascular events $(n=13)$ compared to those patients who did not develop a new macrovascular complication within one year follow-up: $110 \mathrm{msec}$ (96-125) vs. 93 msec $(90-96) \mathrm{p}=0.001$ and $\mathrm{p}=0.009$ when corrected for potential confounders (Table 3). QRS duration between baseline and one year follow-up was on average 20 
msec decreased in patients with new macrovascular complications compared to a 5 msec increase in QRS duration for those without new complications ( $p=0.006)$. Patients with new microvascular $(n=21)$ or neurogenic $(n=15)$ complications at one year follow-up had a QRS-duration at baseline similar to those without these events (Figure 3).
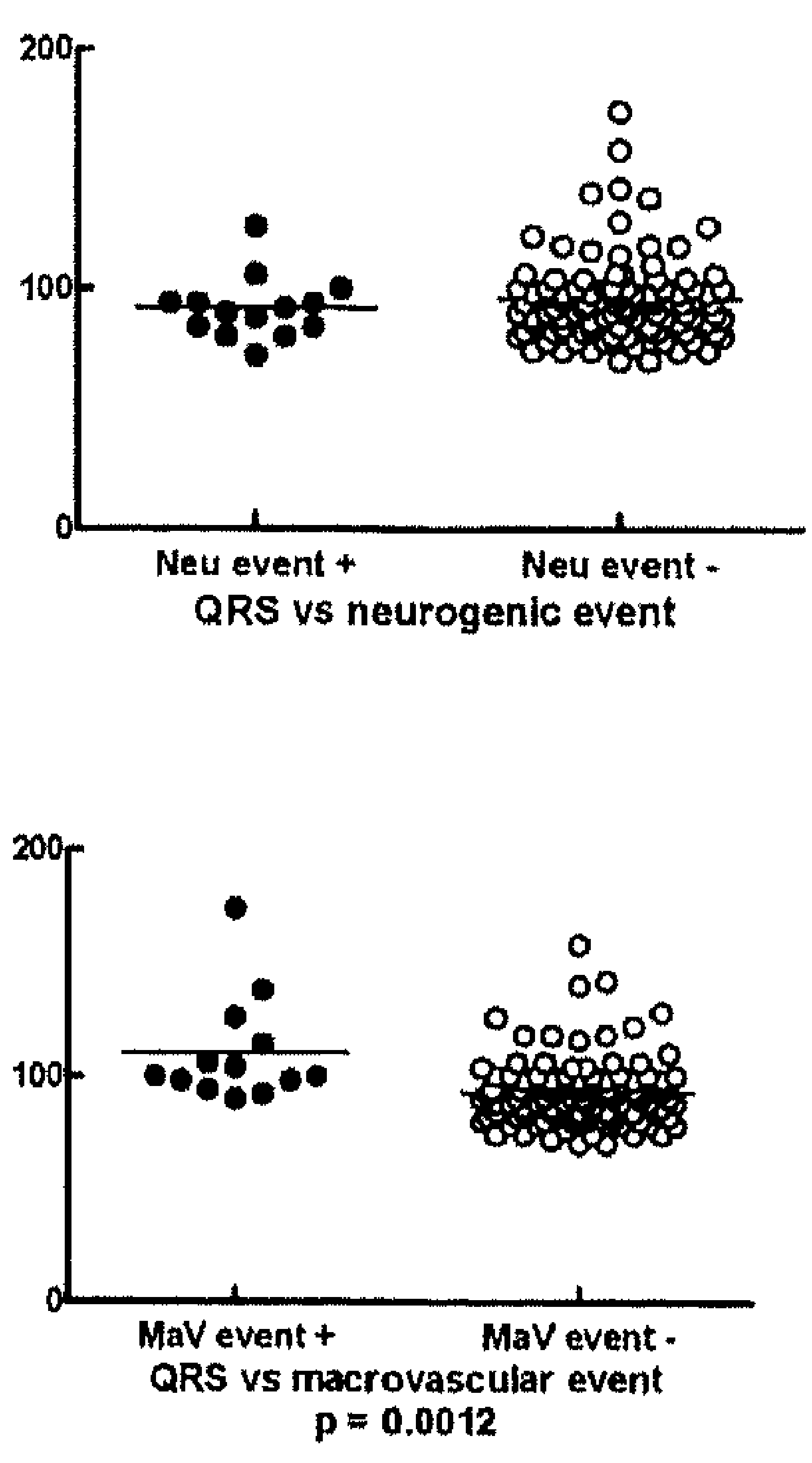

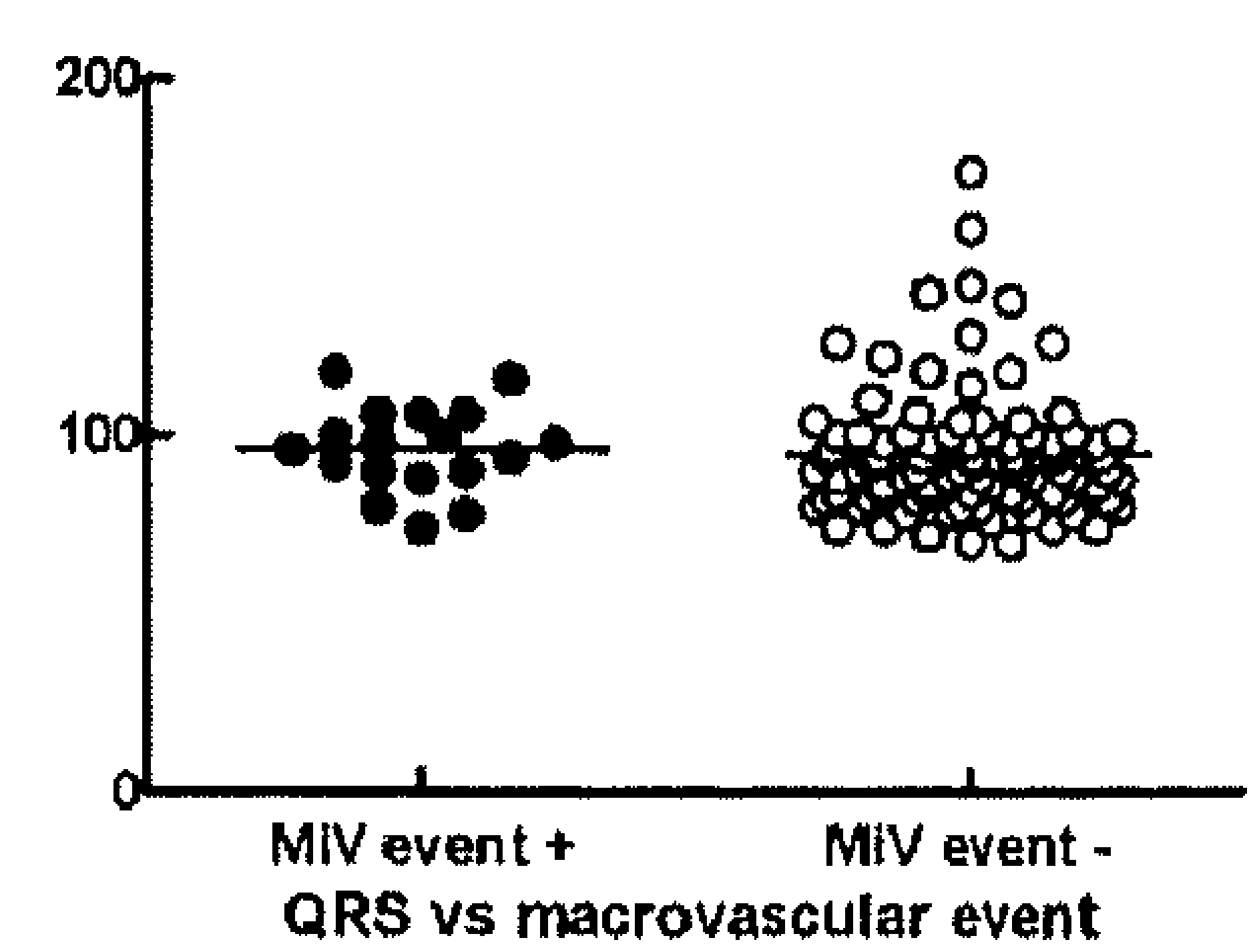

Tot event vs QRS

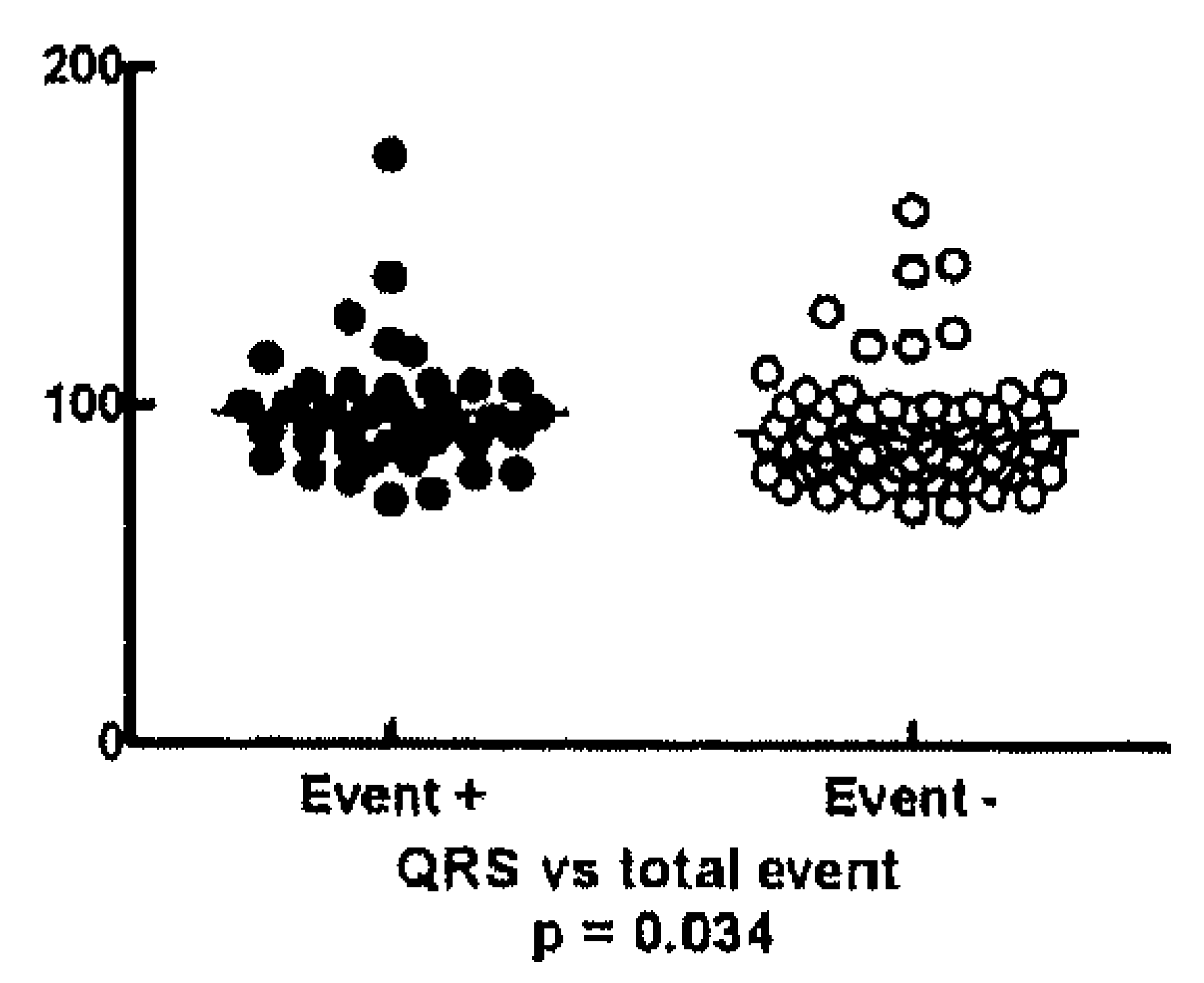

Figure 3:

QRS-duration at baseline in type-2 diabetes patients with or without new neurogenic events (a), new microvascular events (b), new macrovascular events (c) and the total of new events (d) after 1 year.

\section{Discussion}

The expanding population of type-2 diabetes patients at increased risk of developing one or more form of cardiovascular disease makes it important to identify those patients who are at greatest risk to develop these complications. On first assessment at the diabetes outpatient clinic, after referral by their general practitioner, type-2 diabetic patients are commonly screened for diabetic complications by 24 hour microalbuminuria testing, retinal fundoscopy, thorough physical examination with focus on cardiovascular and neurogenic complications and an electrocardiogram (ECG).

To investigate the relationships between ECG parameters at baseline and current or incident diabetic complications we undertook the present study. The main 
outcomes of this study are two-fold: first, the observed relation between duration of QTc-interval and prevalent neurogenic complications and second, the relation between QRS-duration and new macrovascular events, independent from potential confounders including common cardiovascular risk factors.

The duration of the QTc-interval is a representation of the interval containing ventricular excitation and repolarisation. This interval is affected by autonomic tone and reflects myocardial refractoriness and electrical stability. The heart ratecorrected QT-interval (QTC-interval) has been studied in association with various cardiovascular complications in both population-based studies and diabetic patients 9,14,15. In the general population, a prolonged duration of QTc-interval has been associated with ageing, female sex, arterial hypertension (mainly systolic blood pressure), underlying coronary artery disease, and ECG-estimated left ventricular mass (LVM). Furthermore, diabetes and impaired glucose tolerance have been associated with QTC-interval prolongation ${ }^{16-18}$ and correlations between intimalmedial thickness of the carotid artery and QTC-interval showed a relation between atherosclerosis and duration of QTc-interval 19. Most importantly, QTc-interval prolongation has been shown to be an independent predictor of stroke ${ }^{20}$ as well as a predictive factor for cardiovascular morbidity and mortality 21 in type-2 diabetes.

Although no correlations between QTc-interval and the occurrence of macro- or microvascular complications were observed in the presented type-2 diabetes cohort, the observed significantly prolonged QTc-intervals in women compared to men are in accordance with the reported association between QTc-interval duration and female sex 10. Also, QTc-interval positively correlated with the presence of neurogenic complications (diabetic neuropathy and/or diabetic ulcers) in that patients with neurogenic complications had a significantly prolonged duration of the QTc-interval. This association with prevalent neurogenic complications can be due to cardiac vagal dysfunction 22 caused by hyperinsulinemia (usually present in type-2 diabetes) which supposedly causes sympathetic activation, subsequently enhancing myocardial cell membrane refractoriness 18,23 . Insulin levels, however, were not analyzed in this study. Therefore, hyperinsulinemia could not be confirmed as a candidate cause of cardiac vagal dysfunction in the study population. Associations between blood pressure or future stroke and QTC-interval were not present in this type-2 diabetes cohort. The lack of association with future stroke is probably caused by the relatively short follow up in this study ( 1 year).

QRS-duration is a measure of ventricular depolarization, reflecting ventricular structural abnormalities (i.e., damage and hypertrophy). It has been known for a long time that conduction disturbances are associated with poor short as well as long-term prognosis of patients with acute myocardial infarction 24,25. QRSprolongation has been associated with left ventricular dysfunction 26 , is of 
prognostic value in acute myocardial infarction 6 , and has been associated with an increased risk of death and exercise-induced myocardial ischemia 27.

In this study the relationships between QRS-duration on the standard 12-lead electrocardiogram and the prevalence and incidence of cardiovascular complications in a cohort of type-2 diabetes patients were assessed. Although only a trend towards longer QRS-durations in patients with existing micro- and macrovascular complications was observed, patients who suffered from a new macrovascular event as recorded after 1 year had a significantly prolonged QRS-duration as compared to those who did not suffer from such an event. Because the type-2 diabetes cohort studied was relatively small, no cutoff could be established to identify patients at highest risk.

The mechanisms by which a prolonged QRS-duration is associated with the increased risk of macrovascular events in type-2 diabetes are not clear. Multiple physiological parameters like increased left ventricular mass ${ }^{26}$ or involvement of a poor metabolic state slowing conduction ${ }^{28} \mathrm{can}$ lead to longer QRS-duration in the type-2 diabetic patient.

Upon analyzing risk factors in relation to ECG conduction abnormalities we determined a statistically significant correlation between QRS duration and the plasma level of soluble TF. The latter protein probably reflects cellular activation, without being specifically linked to one particular cell type and is a risk factor for microvascular disease in the same patient cohort ${ }^{12}$. Part of the observed correlation may point to a microvascular origin of QRS prolongation, due to impaired microvascular circulation, but it is remarkable that this particular conduction abnormality was correlated with macro- rather than microvascular disease. Another explanation may be that soluble $\mathrm{TF}$ reflects ongoing flow-reflow phenomena that may in part be attributable by release of TF containing cellular debris and microparticles from atherosclerotic lesions in the coronary circulation 29,30 .

Although the relatively small study population size did not allow us to calculate predictive values for the measured ECG parameters and present or incident cardiovascular disease, implications of these findings should possibly be a more aggressive treatment with respect to prevention of cardiovascular disease in those type-2 diabetes patients with a prolonged QRS-duration on admission to a diabetic outpatient clinic. Together with the relations seen between duration of QTc-interval and the presence of neurogenic disease the diagnostic value of a standard 12-lead electrocardiogram in this group of patients is of greater importance than only to document previous cardiovascular complications. In spite of this and in accordance with current guidelines our data do not give a basis for routine ECG screening of patients with diabetes. However, the ability to detect by a single 12-lead ECG clinically useful data at initial screening of diabetics may be taken into account as a risk indicator in future studies. 


\section{Acknowledgments}

We like to thank Vincent Rietveld, MSc for his assistance in collecting the data. Arne Dielis, MD and Martin H. Prins, MD provided statistical advice. Hugo ten Cate was a Clinical Established Investigator of the Netherlands Heart Foundation (1998T13). Hjalmar Hansen was supported by a grant from the Netherlands Heart Foundation (2000B062). 


\section{References}

1. Haffner SM, Lehto S, Ronnemaa T, Pyorala K, Laakso M. Mortality from coronary heart disease in subjects with type 2 diabetes and in nondiabetic subjects with and without prior myocardial infarction. N Engl J Med. 1998;339:229-234.

2. de Vegt F, Dekker JM, Ruhe HG, et al. Hyperglycaemia is associated with all-cause and cardiovascular mortality in the Hoorn population: the Hoorn Study. Diabetologia. 1999;42:926-931.

3. Mankovsky BN, Ziegler D. Stroke in patients with diabetes mellitus. Diabetes Metab Res Rev. 2004;20:268-287.

4. Costa LA, Canani LH, Lisboa HR, Tres GS, Gross JL. Aggregation of features of the metabolic syndrome is associated with increased prevalence of chronic complications in Type 2 diabetes. Diabet Med. 2004;21:252-255.

5. Kannel WB, Ho K, Thom T. Changing epidemiological features of cardiac failure. Br Heart J. 1994;72:53-9.

6. Pudil R, Feinberg MS, Hod H, Boyko V, Mandelzweig L, Behar S. The prognostic significance of intermediate QRS prolongation in acute myocardial infarction. Int J Cardiol. 2001;78:233239.

7. Takebayashi K, Aso $Y$, Sugita R, Takemura $Y$, Inukai T. Clinical usefulness of corrected QT intervals in diabetic autonomic neuropathy in patients with type 2 diabetes. Diabetes Metab. 2002;28:127-132.

8. Veglio $M$, Bruno $G$, Borra $M$, et al. Prevalence of increased QT interval duration and dispersion in type 2 diabetic patients and its relationship with coronary heart disease: a population-based cohort. J Intern Med. 2002;251:317-324.

9. Cardoso CR, Salles GF, Deccache W. Prognostic value of QT interval parameters in type 2 diabetes mellitus: results of a long-term follow-up prospective study. J Diabetes Complications. 2003;17:169-178.

10. Rana BS, Lim PO, Naas AA, et al. QT interval abnormalities are often present at diagnosis in diabetes and are better predictors of cardiac death than ankle brachial pressure index and autonomic function tests. Heart. 2005;91:44-50.

11. Bazett HC. An analysis of the time relations of electrocardiograms. Heart. 1920;7:353-370.

12. Sommeijer DW, Hansen HR, van Oerle R, et al. Soluble tissue factor is a candidate marker for progression of microvascular disease in patients with Type 2 diabetes. $J$ Thromb Haemost. 2006;4:574-580.

13. Friedewald WT, Levy RI, Fredrickson DS. Estimation of the concentration of low-density lipoprotein cholesterol in plasma, without use of the preparative ultracentrifuge. Clin Chem. 1972;18:499-502.

14. Rutter MK, Viswanath S, MCComb JM, Kesteven P, Marshall SM. QT prolongation in patients with Type 2 diabetes and microalbuminuria. Clin Auton Res. 2002;12:366-372.

15. Rana BS, Band MM, Ogston S, Morris AD, Pringle SD, 5truthers AD. Relation of QT interval dispersion to the number of different cardiac abnormalities in diabetes mellitus. Am J Cardiol. 2002;90:483-487.

16. Festa A, D'Agostino R, Jr., Rautaharju P, Mykkanen L, Haffner SM. Relation of systemic blood pressure, left ventricular mass, insulin sensitivity, and coronary artery disease to $Q T$ interval duration in nondiabetic and type 2 diabetic subjects. Am J Cardiol. 2000;86:1117-1122. 
17. Rautaharju PM, Manolio TA, Psaty BM, Borhani NO, Furberg CD. Correlates of QT prolongation in older adults (the Cardiovascular Health Study). Cardiovascular Health Study Collaborative Research Group. Am J Cardiol. 1994;73:999-1002.

18. Dekker JM, Feskens EJ, Schouten EG, Klootwijk P, Pool J, Kromhout D. QTc duration is associated with levels of insulin and glucose intolerance. The Zutphen Elderly Study. Diabetes. 1996;45:376-380.

19. Takebayashi K, Aso Y, Matsutomo R, Wakabayashi S, Inukai T. Association between the corrected QT intervals and combined intimal-medial thickness of the carotid artery in patients with type 2 diabetes. Metabolism. 2004;53:1152-1157.

20. Cardoso CR, Salles GF, Deccache W. QTC interval prolongation is a predictor of future strokes in patients with type 2 diabetes mellitus. Stroke. 2003;34:2187-2194.

21. Sawicki PT, Kiwitt $S$, Bender $R$, Berger $M$. The value of $Q T$ interval dispersion for identification of total mortality risk in non-insulin-dependent diabetes mellitus. J Intern Med. 1998;243:49-56.

22. Takahashi $N$, Nakagawa $M$, Saikawa $T$, et al. Regulation of QT indices mediated by autonomic nervous function in patients with type 2 diabetes. Int J Cardiol. 2004;96:375-379.

23. Ferrannini E, Galvan AQ, Gastaldelli A, et al. Insulin: new roles for an ancient hormone. Eur $\mathrm{J}$ Clin Invest. 1999;29:842-852.

24. Col JJ, Weinberg SL. The incidence and mortality of intraventricular conduction defects in acute myocardial infarction. Am J Cardiol. 1972;29:344-350.

25. Julian DG, Vellani CW, Godman MJ, Terry G. Prolongation of QR5 duration in acute myocardial infarction. Prog Cardiovasc Dis. 1970;13:56-71.

26. Murkofsky RL, Dangas G, Diamond JA, Mehta D, Schaffer A, Ambrose JA. A prolonged QRS duration on surface electrocardiogram is a specific indicator of left ventricular dysfunction [see comment]. J Am Coll Cardiol. 1998;32:476-482.

27. Elhendy A, Hammill SC, Mahoney DW, Pellikka PA. Relation of QRS Duration on the Surface 12-Lead Electrocardiogram With Mortality in Patients With Known or Suspected Coronary Artery Disease. Am J Cardiol. 2005;96:1082-1088.

28. Sheridan DJ, Culling W, Penny WJ. Electrophysiological disturbances associated with acute myocardial infarction. Eur Heart J. 1986;7 5uppl B:11-18.

29. Bonderman D, Teml A, Jakowitsch J, et al. Coronary no-reflow is caused by shedding of active tissue factor from dissected atherosclerotic plaque. Blood. 2002;99:2794-2800.

30. Golino P, Ragni M, Cirillo $P$, et al. Effects of tissue factor induced by oxygen free radicals on coronary flow during reperfusion. Nat Med. 1996;2:35-40. 
Chapter 4

Detection of advanced glycated end products (AGEs) in urine from patients with type 2 diabetes: a pilot cohort study

Hjalmar R. Hansen • Henri M.H. Spronk • Tom Teerlink • Rob Barto • Pieter H. Reitsma Casper G. Schalkwijk • Hugo ten Cate 


\begin{abstract}
Advanced glycation and lipoxidation end products (AGEs/ALEs) are a complex and heterogeneous group of compounds that have been implicated in diabetes related vascular complications. A new procedure to determine in urine the levels of $N$ (carboxymethyl)lysine (CML) and $N^{k}$-(carboxyethyl)lysine (CEL), two major products of oxidative modification of glycated proteins, was used to determine whether relationships exist between urinary levels of these AGEs and the presence of cardiovascular complications in 128 type- 2 diabetics. The main outcomes of this study are firstly that no associations were observed between urinary CML/CEL concentrations and diabetic complications and that there was no relation between blood and urine concentration of these AGEs. Secondly, we confirm the relationship between AGEs in plasma and endothelial dysfunction as seen by a correlation with soluble tissue factor and furthermore we find significantly higher levels of CML in those diabetes patients with diabetic retinopathy. We conclude that while measurement of AGEs in blood is a relevant marker of vascular disease in diabetes, the assay of AGEs in urine may not have additional value.
\end{abstract}




\section{Introduction}

Patients with type-2 diabetes have a 2-4 fold increased risk for cardiovascular morbidity and mortality as compared with non diabetic subjects ${ }^{1,2}$. This increase can only be partly explained by generally recognized risk factors, such as hypertension and dyslipidemia. Large prospective studies of patients with type-1 diabetes have now quite convincingly shown an association between insufficient glycemic regulation and complications of cardiovascular disease, including myocardial infarction, establishing that hyperglycemia is also a risk factor for cardiovascular disease. One of the consequences of hyperglycemia is the increased formation of advanced glycation end products (AGEs) in vivo, via the Maillard reaction. AGEs are formed by a non-enzymatic reaction between reducing sugars and biological amines. Because of their marked stability, glycated proteins accumulate slowly over a person's lifespan, and can contribute to age-associated structural and functional changes in different organs including large blood vessels. AGEs have been implicated in the normal ageing process as well as in the pathogenesis of a wide and seemingly disparate range of pathologies such as connective tissue diseases, atherosclerosis, Alzheimer's disease, as well as diabetic complications ${ }^{3 \cdot 6}$. AGE depositions have been demonstrated in atherosclerotic plaques and myocardium in patients with diabetes and atherosclerosis ${ }^{7}$, and the cross-linking abilities of AGEs may contribute to the increased stiffening of collagen and possibly to vascular hypertrophy,8.9. Clinical studies have confirmed that circulating AGE levels are higher in diabetics then in non-diabetic subjects. Within diabetic patients, serum AGE concentrations have been reported to be increased in patients with microvascular as well as macrovascular complications $\mathbf{s}^{10-12}$.

AGEs have been associated with specific markers of endothelial cell activation, such that in conjunction with such markers, AGEs would reflect endothelial cell damage in the course of vascular disease. In a recent cohort study we established that soluble tissue factor, a circulating protein involved in the regulation of blood coagulation, was strongly correlated to microvascular disease in patients with type 2 diabetes ${ }^{13}$. Consequently we were interested to determine whether AGEs in serum would also be correlated with soluble tissue factor in the same study cohort.

A second, more technical, study question was whether detection of AGEs in urine would increase the diagnostic yield, with regard to the presence of diabetic complications, knowing that microalbuminuria is an early and very sensitive indicator of nephropathy and cardiovascular risk. In analogy, we hypothesized that the excretion of urinary AGEs might also be a more sensitive indicator of vascular organ damage. 


\section{Patients and Methods}

\section{Patient population}

This study involved 128 patients with type- 2 diabetes ( 76 men and 52 women), which were recruited from the outpatient clinic of the Slotervaart hospital, Amsterdam, The Netherlands, and have been described elsewhere ${ }^{13}$. Men and women with a minimum age of 25 years and with type 2 diabetes mellitus were eligible for the study. Excluded were patients with undetectable C-peptide levels, insulin treatment before puberty, history of ketoacidosis, active chronic inflammatory disease or cancer. Their mean age (95\% CI) was 59.1 (56.9-61.3) years, body mass index 29.7 (28.7-30.6), and known duration of diabetes was 7.2 (5.8-8.5) years. All patients gave informed consent and the study was approved by the institutional Ethical Review Board of the Slotervaart Hospital, Amsterdam.

\section{Study design}

At inclusion and after one year follow-up, study subjects were screened and were given a thorough physical examination and medical history was recorded. Special focus was on the presence of cardiovascular complications. Microvascular disease included one or more of the following: retinopathy (as diagnosed by fundoscopy by an ophthalmologist through dilated pupils) or microalbuminuria (microalbumin excretion in urine $>30 \mathrm{mg} / 24 \mathrm{~h}$ ). Neuropathy was defined as neurogenic ulcers or peripheral sensory neuropathy assessed clinically by electromyography. Macrovascular disease included one or more of the following: documented myocardial infarction, angina pectoris, cerebrovascular accident or intermittent claudication. Further data were obtained on the duration of type-2 diabetes, medication use, body mass index, blood pressure (high blood pressure was defined as systolic pressure $>140 \mathrm{mmHg}$ and/or diastolic pressure $>85 \mathrm{mmHg}$ ) and lifestyle parameters.

\section{Laboratory measurements}

Blood sampling consisted of a standard venapuncture at which blood was collected into $3.2 \%$ trisodium citrate (Beckton Dickinson, San Jose, CA, USA) as described previously ${ }^{13}$. Citrated plasma was stored at $-80^{\circ} \mathrm{C}$ until use. Plasma triglycerides, total cholesterol and high density lipoprotein (HDL)-cholesterol were measured enzymatically (Synchron LX20/CX7delta(B), Beckman Coulter, Fullerton, California, USA). Low density lipoprotein (LDL)-cholesterol was calculated using the Friedewald formula ${ }^{14} . \mathrm{HbA}_{1 \mathrm{c}}$ was determined in whole blood by high-performance liquid chromatography using a mono $\mathrm{S}$ column (Pharmacia diagnostics, Uppsala, Sweden). $\quad N^{\epsilon}$-(carboxymethyl)lysine (CML) and $N^{\epsilon}$-(carboxyethyl)lysine (CEL) measurements were done as described previously15. 


\section{Statistical analysis}

Data are presented as median (inter-quartile range) for non-normal or mean ( $95 \%$ confidence interval) for normal distributed variables. Differences between groups (patients with cardiovascular complications vs. patients without complications) were assessed using non-paired Student's $t$-test for normally distributed variables or Mann-Whitney $U$ test when the distribution was not normal. For comparison of data from patients with type-2 diabetes at baseline with data after one year followup a paired $t$-Test or Wilcoxon rank test was used, depending on the normality of the distribution. $P$ values $<0.05$ were considered statistically significant. Statistical analyses were performed using SPSS version 12.01 for Microsoft Windows.

\section{Results}

\section{Study population}

One hundred and twenty-eight patients with type-2 diabetes were evaluated in this study, of which the baseline characteristics have been published previously ${ }^{13}$. Twenty nine percent of the type-2 diabetes patients had current microvascular complications (retinopathy and/or nephropathy), 40\% had current macrovascular complications (myocardial infarction, angina pectoris, cerebrovascular event, or peripheral artery disease), and $23 \%$ suffered from current neurogenic complications (neuropathy, neurogenic ulcer). Sixty percent of all patients had one or more types of complications at inclusion.

Mean plasma CEL concentration was $0.97 \mu \mathrm{M}(0.92-1.0)$ and was not significantly different between type-2 diabetic males and females (0.96(0.87-1.04) vs. 0.99(0.91383). Mean plasma CML concentration was $1.51 \mu \mathrm{M}(1.40-1.54)$ and was significantly lower in type-2 diabetic males when compared to females $(1.35(1.26$ $1.45)$ vs. $1.56(1.46-1.67), p=0.0047)$.

Mean urinary CEL concentration was $9.21 \mu \mathrm{M}(8.33-10.10)$ and was not different between males and females (9.71(8.47-10.96) vs. 8.49(7.25-9.72). Mean urinary CML concentration was $6.34 \mu \mathrm{M}(5.66-7.02)$ and no differences between sexes were observed $(6.51(5.83-7.19)$ vs. $6.09(4.71-7.47)$.

Table 1

Correlations of plasma $\mathrm{CEL} / \mathrm{CML}$ with risk factors for cardiovascular disease.

\begin{tabular}{lll}
\hline Correlations plasma CEL & Plasma CML & $r=0.4321^{*}$ \\
Correlations plasma CML & Diabetes duration & $r=0.2756^{* *}$ \\
& Plasma CEL & $r=0.4321^{*}$ \\
& Age & $r=0.3084^{* *}$ \\
& Body Mass Index & $r=-0.2726^{* *}$ \\
& Total cholesterol & $r=0.2116^{* *}$ \\
& HDL-cholesterol & $r=0.3200^{* *}$ \\
\hline${ }^{*} p<0.001,{ }^{* *} p<0.01$ & Soluble Tissue Factor & $r=0.3022^{* \star}$
\end{tabular}


Relationship between plasma CEL/CML and laboratory markers

To investigate relationships between risk factors for cardiovascular disease and the measured plasma CEL and CML values, Spearman-Rho correlations were calculated. CML correlated significantly with age, body mass index, HDL-cholesterol and soluble tissue factor, CEL only correlated with diabetes duration (Table 1). No correlations were observed between plasma $C M L$ and urine $\mathrm{CML}(\mathrm{r}=-0.1134, \mathrm{p}=$ 0.3329 ) or plasma CEL and urine CML ( $r=0.1031, \mathrm{p}=0.3788$ ).

Relationship between plasma CEL/CML concentrations and current complications In order to investigate the relationships between the plasma CEL/CML concentrations at baseline and prevalent cardiovascular complications at baseline, levels of CEL/CML were compared between patients with and without cardiovascular complications (table 2). No significant differences were seen between groups of complications. After dividing the patients with microvascular complications in those with or without retinopathy, or nephropathy respectively, we observed significantly higher concentrations of CML in the patient group with retinopathy compared to those not having retinopathy $(1.71(1.47-1.96)$ vs. $1.43(1.36-1.51) \mathrm{p}=0.0085)$. No differences were seen between type-2 diabetes patients with or without nephropathy (Figure 1).

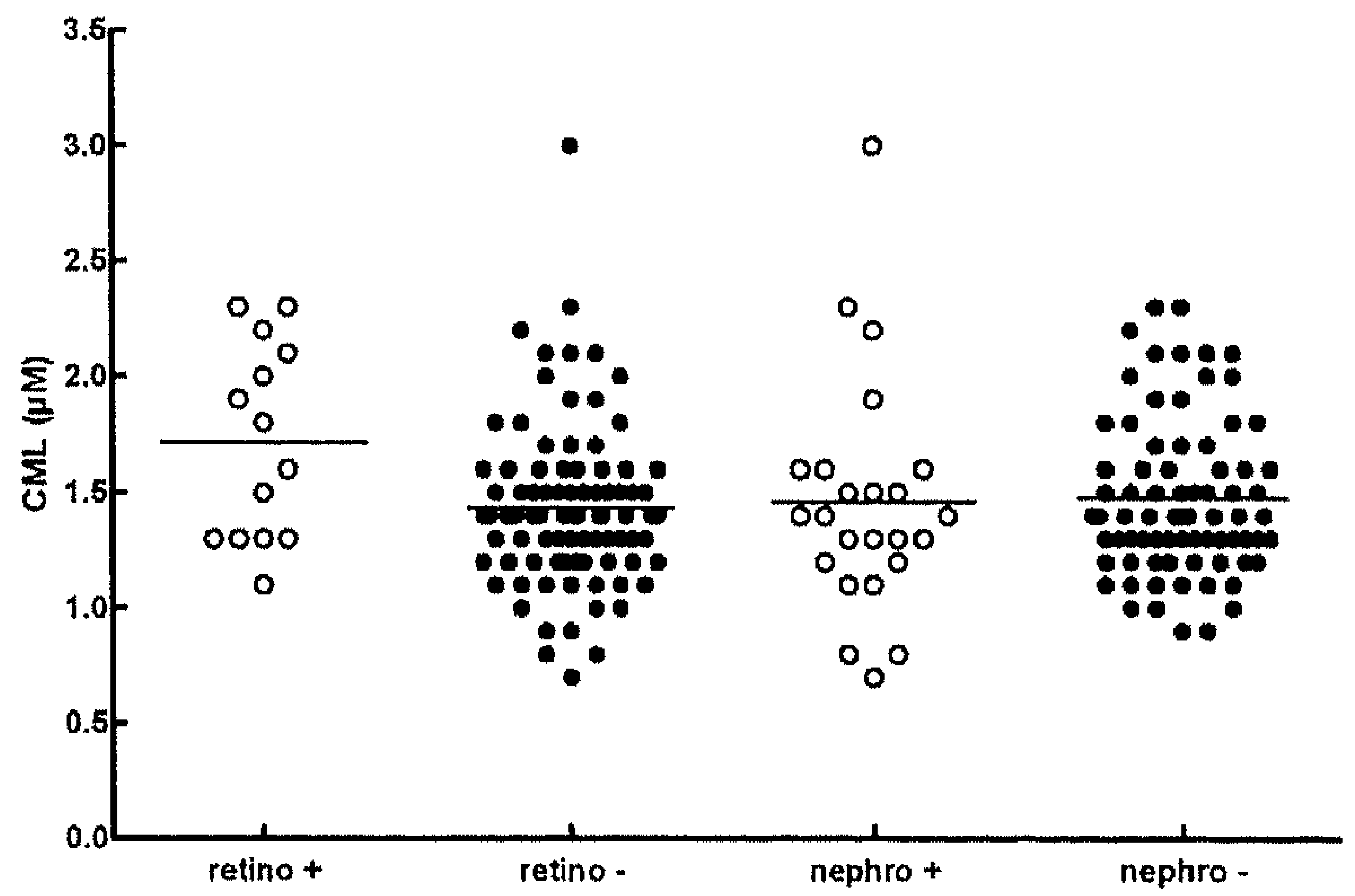

Figure 1

Concentration of $N^{z}$-(carboxymethyl)lysine (CML) in type-2 diabetes patients with and without diabetic retinopathy or nephropathy, respectively. 
Relationship between urine CEL/CML concentrations and current complications In order to investigate the relationships between the urinary CEL/CML concentrations at baseline and prevalent cardiovascular complications at baseline, levels of CEL/CML in urine were compared between patients with and without cardiovascular complications (Table 2). No significant differences were seen among any of the subgroups of complications.

Table 2

Plasma and urine concentrations of CEL and CML $(\mu M)$ in different groups of complications.

\begin{tabular}{|c|c|c|c|c|}
\hline & $\begin{array}{l}\text { Plasma } \\
\text { concentration CEL }\end{array}$ & $\begin{array}{l}\text { Plasma } \\
\text { concentration } \mathrm{CML}\end{array}$ & $\begin{array}{l}\text { Urine } \\
\text { concentration CEL }\end{array}$ & $\begin{array}{l}\text { Urine } \\
\text { concentration } \mathrm{CML}\end{array}$ \\
\hline $\begin{array}{l}\text { Total } \\
\text { Compl }+\end{array}$ & $0.99(0.92-1.06)$ & $1.49(1.39 \cdot 1.59)$ & $9.29(8.34-10.24)$ & $6.76(5.72-7.80)$ \\
\hline $\begin{array}{l}\text { Total } \\
\text { compl - }\end{array}$ & $0.95(0.88-1.02)$ & $1.43(1.33-1.52)$ & $9.11(7.47-10.75)$ & $5.82(4.98-6.66)$ \\
\hline $\begin{array}{l}\text { Macrovascular } \\
\text { compl + }\end{array}$ & $1.01(0.92-1.10)$ & $1.50(1.37-1.62)$ & $9.30(7.85-10.74)$ & $6.79(5.35-8.23)$ \\
\hline $\begin{array}{l}\text { Macrovascular } \\
\text { compl - }\end{array}$ & $0.95(0.89-1.01)$ & $1.45(1.36 \cdot 1.54)$ & $9.18(8.06 \cdot 10.30)$ & $6.05(5.38-6.72)$ \\
\hline $\begin{array}{l}\text { Microvascular } \\
\text { compl + }\end{array}$ & $1.00(0.91-1.09)$ & $1.56(1.39-1.73)$ & $8.66(7.60-9.73)$ & $7.03(5.15-8.90)$ \\
\hline $\begin{array}{l}\text { Microvascular } \\
\text { compl - }\end{array}$ & $0.96(0.90-1.03)$ & $1.43(1.36-1.50)$ & $9.57(8.43-10.72)$ & $6.06(5.44-6.69)$ \\
\hline $\begin{array}{l}\text { Neurogenic compl } \\
+\end{array}$ & $1.04(0.92-1.16)$ & $1.55(1.40-1.69)$ & $9.54(8.05-11.04)$ & $7.34(4.87-9.82)$ \\
\hline Neurogenic compl - & $0.95(0.89-1.01)$ & $1.44(1.36-1.53)$ & $9.26(8.26-10.29)$ & $6.07(5.48-6.64)$ \\
\hline
\end{tabular}

Relationship between plasma and urine CEL/CML concentrations and new cardiovascular events

After one year follow-up we obtained clinical data from 117 patients with type-2 diabetes; 8 patients were lost to follow-up due to moving to another region and 3 declined follow-up assessment. In these 117 patients (91\% of the initial cohort) 48 new cardiovascular complications were diagnosed in a total of 41 patients, including two cardiovascular deaths, 1 non-fatal myocardial infarction, 4 ischemic strokes, 3 new cases of angina pectoris, 2 cases with a presentation of intermittent claudication, 8 newly detected cases of retinopathy, 13 micro-albuminuria, 13 neuropathy and 2 neurogenic ulcers. Relationships between the plasma and urine concentrations of respectively CEL and CML at baseline and the incidence of new micro-, macro- and neurogenic complications during follow-up were determined through comparison of these parameters between patients with and without those new complications. No significant differences were seen among the subgroups (data not shown). 


\section{Discussion}

The accumulation of AGEs has been recognized as an important pathophysiological mechanism in the development of vascular complications in diabetic patients ${ }^{16}$. Circulating AGEs bind to their cognate receptors (RAGEs), and this interaction modulates several cellular responses in the vascular endothelium, including the induction of pro-inflammatory cytokines (IL-6, TNF-a) ${ }^{17,18}$, increased expression of adhesion molecules including E-selectin, intracellular adhesion molecule-1 (ICAM1) and vascular cell adhesion molecule-1 (VCAM-1), as well as the procoagulant protein tissue factor ${ }^{3,19,20 .}$

Endothelial dysfunction plays an important role in the development of long-term diabetic complications ${ }^{21}$ and it has been shown both in vivo as well as in vitro that E-selectin, ICAM-1, and VCAM-1 correlate well with endothelial dysfunction.

Experimental studies also support the involvement of AGEs in other functional aspects of the atherosclerotic process. In the arterial vessel wall AGEs accelerate cross-linking of collagen molecules, which may lead to loss of collagen elasticity22. The direct effect of AGEs on arterial stiffness is illustrated by the effect of cross-link breakers such as aminoguandine that improves the arterial compliance in both animal models of atherosclerosis 23,24 as well as in humans ${ }^{25}$.

In our study we focused on two aspects of AGEs in relation to type 2 diabetes. First we were interested in further exploring the association between CML and CEL and other markers of vascular disease in diabetes. In the present study, serum levels of $\mathrm{CML}$ and CEL showed a good correlation with each other, but were not significantly different between patients with or without atherosclerotic complications. Our data do, however, confirm an association between AGEs and (micro)vascular disease, as shown by higher levels of CML in patients with diabetic retinopathy. As in other vascular beds, AGEs have been localized in the retinal vessels of diabetics ${ }^{26,27}$, and the association seen in this study confirms a possible role of CML in the pathogenesis of diabetic retinopathy. This association is further illustrated by the positive correlation with soluble tissue factor, an independent marker of microvascular disease ${ }^{13}$. This outcome is in accordance with Lieuw-A-Fa et al showing significant associations of plasma levels of CML and CEL with markers of endothelial dysfunction, including soluble VCAM-1, VWF and soluble thrombomodulin ${ }^{15}$. Taken together, circulating AGEs may be considered as additional markers of endothelial cell activation or (micro)vascular disease.

The observed positive correlation between total cholesterol, HDL-cholesterol and plasma levels of CML suggest another route of the formation of AGEs in type-2 diabetics. It has been shown that some AGEs constructs could be formed from oxidized lipid precursors; these structures have been termed advanced lipoxidation end products (ALEs). Higher levels of lipids as observed in type-2 diabetes could be a source for these ALEs. The accumulation of CML in vascular collagen in atherosclerosis in absence of diabetes suggests that CML is partly formed by 
lipoxidation reactions ${ }^{28}$. The loss of normal lipid regulation in type-2 diabetics can attenuate the formation of AGEs in these patients. Another explanation for the observed correlation between cholesterol levels and CML could be the ingestion of AGE-rich fatty food 29 .

The second objective of this study was to asses the potential of detecting urinary AGEs as a candidate marker for diabetic vascular disease, including nephropathy. The relationship between AGEs and nephropathy was observed by Lieuw-A-Fa and colleagues showing a significant association between plasma concentrations of CEL/CML and creatinine clearance in type-1 diabetics ${ }^{15}$. Interestingly, there was no statistically significant correlation between plasma and urinary AGEs. Although this study cannot give any indications of possible mechanisms, it seems plausible that urinary AGE concentrations do not directly reflect blood AGE concentration and that the clearance of plasma AGEs by the kidney is an active selective and perhaps regulated, mechanism instead of being based on a passive gradient diffusion mechanism.

In summary, we demonstrate a relationhip with AGEs and microvascular complications, especially with retinopathy, in type-2 diabetic patients as has been shown for soluble tissue factor. The observed higher levels of CML in subjects suffering from retinopathy suggest a role for AGEs in the development of microvascular disease. However, no evidence was obtained that these markers may be associated with macrovascular or neurogenic complications and development of clinical signs of cardiovascular disease in patients with type-2 diabetes. 


\section{References}

1. Kannel WB, MCGee DL. Diabetes and cardiovascular disease. The Framingham study. Jama. 1979;241:2035-2038.

2. Haffner SM, Lehto S, Ronnemaa T, Pyorala K, Laakso M. Mortality from coronary heart disease in subjects with type 2 diabetes and in nondiabetic subjects with and without prior myocardial infarction. N Engl J Med. 1998;339:229-234.

3. Singh R, Barden A, Mori T, Beilin L. Advanced glycation end-products: a review. Diabetologia. 2001;44:129-146.

4. Brownlee M. Advanced protein glycosylation in diabetes and aging. Annu Rev Med. 1995;46:223-234.

5. Bucala R, Cerami A. Advanced glycosylation: chemistry, biology, and implications for diabetes and aging. Adv Pharmacol. 1992;23:1-34.

6. Vlassara $H$, Palace MR. Diabetes and advanced glycation endproducts. J Intern Med. 2002;251:87-101.

7. Nakamura $Y$, Horii $Y$, Nishino $T$, et al. Immunohistochemical localization of advanced glycosylation end products in coronary atheroma and cardiac tissue in diabetes mellitus. Am J Pathol. 1993;143:1649-1656.

8. Sims TJ, Rasmussen LM, Oxlund H, Bailey AJ. The role of glycation cross-links in diabetic vascular stiffening. Diabetologia. 1996;39:946-951.

9. Zieman SJ, Kass DA. Advanced glycation endproduct crosslinking in the cardiovascular system: potential therapeutic target for cardiovascular disease. Drugs. 2004;64:459-470.

10. Aso $Y$, Inukai $T$, Tayama $K$, Takemura $Y$. Serum concentrations of advanced glycation endproducts are associated with the development of atherosclerosis as well as diabetic microangiopathy in patients with type 2 diabetes. Acta Diabetol. 2000;37:87-92.

11. Kiuchi $K$, Nejima J, Takano $T$, Ohta $M$, Hashimoto $H$. Increased serum concentrations of advanced glycation end products: a marker of coronary artery disease activity in type 2 diabetic patients. Heart. 2001;85:87-91.

12. Uchimura $T$, Nakano $K$, Hashiguchi $T$, et al. Elevation of $\mathrm{N}$-(carboxymethyl)valine residue in hemoglobin of diabetic patients. Its role in the development of diabetic nephropathy. Diabetes Care. 2001;24:891-896.

13. Sommeijer DW, Hansen HR, van Oerle R, et al. Soluble tissue factor is a candidate marker for progression of microvascular disease in patients with Type 2 diabetes. $J$ Thromb Haemost. 2006;4:574-580.

14. Friedewald WT, Levy RI, Fredrickson DS. Estimation of the concentration of low-density lipoprotein cholesterol in plasma, without use of the preparative ultracentrifuge. Clin Chem. 1972;18:499-502.

15. Lieuw AFML, van Hinsbergh VW, Teerlink T, et al. Increased levels of N(epsiton)(carboxymethyl)lysine and $\mathrm{N}$ (epsilon)-(carboxyethyl)lysine in type 1 diabetic patients with impaired renal function: correlation with markers of endothelial dysfunction. Nephrol Dial Transplant. 2004;19:631-636.

16. Brownlee $M$. The pathobiology of diabetic complications: a unifying mechanism. Diabetes. 2005;54:1615-1625.

17. Yan SD, Schmidt AM, Anderson GM, et al. Enhanced cellular oxidant stress by the interaction of advanced glycation end products with their receptors/binding proteins. J Biol Chem. 1994;269:9889-9897. 
18. Throckmorton DC, Brogden AP, Min B, Rasmussen H, Kashgarian M. PDGF and TGF-beta mediate collagen production by mesangial cells exposed to advanced glycosylation end products. Kidney Int. 1995;48:111-117.

19. Brownlee M. Negative consequences of glycation. Metabolism. 2000;49:9-13.

20. Gugliucci A. Glycation as the glucose link to diabetic complications. J Am Osteopath Assoc. 2000;100:621-634.

21. Schalkwijk CG, Stehouwer CD. Vascular complications in diabetes mellitus: the role of endothelial dysfunction. Clin Sci (Lond). 2005;109:143-159.

22. Aronson D. Cross-linking of glycated collagen in the pathogenesis of arterial and myocardial stiffening of aging and diabetes. J Hypertens. 2003;21:3-12.

23. Panagiotopoulos S, O'Brien RC, Bucala R, Cooper ME, Jerums G. Aminoguanidine has an antiatherogenic effect in the cholesterol-fed rabbit. Atherosclerosis. 1998;136:125-131.

24. Figarola JL, Scott S, Loera S, et al. LR-90 a new advanced glycation endproduct inhibitor prevents progression of diabetic nephropathy in streptozotocin-diabetic rats. Diabetologia. 2003;46:1140-1152.

25. Kass DA, Shapiro EP, Kawaguchi $M$, et al. Improved arterial compliance by a novel advanced glycation end-product crosslink breaker. Circulation. 2001;104:1464-1470.

26. Stitt AW, Li YM, Gardiner TA, Bucala R, Archer DB, Vlassara H. Advanced glycation end products (AGEs) co-localize with AGE receptors in the retinal vasculature of diabetic and of AGE-infused rats. Am J Pathol. 1997;150:523-531.

27. Hammes HP, Martin S, Federlin K, Geisen K, Brownlee M. Aminoguanidine treatment inhibits the development of experimental diabetic retinopathy. Proc Natl Acad Sci U S A. 1991;88:11555-11558.

28. Baynes JW, Thorpe SR. Glycoxidation and lipoxidation in atherogenesis. Free Radic Biol Med. 2000;28:1708-1716.

29. O'Brien J, Morrissey PA. Nutritional and toxicological aspects of the Maillard browning reaction in foods. Crit Rev Food Sci Nutr. 1989;28:211-248. 
Chapter 5

Circulating Matrix Gla protein: a potential marker for vascular complications of type 2

diabetes mellitus

Hjalmar R. Hansen - Leon J. Schurgers • Cees Vermeer • Pieter H. Reitsma Henri M.H. Spronk • Hugo ten Cate 


\begin{abstract}
Arterial calcification is generally regarded as an independent risk factor for cardiovascular morbidity and mortality. Medial calcification is an age dependent process, associated with type- 2 diabetes, and a strong and independent predictor of coronary artery disease and cardiovascular mortality. Although the precise molecular mechanism is unknown, matrix Gla-protein (MGP) appears to be a potent inhibitor of arterial calcification and its activity depends on vitamin $\mathrm{K}$ (VK). To determine the relationship between incomplete carboxylation of MGP and prevalent or new vascular complications a prospective cohort study of 128 patients with type2 diabetes in whom blood samples were collected at baseline and after one year of follow-up was undertaken.

Patients with type-2 diabetes had median plasma levels of MGP-related antigen containing amino acids 3 through 15 (MGP3-15) of $5.3 \mathrm{nM}$ (range: $4.9-6.2 \mathrm{nM}$ ) and were not different between subjects with and without microvascular, macrovascular, or neurogenic complications. Incomplete carboxylated MGP (GluMGP) levels were $58.9 \%$ on average at inclusion and were significantly lower in subjects suffering from microvascular complications at inclusion $(55.4 \%, 95 \% \mathrm{CI}$ : $51.88-58.82)$ compared to those without retinopathy or nephropathy $(60.1 \%, 95 \%$ CI: 58.39-61.88). More precisely, lower Glu-MGP levels were mainly associated with nephropathy rather than with retinopathy. Plasma MGP3-15 or Glu-MGP levels in type-2 diabetes were not associated with new complications. Glu-MGP levels were negatively associated with pulse pressure $(r=-0.210, p<0.02)$ in the total group of type-2 diabetes.

In conclusion, plasma Glu-MGP levels are associated with prevalent nephropathy in type-2 diabetes and possibly related to arterial stiffness caused by arterial calcification.
\end{abstract}




\section{Introduction}

Type-2 diabetes is a chronic metabolic disorder that is accompanied by considerable cardiovascular mortality due to myocardial infarction, heart failure, stroke, or "sudden death". In addition, chronic morbidity is often seen in the form of major vascular complications including peripheral arterial disease and/or microvascular complications such as retinopathy and nephropathy 1-4. Arterial calcification occurs in two distinct forms and is one of the major contributors to morbidity and mortality in diabetes 5 . Intimal calcification occurs always in the context of atherosclerosis whereas medial calcification can occur in its absence. Medial calcification is an age dependent process but is also strongly associated with diseases like uremia 6 , type-2 diabetes mellitus in general 5,7 and more specifically diabetic neuropathy 7. It appears to be a strong and independent predictor of coronary artery disease and cardiovascular mortality 5,7,8. Calcification of the arterial media leads to stiffening of the arterial tone 9 , subsequently causing an increase in cardiac work and systolic blood pressure, which is a highly significant predictor of myocardial infarction and cardiac death 10 .

Matrix Gla protein (MGP) is a so-called vitamin $\mathrm{K}$-dependent protein and most likely involved in inhibition of vascular calcification. Vitamin $K$ is the cofactor for the enzyme $\gamma$-glutamyl carboxylase which converts certain glutamic acid (Glu) residues into $y$-carboxy glutamic acid (Gla) residues within the vitamin K-dependent proteins. Although the precise molecular mechanism of MGP function is not known, recent data demonstrate that it plays a major role in the inhibition of soft-tissue calcification. Targeted deletion of the MGP gene in mice resulted in extensive medial calcification of the aorta, leading to death within eight weeks after birth due to ruptures of the thoracic or abdominal aorta 11. The importance of MGP Gla-residues in the prevention of vascular calcification was shown by inhibition of $\gamma$-glutamyl carboxylation in rats with warfarin 12,13. Within 2 to 3 weeks of treatment, arterial calcification was found around the elastic lamellae of the media. Furthermore, in humans, the presence of incompletely carboxylated MGP was demonstrated in association with intimal and medial calcification 14. Serum MGP levels, assayed using a competitive ELISA with an antibody directed against amino acids 3-15, were decreased in subjects with coronary artery calcification 15 and in subjects after percutaneous coronary intervention 14. Based on the knowledge that only fully carboxylated MGP can inhibit calcification it was hypothesized that two independent alterations in the MGP-pathway contribute to the progression of vascular calcification 14: attenuated expression or incomplete carboxylation of MGP in the arterial vessel wall.

We investigated the hypothesis that MGP plasma levels in patients with type-2 diabetes are a useful surrogate marker of vascular morbidity in an explorative 
cohort study comprising 128 type-2 diabetes patients. Specifically, we set out to determine the relationship between incomplete carboxylation of MGP and prevalent or new vascular complications in a group of consecutively analyzed patients with type-2 diabetes.

\section{Patients and methods}

Patient population

Patients were recruited from the outpatient clinic of the Slotervaart hospital, Amsterdam, The Netherlands and have been described elsewhere 16. Men and women with a minimum age of 25 years with type 2 diabetes mellitus were eligible for the study. Excluded were patients with undetectable C-peptide levels, insulin treatment before puberty, history of ketoacidosis, active chronic inflammatory disease or cancer. All patients gave informed consent and the study was approved by the institutional Ethical Review Board of the Slotervaart Hospital, Amsterdam.

\section{Study design}

At inclusion and after one year follow-up, patients were interviewed and given a physical examination. Patients were evaluated with respect to microvascular, macrovascular, and neurogenic complications. Microvascular disease included retinopathy (diagnosed by fundoscopic examination) and/or microalbuminuria (microalbumin $>30 \mathrm{mg} / 24 \mathrm{~h}$ ). Macrovascular disease included: documented myocardial infarction, angina pectoris, cerebrovascular accident, and intermittent claudication. Neurogenic disease included: neuropathy (diagnosed by electromyography) and neuropathic ulcera and/or Charcot's foot. Further data were obtained on duration of type 2 diabetes, medication use, body mass index (BMI), and blood pressures measured twice on the right arm after the participant had been seated for at least 5 minutes. High blood pressure was defined as systolic pressure $\geq 140 \mathrm{mmHg}$ and/or diastolic pressure $\geq 85 \mathrm{mmHg}$. Pulse pressure was defined as the difference between the mean systolic and mean diastolic blood pressure.

\section{Blood sampling and laboratory procedures}

Blood samples were obtained by standard vena puncture and collected into $3.2 \%$ trisodium citrate (Beckton Dickinson, San Jose, CA, USA) as described previously 16. Citrated plasma was stored at $-80^{\circ} \mathrm{C}$ until use.

Total or fragmented MGP containing amino acids 3 through 15 (MGP3-15) was analyzed as described before 17 using the competitive ELISA kit from Biomedica (Vienna, Austria). In brief, a monoclonal antibody (aMGP3-15) directed against the nonphosphorylated peptide sequence SHESMESYELNPF (sMGP3-15) was coated in microwell plates by incubation at $4^{\circ} \mathrm{C}$ overnight in $100 \mathrm{mM}$ phosphate-buffered 
saline, pH 7.5 (PBS). Plates were subsequently washed three times with $0.1 \%(\mathrm{v} / \mathrm{v})$ Triton X-100 in PBS and blocked with $0.1 \%(\mathrm{w} / \mathrm{v})$ cold waterfish gelatine in PBS for 1 hour at RT. After three wash cycles with PBS, plates were dried overnight at 30 ${ }^{\circ} \mathrm{C}$. SMGP3-15 peptide added to human affinity-stripped serum was used as calibrator. Biotinylated MGP3-15 added simultaneously to standards, controls, and samples was used as tracer and bound tracer was detected using HRP-labeled streptavidin.

Glu-MGP was assessed using an ELISA which has been described previously (Cranenburg, E et al, submitted). In brief, polyclonal Rabbit-anti-Mouse IgG (Dako, No. Z0109) was diluted 2000-fold in carbonate buffer $(100 \mathrm{mmol} / \mathrm{L}$ sodium carbonate, $\mathrm{pH}$ 9.6) and used for the coating of the microtiter plate $(100 \mu \mathrm{L} /$ well $)$. After incubation for 1.5 hours at $37{ }^{\circ} \mathrm{C}$, remaining protein-binding sites were blocked with $200 \mu \mathrm{L}$ of blocking buffer ( $2 \%$ (w/v) HNBSA consisting of HEPES-NaCl buffer (175 mM NaCl, $25 \mathrm{mM} \mathrm{HEPES}$ ) and $2 \%$ (w/v) BSA (Sigma, Zwijndrecht, The Netherlands), adjusted to $\mathrm{pH} 7.7$ ) and incubated for 2 hours at room temperature. After emptying the wells on a towel, the microtiter plate was incubated for 4 hours at RT with $100 \mu \mathrm{L}$ anti-uc-MGP $(0.7 \mu \mathrm{g} / \mathrm{ml}$ in $2 \% \mathrm{HNBSA}$ ) (VitaK BV, Maastricht, the Netherlands). After incubation, plates are washed with 5 cycles of $300 \mu \mathrm{L}$ washing buffer $(0.05 \%(\mathrm{v} / \mathrm{v})$ Tween-20 in HEPES-NaCl buffer). An amount of $5 \mu \mathrm{L}$ of serum sample or standard was diluted in $70 \mu \mathrm{L}$ of $2 \%$ HNBSA, and $20 \mu \mathrm{L}$ was supplemented with $100 \mu \mathrm{L}$ of tracer ucMGP (biotinylated 35-54 ucMGP 1.0 $\mathrm{mg} / \mathrm{mL}$ ). After gentle vortexing, $100 \mu \mathrm{L}$ of sample was transferred to the microtiter plate and incubated overnight hour at $4^{\circ} \mathrm{C}$. After 5 washing cycles with $300 \mu \mathrm{L}$ HEPES-Tween washing buffer, the plate was incubated with $100 \mu \mathrm{L}$ Streptavidineperoxide (Zymed, Breda, The Netherlands; 10000-fold diluted in $0.5 \%(\mathrm{w} / \mathrm{v})$ HNBSA). Plates were washed with 5 cycles of $300 \mu \mathrm{L}$ washing buffer and stained with $100 \mu \mathrm{L}$ of 3, 3',5,5'tetramethylbenzidine (TMB, KPL, Gennep, The Netherlands). The staining process was stopped by adding $50 \mu \mathrm{L}$ of $1 \mathrm{~mol} / \mathrm{L} \mathrm{H}_{2} \mathrm{SO}_{4}$, and the plate was read at $450 \mathrm{~nm}$. As standard synthetic full length noncarboxylated MGP was used.

\section{Statistical analysis}

Data are presented as medians (with range) or as means with $95 \%$ CIs. Differences between groups (patients with type 2 diabetes vs. controls and patients with cardiovascular complications vs. patients without complications) were assessed using non-paired Student's t-test or Mann-Whitney $U$ test when distribution was not normal. For comparison of data from patients with type 2 diabetes at baseline with data after one year follow up a paired t-Test or Wilcoxon rank test was used. Logistic regression analysis was performed for each marker associated with existing cardiovascular complications on univariate analysis. $\mathrm{P}$ values $<0.05$ were 
considered statistically significant. Statistical analyses were performed using SPSS version 11.5 .

\section{Results}

Since the study was primarily designed as a prospective cohort investigation the comparison with healthy individuals was not considered relevant. One hundred and twenty-eight patients with type-2 diabetes were evaluated in this study, of which the baseline characteristics are summarized in Table 1. At inclusion, $60 \%$ of all patients had one or more types of complications, divided in $29 \%$ of the type- 2 diabetes patients with prevalent microvascular complications (retinopathy and/or nephropathy), $40 \%$ with prevalent macrovascular complications (myocardial infarction, angina pectoris, cerebrovascular event, or peripheral artery disease), and $23 \%$ with prevalent neurogenic complications (neuropathy, neurogenic ulcer).

Plasma levels of MGP-related antigen containing amino acids 3 through 15 (MGP315) were not normally distributed amongst type-2 diabetes patients, with a median level of $5.3 \mathrm{nM}$ (range: $4.9-6.2 \mathrm{nM}$ ). Furthermore, MGP3-15 levels were comparable between type-2 diabetes patients without any complications ( $5.3 \mathrm{nM}, 5.0-6.2)$ and with one or more of the following complications: microvascular, macrovascular, or neurogenic (5.3 nM, 4.9-6.3). Patients with microvascular (5.2 nM, $4.9-6.3)$, macrovascular ( $5.4 \mathrm{nM}, 4.9-6.2)$, or neurogenic (5.6 nM, 4.9-6.2) complications had plasma MGP3-15 levels not different from those patients without the complication (5.4 nM, 4.9-6.2; $5.3 \mathrm{nM}, 5.0-6.2 ; 5.3 \mathrm{nM}, 4.9-6.2$, respectively).

At inclusion, Glu-MGP plasma levels were $58.9 \%$ (95\% CI: 57.17 - 60.39) for the total cohort of type-2 diabetes patients. No differences in Glu-MGP plasma levels were observed between type- 2 diabetes patients in the overall complication group (including all types of diabetic complications) at inclusion and those without (Figure 1). Subjects suffering from microvascular complications at inclusion showed lower plasma Glu-MGP levels $(55.4 \%$, 95\% CI: $51.88-58.82$ ) compared to those without retinopathy or nephropathy $(60.1 \%, 95 \%$ CI: $58.39-61.88)$, whereas no alterations were found for macrovascular and neurogenic complications (Figure 1). The lower plasma Glu-MGP levels were mainly due to nephropathy instead of retinopathy since patients with microalbuminuria showed decreased levels $(54.9 \%, 95 \% \mathrm{CI}$ : 50.75-58.95) compared to subjects without microalbumin levels below $30 \mathrm{mg} / 24$ hrs (59.8\%, 95\%CI: 58.08-61.51).

No correlations were observed between plasma MGP3-15 levels and any of the markers of coagulation and inflammation described previously ${ }^{16}$, whereas plasma Glu-MGP levels in type- 2 diabetes patients were negatively associated with age $(r=-$ $0.343, \mathrm{p}<0.0001)$ and soluble tissue factor sTF $(\mathrm{r}=-0.247, \mathrm{p}<0.01)$. Also, a 
positive correlation was shown between Glu-MGP levels and plasminogen activator inhibitor 1 (PAI1, $r=0.196, p<0.05$ ).

Table 1.

Characteristics of subjects with type 2 diabetes

\begin{tabular}{|c|c|}
\hline Baseline characteristics & $\begin{array}{l}\text { Type } 2 \text { diabetes } \\
\text { patients } n=128\end{array}$ \\
\hline Age (years) & $59.1(30.6-87.5)$ \\
\hline Sex ( $\%$ male $)$ & $60 \%$ \\
\hline Ethnic background (Caucasian/ northern Africa / Asia /other) (n) & $84 / 20 / 8 / 16$ \\
\hline Duration of diabetes until sample date (years) & $7.2(0.0-32.2)$ \\
\hline Alcohol (\%) & $35 \%$ \\
\hline Smoking ( $(8)$ & $25 \%$ \\
\hline Diet adjusted for diabetes (\%) & $48 \%$ \\
\hline Type 2 diabetes in family $(*)$ & $70 \%$ \\
\hline Type 2 diabetes medication (oral / insulin /oral \&insulin) (n) & $58 / 39 / 31$ \\
\hline Systolic blood pressure $(\mathrm{mmHg})$ & $142(105-210)$ \\
\hline Diastolic blood pressure $(\mathrm{mmHg})$ & $81(50-110)$ \\
\hline $\mathrm{BMI}\left(\mathrm{kg} / \mathrm{m}^{2}\right)$ & $29.6(25.9-32.7)$ \\
\hline $\mathrm{Hb}(\mathrm{mmol} / \mathrm{l})$ & $8.8(6.3-10.5)$ \\
\hline Leucocytes $\left(10^{9} / 1\right)$ & $7.8(3.1-21.5)$ \\
\hline Thrombocytes $\left(10^{9} / \mathrm{l}\right)$ & $250(129-399)$ \\
\hline Glucose (mmol/l) & $9.6(2.9-20.9)$ \\
\hline $\mathrm{HbA}_{\mathrm{tc}}(\%)$ & $7.5(5.2-11.8)$ \\
\hline Creatinine (mmol/24hr) & $82(7-139)$ \\
\hline Total cholesterol (mmol/l) & $5.12(2.56-7.80)$ \\
\hline HDL cholesterol (mmol/l) & $1.21(0.68-4.90)$ \\
\hline LDL cholesterol (mmol/l) & $3.13(1.00-5.71)$ \\
\hline Triglycerides $(\mathrm{mmol} / \mathrm{l})$ & $1.73(0.47-4.66)$ \\
\hline Homocysteine $(\mu \mathrm{mol} / \mathrm{l})$ & $10.9(3.9-24.8)$ \\
\hline Microalbumin (mg $/ 24 \mathrm{hr}$ ) & $51(2-826)$ \\
\hline
\end{tabular}

Given the association of plasma solTF levels with prevalent microvascular complications ${ }^{16}$ and the correlation between Glu-MGP and solTF in type-2 diabetes, the predictive value of Glu-MGP was calculated. Nephropathy was only independently associated with soluble $\mathrm{TF}(\operatorname{Exp}(\mathrm{B}) / \mathrm{OR} 1.006(1.001-1.011))$ 16, whereas Glu-MGP was excluded in univariate analysis with $\operatorname{Exp}(\mathrm{B}) / \mathrm{OR}$ of 0.962 (0.911-1.016).

To investigate the relationship between the different parameters at baseline and incidence of micro-, macro- and neurogenic cardiovascular complications within one year follow-up, plasma Glu-MGP levels were compared between patients with and without new complications. Incidence of complications after one year follow-up assessment has been reported previously ${ }^{16}$. In brief, clinical data after one year follow up were obtained from 87 patients and 12 new macrovascular, 13 microvascular, and 13 neurogenic complications were observed. The level of MGP3-15 
and Glu-MGP remained unchanged after one year follow-up compared to baseline levels. Neither MGP3-15 nor Glu-MGP was associated with new complications. Moreover, Glu-MGP levels at baseline $(59.3 \%, 95 \%$ CI: 56.82-60.52) did not predict incident nephropathy $(56.7 \%, 95 \% \mathrm{CI}: 54.04-61.73)$.
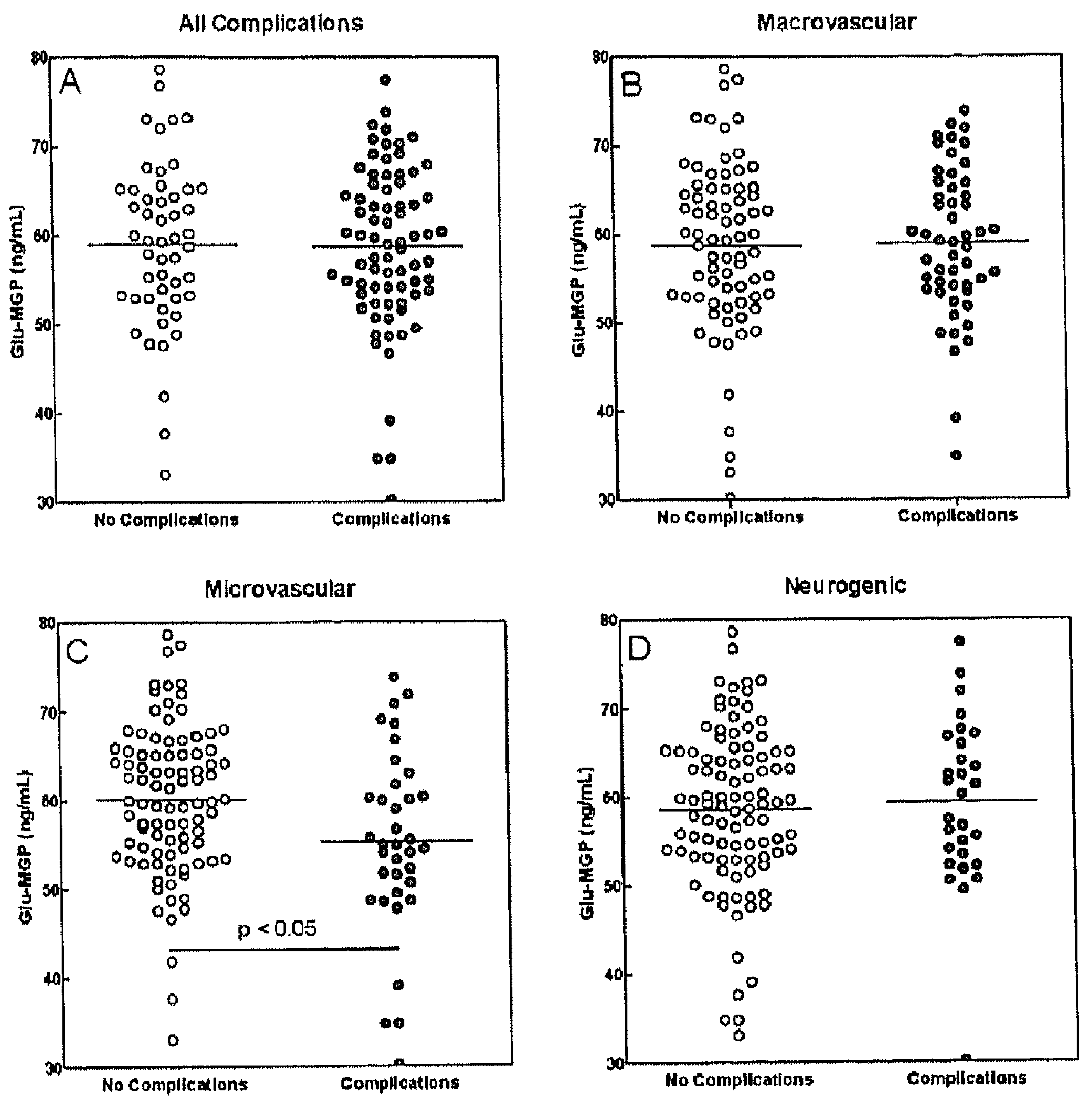

Figure 1

Decreased plasma Glu-MGP levels in type-2 diabetes patients with microvascular complications (panel C), included retinopathy (diagnosed by fundoscopic examination) and/or microalbuminuria (microalbumin $>30 \mathrm{mg} / 24 \mathrm{~h}$ ). No differences in Glu-MGP levels were observed between type-2 diabetes patients with or without complications (panel $A$ ), or between subjects with and without either macrovascular (panel B) or neurogenic complications (panel D).

Pulse pressure, defined as the difference between systolic and diastolic blood pressure, was $61.0 \mathrm{mmHg}$ (95\% CI: $57.46-64.48)$ on average in type-2 diabetes patients. Subjects with microvascular complications $(68.1 \mathrm{mmHg}, 95 \% \mathrm{CI}: 61.85-$ 74.2) had a higher pulse pressure then those without $(58.1 \mathrm{mmHg}, 95 \% \mathrm{CI}: 53.96-$ 62.31). This observation was mainly due to an increased pulse pressure in patients 
with nephropathy at inclusion $(66.8 \mathrm{mmHg}, 95 \% \mathrm{CI}: 61.31-72.33$, and for patients without nephropathy $59.3 \mathrm{mmHg}, 95 \%$ CI 55.08-63.51). An inverse correlation between plasma Glu-MGP levels and pulse pressure was observed $(r=-0.21, p<$ 0.02 ) in the total group of type-2 diabetes.
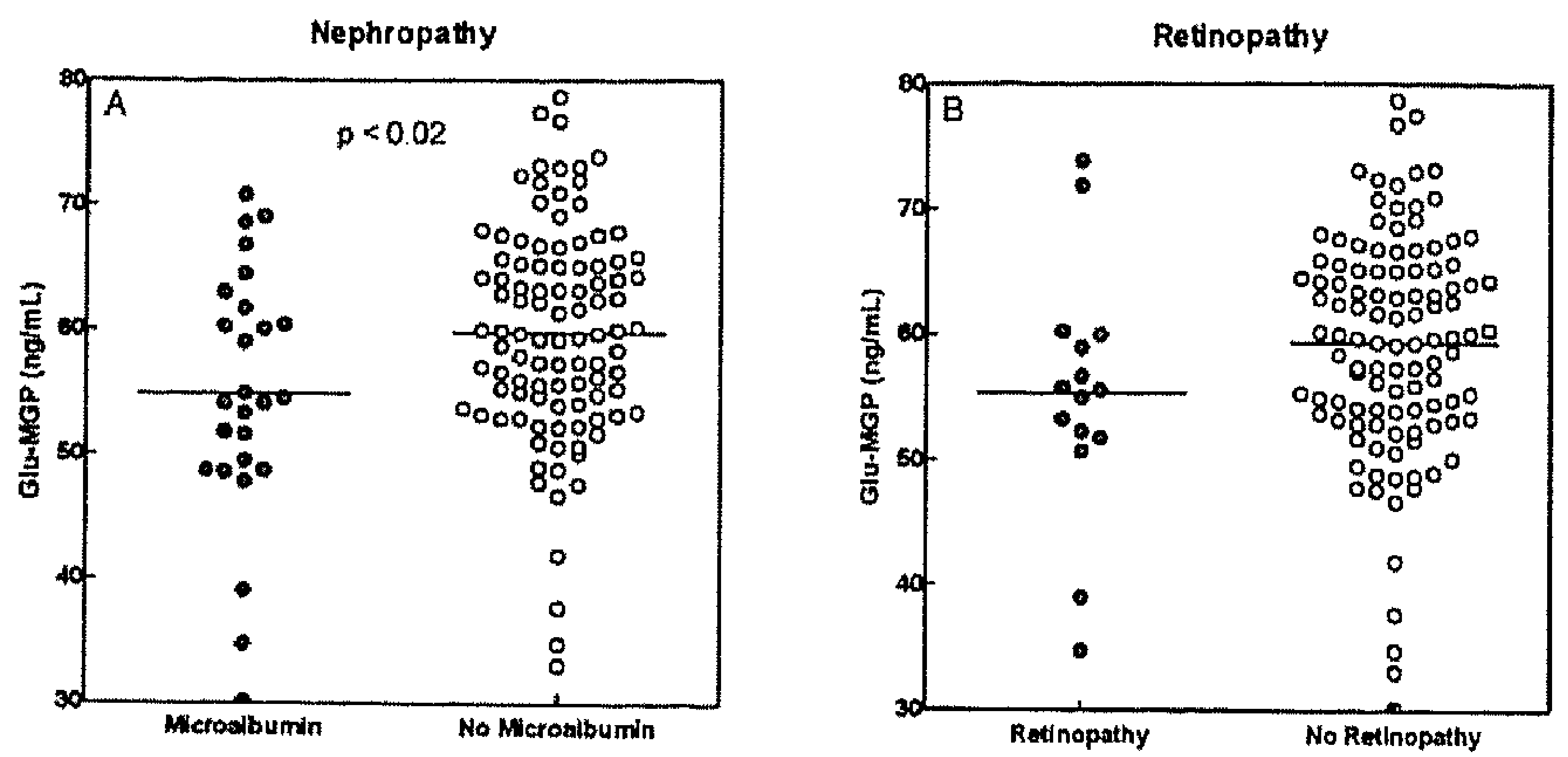

Figure 2

Decreased plasma Glu-MGP levels in type-2 diabetes with nephropathy (panel A) defined as microalbumin above $30 \mathrm{mg}$ per 24 hours urine. No differences in Glu-MGP levels were observed between type-2 diabetes patients with or without retinopathy (panel B).

\section{Discussion}

Arterial calcification is inhibited by the vitamin K-dependent protein MGP which, when fully carboxylated, appears to be a strong inhibitor of the process. Particularly medial calcification is associated with type-2 diabetes 5,7 and is a strong predictor of cardiovascular complications 8,18 . Whether, based on this relationship between MGP and cardiovascular risk, determination of the plasma MGP levels, and mainly GluMGP, could be a relevant marker for vascular complications in type-2 diabetes patients is unknown. In order to address this issue the present study was undertaken.

The main outcome of the current study was that MGP3.15 was neither associated with the presence of microvascular, macrovascular, and neurogenic complications in type-2 diabetes, nor was MGP3-15 a predictor for new complications. Plasma GluMGP levels were, however, decreased in patients with microvascular complications, most evident in those with nephropathy. This correlation was lost when corrected for soluble tissue factor, which appears to be a stronger marker for vascular complication in type-2 diabetes. Plasma Glu-MGP levels did also not predict the occurrence of new complications after one year follow up. 
Arterial stiffening leads towards an increase of pulse pressure due to increased central systolic blood pressure and decreased diastolic blood pressure 19. Although pulse pressure analysis is an indirect method to asses arterial stiffening 20 and largely determined by cardiac function and timing of wave reflections ${ }^{21}$, it is also a significant predictor of coronary heart disease. The observed increase in pulse pressure suggests the occurrence of arterial stiffening in type-2 diabetes patients suffering from nephropathy. A relationship between arterial stiffness and kidney function was addressed in two recent studies. First, in patients with untreated isolated systolic hypertension it was demonstrated that pulse pressure as a marker of arterial stiffening is associated with an age-related decline in glomerular filtration rate 22 . Second, Bahous et al. suggested interactions between kidney function and arterial stiffness in a living kidney donor/recipient cohort ${ }^{23}$.

Although type-2 diabetes is associated with increased arterial stiffness 24 , the underlying cause remains unclear. One possible factor contributing to increased vascular stiffening is arterial calcification which is associated with type-2 diabetes 5 and a common complication in chronic kidney disease and end stage renal disease 20. The observed relationship between Glu-MGP and pulse pressure suggests the involvement of decreased vitamin $\mathrm{K}$ intake or improper $\mathrm{\gamma}$-glutamyl carboxylation of MGP in the onset of vascular complications in type-2 diabetes. Although pulse pressure analysis is an indirect method to asses arterial stiffening 20 and largely determined by cardiac function and timing of wave reflections 21 , it is also a significant predictor of coronary heart disease. Whether pulse wave velocity is a better tool to assess arterial stiffness is beyond the scope of this study and we suggest including this analysis in a larger cohort study, together with quantification of arterial calcification.

Using an animal model of arterial calcification it was shown that inhibition of vascular $y$-glutamyl carboxylation resulted in the formation of Glu-MGP 12,13, and that calcification could be resolved by high vitamin $\mathrm{K}$ (Schurgers et al, unpublished data). Impaired $\gamma$-glutamyl carboxylation of extra-hepatic vitamin K-dependent proteins in diabetic patients is relatively unexplored. In the adult population vitamin $\mathrm{K}$ intake is sufficient to meet the requirement of the liver (bleeding as a consequence of a clinical deficiency of vitamin $\mathrm{K}$ is rare), whereas the vitamin $\mathrm{K}$ requirement of extrahepatic tissues is not met by the daily diet 25 . Low dietary vitamin $\mathrm{K}$ intake has been suggested to impair $\mathrm{y}$-glutamyl carboxylation of osteocalcin in bone, resulting in low bone mineral density and increased risk for osteoporosis $26-28$. The fact that plasma Glu-MGP levels were decreased in patients with microvascular complications is in agreement with observations by Price et al. 12,13 and suggests the deposition of Glu-MGP in the vicinity of calcification within the arterial vessel wall. This hypothesis is supported by immunohistochemical data 
showing a strong association between Glu-MGP and arterial calcification in that MGP was localized around the calcified area ${ }^{14}$.

The present study demonstrated an association between plasma Glu-MGP levels and nephropathy in type-2 diabetes possibly related to arterial stiffening caused by arterial calcification. Due to the relative small cohort, the use of pulse pressure instead of pulse wave velocity to asses arterial stiffness, and the lack of quantitative calcification scores, this study should be considered as an explorative pilot study. Therefore, a larger cohort study is needed, including recording of pulse wave velocity and calcification, to demonstrate the applicability of plasma Glu-MGP assessment as a novel marker for arterial calcification and vascular complications. 


\section{References}

1. Stamler J, Vaccaro O, Neaton JD, Wentworth D. Diabetes, other risk factors, and 12-yr cardiovascular mortality for men screened in the Multiple Risk Factor Intervention Trial. Diabetes Care. 1993; 16:434-444.

2. Standl E, Balletshofer B, Dahl B, et al. Predictors of 10-year macrovascular and overall mortality in patients with NIDDM: the Munich General Practitioner Project. Diabetologia. 1996;39:1540-1545.

3. Juhan-Vague I, Thompson SG, Jespersen J. Involvement of the hemostatic system in the insulin resistance syndrome. A study of 1500 patients with angina pectoris. The ECAT Angina Pectoris Study Group. Arterioscler Thromb. 1993;13:1865-1873.

4. Mogensen CE. Microalbuminuria predicts clinical proteinuria and early mortality in maturityonset diabetes. N Engl J Med. 1984;310:356-360.

5. Everhart JE, Pettitt DJ, Knowler WC, Rose FA, Bennett PH. Medial arterial calcification and its association with mortality and complications of diabetes. Diabetologia. 1988;31:16-23.

6. Parfitt AM. Soft-tissue calcification in uremia. Arch Intern Med. 1969;124:544-556.

7. Edmonds ME, Morrison N, Laws JW, Watkins PJ. Medial arterial calcification and diabetic neuropathy, Br Med J (Clin Res Ed). 1982;284:928-930.

8. Lehto $S$, Niskanen L, Suhonen M, Ronnemaa T, Laakso M. Medial artery calcification. A neglected harbinger of cardiovascular complications in non-insulin-dependent diabetes mellitus. Arterioscler Thromb Vasc Biol. 1996;16:978-983.

9. Blacher J, Guerin AP, Pannier B, Marchais SJ, London GM. Arterial calcifications, arterial stiffness, and cardiovascular risk in end-stage renal disease. Hypertension. 2001;38:938-942.

10. Madhavan S, Ooi WL, Cohen H, Alderman MH. Relation of pulse pressure and blood pressure reduction to the incidence of myocardial infarction. Hypertension. 1994;23:395-401.

11. Luo G, Ducy P, Mckee MD, et al. Spontaneous calcification of arteries and cartilage in mice lacking matrix GLA protein. Nature. 1997;385:78-81.

12. Price PA, Faus SA, Williamson MK. Warfarin causes rapid calcification of the elastic lamellae in rat arteries and heart valves. Arterioscler Thromb Vasc Biol. 1998;18:1400-1407.

13. Price PA, Faus SA, Williamson MK. Warfarin-induced artery calcification is accelerated by growth and vitamin D. Arterioscler Thromb Vasc Biol. 2000;20:317-327.

14. Schurgers LJ, Teunissen $\mathrm{KJ}$, Knapen $\mathrm{MH}$, et al. Novel conformation-specific antibodies against matrix gamma-carboxyglutamic acid (Gla) protein: undercarboxylated matrix Gla protein as marker for vascular calcification. Arterioscler Thromb Vasc Biol. 2005;25:16291633.

15. Jono S, Ikari $Y$, Vermeer $C$, et al. Matrix Gla protein is associated with coronary artery calcification as assessed by electron-beam computed tomography. Thromb Haemost. 2004;91:790-794.

16. Sommeijer DW, Hansen HR, van Oerle R, et al. Soluble tissue factor is a candidate marker for progression of microvascular disease in patients with Type 2 diabetes. J Thromb Haemost. 2006;4:574-580.

17. Schurgers LJ, Teunissen $\mathrm{KJ}$, Knapen $\mathrm{MH}$, et al. Characteristics and performance of an immunosorbent assay for human matrix Gla-protein. Clin Chim Acta. 2005;351:131-138.

18. Raggi P, Cooil B, Ratti C, Callister TQ, Budoff M. Progression of coronary artery calcium and occurrence of myocardial infarction in patients with and without diabetes mellitus.

Hypertension. 2005;46:238-243. 
19. London GM. Large arteries haemodynamics: conduit versus cushioning function. Blood Press Suppl. 1997;2:48.51.

20. London GM, Marchais SJ, Guerin AP, Metivier F. Arteriosclerosis, vascular calcifications and cardiovascular disease in uremia. Curr Opin Nephrol Hypertens. 2005;14:525-531.

21. Van Bortel $L M$. Is arterial stiffness ready for daily clinical practice? J Hypertens. 2006;24:281-283.

22. Verhave JC, Fesler P, du Cailar G, Ribstein J, Safar ME, Mimran A. Elevated pulse pressure is associated with low renal function in elderly patients with isolated systolic hypertension. Hypertension. 2005;45:586-591.

23. Bahous SA, Stephan A, Blacher J, Safar ME. Aortic stiffness, living donors, and renal transplantation. Hypertension. 2006;47:216-221.

24. Schram MT, Henry RM, van Dijk RA, et al. Increased central artery stiffness in impaired glucose metabolism and type 2 diabetes: the Hoorn Study. Hypertension. 2004;43:176-181.

25. Vermeer $C$, Shearer MJ, Zittermann A, et al. Beyond deficiency: potential benefits of increased intakes of vitamin $K$ for bone and vascular health. Eur J Nutr. 2004;43:325-335.

26. Hart JP, Shearer MJ, Klenerman L, et al. Electrochemical detection of depressed circulating levels of vitamin K1 in osteoporosis. J Clin Endocrinol Metab. 1985;60:1268-1269.

27. Szulc P, Arlot M, Chapuy MC, Duboeuf F, Meunier PJ, Delmas PD. Serum undercarboxylated osteocalcin correlates with hip bone mineral density in elderly women. $J$ Bone Miner Res. 1994;9:1591-1595.

28. Luukinen $\mathrm{H}$, Kakonen SM, Pettersson $\mathrm{K}$, et al. Strong prediction of fractures among older adults by the ratio of carboxylated to total serum osteocalcin. J Bone Miner Res. 2000;15:2473-2478. 
Chapter 6

Lessons from mouse models for arterial thrombosis: does clotting make a difference in human cardiovascular disease?

Chapter in The Physiological Genomics of the Critically Ill Mouse. Ed. Can Ince, Kluwer Academic Publishers, Norwell, MA (2004) 


\section{General introduction}

Cardiovascular disease is the leading cause of death worldwide and arterial thrombosis, usually superimposed on atherosclerosis, is the immediate cause of acute myocardial infarction (AMI) and stroke.

The pathophysiology of arterial vascular disease is multifactorial and the formation of the two key lesions (thrombosis and atherosclerosis) involves a large number of physiologic systems, including hemostasis and coagulation, blood pressure regulation, and cholesterol and carbohydrate metabolism. Combinations of genetic and acquired factors likely drive each of these biological systems. Whereas acquired factors have been identified to a large extent, the nature and importance of genetic influences remains disputed. Populationbased studies have shown roles for genetic factors in AMI and stroke ${ }^{1,2}$, but to this date no major gain of function mutation has been identified for genes that dictate the regulation of the hemostatic, coagulation or fibrinolytic systems. A few polymorphisms in coagulation have been identified, but their exact role regarding the coagulation and fibrinolysis proteins in the pathophysiology of AMJ and other cardiovascular complications in humans remains unclear ${ }^{3.5}$. In addition to the known hemostatic proteins, a number of additional factors such as leptin, may also modulate hemostasis and thrombosis and may be relevant in this regard.

In light of the steady development of experimental animal models for studying genetic and acquired influences on cardiovascular disease, the purpose of this review is to determine whether transgenic mouse models contribute to a better understanding of the complex mechanisms that drive arterial thrombosis. To do this we will adress a number of established and candidate risk factors for arterial thrombosis and discuss the relevant data from recent mouse experiments. In addition, we will speculate about the potential relevance of these novel data.

\section{Pathophysiology of arterial thrombosis}

In general, the onset of arterial thrombosis involves complex interactions between subendothelium, platelets and activated coagulation factors. In addition, the basis for thrombosis in cardiovascular disease usually is atherosclerosis of one or more major arteries, and the thrombotic trigger may be one or more of the following: superficial erosion of vascular endothelium, disruption of microvessels influencing plaque progression, or rupture of the fibrous plaque cap ${ }^{6}$. In hemostasis terms, upon contact of blood with subendothelium, collagen associated von Willebrand factor (VWF) becomes exposed and the initial platelet contact with the wound is mediated by tethering to this insoluble form of VWF. This tethering causes platelet activation and upregulation of the platelet glycoprotein (GP) IIb-IIla and $\alpha$ llb $\beta 3$ (integrin) functions. Stable adhesion of platelets is established by $\alpha 2 \beta 1$ binding to the exposed collagen and platelet GPIIb-IIla binding to VWF and fibrinogen ${ }^{7}$. Once platelets are activated, the GPIlb-IIla receptor undergoes a conformational change to a high affinity ligand binding state. More platelets then adhere 
via fibrinogen or VWF binding to GPIIb-Illa receptors, thus propagating thrombus formation. During this entire process, fibrin production is initiated by exposure of circulating coagulation proteins and blood cells to tissue factor in the ruptured atherosclerotic plaque leading to enhanced production of thrombin. Besides activating fibrinogen that contributes to fibrin plug formation, thrombin is a potent platelet activator, and feedback activator of the intrinsic coagulation system, causing a cascade of intrinsic factor activation steps leading to accelerated blood coagulation and stabilization of the arterial thrombus. In this reaction, platelets provide a surface for activated coagulation proteins, while other cells, including monocytes and granulocytes, participate by interacting with platelets, exposing tissue factor, and shedding procoagulant microparticles.

Based on this model of primary and secondary hemostasis and relevant clinical data we now discuss a number of risk factor proteins.

\section{A. Procoagulant proteins: fibrinogen}

Circulating fibrinogen is made up of three pairs of polypeptide chains, named $\alpha, \beta$ and $\gamma$. In vitro studies have shown that the synthetic rate of the $\beta$-chain is the rate-limiting step in the production of fibrinogen ${ }^{8}$. This predicts that mutations that affect the production of the $\beta$-chain might influence plasma levels of fibrinogen. A raised fibrinogen concentration has been shown to be a strong independent risk factor for myocardial infarction, peripheral vascular disease and stroke in both men and women. However, initial studies in transgenic mice with increased fibrinogen $\beta$-chain production failed to show an increase in overall plasma fibrinogen levels?.

To investigate the role of fibrinogen in acute thrombosis, studies have been performed with fibrinogen gene knockout mice. In an in vivo model mesenterial arterioles were treated with ferric chloride $\left(\mathrm{FeCl}_{3}\right)$ to induce thrombus formation. In this model, $\mathrm{FeCl}_{3}$ induced injury triggers the generation of free radicals leading to the disruption of endothelium and exposure of the subendothelial matrix to the bloodstream. The presumed two major roles of fibrinogen in thrombus formation are to serve as most important ligand of $\alpha$ llb $\beta 3$ mediated platelet aggregation and to contribute to the formation of an insoluble fibrin matrix to stabilize the thrombus.

Upon stimulation with $\mathrm{FeCl}_{3}$, thrombi do occur in fibrinogen -/. mice, however they fail to resist shear stress and get easily stripped off the vessel wall to be carried downstream. Although all $\mathrm{FeCl}_{3}$ treated vessels occlude with a mean 'time to occlusion' indistinguishable from their wild-type counterparts, none of the fibrinogen - /- mice occlude at the site of injury but as a consequence of downstream embolization of the unstable thrombus. Thus, the most vulnerable point in thrombi formed in fibrinogen - $/$ mice appears to be located at the thrombus-vessel wall interface, suggesting that fibrinogen is primarily important in securing platelet-vessel wall interactions. Therefore, it is likely that the key role of fibrinogen at high shear is not primarily in platelet aggregation, but rather in formation of a stable thrombus ${ }^{10}$. 


\section{Von Willebrand Factor}

Von Willebrand factor (VWF) is a complex multimeric glycoprotein that is produced by endothelial cells and stored in the so-called Weibel-Palade bodies. It is also synthesized by megakaryocytes, stored and secreted by platelet a-granules. High plasma levels of vWF have been associated with AMI and several polymorphisms of the VWF-gene have been linked to vWF plasma concentrations ${ }^{11}$.

Experiments with mice lacking VWF were done to learn more about the role of this protein in arterial thrombosis. In these experiments Denisa Wagner and colleagues ${ }^{10}$ used a $\mathrm{FeCl}_{3}$ mesenteric arterial thrombosis model combined with intravital microscopy allowing monitoring of the deposition of fluorescently labelled platelets at the injured site in real time.

In wild-type mice, unstable platelet interactions with the vessel wall started 20-30 seconds after topical application of $\mathrm{FeCl}_{3}$. Between 2 and 3 minutes later numerous fluorescent adherent platelets were observed. However, in the VWF deficient mice, platelet interactions with the vessel wall started considerably later, and less adherent platelets were observed in the same time interval. The time to form a thrombus was about twice as long in $\mathrm{VWF}^{\prime \prime}$ mice as compared to wild-type mice, but eventually a stable thrombus was formed even in the complete absence of VWF.

When the same experiments were performed with mice lacking VWF and fibrinogen, platelet adhesion and aggregation rather surprisingly still occurred. The time needed for the first platelet deposition and for initiation of the thrombus was similar in the double knockout mice as compared to $\mathrm{VWF}^{-/}$mice and the time required for the formation of a thrombus was about 3 times longer than in wild-type mice. This suggests that there are additional candidate proteins responsible for platelet cross-linking ${ }^{10}$ and strengthens the concept that arterial thrombosis is not a process that depends on a few molecules but rather on a complex interplay of haemostatic and procoagulant elements. This finding explains why single gene mutations in fibrinogen or vWF will not easily suffice to either substantially enhance or reduce the clinical risk of arterial thrombosis.

\section{Glycoprotein IIb/IIIa (GPIIb/IIIa)}

Platelet glycoproteins (GP) are membrane receptors with an important role in both platelet adhesion and aggregation, and can bind to a variety of circulating ligands to promote clot formation ${ }^{12}$. Platelet GPIIb/llla (integrin $\alpha$ llb $\beta 3$ ) has been identified as the platelet fibrinogen receptor. The binding of adhesive proteins such as fibrinogen or VWF to GPIIb/llla on activated platelets is thought to be a critical event leading to platelet aggregation. The clinical influence of polymorphisms in GPIIb/IIIa ${ }^{13}$ as well as the efficacy of platelet inhibiting agents directed against GPIIb/llla in patients with cardiovascular disease show the important role of this glycoprotein in AMI and stroke ${ }^{14,15}$

Wild-type mice $\left(\beta 3^{+/+}\right)$, $\beta 3$-integrin-deficient mice $\left(\beta 3^{-/ 1}\right)$, and wild-type mice treated with a hamster monoclonal antibody (1B5) that blocks murine allb $\beta 3$ function were tested in a 
model of large-vessel thrombosis. In this large-vessel model, $\mathrm{FeCl}_{3}$ was used to injure the carotid artery, and the time to occlusion was measured. $\ln \beta 3^{+/+}$mice, the median time to occlusion was 6.7 minutes, whereas occlusion did not occur in any of the $\beta 3 \%$ mice. The addition of an antibody directed against GPllb/llla prolonged the bleeding time, inhibited ex vivo platelet aggregation, and protected mice from the effects of thrombosis induced by $\mathrm{FeCl}_{3}$. Microscopic examination of the arteries revealed extensive platelet thrombi, fibrin, and red cells that obstructed the lumen of the carotid arteries in wild-type mice, whereas arteries from $\beta 3^{\%}$ mice were patent and lined primarily with only a single layer of platelets ${ }^{16}$, corroborating the clinical notion of an important contribution of this particular glycoprotein to arterial thrombosis.

\section{B. Inhibitors of coagulation: Tissue factor pathway inhibitor (TFPI)}

Tissue factor is known as the primary initiator of the extrinsic coagulation pathway and is abundant in atherosclerotic plaques where its content appears to predict plaque thrombogenicity ${ }^{17,18}$. Tissue factor reacts with coagulation factor VIla (FVIla) to form the tissue factor-FVlla complex that activates factors IX and X. FXa converts prothrombin to thrombin, which then cleaves fibrinogen to fibrin, and thrombin activates factor XIII so it can cross-link to the fibrin clot.

Tissue factor pathway inhibitor (TFPI) is a proteinase inhibitor that regulates the extrinsic coagulation pathway. TFPI inhibits tissue factor-dependent coagulation initially by binding FXa and subsequently by binding to tissue the factor-FVIla complex to form a quaternary complex. These interactions prevent further production of FIXa and FXa, as well as autoactivation of FVII in the tissue factor- FVII complex thereby inhibiting the formation of fibrin $^{19}$. Through the inhibition of tissue factor activity, TFPI may attenuate plaque thrombogenicity and in rabbit models of arterial thrombosis increased (local) concentrations of TFPI inhibit thrombus formation ${ }^{20}$, while reduced TFPI activity enhances thrombus formation. Mice genetically engineered to be completely deficient in functional TFPI demonstrate embryonic lethality apparently due to disseminated intravascular coagulation, whereas mice heterozygous for TFPI deficiency appear normal, although plasma TFPI activity is reduced by $50 \%{ }^{21}$. Eitzman and co-workers constructed homozygous mice that were deficient for apolipoprotein $E$ (apoE) and had a heterozygous deficiency for TFPI $\left(\mathrm{TFPI}^{+/}\right)$. ApoE ${ }^{-1 \cdot}$ mice were used because of their susceptibility for developing atherosclerotic plaques throughout the vascular tree. In their experiments $\mathrm{TFPI}^{+/}$, apoE ${ }^{\prime \prime}$ mice showed a significantly decreased time to form thrombi after photochemical injury of the carotid artery than $\mathrm{TFPl}^{+/+}$, apoE ${ }^{\prime /}$ mice. When these experiments were performed without the atherosclerotic background of apoE knockout mice no difference was observed in the time to form thrombi. This strongly suggests a role for endogenous TFPI as an important regulator of arterial thrombosis but only in the presence of an atherosclerotic background. 


\section{Thrombomodulin}

Thrombosis in arteries and veins is physiologically prevented by specific mechanisms involving the natural anticoagulant systems. Among these, the protein $C$ pathway provides an anticoagutant defence mechanism of vascular endothelium interacting with the blood clotting system. As an endothelial cell membrane bound glycoprotein, thrombomodulin (TM), binds to thrombin and this complex activates circulating protein C. Activated protein $C$ (APC) inactivates coagulation factors Va and VIlla

To establish the role of thrombomodulin in arterial thrombosis, mice with a functional thrombomodulin deficiency were compared to wild-type mice in a $\mathrm{FeCl}_{3}$ model of carotid artery thrombosis. In two separate studies, the mice with the functional TM deficiency show a significant shorter time needed to establish full occlusion of the carotid artery as compared to wild-type littermates. This difference was apparently neither due to differences in thrombus composition, nor to an altered response of the vessel wall (i.e. by inflammation) and may be solely attributable to hypercoagulability of blood ${ }^{22,23}$. These studies provide strong evidence for a specific contribution of the protein $C$ pathway to arterial thrombosis, although the interaction with atherosclerosis needs further investigation. The latter may be relevant because of the observation that mutations in the protein C pathway or in factors leading to APC resistance (factor V Leiden) may influence the risk of arterial thrombosis in relatively young individuals ${ }^{24}$.

\section{Fibrinolysis: Plasminogen activator inhibitor-1 (PAl-1) and Vitronectin}

Thrombi dissolve only after activation of the fibrinolytic system, which functions to degrade intravascular fibrin. Endogenous fibrinolysis is initiated by tissue-type plasminogen activator $(\mathrm{t}-\mathrm{Pa})$ and urokinase-type plasminogen activator ( $\mathrm{U}-\mathrm{Pa})$, which are serine proteinases activating the proenzyme plasminogen to the broad specificity enzyme plasmin. PAl-1 is a fast acting, specific inhibitor of t-Pa and U-Pa, and thereby a critical regulator of plasminogen activation. An increased plasma level of PAI-1 results in reduced plasmin degradation of fibrin and thus, would be expected to be prothrombotic.

There has been much discussion about the role of PAl-1 in the mechanism of thrombolysis of platelet-rich arterial thrombi. To study the role of PAl-1 in endogenously mediated arterial thrombolysis, wild-type mice (with normal PAl-1 expression) were compared with PAl-1 deficient mice in a $\mathrm{FeCl}_{3}$ arterial thrombosis model ${ }^{25}$. This study showed that PAl-1 deficient mice exhibit a significant reduction in intraluminal thrombosis 24 hours after arterial injury as compared to wild-type mice. These data suggest an important role for PAl-1 in inhibiting the lysis of platelet-rich thrombi formed in response to arterial injury,. This is consistent with in vitro experiments demonstrating that clots containing PAl-1deficient platelets lyse more rapidly than clots with normal PAl- 1 content ${ }^{26}$.

In addition, Zhu et al. ${ }^{27}$ conclude from the shorter reperfusion times observed during thrombolytic therapy of platelet-rich arterial thrombi in PAl-1 deficient mice, that PAI-1 is a major determinant of resistance to thrombolysis by pharmacological t-PA concentrations. 
In studies of photochemically induced arterial thrombosis, a significant prolongation of the time required to thrombotic vessel occlusion was observed in PAl-1 deficient mice, whereas $u-P A$ and $t$-PA deficiencies had no effect on closure time. The infusion of PAl-1 restores thrombus development in PAl-1 deficient mice. This also suggests a role for PAl-1 controlling fibrinolysis in the early phases of thrombus development. If PAI-1\% mice were reconstituted with $\mathrm{PAl}-1^{+/+}$platelets it was observed that the normal thrombotic response seen in wild-type mice was not restored, indicating that this type of experimental thrombosis is not controlled by platelet PAI-1, but is more likely the result of secretion from vascular endothelial cells ${ }^{25}$.

Vitronectin (VN) is a major single chain plasma glycoprotein, which is also present in platelets and on the extracellular matrix of many tissues. VN binds multiple ligands, including integrins, the urokinase receptor (UPAR), collagen, complement C5b-7, and heparin. VN binding to PAl-1 converts PAl-1 from a latent to an active form. These interactions suggest many potentially regulatory functions for VN. To get more insight in the role of $\mathrm{VN}$ in the earliest response to vascular injury, different groups have used $\mathrm{VN}$ deficient mice in different models of arterial thrombosis.

Konstantinides et $\mathrm{al}^{28}$ used the $\mathrm{FeCl}_{3}$ artery model in $\mathrm{VN}$-deficient mice and observed that although the mean time to occlusion after $\mathrm{FeCl}_{3}$ injury did not differ between wild-type and $\mathrm{VN}^{-1}$ mice, a large proportion of the thrombi in the $\mathrm{VN}^{-1}$ mice were unstable and frequently embolized. This instability may reflect the absence of the stabilising effect of VN on PAI-1 at the site of injury or impaired hemostatic function because of a defect in platelet aggregation in the $\mathrm{VN}^{-1}$ mice.

The same experiments were performed by Eitzman and colleagues ${ }^{29}$ with the difference that the latter group used a photochemical method of arterial vessel injury. For this method mice are intravenously injected with rose bengal and a green light laser $(540 \mathrm{~nm})$ is applied to the desired site of injury. When this method is used on $\mathrm{VN}^{-1}$ mice they show a longer time to occlusion compared with wild-type mice. Konstantinides et al ${ }^{30}$ proposed that differences found in neointima formation between studies using carotid artery ligation in mice deficient for PAl-1 or vitronectin can be possibly explained by the presence or absence of thrombus/fibrin in these models ${ }^{31,32}$, implying differential roles of PAI-1 and VN depending on the phase of wound healing response. A similar explanation may underlie the observed differences in time to occlusion described above.

\section{Metabolism and risk of thrombosis: the "case" of Leptin}

Although obesity is considered an independent risk factor for cardiovascular disease ${ }^{33}$ the mechanisms that link obesity to cardiovascular disease are still unclear. Obesity is associated with accelerated atherothrombosis and an increased incidence of cardiovascular morbidity and mortality. Numerous observations suggest that it is the interaction between metabolic factors that frequently accompany obesity (e.g. insulin resistance, hyperinsulinemia, hypertension, hypertriglyceridemia, and decreased HDL cholesterol 
levels) that promote the progression of atherosclerosis in obese individuals ${ }^{34}$. In addition, alterations in the hemostatic balance in the circulation may contribute to acceleration of atherothrombosis in obese individuals ${ }^{35}$.

Leptin, the 167 amino acid product of the $O B$ gene is a major regulator of fat and energy storage in mammals ${ }^{36}$. It is an adipocyte-derived hormone and has a stimulatory effect on platelet aggregation induced by adenosine diphosphate ${ }^{37}$. Since leptin levels increase with the development of obesity, this hormone may play a role in the risk of arterial thrombotic vascular complications associated with obesity. The identification of a long-form functional leptin receptor $(\mathrm{OB}-\mathrm{Rb})$ on human platelets suggests there might be signalling between the adipocyte and the platelet ${ }^{38}$.

To investigate to role of leptin in arterial vascular injury, the group of David Eitzman ${ }^{29}$ used a photochemical induced arterial injury model on the carotid artery of leptin deficient $(\mathrm{ob} / \mathrm{ob})$ and leptin-receptor deficient $(\mathrm{db} / \mathrm{db})$ mice. Compared to wild-type mice, both leptin and leptin-receptor deficient mice showed a prolonged time to occlusion compared with wild-type mice. Administering recombinant murine leptin reduced this effect in the leptin deficient mice to occlusion times comparable to the wild-types whereas this effect was not observed in the leptin-receptor deficient mice. These data show that leptin contributes to arterial thrombosis and that its effect is probably mediated by the platelet leptin receptor.

\section{Conclusion}

Although the ultimate assessment of the contribution of risk factors to arterial thrombosis in humans can only be solved by well-designed and powerful clinical studies, the elucidation of the molecular mechanisms of thrombosis requires animal experimentation. The major contribution of transgenic and knockout mouse development for thrombosis studies has been that exploration of the role of specific proteins has become feasible. In this paper we reviewed a number of studies devoted to proteins involved in the blood coagulation process, particularly relevant to arterial thrombosis. The selected papers mostly investigated arterial thrombosis by induction of thrombosis in the carotid artery of mice, utilizing ferric chloride in the majority of experiments. Such an approach has obvious limitations in the sense that ferric chloride induced fibrin-platelet thrombus formation is hardly comparable to the pathophysiological process of atherothrombosis in humans, which requires the presence of advanced atherosclerosis, a process taking many years to develop. In spite of such limitations, the reviewed data provide valuable information that may be relevant for clinical research. The fact that many outcomes might have been predicted on the basis of knowledge of the human phenotype (such as impaired thrombus formation in GPIIb/llla deficient mice) strengthens the notion that these mouse models are relevant as models for human arterial vascular disease. 


\section{What are the major outcomes and how should these be interpreted?}

The studies on platelet surface receptors and adhesive proteins reveal differential roles for the involved proteins in the initial stages of thombosis. While some proteins (fibrinogen, VWF) are essential for thrombus stability, the GPIlb/lla complex appears to be crucial in thrombus formation: absence of the complex completely prevents formation of thrombus. These data support the important role of GPIlb/llla inhibitors in preventing arterial thrombosis in patients and may help to understand the complex interactions between platelets, vessel wall and blood coagulation proteins.

Studies on natural anticoagulants provide new insights that substantiate the role of tissue factor as agonist in arterial thrombosis, and shed new light on the role of the protein $C$ system in this regard. Inhibition of thrombus formation by TFPI appears to be extensively influenced by the underlying vessel wall integrity: atherosclerosis is a major modifier of TFPI function. This observation may point to clinically relevant interactions that may help to better understand the weight of risk factors at different ages and stages of atherosclerotic vascular disease. The same may be of importance for the protein $C$ related proteins: recent studies suggest that in specific and oftentimes young individuals, defects in the protein $C$ mechanism are important risk factors for arterial thrombosis ${ }^{24}$, while this risk may be absent at more advanced ages. The implementation of mouse models with specific defects in the protein $C$ system allows for studying interactions between risk factors and outcomes (thrombosis, AMl, stroke) at different ages and stages of atherosclerosis. Such mechanistic studies would never be possible in humans. Finally, the interactions between PAl-1 and vitronectin offers puzzling views on the process of thrombus formation, but also on thrombus interaction with the vessel wall and its effects on intima media integrity. Where human studies do not provide information beyond recognizing an association between a plasma level of PAl-1, its genetic mutation, and clinical outcomes, murine studies lead the way to novel insights into complex functional interactions. All these interactions may be influenced by a number of metabolic and other factors and leptin is just one example of a protein that shows to influence platelet function and subsequent tendency to thrombosis.

We conclude that murine models of dysfunctional coagulation and fibrinolysis proteins offer substantial opportunities for research of the molecular basis of complex disorders including atherothrombosis. The development of sophisticated technology for assessment of the molecular process of thrombosis in vivo further advances this line of research ${ }^{39}$.

\section{Acknowledgements}

$\mathrm{HtC}$ is a Clinical Established Investigator of the Netherlands Heart Foundation. $\mathrm{HH}$ was sponsored through a project grant from the Netherlands Heart Foundation (2000B062) 


\section{References}

1. Rissanen AM, Nikkila EA. Coronary artery disease and its risk factors in families of young men with angina pectoris and in controls. Br Heart J. 1977;39:875-883.

2. Williams MS, Bray PF. Genetics of arterial prothrombotic risk states. Exp Biol Med (Maywood). 2001;226:409-419.

3. Boekholdt SM, Bijsterveld NR, Moons AH, Levi M, Buller HR, Peters RJ. Genetic variation in coagulation and fibrinolytic proteins and their relation with acute myocardial infarction: a systematic review. Circulation. 2001;104:3063-3068.

4. Yamada $\mathrm{Y}$, Izawa $\mathrm{H}$, Ichihara $\mathrm{S}$, et al. Prediction of the risk of myocardial infarction from polymorphisms in candidate genes. N Engl J Med. 2002;347:1916-1923.

5. Longstreth WT, Jr., Rosendaal FR, Siscovick DS, et al. Risk of stroke in young women and two prothrombotic mutations: factor $V$ Leiden and prothrombin gene variant (G20210A). Stroke. 1998;29:577-580.

6. Libby P. Inflammation in atherosclerosis. Nature. 2002;420:868-874.

7. Savage B, Almus-Jacobs F, Ruggeri ZM. Specific synergy of multiple substrate-receptor interactions in platelet thrombus formation under flow. Cell. 1998;94:657-666.

8. Roy SN, Mukhopadhyay G, Redman CM. Regulation of fibrinogen assembly. Transfection of Hep G2 cells with B beta cDNA specifically enhances synthesis of the three component chains of fibrinogen. J Biol Chem. 1990;265:6389-6393.

9. Rezaee F, Maas A, Verheijen JH, Koopman J. Increased hepatic fibrinogen Bbeta-gene transcription is not enough to increase plasma fibrinogen levels. A transgenic mouse study. Thromb Haemost. 2001;85:1025-1030.

10. $\mathrm{Ni} \mathrm{H}$, Denis $\mathrm{CV}$, Subbarao $\mathrm{S}$, et al. Persistence of platelet thrombus formation in arterioles of mice lacking both von Willebrand factor and fibrinogen. J Clin Invest. 2000;106:385-392.

11. Keightley AM, Lam YM, Brady JN, Cameron CL, Lillicrap D. Variation at the von Willebrand factor (VWF) gene locus is associated with plasma VWF:Ag levels: identification of three novel single nucleotide polymorphisms in the VWF gene promoter. Blood. 1999;93:4277. 4283.

12. Ruggeri ZM. Mechanisms initiating platelet thrombus formation. Thromb Haemost. 1997;78:611-616.

13. Newman PJ. Platelet alloantigens: cardiovascular as well as immunological risk factors? Lancet. 1997;349:370-371.

14. Use of a monoclonal antibody directed against the platelet glycoprotein Ilb/llla receptor in high-risk coronary angioplasty. The EPIC Investigation. N Engl J Med. 1994;330:956-961.

15. Platelet glycoprotein $\mathrm{llb} / \mathrm{llla}$ receptor blockade and low-dose heparin during percutaneous coronary revascularization. The EPILOG Investigators. N Engl J Med. 1997;336:1689-1696.

16. Smyth SS, Reis ED, Vaananen $H$, Zhang $W$, Coller BS. Variable protection of beta 3-integrin-deficient mice from thrombosis initiated by different mechanisms. Blood. 2001;98:10551062.

17. Toschi V, Gallo R, Lettino $M$, et al. Tissue factor modulates the thrombogenicity of human atherosclerotic plaques. Circulation. 1997;95:594-599.

18. Badimon JJ, Lettino $M$, Toschi $V$, et al. Local inhibition of tissue factor reduces the thrombogenicity of disrupted human atherosclerotic plaques: effects of tissue factor pathway inhibitor on plaque thrombogenicity under flow conditions. Circulation. 1999;99:1780-1787. 
19. Bajaj MS, Birktoft JJ, Steer SA, Bajaj SP. Structure and biology of tissue factor pathway inhibitor. Thromb Haemost. 2001;86:959-972.

20. Nishida $T$, Ueno $\mathrm{H}$, Atsuchi $\mathrm{N}$, et al. Adenovirus-mediated local expression of human tissue factor pathway inhibitor eliminates shear stress-induced recurrent thrombosis in the injured carotid artery of the rabbit. Circ Res. 1999;84:1446-1452.

21. Huang ZF, Higuchi D, Lasky N, Broze GJ, Jr. Tissue factor pathway inhibitor gene disruption produces intrauterine lethality in mice. Blood. 1997;90:944-951.

22. Dorffler-Melly J, de Kruif M, Schwarte LA, et al. Functional thrombomodulin deficiency causes enhanced thrombus growth in a murine model of carotid artery thrombosis. Basic Res Cardiol. 2003;98:347-352.

23. Weiler $\mathrm{H}$, Lindner $\mathrm{V}$, Kerlin $\mathrm{B}$, et al. Characterization of a mouse model for thrombomodulin deficiency. Arterioscler Thromb Vasc Biol. 2001;21:1531-1537.

24. Strater R, Becker $S$, von Eckardstein A, et al. Prospective assessment of risk factors for recurrent stroke during childhood--a 5-year follow-up study. Lancet. 2002;360:1540-1545.

25. Farrehi PM, Ozaki CK, Carmeliet P, Fay WP. Regulation of arterial thrombolysis by plasminogen activator inhibitor-1 in mice. Circulation. 1998;97:1002-1008.

26. Fay WP, Eitzman DT, Shapiro AD, Madison EL, Ginsburg D. Platelets inhibit fibrinolysis in vitro by both plasminogen activator inhibitor-1-dependent and -independent mechanisms. Blood. 1994;83:351-356.

27. Zhu $Y$, Carmeliet $P$, Fay WP. Plasminogen activator inhibitor 1 is a major determinant of arterial thrombolysis resistance. Circulation. 1999;99:3050-3055.

28. Konstantinides S, Schafer K, Thinnes T, Loskutoff DJ. Plasminogen activator inhibitor-1 and its cofactor vitronectin stabilize arterial thrombi after vascular injury in mice. Circulation. 2001;103:576-583.

29. Eitzman DT, Westrick RJ, Nabel EG, Ginsburg D. Plasminogen activator inhibitor-1 and vitronectin promote vascular thrombosis in mice. Blood. 2000;95:577-580.

30. Konstantinides S, Schafer K, Loskutoff DJ. Do PAl-1 and vitronectin promote or inhibit neointima formation? The exact role of the fibrinolytic system in vascular remodeling remains uncertain. Arterioscler Thromb Vasc Biol. 2002;22:1943-1945.

31. Peng L, Bhatia N, Parker AC, Zhu Y, Fay WP. Endogenous vitronectin and plasminogen activator inhibitor-1 promote neointima formation in murine carotid arteries. Arterioscler Thromb Vasc Biol. 2002;22:934-939.

32. de Waard V, Arkenbout EK, Carmeliet P, Lindner V, Pannekoek H. Plasminogen activator inhibitor 1 and vitronectin protect against stenosis in a murine carotid artery ligation model. Arterioscler Thromb Vasc Biol. 2002;22:1978-1983.

33. Kenchaiah S, Evans JC, Levy D, et al. Obesity and the risk of heart failure. $N$ Engl J Med. 2002;347:305-313.

34. Laakso M. Hyperglycemia and cardiovascular disease in type 2 diabetes. Diabetes. 1999;48:937-942.

35. Fuster V, Badimon L, Badimon JJ, Chesebro JH. The pathogenesis of coronary artery disease and the acute coronary syndromes (2). N Engl J Med. 1992;326:310-318.

36. Zhang Y, Proenca R, Maffei M, Barone M, Leopold L, Friedman JM. Positional cloning of the mouse obese gene and its human homologue. Nature. 1994;372:425-432.

37. Nakata M, Yada T, Soejima N, Maruyama I. Leptin promotes aggregation of human platelets via the long form of its receptor. Diabetes. 1999;48:426-429. 
38. Maruyama I, Nakata M, Yamaji K. Effect of leptin in platelet and endothelial cells. Obesity and arterial thrombosis. Ann N Y Acad Sci. 2000;902:315-319.

39. Celi A, Merrill-Skoloff G, Gross P, et al. Thrombus formation: direct real-time observation and digital analysis of thrombus assembly in a living mouse by confocal and widefield intravital microscopy. J Thromb Haemost. 2003;1:60-68. 
Chapter 7

Hyperglycemia accelerates arterial thrombus formation in vivo

Hjalmar R. Hansen • Jef L. Wolfs • Dirkje W. Sommeijer • Eduard Bevers • Arnaud D. Hauer Johan Kuiper - Henri M.H. Spronk • Pieter H. Reitsma • Hugo ten Cate 


\begin{abstract}
Endothelial dysfunction and a hypercoagulant state are potential contributors to the increased risk of atherothrombotic complications in diabetes mellitus. The aim of the study was to characterize hyperglycemia dependent blood coagulation determinants that could be associated with in vivo arterial thrombus formation. Streptozotocin induced hyperglycemia caused a mild hypercoagulable phenotype after ferric chloride induced arterial thrombosis. The extend of thrombus formation was comparable between control and hyperglycemic animals, whereas diabetic mice showed an increased rate of thrombus formation. Neither tissue factor activity nor the mRNA levels of tissue factor, monocyte chemotactic protein-1 (MCP-1), E-selectin, vascular adhesion molecule-1 (VCAM-1), or intercellular adhesion molecule-1 (ICAM-1) in aortic homogenates were altered due to hyperglycemia. Collagen-induced platelet procoagulant activity, assayed by means of a prothrombinase assay, was comparable between platelets isolated from control and hyperglycemic mice. Thrombin, a weak agonist to induce platelet procoagulant activity, synergistically enhanced the collagen-induced procoagulant activity. Furthermore, collagen/thrombin-induced platelet procoagulant activity was increased after 10 weeks of streptozotocin induced hyperglycemia, suggesting a high glucose induced shift towards increased phosphatidylserine (PS) exposure on activated platelets or an increased population of activated platelets expressing PS.

In conclusion, our data support a direct influence of hyperglycemia on thrombin generation in blood, probably by amplifying platelet membrane catalytic functions, contributing to accelerated arterial clot formation.
\end{abstract}




\section{Introduction}

Diabetes mellitus is a leading cause of cardiovascular disease in large parts of the world ${ }^{1}$. Although the two main types of diabetes differ in cause and phenotype, hyperglycemia is a hallmark of both. In type- 1 diabetes hyperglycemia is caused by pancreatic beta cell failure, whereas in type-2 disease it is primarily due to insulin resistance of tissues, with secondary pancreatic insufficiency as a late complication. Increased glucose concentrations have a major impact on several biological functions and the increased formation of advanced glycated endproducts (AGEs) is thought to be a major determinant in vascular morbidity ${ }^{2,3}$. In patients with type-1 or type-2 diabetes atherothrombotic complications are more frequent than in non-diabetic individuals ${ }^{4,5}$. A recent large clinical study showed that also in patients with type-1 diabetes, strict regulation of glucose levels in blood was apparently associated with a reduced rate of major cardiovascular events and mortality ${ }^{6}$. This study, as well as others, suggest that elevated blood glucose is a major determinant of atherothrombosis but the proposed mechanisms are sometimes controversial or not fully understood ${ }^{7-11}$.

Diabetes and particularly type- 2 disease is associated with several factors that are compatible with a hypercoagulable state in blood ${ }^{12-19}$. The latter is the result of increased activation of plasma coagulation activity and probably also of increased platelet reactivity 20,21. Particularly, in type-2 diabetes features of insulin resistance such as elevated plasminogen activator inhibitor -1 (PAl-1) concentrations may be significant in relation to atherothrombotic complications ${ }^{22,23}$. In order to characterize the blood coagulation determinants involved in hyperglycemia associated arterial thrombus formation we carried out experiments in mice made diabetic through streptozotocin administration.

\section{Mice, materials and methods}

\section{Animals and Treatment}

Female C57BL/6 mice were obtained from Charles River (Maastricht, The Netherlands). The study was approved by the Institutional Animal Care and Use Committees of the Academic Medical Center, University of Amsterdam, as well as of the University of Maastricht, both in the Netherlands.

Hyperglycemia was induced by a single intraperitoneal infusion of streptozotocin (STZ) ( $200 \mathrm{mg} / \mathrm{kg}$ body weight) in $50 \mathrm{mM}$ citrate buffer $(\mathrm{pH} \mathrm{4})^{24}$ at the age of 8 weeks. If one STZ injection did not induce hyperglycemia (glucose $>10 \mathrm{mmol} / \mathrm{L}$ ) after 4 days, the injection was repeated with one single intraperitoneal injection of $150 \mathrm{mg} \mathrm{STZ} \mathrm{per} \mathrm{kg} \mathrm{body} \mathrm{weight.}$ Control mice were injected with citrate buffer alone.

\section{Arterial thrombosis}

Ten weeks after streptozotocin injection mice were anesthetized by intraperitoneal injection of $70 \mu \mathrm{l} / \mathrm{g}$ FFM mixture (Fentanyl $(0.315 \mathrm{mg} / \mathrm{ml}$ )- Fluanisone $(10 \mathrm{mg} / \mathrm{ml}$ ) (Janssen Pharmaceutical, Beerse, Belgium), Midazolam $(5 \mathrm{mg} / \mathrm{ml}$ ) (Roche, Mijdrecht, The 
Netherlands)). Body temperature was monitored with a rectal probe and maintained at $37^{\circ} \mathrm{C} \pm 1^{\circ} \mathrm{C}$ via a heating pad and a halogen-heating lamp. During anesthesia extra oxygen $(1 \mathrm{~L} / \mathrm{min})$ was supplied via a tube placed at the nose of the mouse. Acute arterial thrombosis was induced by application of ferric chloride $\left(25 \% \mathrm{FeCl}_{3}\right)$ to the left carotid artery, as described ${ }^{25}$, resulting in the formation of platelet and fibrin-rich thrombi ${ }^{26}$. Before and after application of ferric chloride a Doppler flow probe was placed around the artery to measure blood flow. Time to occlusion (TTO) was defined as the time after initiation of arterial injury with ferric chloride required for blood flow to decline to $<0.2$ $\mathrm{mL} / \mathrm{min}$ (Figure $1 \mathrm{~A}$ ). Closing time was defined as the time from the start of the flow reduction i.e. thrombus formation to the final occlusion (Figure $1 \mathrm{~A}$ ).
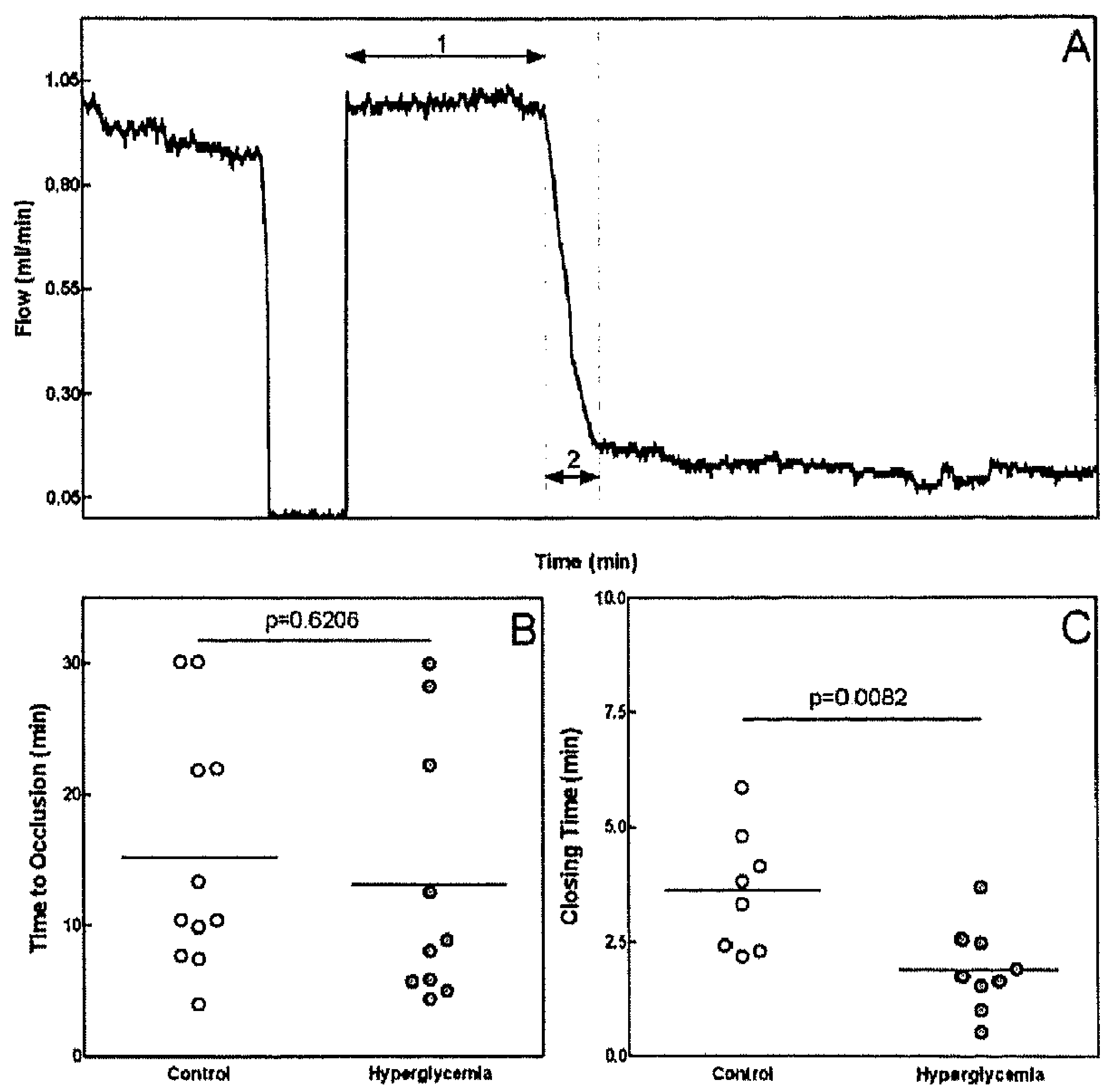

Figure 1

Ferric chloride induced arterial thrombosis in carotid artery.

Panel A: Typical example of flow pattern during ferric chloride induced arterial thrombosis of the cartotid artery with measurement of time to occlusion (TTO) and closing time . 1: Time to occlusion; 2: Closing Time.

Effects of streptozotocin induced hyperglycemia on arterial thrombosis. Panel B: No effects of hyperglycemia on time to occlusion (TTO). Panel $C$ : More rapid thrombus formation in hyperglycemic mice, measured from the start of thrombus formation to final occlusion(closing lime). Closing time was only measured when a thrombus was formed during the experiment (one vessel did not occlude after ferric chloride treatmend in 9 diabetic mice and thrombus formation was absent in 3 out of 8 control carotid arteries). 


\section{Plasma analysis}

Blood glucose levels were measured with a Glucometer ${ }^{\circledR}$ Elite (Bayer Diagnostics, Mijdrecht, The Netherlands) in a drop of blood from the tail vein. At the end of the experiment $3.2 \%(\mathrm{w} / \mathrm{v})$ sodium citrate in a total volume of body weight $(\mathrm{gr}) / 13 \times 100 \mu \mathrm{L}$ was i.v. administrated in the vena cava 20-30 seconds prior to blood drawing from the same vein into a syringe. Blood samples were centrifuged for 15 minutes at $3000 \mathrm{rpm}$ at RT, subsequently plasma was centrifuged for 5 minutes at $13000 \mathrm{rpm}$ to remove remaining cells and platelets, and immediately frozen at $-80^{\circ} \mathrm{C}$. Plasma levels of thrombinantithrombin (TAT) complexes were measured by a specific murine sandwich TAT ELISA as described previously ${ }^{27}$.

\section{Tissue harvesting and histological analysis}

At the end of the experiments, aortas were collected and stored at $-80^{\circ} \mathrm{C}$ whereas the left carotid arteries were formalin-fixed, embedded in paraffin, and sectioned. For immunohistochemical analysis paraffin sections of $4 \mu \mathrm{m}$ were deparaffinized and rehydrated. Sections were incubated with $1.5 \% \mathrm{H}_{2} \mathrm{O}_{2}$ in PBS for 20 minutes and then blocked with TENG-T ( $10 \mathrm{mM}$ Tris, $5 \mathrm{mM}$ EDTA, $150 \mathrm{mM} \mathrm{NaCl}, 0.25 \%$ gelatin, $0.05 \%$ (vol/vol) Tween-20\%, $\mathrm{pH}$ 8.0) for 30 minutes at room temperature. Thereafter, sections were washed and incubated with primary antibodies against TF and fibrin $0 / N$ at $4^{\circ} \mathrm{C}$. Rabbit anti-mouse TF antibody antibodies were developed in our laboratory by immunization of rabbits with a mixture of $500 \mu$ Freund's Complete Adjuvant (Difco) and murine TF peptide P5 ${ }^{28}$. Final concentration of anti-TF antibody was $1.3 \mu \mathrm{g} / \mathrm{ml}$. Rabbit anti-rat fibrin antibody was kindly provided by Dr. J. Emeis, TNO, The Netherlands and used in a 1:1000 dilution ${ }^{29}$. After incubation with the primary antibodies tissue sections were washed and goat anti-rabbit (DAKO A/S, Glostrup, Denmark) was used as the secondary antibody in a 1:250 dilution for 1 hour at room temperature, and than washed with PBS. The sections were incubated with $S A B C$ complex (DAKO A/S) for one hour at room temperature, and washed. Enzyme activity was detected with AEC (Sigma) after incubation for 5 minutes. Specificity controls included normal rabbit immunoglobulin in place of specific primary antibodies. For evaluation of TF and fibrin immunostaining a semi quantitative score approach was chosen using a magnification of 20 times. For TF quantification the following criteria were used: 0 : no staining in thrombus and vessel wall; 1 : focal staining in thrombus; 2: diffuse staining in thrombus; 3 : positive staining in thrombus and focal staining in vessel wall. For fibrin immunostaining the following criteria were used: 0 : no staining in thrombus; 1: focal positive staining in thrombus. The degree of staining was evaluated blinded for treatment strategies.

\section{Tissue factor activity}

Tissue factor activity was determined using an in-house assay. In brief, arterial tissue parts were homogenized in TBS, $50 \mathrm{mM} \mathrm{n-octyl} \mathrm{B-d-glucopyranoside,} \mathrm{pH} 8.4$ and immediately frozen in liquid nitrogen and subsequently thawed at $37^{\circ} \mathrm{C}$. Supernatants were collected through centrifugation at $14000 \mathrm{rpm}, 4{ }^{\circ} \mathrm{C}$ for $15 \mathrm{~min}$, and stored at $-80{ }^{\circ} \mathrm{C}$. For tissue 
factor activity samples were diluted in $25 \mathrm{mM} \mathrm{HEPES}, 175 \mathrm{mM} \mathrm{NaCl}, \mathrm{pH} 7.7$ and incubated with reaction buffer at $37^{\circ} \mathrm{C}$ for $20 \mathrm{~min}$. Final concentrations were: $0.72 \mathrm{nM}$ recombinant factor Vlla (Novo Nordisk, Bagsvard, Denmark), $60 \mathrm{nmol} / \mathrm{L}$ bovine factor X (Sigma-Aldrich, St. Louis, MO), $3 \mathrm{mmol} / \mathrm{L} \mathrm{Ca}^{2+}, 7.2 \mu \mathrm{mol} / \mathrm{L}$ 20:80 PS:PC. Factor Xa activity was kinetically measured using the chromogenic substrate S-2765 (Chromogenix, final concentration of 0.7 $\mathrm{mg} / \mathrm{mL}$ diluted in $50 \mathrm{mM}$ Tris $-\mathrm{HCl}, 175 \mathrm{nM} \mathrm{NaCl}, 30 \mathrm{mM} \mathrm{Na2EDTA}, \mathrm{pH}$ 7.4) for $15 \mathrm{~min}$. each $15 \mathrm{sec}$. at $405 \mathrm{~nm}$ at $37^{\circ} \mathrm{C}$.

\section{Quantitative RT-PCR}

Expression of genes involved in inflammation and coagulation, interleukin 1-Beta (IL-1B), TF, intercellular adhesion molecule-1 (ICAM-1), vascular adhesion molecule-1 (VCAM-1), monocyte chemoattractant peptide-1 (MCP-1), and endothelial selectin (E-selectin) was analyzed on the mRNA level by quantitative real time PCR as earlier described ${ }^{30}$. Total RNA was extracted from homogenates from the descending aorta using Trizol reagent (Life Technologies) according to the manufacturer's instructions. Purified RNA was reverse transcribed (RevertAid M-Mul V Reverse Transcriptase) according to the protocols supplied by the manufacturer. Quantitative gene expression was performed on an ABI PRISM 7700 combination of hardware and software (Applied Biosystems, Foster City, CA) using SYBR Green technology. PCR primers were designed using Primer Express 1.7 software with the manufacturer's default settings (Applied Biosystems) and validated for identical efficiencies (slope $=-3.3$ for a plot of $C t$ versus log ng CDNA, primer details available on request). SYBR Green master mix $(19 \mu \mathrm{l})$ was added to $5 \mu \mathrm{l}$ CDNA (corresponding to $50 \mathrm{ng}$ of total RNA input) and $300 \mathrm{nM}$ of forward and reverse primers in water. The samples were heated for $2 \mathrm{~min}$ at $50^{\circ} \mathrm{C}$ and $10 \mathrm{~min}$ at $95^{\circ} \mathrm{C}$. Subsequently $40 \mathrm{PCR}$ cycles consisting of 15 sec at $95^{\circ} \mathrm{C}$ and $60 \mathrm{sec}$ at $60^{\circ} \mathrm{C}$ were applied. At the end of the run, samples were heated to $95^{\circ} \mathrm{C}$ with a ramp time of $20 \mathrm{~min}$ to construct dissociation curves to check that single PCR products were obtained. The absence of genomic DNA contamination in the RNA preparations was confirmed by using total RNA samples that had not been subjected to reverse transcription. Acidic ribosomal phosphoprotein PO (36B4) was used as the standard housekeeping gene ${ }^{30}$. Ratios of target gene and 36B4 expression levels (relative gene expression numbers) were calculated by subtracting the threshold cycle number $(\mathrm{Ct})$ of the target gene from $\mathrm{Ct}$ of $36 \mathrm{~B} 4$ and raising 2 to the power of this difference. $\mathrm{Ct}$ values are defined as the number of PCR cycles at which the fluorescent signal during the PCR reaches a fixed threshold. Target gene mRNA expressions are thus expressed relative to 36B4 expression.

Platelet purification and procoagulant activity

Blood was collected as described above. To each volume citrated murine blood, five volumes of HEPES buffer containing 10\% (w/v) BSA (10 mM HEPES, $137 \mathrm{mM} \mathrm{NaCl}, 2.7 \mathrm{mM}$ $\mathrm{KCL}, 2 \mathrm{mM} \mathrm{MgCl}$, $5 \mathrm{mM}$ glucose, $\mathrm{pH}$ 7.4) were added. The platelet rich plasma was collected after centrifugation for $6 \mathrm{~min}$. at $200 \mathrm{~g}$ and subsequently the platelet 
concentration was determined using a Coulter counter and adjusted at $1 \times 10^{6} / \mathrm{ml}$ using HEPES buffer containing 0.05\% (w/v) BSA.

Platelets were activated with collagen $(5 \mu \mathrm{g} / \mathrm{mL})$ and thrombin $(4 \mathrm{nM})$ in the presence of $\mathrm{CaCl}_{2}(3 \mathrm{mM})$ for $10 \mathrm{~min}$ at $37^{\circ} \mathrm{C}$ under continuous stirring. Platelet procoagulant activity was measured by addition of factor $\mathrm{Xa}$, factor $\mathrm{Va}$ and prothrombin to the activated platelet suspension. More specifically, the following conditions were used (final concentrations): platelet concentration, $0.7 \times 10^{6} / \mathrm{ml}, 1 \mathrm{nM}$ factor $\mathrm{Xa}, 2 \mathrm{nM}$ factor $\mathrm{Va}, 3 \mathrm{mM}$ $\mathrm{CaCl}_{2}$. Thrombin formation was started by addition of prothrombin (555 $\left.\mathrm{nM}\right)$ and arrested after 4 minutes by addition of 5 mM EDTA. Thrombin was measured using the chromogenic substrate $\mathbf{5 2 2 3 8 .}$

Bovine serum albumin (BSA, essentially fatty acid free), was obtained from Sigma (St Louis, $\mathrm{MO}$ ). Coagulation factors factor $\mathrm{Xa}$, factor $\mathrm{Va}$, prothrombin and thrombin were purified from bovine blood as described before (Rosing et al., 1980). Thrombin-specific chromogenic substrate 52238, was obtained from Chromogenix (Mölndal, Sweden). Horse tendon collagen was from Horm Nycomed (Münich, Germany). All other reagents were of the highest grade commercially available.

\section{Statistics}

Data are represented as mean with standard error of mean for normally and as median with $25-75 \%$ quartiles for non-normally distributed variables. Differences between groups were assessed using non-paired Student's $t$-test for data with normal distribution or MannWhitney test for data with non-normal distribution. $P$ values $<0.05$ were considered statistically significant. Statistical analysis was performed using SPSS version 12.01 for Microsoft Windows.

\section{Results}

Determination of levels of glucose and TAT complexes

Ten weeks after streptozotocin treatment blood glucose levels were significantly increased in hyperglycemic mice $(22.2 \pm 2.0 \mathrm{mmol} / \mathrm{L})$ as compared to control mice $(6.7 \pm 2.5$ $\mathrm{mmol} / \mathrm{L}, \mathrm{p}<0.001)$. Plasma TAT-levels were not different between control and hyperglycemic animals.

\section{Acute arterial thrombosis}

Ten weeks of hyperglycemia had no effect on time to occlusion (TTO) (Figure 1B). However, we observed a shortening of the time from the start of thrombus formation until occlusion (closing time) (Figure $1 \mathrm{~A}$ ) in the diabetic mice compared to control mice (nondiabetic mice $3.6 \pm 0.5$ vs. diabetic mice $2.0 \pm 0.3 \mathrm{~min} ; \mathrm{p}=0.008)$. After the induction of carotid thrombosis plasma TAT complexes were considerably higher in diabetic mice (diabetic $2.2 \mathrm{ng} / \mathrm{mL}(0.5-21.2)$ than in non-diabetic mice: $0.38 \mathrm{ng} / \mathrm{mL}(0.2-1.0), p=0.032$ ). 
Thrombus composition and immunohistochemistry

Serial sections of the left carotid artery segment that had been treated with ferric chloride showed total occlusion by a platelet rich thrombus. Occasionally small islands of erythrocytes amidst platelets was seen in adjacent sections. Ferric chloride was seen in the vessel wall and on the endothelium in the vessel lumen of the segment that had been treated. No difference could be observed in thrombus composition between mice with and without hyperglycemia. Furthermore, occluded arteries from mice with and without hyperglycemia showed similar immunostaining for fibrin and TF (Table 1) upon ferric chloride induced arterial thrombosis. To assess whether hyperglycemia would influence TF activity we determined this in aorta homogenates. This analysis showed comparable levels in aortas from control and hyperglycemic animals (1762 $\mathrm{PM} \pm 272$ and $2086 \mathrm{pM} \pm 566$, respectively).

Table 1

Immunostaining of thrombi from non-diabetic mice, diabetic mice and diabetic mice with simvastatin treatment. Data are presented as median with $25 ; 75$ quartiles. No significant differences were observed between the three groups.

\begin{tabular}{lllll}
\hline $\begin{array}{l}\text { Staining of occluded } \\
\text { artery }\end{array}$ & $\begin{array}{l}\text { Non-diabetic mice } \\
(\mathrm{N}=11)\end{array}$ & $\begin{array}{l}\text { Diabetic mice } \\
(\mathrm{N}=19)\end{array}$ & $\begin{array}{l}\text { Diabetic mice } \\
\text { simvastatin treatment } \\
(\mathrm{N}=8)\end{array}$ & with \\
& & $2.0(1.0 ; 3.0)$ & $2.0(1.0 ; 3.0)$ & 0.72 \\
\hline $\begin{array}{l}\text { Tissue factor } \\
\text { Fibrin }\end{array}$ & $1.0(1.0 ; 2.5)$ & $1.0(0.25 ; 1.0)$ & $1.0(0.25 ; 1.0)$ & 0.76 \\
\hline
\end{tabular}

\section{RT-PCR}

Gene expression of TF, MCP-1, IL-1B, E-selectin, ICAM-1, and VCAM-1 in the descending aorta was compared between control mice $(n=11)$ and hyperglycemic mice $(n=19)$. The relative gene expression levels of mRNA encoding TF, MCP-1, E-selectin, ICAM-1, and VCAM-1 did not differ between hyperglycemic and control aortas (Figure 2). Only the level of IL-1B mRNA was significantly lower in aortas from hyperglycemic mice $\left(0.42 \cdot 10^{-3}\right.$ $\left(0.22 \cdot 10^{-3} ; 0.93^{\cdot} 10^{-3}\right)$ as compared to aortas from control mice $\left(1.0^{0} 10^{-3}\left(0.6 \cdot 10^{-3} ; 1.8 \cdot 10^{-3}\right)\right.$ $(p=0.04)$ (Figure 2).

Platelet prothrombinase activity

In a second experiment C57BIJ6 mice were again made hyperglycemic by streptozotocin as indicated above. Mean blood glucose values were $15.9 \pm 1.3 \mathrm{mmol} / \mathrm{L}$ in the diabetic group $(n=8)$ and $8.2 \pm 0.4 \mathrm{mmol} / \mathrm{L}$ in control mice $(n=7)$. Platelet prothrombinase activity as analyzed by thrombin formation in response to collagen alone was not different between hyperglycemic and control animals (Figure $3 \mathrm{~A}$ ). In an assay in which collagen and thrombin were added in combination to induce platelet prothrombinase activity, thrombin formation was enhanced in hyperglycemic animals $(62.79 \mathrm{nM} / \mathrm{min} \pm 4.63)$ as compared to control mice $(48.09 \pm 2.02 \mathrm{nM} / \mathrm{min}, \mathrm{p}=0.016$, data given for the 4 minutes time point) (Figure $3 \mathrm{~B})$. 


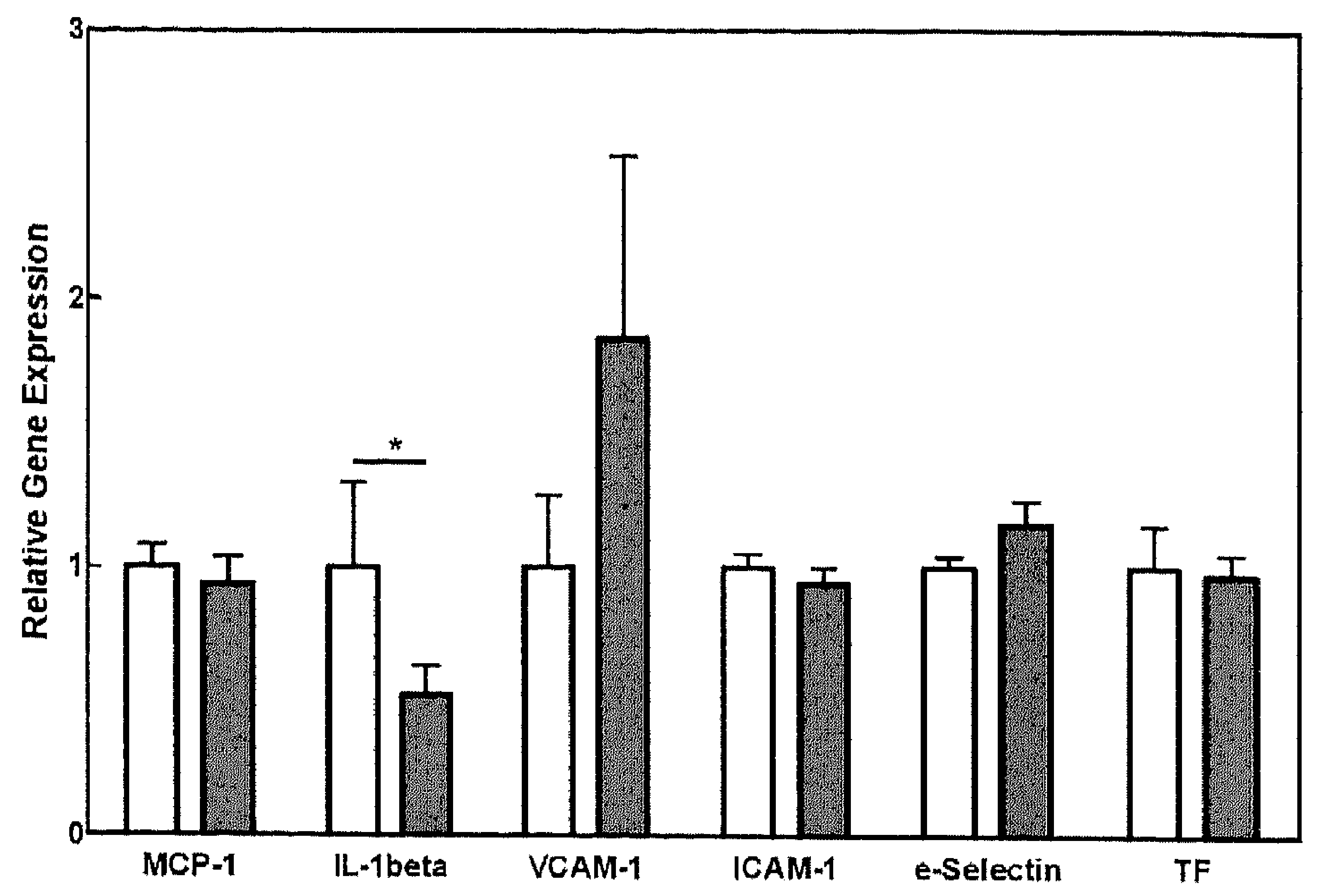

Figure 2

Relative inRNA levels in aorta's from control mice (white bars, $\mathrm{n}=11$ ) and streptozotocin induced hyperglycemic mice (gray bars, $n=19$ ). Relative expression levels of MCP-1, IL-1 beta, VCAM-1, ICAM-1, e-Selectin, and tissue factor (TF) in aortas from hyperglycemic animals are given as ratio of relative expression levels in control aortas. * Significantly lower IL-1 $\beta$ mRNA in streptozotocin induced hyperglycemic mice $(\mathrm{p}=0.039)$ as compared to non-treated control mice.

\section{Discussion}

Although hyperglycemia is a characteristic feature of diabetes type-1 and -2, its influence on atherothrombosis remains poorly characterized. Glucose mediated increased production of AGEs may be a critical mechanism inducing inflammatory and prothrombotic changes in the vasculature. In order to address the impact of high blood glucose on mechanisms of atherothrombosis we employed a model of type-1 diabetes in mice. In such hyperglycemic mice thrombus formation was induced by application of ferric chloride to the carotid artery. The application of ferric chloride is known to induce endothelial cell damage, leading to exposure of subendothelial platelet binding and activating proteins including collagen.

In general, thrombus formation depends on interactions of the damaged vessel wall with blood components. The lack of difference in time to occlusion between hyperglycemic and euglycemic mice in our study suggests that the factor "hyperglycemia" did not have a major impact on any of the components of Virchov's triad. Indeed, we did not find a difference in tissue factor gene expression (both mRNA and protein activity) and tissue factor activity in the arterial vessel wall (aorta), nor a conspicuous difference in 
composition of the clot. In addition, we did not observe a pro-inflammatory action of high blood glucose on the vessel wall as indicated by unaltered gene expression levels of a number of pro-inflammatory mRNAs. Thus, the arterial vessel wall appears not to be grossly perturbed with regard to pro-inflammatory and procoagulant gene expression levels.
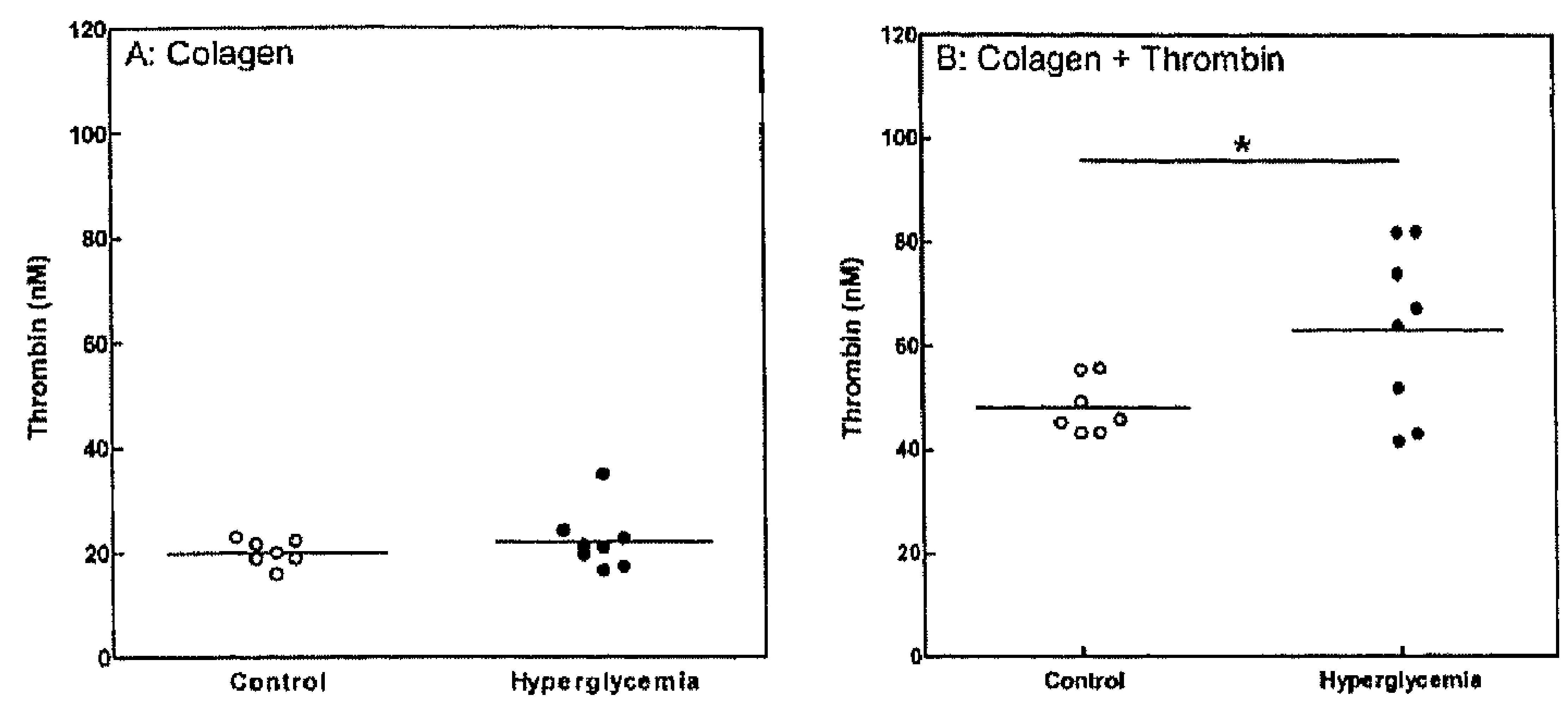

\begin{abstract}
Figure 3
Effect of hyperglycemia on platelet procoagulant activity induced by collagen (panel A) and collagen plus thrombin (panel B) in control $(O)$ and hyperglycemic $(\bullet)$ animals. The concentration of thrombin produced in the prothrombinase reasction was determined at 4 minutes after the reaction was initiated. Values are means and $S D$ of $n=8$ animals per experiment. * Significantly increased with respect to the control group.
\end{abstract}

In contrast, the rate of arterial thrombus formation was significantly accelerated in hyperglycemic animals, which was associated with a marked increase in systemic thrombin generation in the systemic blood as indicated by elevated TAT-complex levels after induction of thrombosis. We hypothesized that these findings could be explained by increased platelet reactivity, since platelets are the main constituent of the arterial clots and since activated platelets can provide a catalytic surface for efficient thrombin generation.

In order to study the contribution of platelets in this process we set up a second experiment involving hyperglycemic mice. Platelets were isolated from control and hyperglycemic and diluted to an appropriate concentration for the study of thrombin generation after collagen stimulation. These conditions mimic the in vivo situation where platelets stick to collagen on the inner surface of the damaged vessal wall, resulting in activation and aggregation. The ex vivo experiment showed increased procoagulant activity after collagen/thrombin induced activation of platelets from hyperglycemia 
animals. Activation of platelets by collagen alone, however, had no effect on procoagulant activity, most likely due to the synergistic effect of collagen and thrombin ${ }^{31}$.

Platelet procoagulant activity is mainly determined by the extent of surface-exposed phosphatidylserine (PS) and the increased procoagulant activity in hyperglycemic mice suggests either an increase in the platelet fraction which exposes PS or an increase in PS exposure within the fraction of platelets exposing PS ${ }^{31}$. The mechanisms involved may consist of different factors that act in concert to lead to a platelet phenotype of enhanced reactivity to usually subthreshold concentrations of stimuli, which is known to occur in platelets from diabetic individuals ${ }^{20,21}$. These factors may be related to altered biomembrane properties due to glycation of surface phospholipids and proteins. Whether this also includes an alteration in the distribution of phosphatidylserine and phosphatidylcholine in the outer platelet membrane remains to be established. Although one study reported such a finding induced by high glucose concentrations in vitro ${ }^{32}$, we have not been able to confirm this in a model of erythrocytes subjected to different glucose concentrations (Wolfs and Bevers, unpublished).

In conclusion, our data support a direct influence of hyperglycemia on thrombin generation in blood, probably by amplifying platelet membrane catalytic functions, which contributes to accelerated arterial clot formation. This effect may increase the likelihood of developing arterial thrombosis and may be relevant for the risk of arterial thrombotic events in patients with diabetes, particularly those with type-1 disease. Given the strong suggestion that strict glucose regulation reduces the risk of arterial thrombotic events, a causal relation between glucose and thrombosis seems plausible. Clinically, this study provides additional evidence for a need for effective platelet inhibiting agents in patients with diabetes mellitus.

\section{Acknowledgments}

We like to thank Joost Daalhuisen en Ingvild Kopp from the Academic Medical Center for their invaluable assistance. Hjalmar Hansen and Arnaud Hauer were supported by grants from the Netherlands Heart Foundation (2000B062 and 2000B198, respectively). 


\section{References}

1. Cohen RA. ATVB in focus: Diabetic vascular disease: pathophysiological mechanisms in the diabetic milieu and therapeutic implications. Arterioscler Thromb Vasc Biol. 2004;24:13401341.

2. Brownlee $M$, Cerami A, Vlassara $H$. Advanced glycosylation end products in tissue and the biochemical basis of diabetic complications. N Engl J Med. 1988;318:1315-1321.

3. Schmidt AM, Yan SD, Wautier JL, Stern D. Activation of receptor for advanced glycation end products: a mechanism for chronic vascular dysfunction in diabetic vasculopathy and atherosclerosis. Circ Res. 1999;84:489-497.

4. Laing SP, Swerdlow AJ, Slater SD, et al. Mortality from heart disease in a cohort of 23,000 patients with insulin-treated diabetes. Diabetologia. 2003;46:760-765.

5. Dorman JS, Laporte RE, Kuller LH, et al. The Pittsburgh insulin-dependent diabetes mellitus (IDDM) morbidity and mortality study. Mortality results. Diabetes. 1984;33:271-276.

6. Nathan DM, Cleary PA, Backlund JY, et al. Intensive diabetes treatment and cardiovascular disease in patients with type 1 diabetes. $N$ Engl J Med. 2005;353:2643-2653.

7. Meigs JB, Singer DE, Sullivan $L M$, et al. Metabolic control and prevalent cardiovascular disease in non-insulin-dependent diabetes mellitus (NIDDM): The NIDDM Patient Outcome Research Team. Am J Med. 1997;102:38-47.

8. Intensive blood-glucose control with sulphonylureas or insulin compared with conventional treatment and risk of complications in patients with type 2 diabetes (UKPDS 33). UK Prospective Diabetes Study (UKPDS) Group. Lancet. 1998;352:837-853.

9. Stratton IM, Adler Al, Neil HA, et al. Association of glycaemia with macrovascular and microvascular complications of type 2 diabetes (UKPDS 35): prospective observational study. Bmj. 2000;321:405-412.

10. Wei M, Gaskill SP, Haffner SM, Stern MP. Effects of diabetes and level of glycemia on allcause and cardiovascular mortality. The San Antonio Heart Study. Diabetes Care. 1998;21:1167-1172.

11. Libby P, Plutzky J. Diabetic macrovascular disease: the glucose paradox? Circulation. 2002; 106:2760-2763.

12. Aso Y, Fujiwara Y, Tayama K, Takebayashi K, Inukai T, Takemura Y. Relationship between soluble thrombomodulin in plasma and coagulation or fibrinolysis in type 2 diabetes. Clin Chim Acta. 2000;301:135-145.

13. Takahashi H, Tsuda A, Tatewaki W, Wada K, Niwano H, Shibata A. Activation of blood coagulation and fibrinolysis in diabetes mellitus: evaluation by plasma levels of thrombinantithrombin III complex and plasmin-alpha 2-plasmin inhibitor complex. Thromb Res. 1989;55:727-735.

14. Ceriello A, Taboga C, Tonutti L, et al. Evidence for an independent and cumulative effect of postprandial hypertriglyceridemia and hyperglycemia on endothelial dysfunction and oxidative stress generation: effects of short- and long-term simvastatin treatment. Circulation. 2002;106:1211-1218.

15. Folsom AR, Wu KK, Rasmussen M, Chambless LE, Aleksic N, Nieto FJ. Determinants of population changes in fibrinogen and factor VII over 6 years: the Atherosclerosis Risk in Communities (ARIC) Study. Arterioscler Thromb Vasc Biol. 2000;20:601-606. 
16. Fujiwara $Y$, Tagami S, Kawakami Y. Circulating thrombomodulin and hematological alterations in type 2 diabetic patients with retinopathy. J Atheroscler Thromb. 1998;5:21. 28.

17. Yamada $T$, Sato A, Nishimori $T$, et al. Importance of hypercoagulability over hyperglycemia for vascular complication in type 2 diabetes. Diabetes Res Clin Pract. 2000;49:23-31.

18. Tschoepe $D$. Activated haemostasis in diabetic vascular complications: a role for tissue factor? Exp Clin Endocrinol Diabetes. 1997;105:204-205.

19. Sommeijer DW, Hansen HR, van Oerle R, et al. Soluble tissue factor is a candidate marker for progression of microvascular disease in patients with Type 2 diabetes. $J$ Thromb Haemost. 2006;4:574-580.

20. Watala $C$, Boncler $M$, Gresner P. Blood platelet abnormalities and pharmacological modulation of platelet reactivity in patients with diabetes mellitus. Pharmacol Rep. 2005;57 Suppl:42-58.

21. Ferroni P, Basili S, Falco A, Davi G. Platelet activation in type 2 diabetes mellitus. J Thromb Haemost. 2004;2:1282-1291.

22. Dunn EJ, Grant PJ. Type 2 diabetes: an atherothrombotic syndrome. Curr Mol Med. 2005;5:323-332.

23. De Taeye B, Smith LH, Vaughan DE. Plasminogen activator inhibitor-1: a common denominator in obesity, diabetes and cardiovascular disease. Curr Opin Pharmacol. 2005;5:149-154.

24. Like AA, Rossini AA. Streptozotocin-induced pancreatic insulitis: new model of diabetes mellitus. Science. 1976;193:415-417.

25. Farrehi PM, Ozaki CK, Carmeliet P, Fay WP. Regulation of arterial thrombolysis by plasminogen activator inhibitor-1 in mice. Circulation. 1998;97:1002-1008.

26. Smyth SS, Reis ED, Vaananen $H$, Zhang $W$, Coller BS. Variable protection of beta 3-integrin-. deficient mice from thrombosis initiated by different mechanisms. Blood. 2001;98:1055. 1062.

27. Sommeijer DW, van Oerle R, Reitsma PH, et al. Analysis of blood coagulation in mice: preanalytical conditions and evaluation of a home-made assay for thrombin-antithrombin complexes. Thromb J. 2005;3:12.

28. de Waard $V$, Hansen $H R$, Spronk $H H$, et al. Differential expression of tissue factor mRNA and protein expression in murine sepsis. The role of the granulocyte revisited. Thromb Haemost. 2006;95:348-353.

29. Wasser MN, Koppert PW, Arndt JW, et al. An antifibrin monoclonal antibody useful in immunoscintigraphic detection of thrombi. Blood. 1989;74:708-714

30. Hoekstra M, Kruijt JK, Van Eck M, Van Berkel TJ. Specific gene expression of ATP-binding cassette transporters and nuclear hormone receptors in rat liver parenchymal, endothelial, and Kupfer cells. J Biol Chem. 2003;278:25448-25453.

31. Wolfs JL, Comfurius P, Rasmussen JT, et al. Activated scramblase and inhibited aminophospholipid translocase cause phosphatidylserine exposure in a distinct platelet fraction. Cell Mol Life Sci. 2005;62:1514-1525.

32. Wilson MJ, Richter-Lowney K, Daleke DL. Hyperglycemia induces a loss of phospholipid asymmetry in human erythrocytes. Biochemistry. 1993;32:11302-11310. 
Chapter 8

al expression of tissue factor mRNA and protein expression in murine sepsis: the role of the granulocyte revisited

Vivian de Waard • Hjalmar R. Hansen - Henri H.M. Spronk • Janneke J. Timmerman Hans Pannekoek • Sandrine Florquin • Pieter H. Reitsma • Hugo ten Cate

Thromb Haemost. 2006; 95(2): 348-53. 


\section{Summary}

Tissue factor (TF) is a transmembrane protein, which is essential for initiation of the coagulation cascade. TF has been reported to play an important role in the progression of endotoxin (lipopolysaccharide, LPS)-mediated endotoxemia, being induced in numerous tissues, such as kidney, spleen and lung. We developed and validated a rabbit anti-murine TF peptide antiserum to localize TF protein in a murine sepsis model. TF protein distribution was compared to localization of TF mRNA and fibrin deposits, the ultimate resultant of procoagulant TF activity. Evident LPS-mediated TF mRNA induction was observed in the tubular area at the cortico-medullar junction in the kidney, and TF activity was increased after 6 hours of endotoxemia. In the spleen, however, TF mRNA was induced in the interfollicular region upon LPS injection, corresponding to increased TF protein in the same area. The clusters of TF-protein positive cells in the spleen are predominantly granulocytes, but no TF mRNA expression was observed within these cells. Based on these observations and the presence of TF-protein positive granulocytes after splenectomy, we hypothesize that granulocytes take-up TF for transport to other locations in order to initiate fibrin formation or to induce pro-inflammatory gene expression upon interaction with factor VIIa. 


\section{Introduction}

Tissue factor (TF) is a transmembrane protein, which together with factor VIIa initiates the extrinsic coagulation pathway, resulting in thrombin generation and ultimately fibrin deposition 1. Under physiological circumstances TF is expressed in a wide variety of cell-types such as epithelial cells in lung and kidney, fibroblasts of the arterial vasculature, and astrocytes in the brain 2. TF expression can be induced in cells from the vasculature, notably in smooth muscle cells, endothelial cells, and monocytes ${ }^{3-9}$.The observations of TF-positive granulocytes suggest that granulocytes also play a role in coagulation. Several groups have shown TF-positive granulocytes in models of sepsis ${ }^{10-12}$, acute obstructive cholangitis ${ }^{13}$, and in blood from healty human volunteers ${ }^{14}$. However, it remains uncertain whether granulocytes actually synthesize $\mathrm{TF}$ mRNA and protein or absorb the protein from other cellular sources ${ }^{15}$.

In gram-negative sepsis, disseminated intravascular coagulation (DIC) is a consequence of the release of bacterial endotoxin (lipopolysaccharide, LPS), resulting in inflammation mediated monocyte activation and $\mathrm{TF}$ expression. In different animal models of endotoxemia $\mathrm{TF}$ is also induced in other cells and tissues including kidney, spleen, and lung ${ }^{16-19}$. The expression of $\mathrm{TF}$ carrying cells and microparticles in the vasculature is probably an important contributor to sepsis associated mortality considering the efficacy of specific inhibitors of the $T F$ factor:VIIa system in limiting DIC and mortality in experimental models of sepsis ${ }^{20}$. 22,23 , although clinical trials do not yet support this concept 24-26.

TF mRNA expression can be induced by pro-inflammatory cytokines and growth factors and the kinetics of synthesis categorizes TF as an immediate-early gene. Yet, mRNA expression does not necessarily reflect the availability of bioactive protein, since TF can be encrypted 27,28 . In order to study its immunohistochemical and functional heterogeneity under normal and septic conditions we developed and validated novel peptide based rabbit polyclonal anti-murine TF antibodies and used them to study the organ-specific pattern of TF expression in a murine sepsis model. In addition, we related the protein distribution of $\mathrm{TF}$ to its activity with a functional assay as well as to fibrin deposition as a measure of activation of blood coagulation.

\section{Material and Methods}

Animals and diets

All studies were performed using female mice of the FVB strain from Charles River Laboratories Inc. (Iffa-Credo, l'Arbresle, France), which were 12 weeks old at the start of the experiments. The animals were housed in normal cages in an environment with a 12 hour light-dark cycle, controlled temperature $\left(20 \pm 2^{\circ} \mathrm{C}\right)$ and humidity (50 
$\pm 10 \%$ ). Animals had free access to water and standard chow diet. LPS (E. coli serotype O55:B5; Sigma Chemical Co., St. Louis, MO) was diluted to the appropriate concentration in sterile saline and injected intraperitoneally $(4 \mathrm{mg} / \mathrm{kg}$ mouse body weight). Mice were killed by exsanguination at respectively $0,2,6$ and 24 hours after LPS injection while they were under fentanyl-fluorisone-midozalam anesthesia, and tissues were frozen at $-80^{\circ} \mathrm{C}$ upon collection using standard dissection techniques. For immunohistochemical and in situ hybridisation analysis tissues were first placed in $4 \%(\mathrm{v} / \mathrm{v})$ phosphate buffered formaldehyde within 30 minutes of death and fixed for 24 hours at room temperature. The Experimental Animal Ethics Committee of the University Amsterdam approved all experimental protocols.

In situ hybridization

Sense and antisense riboprobes were synthesized by in vitro transcription of an 821 base pairs (bp) murine TF CDNA fragment that was cloned into the pGEM- $3 Z$ and $-4 Z$ vector (Promega, Madison, WI), respectively. These plasmids, pcMTF2281 and pcMTF2279, were previously characterized and kindly provided by Dr. D.J. Loskutoff (The Scripps Research Institute, La Jolla, CA) 17. In brief: the constructs were linearized with restriction enzyme BamHI (GIBCO BRL, Gaithersburg, MD) and riboprobes were synthesized for $1 \mathrm{~h}$ at $37^{\circ} \mathrm{C}$, according to manufacturer's instructions for SP6 RNA polymerase (Promega, Madison, WI) and labeled with [ ${ }^{35 S}$ ]-UTP (Amersham Pharmacia Biotech, Buckinghamshire, U.K.). Paraffin sections (5 $\mu \mathrm{m})$ of various tissues were mounted on SuperFrost Plus slides (Menzel-Glaser, Braunschweig, Germany). In situ hybridization was performed by standard procedures. After stringent washes, the in situ sections were covered with nuclear research emulsion (ILFORD Imaging UK Limited, Cheshire, U.K.), exposed for 2 to 4 weeks, then developed and counterstained with hematoxylin and eosin.

Synthesis of $T F$ peptides and immunization of rabbits

Five immunogenic $\mathrm{TF}$ peptides, corresponding to relatively hydrophilic amino-acid (a) sequences within the extracellular domain of murine TF protein ${ }^{29}$ (accession number: NM_010171), were generated: $\mathrm{P} 1$, amino acid (aa, numbering starting with Met as +1) 56-74; P2, aa 103-117; P3, aa 144-157; P4, aa 188-204; P5, aa 225-240. The peptides were synthesized by solid-phase strategies as described earlier ${ }^{30}$. The purity of the peptides was determined by analytical reversed-phase HPLC and proved to be at least $80 \%$. The integrity of the peptides was determined by laser desorption time-of-flight mass spectrometry on a lasermat mass spectrometer (Finnigan MAT, Ringoes, NJ). The peptides were dissolved in $50 \mathrm{nM}$ phosphate buffer ( $\mathrm{pH}$ 6.0) and conjugated to thyroglobulin (Sigma, St. Louis, MO). After overnight dialysis against $0.2 \%(\mathrm{v} / \mathrm{v}) \mathrm{Na}_{2} \mathrm{~S}_{\S} \mathrm{O}_{5}(\mathrm{pH} 5.0), 1 \mathrm{ml}$ peptide-solution was slowly mixed with $1 \mathrm{ml}$ Freund's Complete Adjuvant (Difco, Detroit, MI). The rabbits were injected twice subcutaneous on the back and twice intramuscular in the hind 
legs. Large blood samples were drawn when the rabbits responded with high specific antibody titers.

\section{Affinity purification of TF antibodies}

First, the immunoglobulin (IgG) fraction was purified from the polyclonal antiserum against peptide P5, using Protein A Sepharose CL-4B (Amersham Pharmacia Biotech), according to the manufacturers protocol. The antibodies were eluted from the column using $100 \mathrm{nM}$ glycine- $\mathrm{HCl}(\mathrm{pH}$ 4.0). The fractions were instantly neutralized with $1 \mathrm{M}$ Tris- $\mathrm{HCl}(\mathrm{pH} 7.4)$ and the IgG-containing fractions were pooled and dialyzed against phosphate-buffered saline (PBS). Second, the peptide-specific antibodies were purified from the IgG fraction using affinity purification by BSAcoupled peptide $(2 \mu$ moles/ml Sepharose gel) as a ligand which was coupled to cyanogen bromide-activated Sepharose 4B (Amersham Pharmacia Biotech) according to the manufacturers protocol. The Protein A Sepharose-purified antibodies were led over the column twice. The column was washed extensively with PBS and the specific antibodies were eluted from the column using $100 \mathrm{nM}$ glycine$\mathrm{HCl}(\mathrm{pH}$ 2.5). The fractions were instantly neutralized with $1 \mathrm{M}$ Tris- $\mathrm{HCl}(\mathrm{pH} 7.4)$ and the antibody-containing fractions were pooled, dialyzed against PBS and concentrated using a Centricon YM-30 filter (Millipore, Bedford, MA).

\section{Immunohistochemistry}

Paraffin sections $(5 \mu \mathrm{m})$ were deparaffinized, rehydrated and incubated with 0.3 $\%(\mathrm{v} / \mathrm{v})$ hydrogen peroxide and blocked with $10 \%(\mathrm{v} / \mathrm{v})$ pre-immune goat serum (DAKO, Glostrup, Denmark) in $10 \mathrm{mM}$ Tris- $\mathrm{HCl}$ (pH 8.0), $150 \mathrm{mM} \mathrm{NaCl}$ (TBS). Subsequently, the sections were incubated overnight at $4^{\circ} \mathrm{C}$ with primary antibodies in TBS, followed by incubation with biotinylated secondary goat anti-rabbit antibodies (DAKO) at a 1:200 dilution. For detection of secondary antibodies streptavidin-horseradish peroxidase conjugates (DAKO) were used and staining with amino-ethylcarbazole and hydrogen peroxide. After counterstaining with hematoxylin, the sections were embedded in glycergel (Sigma, St. Louis, MO). The immune-specific anti-TF peptide antibodies were used as primary antibodies at a concentration of $3 \mu \mathrm{g} / \mathrm{ml}$. Rabbit polyclonal anti-rat fibrin antiserum was kindly provided by Dr. J. Emeis (Gaubius Institute, Leiden, The Netherlands) and used in a 1:2000 dilution ${ }^{31}$. Granulocyte-specific FITC labelled monoclonal antibody Ly-6C (BD Biosciences Pharmingen, San Diego, CA) was used at a 1:1000 dilution.

\section{Tissue factor activity}

Tissue factor activity was determined using an in house assay. In brief, tissues were homogenized in TBS, $50 \mathrm{mM}$ n-octyl $\beta$-d-glucopyranoside (pH 8.4) and immediately frozen in liquid nitrogen and subsequently thawed at $37{ }^{\circ} \mathrm{C}$. Supernatants were collected through centrifugation at $14000 \mathrm{rpm}, 4{ }^{\circ} \mathrm{C}$ for $15 \mathrm{~min}$, and stored at -80 
${ }^{\circ} \mathrm{C}$. For tissue factor activity samples were diluted in $25 \mathrm{mM}$ HEPES, $175 \mathrm{mM} \mathrm{NaCl}$ $\left(\mathrm{pH}\right.$ 7.7) and incubated with reaction buffer at $37^{\circ} \mathrm{C}$ for $20 \mathrm{~min}$. Final concentrations were: $0.72 \mathrm{nM}$ recombinant factor VIla (Novo Nordisk, Bagsværd, Denmark), $60 \mathrm{nmol} / \mathrm{L}$ bovine factor X (Sigma-Aldrich, St. Louis, MO), $3 \mathrm{mmol} / \mathrm{L}$ $\mathrm{Ca}^{2+}$, and $7.2 \mu \mathrm{mol} / \mathrm{L} 20: 80 \mathrm{PS}: \mathrm{PC}$. Factor Xa activity was kinetically measured using the chromogenic substrate S-2765 (Chromogenix, final concentration of 0.7 $\mathrm{mg} / \mathrm{mL}$ diluted in $50 \mathrm{mM}$ Tris- $\mathrm{HCl}, 175 \mathrm{nM} \mathrm{NaCl}, 30 \mathrm{mM} \mathrm{Na} 2 \mathrm{EDTA}, \mathrm{pH} 7.4$ ) for 15 min. each $15 \mathrm{sec}$. at $405 \mathrm{~nm}$ at $37{ }^{\circ} \mathrm{C}$. Reference curves were constructed using recombinant human tissue factor with calcium (Innovin, Dade-Behring, Liederbach, Germany). Concentrations of $\mathrm{TF}$ in murine tissues are given in relative values, since human FVIIa has reduced affinity for murine $\mathrm{TF} 32$.

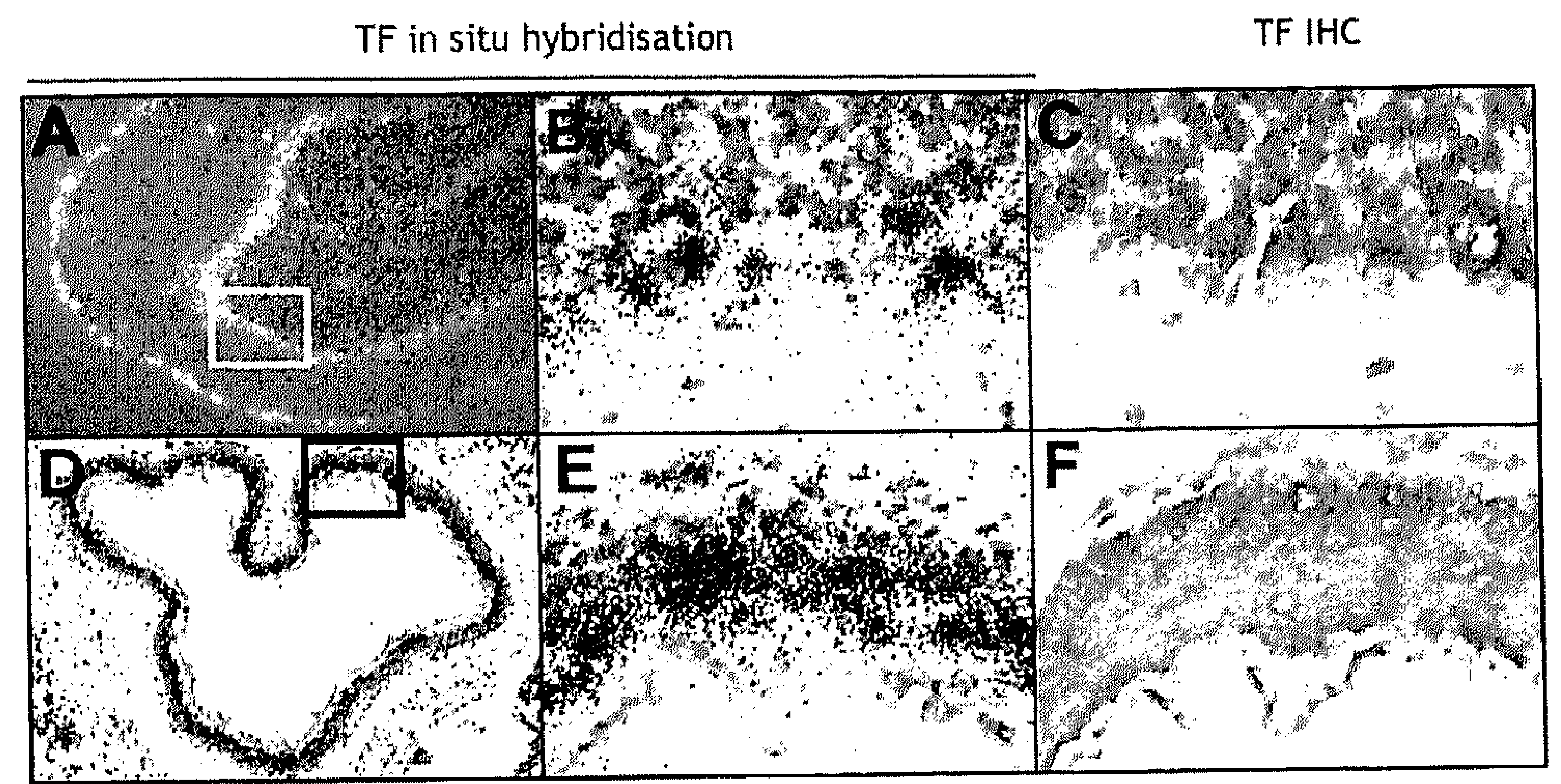

Figure 1.

Validation of the anti-murine TF peptide (P5) antiserum. TF mRNA as determined by radioactive in situ hybridization (white or black silver grains; A, B, D, E) and TF protein as shown by immunohistochemistry with anti-murine P5 antibodies (red; C, F) co-localize in normal brain $(A-C)$ and the trachea (D-F). In situ hybridization was visualized by epiluminescence (A) or bright field microscopy $(B, D, E)$. Panels $B$ and $E$ are the enlarged box areas in $A$ and $D$, respectively. Original magnification $100 \times(A, D), 630 x(B, C, E, F)$. $\mathrm{HC}$, immunohistochemical staining.

\section{Results}

Validation of anti-murine TF antisera

We established whether the rabbit antisera, generated against five different TF peptides (P1-P5), possessed immunoreactivity towards mouse TF. For that purpose, murine cryostat tissue sections were incubated with the five different antisera. Only the antiserum against peptide P5 (aa sequence 225-240: IFSRKTNQNSPGSSTV) showed positive staining, which disappeared upon pre-incubation of the antiserum 
with peptide P5 (data not shown). No staining was observed with any of the other anti-TF peptide (P1-P4) antisera. The anti-murine P5 antiserum was affinity purified and further characterized with formalin-fixed, paraffin-embedded murine tissue sections. Brain and trachea are known to contain TF and were therefore used to validate the protein pattern recognized by the rabbit anti-mouse TF antibody (antimurine P5 antiserum). In addition, the TF mRNA expression pattern was monitored on sequential sections. In Figure 1, TF mRNA and protein expression patterns are compared in brain and trachea. From this figure the co localisation of both mRNA and protein on Purkinje cells in the brain suggests recognition of TF by the rabbit anti-mouse TF antibody (Figure $1 \mathrm{~A}-\mathrm{C}$ ).

Furthermore, TF was localized throughout the cytoplasm of capillary endothelial cells in the murine brain (Figure 2). In trachea, epithelial cells are the source of TF (Figure $1 \mathrm{D}-\mathrm{F}$ ). TF was also synthesized in bronchial epithelial cells in the lung (data not shown). In most tissues, TF mRNA and protein were present in the organ capsule and in the adventitia, surrounding blood vessels (data not shown).

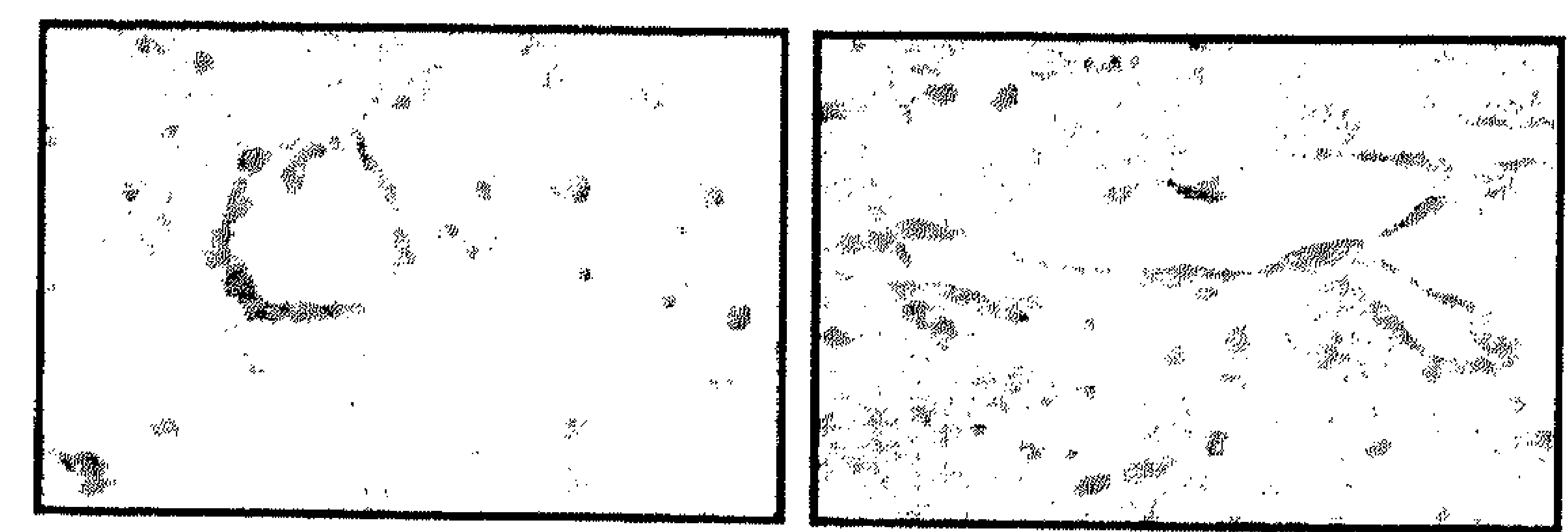

Figure 2

Presence of TF protein in capillary endothelial cels of the brain as shown by immunohistochemistry with anti-murine P5 antibodies (red). Original magnification 400x.

TF MRNA and protein in tissues of LPS-treated mice

It has been previously shown that TF mRNA is induced by LPS in the mouse 17 . We compared TF mRNA and protein localisation in the kidney, spleen, lung, liver, and heart of the mouse, before and after LPS treatment. Kidney and spleen displayed the most intense increment in TF mRNA upon LPS administration. Apart from these tissues, lungs also revealed an increased number of TF mRNA containing cells, presumably epithelial cells and alveolar macrophages. The remaining tissues failed to show prominent changes in TF mRNA expression. Quantitative mRNA analysis showed a trend towards increased TF mRNA expression in kidney and lung six hours after LPS administration (data not shown), an observation which was confirmed by quantitative analysis of TF activity. Kidneys from non-treated animals $(12.5 \pm 2.86 \mathrm{pM})$ were significantly lower in TF activity compared to LPS treated mice $(17.4 \pm 5.08 \mathrm{pM}, \mathrm{p}<0.05)$ after 6 hours of LPS-induced endotoxemia. The same was observed for TF activity in the lungs, where LPS-treated mice showed a trend 
towards higher TF activity when compared to non-treated mice (data nor shown), whereas TF activity remained unchanged in the heart and liver upon LPS treatment.

TF in situ hybridisation

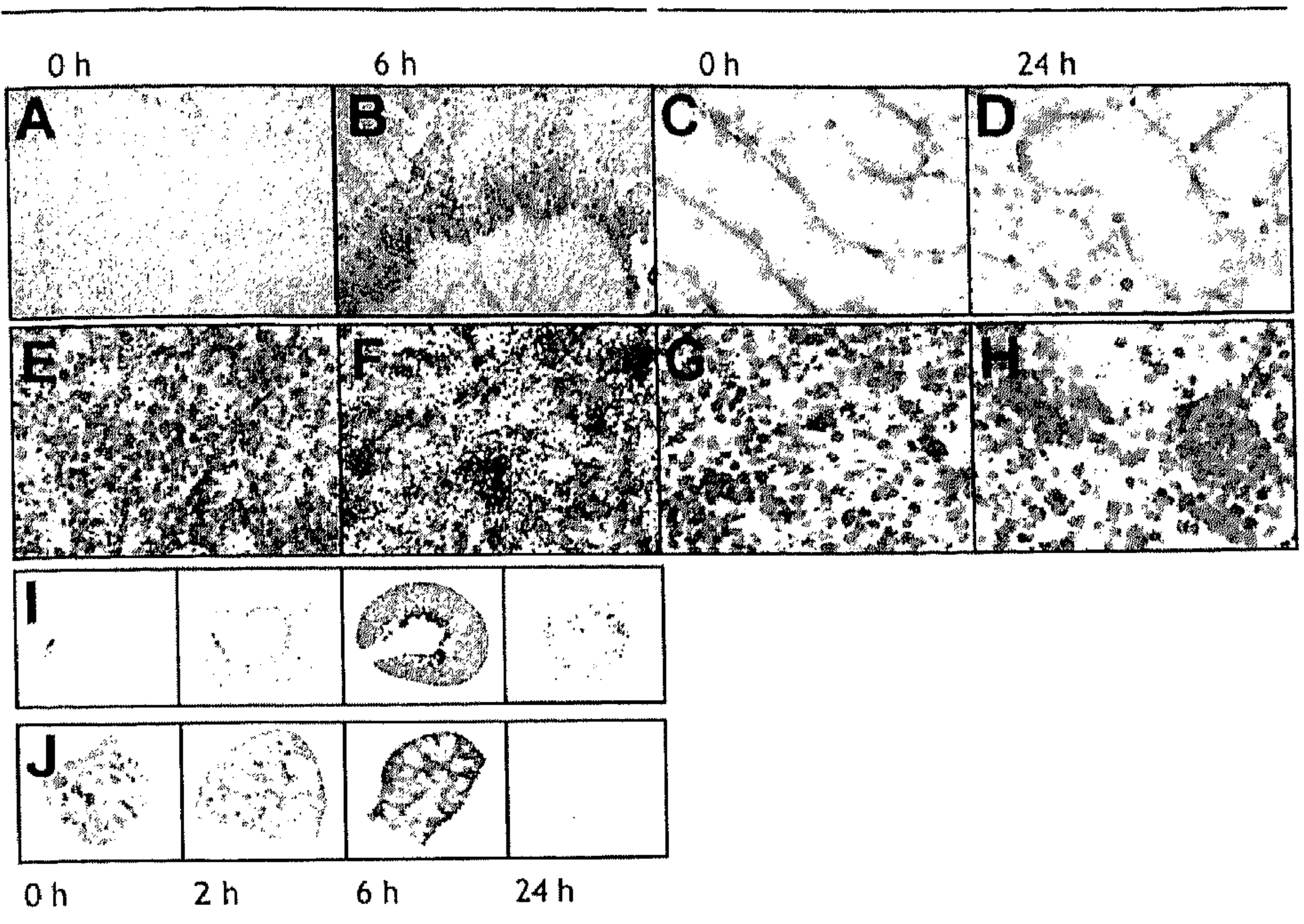

Figure 3

TF mRNA and TF protein in kidney and spleen after LPS injection. TF mRNA as determined by radioactive in situ hybridization (black silver grains; A, B,E,F and on autoradiographic film; $1, J$ ) and TF protein as shown by immunohistochemistry with anti-murine P5 antibodies (C,D,G,H) coand TF protein as shown by immunohistochemistry with antimulation. TF protein is only increased in the interfollicular region of the spleen with a maximum at $24 \mathrm{~h}$ after LPS. Original magnification $100 \times(A, B), 400 \times(C-H)$. $1 \mathrm{HC}$, immunohistochemical staining.

By in situ hybridisation, TF mRNA was present in epithelial cells of the cortex and tubular area at the cortico-medullar junction in the untreated kidney. Occasional TF mRNA-containing cells were seen in the medulla. Induction of TF mRNA synthesis was already visible at $2 \mathrm{~h}$ after LPS administration. TF MRNA was increased throughout the cortex, except for the glomeruli, which revealed TF mRNA synthesis neither in the presence nor in the absence of LPS. Remarkably, the absence of TF mRNA expression in murine glomeruli is in contrast with other species ${ }^{16}$. An increased number of TF mRNA-containing cells were observed in the medulla only after $24 \mathrm{~h}$ after LPS administration (data not shown). Yet, the most striking change in TF mRNA levels was observed in the tubular area at the corticomedullar junction of the kidney which was maximal at $6 \mathrm{~h}$ after LPS injection (Figure 3 A, B, I). Subsequently, TF protein staining was performed on sequential 
sections, using the anti-murine TF peptide (P5) antibodies. Clearly, in the kidney TF mRNA co-localized with TF protein. However, no difference was observed in the tubular expression of TF protein after 24 hours of LPS-induced endotoxemia compared to untreated mice (Figure $3 \mathrm{C}, \mathrm{D}$ ). In the spleen of untreated mice $\mathrm{TF}$ mRNA was detected in the follicles, presumably in the small blood vessels. At $6 \mathrm{~h}$ after LPS administration the most extensive TF mRNA staining was seen in the interfollicular region, also known as 'red pulp', in blood vessels, and clusters of cells (Figure $3 \mathrm{E}, \mathrm{F}, \mathrm{J}$ ). TF protein started to appear in a few cells at $2 \mathrm{~h}$ after LPS and the number of TF-positive cells steadily increased in time with a maximum at $24 \mathrm{~h}$ after LPS injection. Large clusters of cells show TF on their surface (Figure $3 \mathrm{G}, \mathrm{H}$ ). At this point in time, TF mRNA levels had almost returned to control levels (Figure 3 J).

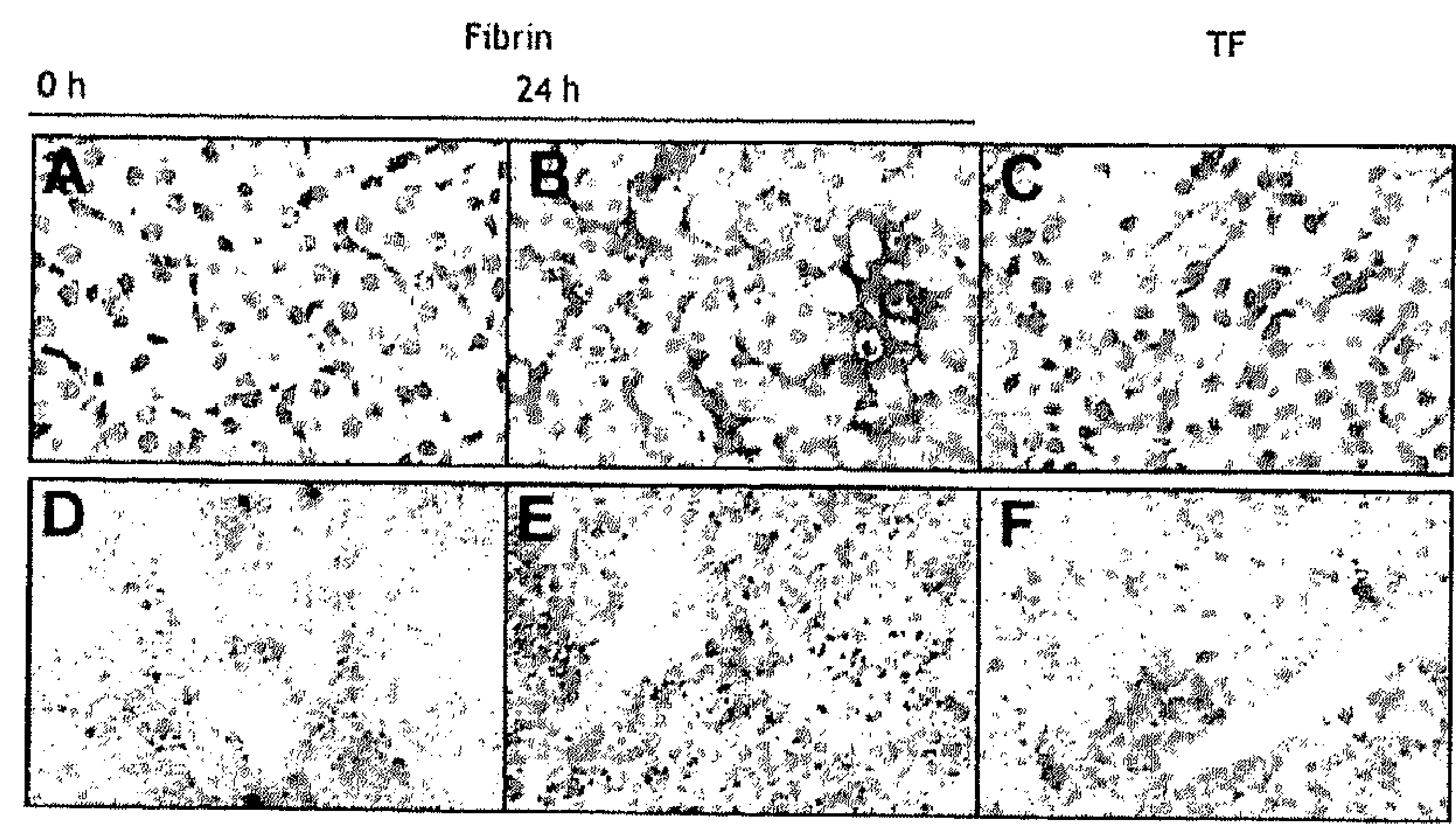

Figure 4

Fibrin deposition in kidney and spleen. Fibrin (A, B, D, E) and TF protein (C, F) is shown by immunohistochemistry (red) in the medulla of the kidney (A-C) and in the red pulp of the spleen (D-F). No fibrin was detected in kidney and spleen of untreated mice (A, D), whereas at $24 \mathrm{~h}$ after LPS injection intense tibrin deposits were observed $(B, E)$. TF protein co-localizes with the area of fibrin deposits in both tissues at $24 \mathrm{~h}$ after LPS-induced endotoxemia. Original magnification $400 \mathrm{x}$ (A-F).

\section{Fibrin in tissues of LPS-treated mice}

To assess whether the increase in TF protein at different locations translates into procoagulant activity in situ we searched for the presence of fibrin deposits. It should be noted that fibrin deposits were not detected in tissues of non-LPS treated control mice (Figure 4A, D). In contrast, upon LPS injection fibrin accumulated most extensively in kidney and spleen. Few fibrin deposits were observed in the liver $24 \mathrm{~h}$ after LPS, whereas the lungs and hearts hardly showed any fibrin.

The kidney displayed the largest number of fibrin deposits in the vascular bed of the medulla, also known as vasa recta (Figure 4B). Occasional glomeruli and 
capillaries in the cortex stained positive for fibrin (data not shown). In the spleen, fibrin was located in the red pulp (Figure 4E).

It should be noted that $\mathrm{TF}$ protein was also present in the kidney and spleen at close vicinity of sites with fibrin deposition (Figure $4 \mathrm{C}, \mathrm{F}$ ), suggesting that the presence of $\mathrm{TF}$ protein conceivably represents procoagulant activity. This is supported by the TF activity measurements, since it is associated with fibrin deposits in the most affected organs in this sepsis model.

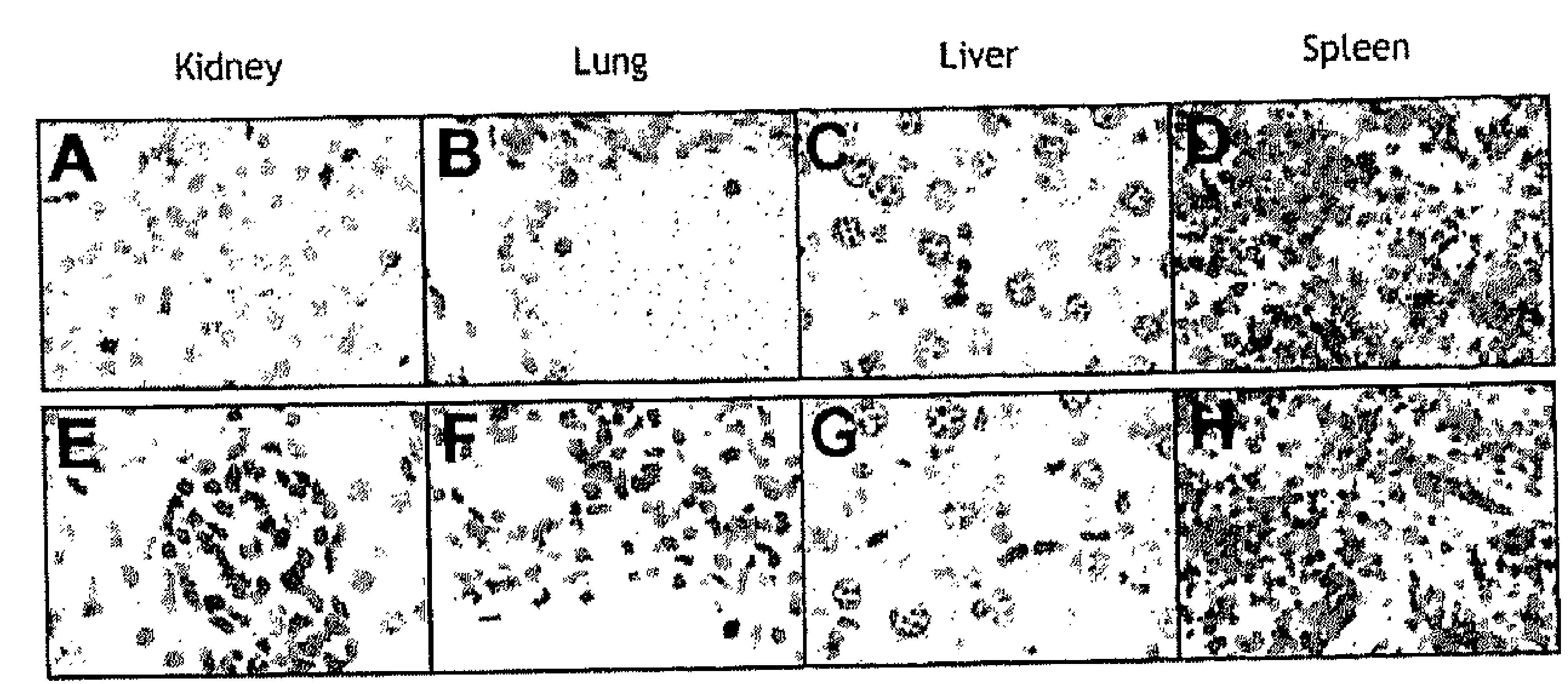

Figure 5

TF protein in granulocytes. TF protein (A-D) and granulocyte-specific (E-H) immunohistochemical staining (red) is shown in the kidney $(A, E)$, lung $(B, F)$, liver $(C, G)$ and spleen $(D, H)$ at $24 \mathrm{~h}$ after LPS injection. Original magnification 630x.

\section{Granulocytes stain positive for $T F$}

Even though only kidney and spleen showed extensive TF mRNA synthesis upon LPS stimulation, TF immunostaining was detectable in all tissues examined. Granulocytes, initially identified by their characteristic nuclear morphology, stained positive for TF protein at the extracellular surface after LPS administration and are observed in kidney, lung, and liver (Figure $5 \mathrm{~A}-\mathrm{C}$ ). Since it is difficult to discriminate between the different cell types in lung tissue, TF-positive granulocytes are best illustrated in the lumen of the larger vessels in the lung. Importantly, however, TF mRNA was never observed in granulocytes in any of these tissues. When a granulocyte-specific immunostaining was performed (Figure $5 \mathrm{E}-\mathrm{H}$ ) it became obvious that the clusters of TF-positive cells in the red pulp of the spleen consisted of granulocytes (Figure 5D). In the spleen of untreated mice, we observed granulocytes only occasionally. Yet, after LPS injection the number of granulocytes in the spleen gradually increased. As previously shown (Figure $2 \mathrm{~F}$ ), this correlates with the extensive presence of TF mRNA in the same region. Granulocytes expressing TF protein on their surface where already observed in the spleen after 2 $\mathrm{h}$ in contrast to kidney, lung and liver where the first TF-positive granulocytes were detected at $6 \mathrm{~h}$ after LPS (data not shown). For these reasons we suspected that the spleen might be involved in the transfer of TF to granulocytes. 
To directly address the possible role of the spleen in TF transport or production, we compared mice that had undergone a splenectomy $(n=12)$ with sham control mice $(n=12)$. Both groups were challenged with LPS as described above and tissues were collected at 2,6 , or 24 hours ( $n=4$ per group). In contrast to our expectation, splenectomy did not influence the staining of granulocytes (data not shown), which was comparable to the results outlined above.

\section{Discussion}

In this study we have investigated the heterogeneity in tissue factor synthesis and protein expression in a murine LPS-induced sepsis model. For this purpose a rabbit anti-murine TF antibody obtained upon immunization with a synthetic peptide derived from the extracellular part (amino acids 225-240) of murine TF was generated and validated. The presence of TF protein was assessed by a combination of immunohistochemical analysis with the novel antibody, while its activity was quantified with an activity assay. The results confirm a marked difference in the pattern and activity of expression of TF, as previously noted by Luther et al. ${ }^{33}$ and Mackman et al 17. The novel findings of the present study are that we have applied the novel antibody to study in parallel TF immunohistochemistry and expression patterns of mRNA as well as TF activity in a mouse model of endotoxemia. This approach re-emphasized the role of the granulocyte as $\mathrm{TF}$ carrying cell and indicated that local capillary expression of TF in the brain occurs. Besides it's role in activation of blood coagulation, endothelial TF may also be involved in activation of cellular processes such as apoptosis and inflammation. Furthermore, it has been suggested that in human's brain endothelial cell derived TF may play an important role in the pathogenesis of leucoencephalopathics such as vascular dementia of Binswanger type ${ }^{34}$.

After injection of LPS in mice TF mRNA expression is strongly up-regulated in the tubular area at the cortico-medullar junction in the kidney and clusters of cells in the red pulp of the spleen. TF protein localisation patterns analyzed by using our rabbit anti-murine TF antibody correlated with TF mRNA presence in these tissues. The LPS-mediated increase in TF mRNA in the spleen parallels the amount of TF protein synthesized at this location. In contrast, however, the evident LPS-mediated increase in TF mRNA synthesis in the kidney is not reflected by a similar enhancement of TF protein in this organ: at face value, the amount of TF protein in LPS-treated and control kidneys is virtually identical. On the other hand, the functional activity of TF in kidneys was significantly increased after LPS stimulation, raising the possibility that the functional assay more accurately reflects subtle changes in TF concentration than immunohistochemical analysis. Alternatively, alterations in conformation of TF may explain in part the increased activity of this glycoprotein. Changes in urinary excretion of $\mathrm{TF}$ as explanation for 
the unaltered pattern of $\mathrm{TF}$ immunostaining as suggested before ${ }^{35,36}$, can not be excluded. Since resorption of urine, possibly containing TF, largely takes place in the medulla it would explain the accumulation of fibrin deposits that are predominantly detected in the vasa recta in the medulla after LPS administration.

The immunohistochemical presence of $\mathrm{TF}$ in brain endothelial

Fibrin deposits and TF-positive granulocyte clusters in the spleen are associated with the interfollicular regions, suggesting that the TF-positive granulocytes show procoagulant activity in this area. Apart from the kidney and spleen the liver showed most fibrin deposits in this LPS-induced sepsis model. Along the same line, the infiltrating granulocytes in the livers of LPS-treated mice were TF-positive, while the abundantly present macrophages did not contain any TF on their surface. These liver-resident macrophages, however, contained large amounts of plasminogen activator inhibitor 1 (PAI-1) protein, the physiological inhibitor of the fibrinolytic system, after LPS injection (data not shown). Together, the presence of TF-positive granulocytes and PAI-1-positive macrophages could have lead to sustained fibrin deposition. The contribution of TF-positive granulocytes would also explain the local deposition of fibrin in patients with acute respiratory distress syndrome ${ }^{37}$ or in patients with progranulocytic leukemia ${ }^{38}$, in which granulocytes are the prevailing type of leukocytes.

The debate on TF synthesis versus exposure on the surface of granulocytes is mostly based on the fact that researchers have not been able to induce TF mRNA or protein in in vitro experiments with this cell type, while monocytes have been shown to be inducible 39,40 . As already described in baboon 16 and rabbit 19 sepsis studies, we found increased TF mRNA expression in the interfollicular regions of the spleen as well, upon LPS-treatment of the mouse. We observed that the induction pattern of TF mRNA coincided with clusters of TF-positive granulocytes. TF mRNA and protein were detected in the spleen as early as $2 \mathrm{~h}$ after LPS injection, whereas in kidney, lung, and liver the first TF protein-positive granulocytes were observed after $6 \mathrm{~h}$ and more prominently at $24 \mathrm{~h}$ after LPS administration. In addition, the presence of TF-protein positive and TF mRNA negative granulocytes in LPSactivated kidney, lung, and liver suggests that accumulate TF for instance by fusing with TF loaded microparticles. Furthermore, it has been suggested that human granulocyte derived TF protein is the major source of circulating procoagulant TF ${ }^{14}$. Splenectomy did not influence the staining of granulocytes for TF protein, eg the spleen does not appear to play an important role in this regard. The lack of TF mRNA in granulocytes still supports, however, the concept of Osterud 15 that the granulocyte acquire rather than produce $\mathrm{TF}$, but both site and mechanism remain obscure. The association of TF with these inflammatory cells suggests a role for $\mathrm{TF}$ in inducing a thrombogenic state during endotoxemia and maybe in inducing proinflammatory genes after interacting with factor VIIa ${ }^{41}$. The availability of specific 
antibodies for murine TF enables the further characterization of the role of cellular $T F$ in inflammatory diseases in different mouse models.

\section{Acknowledgements}

Janneke J. Timmerman was supported by a grant from the Netherlands Organization for Scientific Research. Hugo ten Cate is a Clinical Established Investigator of the Netherlands Heart Foundation. Hjalmar Hansen is supported by a grant from the Netherlands Heart Foundation (nr. 2000B062). The plasmids pcMTF2281 and pcMTF2279 were generated in the Mackman laboratory (Scripps Research Institute, La Jolla, CA, USA) and we gratefully acknowledge the application of these constructs in our study. 


\section{References}

1. Nemerson $\mathrm{Y}$. The reaction between bovine brain tissue factor and factors VII and $\mathrm{X}$. Biochemistry. 1966;5:601-608.

2. Drake TA, Morrissey JH, Edgington TS. Selective cellular expression of tissue factor in human tissues. Implications for disorders of hemostasis and thrombosis. Am J Pathol. 1989;134:1087-1097.

3. Maynard JR, Dreyer BE, Stemerman MB, Pitlick FA. Tissue-factor coagulant activity of cultured human endothelial and smooth muscle cells and fibroblasts. Blood. 1977;50:387396.

4. Taubman MB, Marmur JD, Rosenfield CL, Guha A, Nichtberger S, Nemerson Y. Agonistmediated tissue factor expression in cultured vascular smooth muscle cells. Role of Ca2+ mobilization and protein kinase $C$ activation. J Clin Invest. 1993;91:547-552.

5. Lyberg T, Galdal KS, Evensen SA, Prydz H. Cellular cooperation in endothelial cell thromboplastin synthesis. $\mathrm{Br} J$ Haematol. 1983;53:85-95.

6. Bevilacqua MP, Pober J5, Majeau GR, Cotran RS, Gimbrone MA, Jr. Interleukin 1 (IL-1) induces biosynthesis and cell surface expression of procoagulant activity in human vascular endothelial cells. J Exp Med. 1984;160:618-623.

7. Stern D, Nawroth $P$, Handley D, Kisiel W. An endothelial cell-dependent pathway of coagulation. Proc Natl Acad Sci U S A. 1985;82:2523-2527.

8. Rambaldi A, Alessio $G$, Casali $B$, et al, Induction of monocyte-macrophage procoagulant activity by transformed cell lines. J Immunol. 1986;136:3848-3855.

9. Almdahl SM, Osterud B. Experimental gram-negative septicemia: thromboplastin generation in mononuclear phagocytes from different anatomical sites. Thromb Res. 1987;47:37-46.

10. Lerner RG, Goldstein R, Cummings $G$. Endotoxin induced disseminated intravascular clotting: evidence that it is mediated by neutrophil production of tissue factor. Thromb Res. 1977;11:253-261.

11. Higure A, Okamoto K, Hirata K, et al. Macrophages and neutrophils infiltrating into the liver are responsible for tissue factor expression in a rabbit model of acute obstructive cholangitis. Thromb Haemost. 1996;75:791-795.

12. Todoroki H, Nakamura S, Higure A, et al. Neutrophils express tissue factor in a monkey model of sepsis. Surgery. 2000;127:209-216.

13. Todoroki $\mathrm{H}$, Higure $\mathrm{A}$, Okamoto $\mathrm{K}$, et al. Possible role of platelet-activating factor in the in vivo expression of tissue factor in neutrophils. J Surg Res. 1998;80:149-155.

14. Giesen PL, Rauch U, Bohrmann B, et al. Blood-borne tissue factor: another view of thrombosis. Proc Natl Acad Sci U S A. 1999;96:2311-2315.

15. Osterud B. Tissue factor in neutrophils: no. J Thromb Haemost. 2004;2:218-220.

16. Drake TA, Cheng J, Chang A, Taylor FB, Jr. Expression of tissue factor, thrombomodulin, and E-selectin in baboons with lethal Escherichia coli sepsis. Am J Pathol, 1993;142:1458-1470.

17. Mackman N, Sawdey MS, Keeton MR, Loskutoff DJ. Murine tissue factor gene expression in vivo. Tissue and cell specificity and regulation by lipopolysaccharide. Am J Pathol. $1993 ; 143: 76-84$.

18. Yamamoto $\mathrm{K}$, Loskutoff DJ. Fibrin deposition in tissues from endotoxin-treated mice correlates with decreases in the expression of urokinase-type but not tissue-type plasminogen activator. J Clin Invest. 1996;97:2440-2451. 
19. Ertich J, Fearns C, Mathison J, Ulevitch RJ, Mackman N. Lipopolysaccharide induction of tissue factor expression in rabbits. Infect Immun. 1999;67:2540-2546.

20. Taylor FB, Jr., Chang A, Ruf W, et al. Lethal E. coli septic shock is prevented by blocking tissue factor with monoclonal antibody. Circ Shock. 1991;33:127-134.

21. Levi $M$, ten Cate $H$, Bauer KA, et al. Inhibition of endotoxin-induced activation of coagulation and fibrinolysis by pentoxifylline or by a monoclonal anti-tissue factor antibody in chimpanzees. J Clin Invest. 1994;93:114-120.

22. Creasey AA, Chang AC, Feigen L, Wun TC, Taylor FB, Jr., Hinshaw LB. Tissue factor pathway inhibitor reduces mortality from Escherichia coli septic shock. J Clin Invest. 1993;91:28502860.

23. Biemond $\mathrm{BJ}$, Levi $\mathrm{M}$, ten $\mathrm{Cate} \mathrm{H}$, et al. Complete inhibition of endotoxin-induced coagulation activation in chimpanzees with a monoclonal Fab fragment against factor VII/VIla. Thromb Haemost. 1995;73:223-230.

24. Creasey AA, Reinhart K. Tissue factor pathway inhibitor activity in severe sepsis. Crit Care Med. 2001;29:5126-129.

25. Esmon CT. Role of coagulation inhibitors in inflammation. Thromb Haemost. 2001;86:51-56.

26. de Jonge $E$, van der Poll $T$, Kesecioglu J, Levi M. Anticoagulant factor concentrates in disseminated intravascular coagulation: rationale for use and clinical experience. Semin Thromb Hemost. 2001;27:667-674.

27. Carson SD. Manifestation of cryptic fibroblast tissue factor occurs at detergent concentrations which dissolve the plasma membrane. Blood Coagul Fibrinolysis. 1996;7:303. 313.

28. Bach RR, Moldow CF. Mechanism of tissue factor activation on HL-60 cells. Blood. 1997;89:3270-3276.

29. Hartzell S, Ryder K, Lanahan A, Lau LF, Nathan D. A growth factor-responsive gene of murine BALB/C 3 T 3 cells encodes a protein homologous to human tissue factor. Mol Cell Biol. 1989;9:2567-2573.

30. de Koster HS, Amons R, Benckhuijsen WE, Feijlbrief $M$, Schellekens GA, Drijfhout JW. The use of dedicated peptide libraries permits the discovery of high affinity binding peptides. $J$ Immunol Methods. 1995;187:179-188.

31. Emeis JJ, Lindeman J, Nieuwenhuizen W. Immunoenzyme histochemical localization of fibrin degradation products in tissues. Am J Pathol. 1981;103:337-344.

32. Petersen LC, Norby PL, Branner S, et al. Characterization of recombinant murine factor Vlla and recombinant murine tissue factor: a human-murine species compatibility study. Thromb Res. 2005;116:75-85.

33. Luther $\mathrm{T}$, Flossel $\mathrm{C}$, Mackman $\mathrm{N}$, et al. Tissue factor expression during human and mouse development. Am J Pathol. 1996;149:101-113.

34. Tohgi $\mathrm{H}$, Utsugisawa $\mathrm{K}$, Yoshimura $M$, Nagane $\mathrm{Y}$, Ukitsu $M$. Local variation in expression of pro- and antithrombotic factors in vascular endothelium of human autopsy brain. Acta Neuropathol (Berl). 1999;98:111-118.

35. Fareed J, Callas DD, Hoppensteadt D, Bermes EW, Jr. Tissue factor antigen levels in various biological fluids. Blood Coagul Fibrinolysis. 1995;6 Suppl 1:S32-36.

36. Lwaleed BA, Bass PS, Francis JL. Urinary tissue factor: a potential marker of disease. J Pathol. 1999;188:3-8. 
37. Hammerschmidt DE, Weaver LJ, Hudson LD, Craddock PR, Jacob HS. Association of complement activation and elevated plasma-C5a with adult respiratory distress syndrome. Pathophysiological relevance and possible prognostic value. Lancet. 1980;1:947-949.

38. Bell WR. The fibrinolytic system in neoplasia. Semin Thromb Hemost. 1996;22:459-478.

39. Hair GA, Padula 5 , Zeff $R$, et al. Tissue factor expression in human leukemic cells. Leuk Res. 1996;20:1-11.

40. Osterud B, Rao LV, Olsen JO. Induction of tissue factor expression in whole blood: lack of evidence for the presence of tissue factor expression in granulocytes. Thromb Haemost. 2000;83:861-867.

41. Riewald $M$, Ruf $W$. Orchestration of coagulation protease signaling by tissue factor. Trends Cardiovasc Med. 2002;12:149-154. 
Chapter 9 Prolonged systemic inhibition of thrombin does not diminish nephropathy in
diabetic mice

Hjalmar R. Hansen • Carine J Peutz-Kootstra ^ Pieter H. Reitsma Henri M.H. Spronk Hugo ten Cate 


\section{Abstract}

Background. Diabetic nephropathy is a common complication of type-2 diabetes and the leading cause of end-stage renal disease. Besides an increase in mesangial matrix, which can progress to diffuse or nodular glomerulonecrosis, diabetic nephropathy is also characterized by deposition of fibrin or fibrinogen in glomeruli, suggesting a role for coagulation in the pathogenesis of diabetic renal disease. Therefore, pharmacological inhibition of coagulation might attenuate diabetic nephropathy in vivo.

Methods. Using the specific thrombin inhibitor ximelagatran, coagulation was inhibited in a streptozotocin induced mouse model of diabetes $(n=12)$ and compared with normal fed diabetic mice $(n=14)$ and normal fed control mice $(n=6)$.

Results. Prothrombin times (PT) of plasma were elevated upon ximelagatran treatment $(140.9(63.0-218.7)$ vs. $8.8(8.0-9.6) \mathrm{sec}$ for control animals; $\mathrm{p}<0.01)$, indicating intense systemic anticoagulation. Ten weeks of hyperglycemia led to glomerular hypertrophy, increased mesangial matrix, and fibrin deposition in glomeruli and small vessels of the kidney. Ximelagatran treatment had no influence on hyperglycemia-induced nephropathy including the degree of fibrin deposition. Plasma PAl-1 activity and tissue factor activity in aortas and kidneys were comparable between hyperglycaemic mice either treated or not treated with ximelagatran.

Conclusions. anticoagulation through the specific thrombin inhibitor ximelagatran did not attenuate nephropathy including fibrin deposition in kidneys of hyperglycaemic mice. 


\section{Introduction}

Diabetic nephropathy, defined as the appearance of proteinuria, elevated arterial blood pressure, and diminished glomerular filtration rate, is a common complication of diabetes mellitus and is regarded as the leading cause of end-stage renal disease worldwide'.

The prevalence of diabetic renal disease in the US and European general population surveys ranges from 6 to $10 \%{ }^{2}$. Approximately 30-40\% of all diabetics develop clinical evidence of nephropathy, but a considerably smaller fraction of patients proceeds to endstage renal disease in the absence of specific interventions ${ }^{3}$. Because of the greater prevalence of type-2 diabetes, however, these patients constitute slightly over half the diabetic patients starting hemodialysis each year. Although intensive treatment of diabetes and related problems including hypertension have markedly reduced the onset of microalbuminuria and its progression to overt nephropathy in subjects with diabetes ${ }^{5.6}$, it remains a serious long-term complication. In addition, microalbuminuria (as well as overt nephropathy) is a strong risk indicator of cardiovascular disease in diabetic patients ${ }^{4 \cdot 7}$.

The pathophysiological changes of diabetic nephropathy are histologically different from those of other types of renal disease ${ }^{8}$. The earliest pathological lesions include an increase in thickness of the glomerular capillary basement membrane. Subsequently, the amount of matrix in the mesangium increases, and in some patients this mesangial expansion can progress to more severe diffuse or nodular glomerulonecrosis. One of the other pathophysiological features of diabetic nephropathy is the deposition of fibrin/fibrinogen in glomeruli $i^{10.11}$, suggesting a role for coagulation in the pathogenesis of diabetic renal disease, but its clinical relevance has not been established. Experimental studies indicate several potentially relevant actions of the blood coagulation serine proteases factor $X a$, thrombin as well as the endproduct fibrin in chronic renal disease. Particularly thrombin may, by interacting with the protease activated receptor-1 (PAR-1), induce proinflammatory signalling pathways that induce fibrosis ${ }^{12,13}$. PAR-1 is strongly expressed on endothelial, mesangial and epithelial cells and the cellular effects induced by thrombin appear to be as important as the procoagulant effects of thrombin in an experimental model of anti- GBM glomerulonephritis ${ }^{14}$.

Since thrombin is a crucial enzyme directing pro and anticoagulant properties within the coagulation cascade, but also driving cellular signalling pathways, we hypothesized that pharmacological inhibition of thrombin might attenuate diabetic nephropathy in vivo.

We tested this hypothesis by administering the specific thrombin inhibitor ximelagatran to mice made diabetic by intraperitoneal streptozotocin injection.

\section{Subjects and methods}

Animals and treatment

All studies were performed using female mice of the C57BI/6 strain from Charles River Laboratories Inc. (Iffa-Credo, l'Arbresle, France), which were 12 weeks old at the start of the experiments. The animals were housed in normal cages in an environment with a 12 
hour light-dark cycle, controlled temperature $\left(20 \pm 2^{\circ} \mathrm{C}\right)$ and humidity $(50 \pm 10 \%)$. Animats had free access to water and standard chow diet. Mice were divided into three groups: control mice on normal diet, 14 hyperglycemic mice on normal diet and 12 hyperglycems mice fed special food pellets containing $500 \mu \mathrm{mol} / \mathrm{kg}$ ximelagatran during the 10 weeks of the experiment. Hyperglycemia was induced by a single intraperitoneal injection streptozotocin (STZ) (100 $\mathrm{mg} / \mathrm{kg}$ bodyweight) in $5 \mathrm{mM}$ citrate buffer ( $\mathrm{pH} \mathrm{4}$ ) in the normal cavage and the ximelagatran fed mice 10 weeks prior to tissue collection. Blood glucose levels were measured using a Glucometer Elite (Bayer Diagnostics, Mijdrecht, The Netherlands) in a drop of venous blood from the tail.

Mice were killed by exsanguination at 10 weeks after streptozotocin induced hyperglycemia while they were under isoflurane anesthesia, and tissues were frozen at 20 ${ }^{\circ} \mathrm{C}$ upon collection using standard dissection techniques. For (immuno)histochemical analysis tissues were first placed in $4 \%(\mathrm{v} / \mathrm{v})$ phosphate buffered formaldehyde within 30 minutes of death and fixed for 24 hours at room temperature. The Experimental Animas? Ethics Committee of the University Amsterdam approved all experimental protocols.

\section{Plasma analysis on PAl-1 \& Tissue factor assay tissue homogenates}

Plasminogen activator inhibitor type-1 (PAl-1) activity in plasma was assessed using the commercially available murine PAl-1 activity assay according to the manufacture instructions (Innovative Research, Southfield, MI). Tissue factor activity was determined using an in house assay. In brief, kidneys respectively aorta's were homogenized in TBS, 5 $\mathrm{mM}$ n-octyl B-d-glucopyranoside, $\mathrm{pH} 8.4$ and immediately frozen in liquid nitrogen subsequently thawed at $37{ }^{\circ} \mathrm{C}$. Supernatants were collected through centrifugation $14000 \mathrm{rpm}, 4{ }^{\circ} \mathrm{C}$ for $15 \mathrm{~min}$, and stored at $-80^{\circ} \mathrm{C}$. For tissue factor activity, samples were diluted in $25 \mathrm{mM}$ HEPES, $175 \mathrm{mM} \mathrm{NaCl}$, pH 7.7 and incubated with reaction buffer at $37 \mathrm{C}$ for $20 \mathrm{~min}$. Final concentrations were: $0.72 \mathrm{nM}$ recombinant factor VIla (Novo Nordis Bagsværd, Denmark), $60 \mathrm{nmol} / \mathrm{L}$ bovine factor $X$ (Sigma-Aldrich, St. Louis, MO), $3 \mathrm{mmol} / \mathrm{h}$ $\mathrm{Ca}^{2+}, 7.2 \mu \mathrm{mol} / \mathrm{L}$ 20:80 PS:PC. Factor $\mathrm{Xa}$ activity was kinetically measured using the chromogenic substrate S-2765 (Chromogenix, final concentration of $0.7 \mathrm{mg} / \mathrm{mL}$ diluted $50 \mathrm{mM}$ Tris- $\mathrm{HCl}, 175 \mathrm{nM} \mathrm{NaCl}, 30 \mathrm{mM}$ Na2EDTA, $\mathrm{pH}$ 7.4) for $15 \mathrm{~min}$. each $15 \mathrm{sec}$. at $405 \mathrm{~mm}$ at $37^{\circ} \mathrm{C}$.

Tissue homogenate induced thrombin generation:

The Calibrated Automated Thombogram was obtained from Thrombinoscope $B$ Maastricht, The Netherlands and tissue homogenates were analyzed in a 96-well plat fluorometer (Ascent Reader, Thermolabsystems OY, Helsinki, Finland) equipped with $390 / 460$ filter set and a dispenser. Platelet poor plasma (PPP)-reagent consisted of 5 ph recombinant relipidated tissue factor (rTF) and 4 . phosphatidylserine/phosphatidylcholine/phosphatidylethanolamine vesicles in $\mathrm{HEPE}$ buffered saline. FluCa-solution consisted of Hepes, $\mathrm{pH} 7.35,100 \mathrm{nM} \mathrm{CaCl}, 60 \mathrm{mg} / \mathrm{mL} \mathrm{BSA}$ and $2.5 \mathrm{mM}$ Z-Gly-Gly-Arg-AMC. Tissue homogenate analyses were done in triplicate each single measurement comprised a thrombin generation (TG) and calibrator $\left(\mathrm{CH}^{3}\right.$ 
analysis. In brief, $15 \mu \mathrm{L}$ tissue homogenate $(5 \mathrm{mg}$ total protein per $\mathrm{mL}$ ) and $80 \mu \mathrm{L}$ of plasma were added to each well and TG wells received $20 \mu \mathrm{L}$ of PPP-reagent. The CL wells received $20 \mu \mathrm{L}$ calibrator containing $a_{2}$ macroglobulin-thrombin complexes. Plates were placed in the fluorometer and incubated at $37^{\circ} \mathrm{C}$ for 5 minutes. The dispenser of the fluorometer was flushed with warm $100 \mathrm{mM} \mathrm{CaCl}_{2}$ solution $\left(37^{\circ} \mathrm{C}\right)$ and subsequently flushed with FluCa. Analyses of thrombin generation were started by addition of $20 \mu \mathrm{L}$ FluCa to each well and recorded by means of the Thrombinoscope software.

\section{Immunohistochemistry}

Paraffin sections $(4 \mu \mathrm{m})$ were deparaffinized, rehydrated and incubated with $0.3 \%(\mathrm{v} / \mathrm{v})$ hydrogen peroxide and blocked with $10 \%(\mathrm{v} / \mathrm{v})$ pre-immune goat serum (DAKO, Glostrup, Denmark) in $10 \mathrm{mM}$ Tris- $\mathrm{HCl}(\mathrm{pH} \mathrm{8.0)}, 150 \mathrm{mM} \mathrm{NaCl}$ (TBS). Subsequently, the sections were incubated overnight at $4^{\circ} \mathrm{C}$ with polyclonal anti-rat fibrin antibodies in TBS, followed by incubation with biotinylated secondary goat anti-rabbit antibodies (DAKO) at a 1:200 dilution. For detection of secondary antibodies streptavidin-horseradish peroxidase conjugates (DAKO) were used and staining with amino-ethylcarbazole and hydrogen peroxide. After counterstaining with hematoxylin, the sections were embedded in glycergel (Sigma, St. Louis, MO). Rabbit polyclonal anti-rat fibrin antiserum was kindly provided by Dr. J. Emeis (Gaubius Institute, Leiden, The Netherlands) and used in a 1:2000 dilution.

McMannus' periodic acid schiff's (PAS) staining was performed according to the protocol provided by the department of Pathology, Academic Hospital Maastricht, Maastricht, The Netherlands. In brief, paraffin sections $(2 \mu \mathrm{m})$ were deparaffinized, rehydrated and incubated with $0.5 \%(\mathrm{v} / \mathrm{v})$ periodic acid for $5 \mathrm{~min}$. After washing with distilled water, tissues were incubated with Schiff reagent for $15 \mathrm{~min}$, washed in lukewarm tap water for 5 min, and counterstain in Mayer's hematoxylin solution for 1 minute.

\section{Statistics}

Data are expressed as means with $95 \% \mathrm{Cl}$. Non-normal distributed data are expressed as medians with 25.75 interquartile range. $P$ values $<0.05$ were considered statistically significant. Statistical analyses were performed using SPSS version 12.0 for Microsoft Windows. For evaluation of immunostaining a semi-quantitative score approach was chosen using the following criteria: 1 = weak staining; 2 = moderate staining; $3=$ strong staining.

\section{Results}

Induction of diabetes

10 weeks after streptozotocin-induced hyperglycemia blood glucose levels in the treated animals were significantly higher compared to the non-treated control mice (15.0 (11.418.6) vs. $9.2(7.2 \times 11.2) \mathrm{mmol} / \mathrm{L} ; \mathrm{p}<0.05)$. No differences in blood glucose levels were 
observed between the ximelagatran fed and the normal chow fed hyperglycemic mice $(15.2(11.9-15.4)$ vs. $14.7(4.9-25.5) \mathrm{mmol} / \mathrm{L})$.

\section{Measurement of plasma coagulation}

Prothrombin times (PT) of plasma were measured as marker of anticoagulant treatment with ximelagatran. Compared to the control group, the normal chow fed hyperglycemic mice had normal prothrombin times (control 9.3 (7.8-10.9) sec vs. hyperglycemic 8.8 (8.09.6)). Ximelagatran treatment significantly increased the prothrombin times of plasmas compared to the normal diet diabetic mice $(140.9(63.0-218.7)$ vs. $8.8(8.0-9.6)$ sec; $\mathrm{p}<0.01$ ).

Since thrombin may induce via PAR-1 a number of procoagulant genes, including PAl-1 and tissue factor, we measured the activity of these proteins in plasma and in vascular and renal tissue, respectively. PAl-1 activity was neither detectable in plasma from control animals nor in plasma from hyperglycemic animals with or without ximelagatran. Tissue factor activity in aorta homogenates were not different between control and hyperglycemic mice (1762 $\pm 272 \mathrm{pM}$ and $2086 \pm 566 \mathrm{pM}$, respectively). Also, aortic tissue factor activity was comparable between non-treated $(2086 \pm 566 \mathrm{pM})$ and ximelagatran treated hyperglycemic mice $(1968 \pm 312 \mathrm{pM})$ (Figure 1a, b, c). The same observations were made for kidneys: tissue factor activity was comparable between kidneys from non-treated $(39 \pm 12 \mathrm{pM})$ and ximelagatran treated $(42 \pm 12 \mathrm{pM})$ hyperglycemic animals (Figure $1 \mathrm{~d}, \mathrm{e})$. No differences were observed in the overall thrombogenicity as determined by tissue homogenate induced thrombin generation (data not shown).

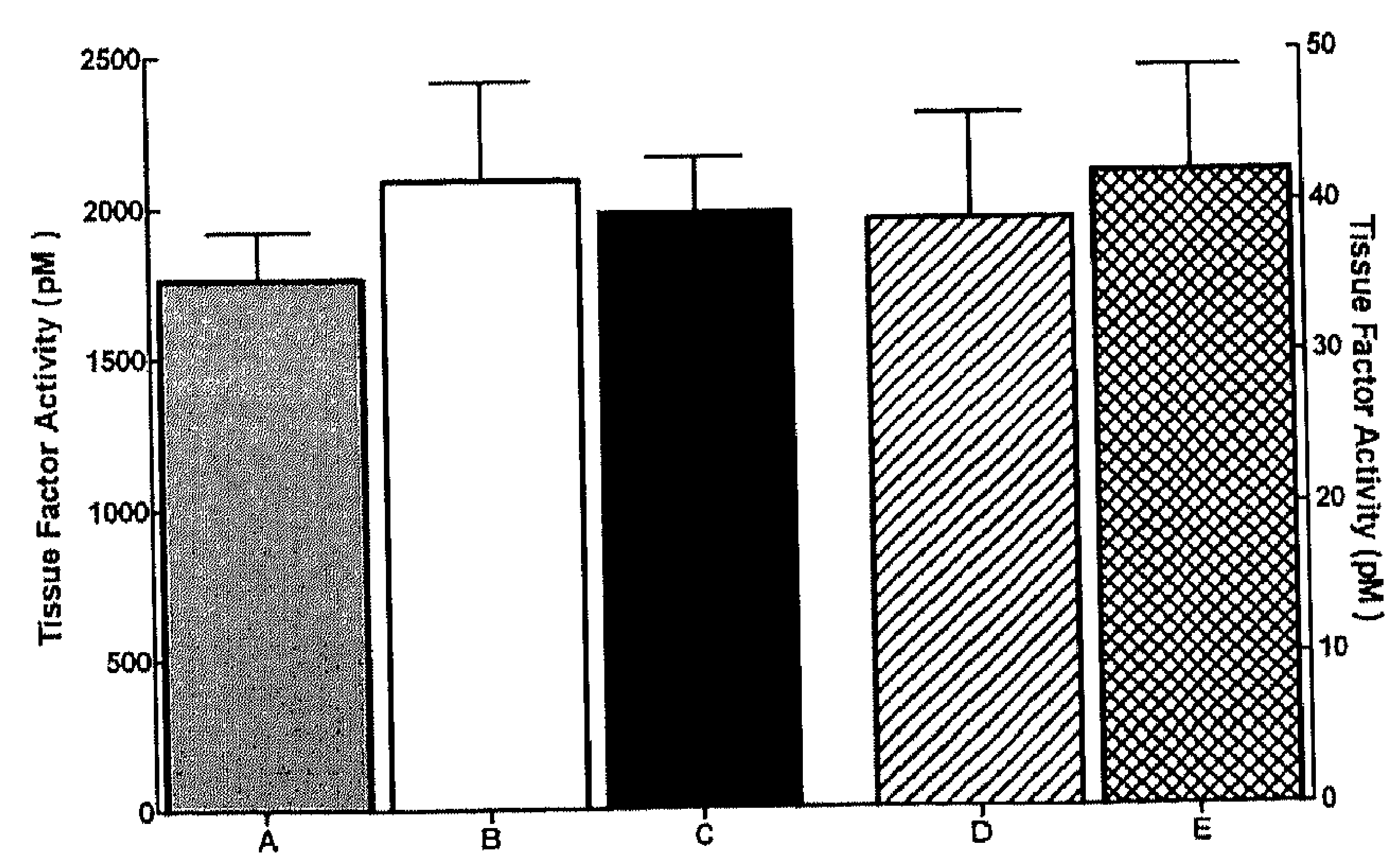

Figure 1

Tissue factor activity in aorta ( $a, b, c$; left $\mathrm{Y}$ axis) respectively kidney homogenates (d, e; right $Y$ axis) in pM. 


\section{Morphology}

Ten weeks of hyperglycemia caused glomerular hypertrophy and increased mesangial matrix in kidneys of the streptozotocin treated mice, whereas these morphological changes characteristic for diabetic nephropathy were not observed in control mice. No differences in morphology were seen between hyperglycaemic mice on either the normal diet or diet containing ximelagatran (Figure $2 a, b, c)$.

\section{Immunohistochemistry}

Fibrin depositions in the glomeruli and small vessels were observed in all hyperglycaemic kidneys and not in the control kidneys. Semi-quantitative scoring of fibrin depositions by three independent observers did not reveal any differences in the amount of fibrin depositions (data not shown) and/or location (Figure 2 a, b, c) between the ximelagatran treated and the non-treated hyperglycemic mice.

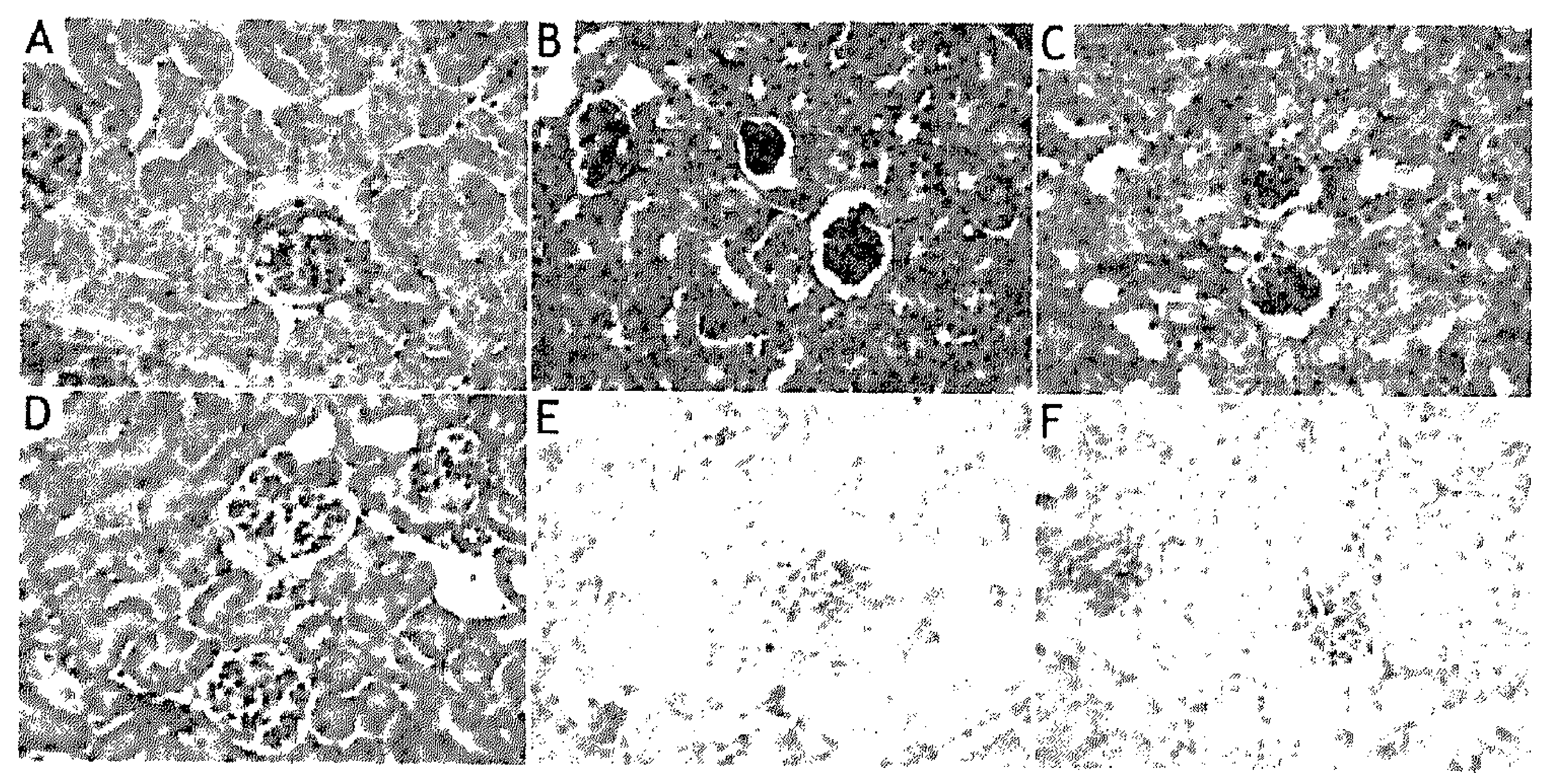

Figure 2

McMannus' periodic acid schiff's (PAS) staining of mouse kidney. Compared to control animals (panel A) increased mesangial matrix was observed in kidneys from streptozotocin treated mice (panel B, 10 weeks of treatment). No differences in morphology were observed between kidneys from hyperglycemic mice treated without (panel B) or with ximelagatran (panel C, 10 weeks of treatment).

Immunohistochemical staining of mouse kidney with anti-fibrin antibody. No fibrin deposition could be observed in kidneys of control animals (panel D), whereas fibrin was present in the glomeruli and small vessels in kidneys of all hyperglycemic mice (panels $\mathrm{E}$ and F). Fibrin deposition was equal between kidneys from hyperglycemic mice treated without (panel E) or with ximelagatran (panel F, 10 weeks of treatment). Magnification $400 x$. 


\section{Discussion}

Several lines of evidence suggest that activated blood coagulation may play a causal role in the pathogenesis of diabetic nephropathy. Activation of plasma coagulation proteins generates serine proteases such as thrombin that has pro-inflammatory cellular effects, but also catalyzes fibrin formation that may compromise glomerular capillary blood flow $11,15,16$ and displays chemotactic properties ${ }^{14}$. In addition, fibrin breakdown products have distinct proinflammatory properties. Taken together, a pro- inflammatory influence may result, and, in accordance with experiments in other models such as experimental antiglomerular basement membrane glomerulonephritis a protective effect of thrombin inhibition may be postulated ${ }^{14}$. To test this hypothesis directly we administered the specific thrombin inhibitor ximelagatran for the entire period during which the mice were exposed to the hyperglycemic effect of streptozotocin. Direct thrombin inhibitors (e.g. hirudin, bivalirudin and ximelagatran) produce a predictable anticoagulant response because they are minimally bound to plasma proteins. Moreover, direct thrombin inhibitors can attenuate both fibrin-bound and fluid-phase thrombin because they bind directly to thrombin, also when bound to fibrin and function independently of antithrombin ${ }^{17}$. In this study we use ximelagatran which is rapidly converted to melagatran after absorption from the small intestine. At the end of the study period the anticoagulant effect was documented by showing a profound prolongation of the prothrombin time ${ }^{33}(-10$-fold), which, based on the effective antithrombotic effect of much lower anticoagulant concentrations in humans, should have prevented fibrin formation.

The main outcome of this study is, however, that there is no attenuation of fibrin deposition in the diabetic kidneys in mice treated with ximelagatran as compared to those not treated. In comparison, in control animals no fibrin at all was seen in the kidneys confirming that the presence of fibrin was related to the induced hyperglycemia. Moreover, no difference in the other histological features of nephropathy was noted in anticoagulated versus non-anticoagulated mice.

The appearance of fibrin in the kidney of diabetic animals may be dependent on different causal factors. First, systemic hypercoagulability, as is seen in humans with diabetes, may contribute to fibrin generation. The hypercoagulable state in diabetes may start with increased availability of tissue factor. Indeed, increased levels of plasma soluble tissue factor are associated with prevalent microvascular complications, such as nephropathy, in type-2 diabetes ${ }^{18-20}$. Also, tissue factor is expressed on circulating monocytes in diabetic patients ${ }^{21}$, and a higher percentage of tissue factor positive microparticles have been observed in patients with type-2 diabetes ${ }^{22}$. In addition, this hypercoagulability depends on increased levels of coagulation proteins including fibrinogen in plasma and organs ${ }^{10,23,24}$, inhibited fibrinolysis, platelet hyperreactivity and the generation of a fibrin structure that is intrinsically resistant to lysis ${ }^{25}$. Elevated levels of fibrinogen are important for increasing the survival of the provisional clot matrix on transformation of fibrinogen to fibrin at the site of injured endothelium ${ }^{26}$. Increases in plasma levels of TAT-complexes have been demonstrated in diabetic patients when compared to non-diabetics, and are higher in 
patients with nephropathy than those without $\mathrm{it}^{23.27 .28}$. Both of these coagulation markers have been shown to be elevated already in early stages of both diabetic nephropathy and retinopathy.

It seems unlikely that in severely anticoagulated blood, such as in our study, thrombin and fibrin generation would occur at any measurable rate, which suggests that other factors are involved in renal fibrin accretion. Such factors may be locally derived. Experimental data show that tissue factor mRNA is upregulated in the kidneys of diabetic mice, possibly contributing to nephropathy ${ }^{16.29}$ and contributing to local fibrin formation. In previous experiments in diabetic mice we also observed increased tissue factor procoagulant activity as compared to non- diabetic mice ${ }^{19}$. Although with the presently used chromogenic assay no difference in renal tissue factor activity was found between diabetic and control mice, its local influence in driving thrombin and fibrin formation may still be evident. Since most of renal tissue factor is expressed in tubular cells ${ }^{30}$, at least under inflammatory conditions, it may well be possible that the anticoagulant effect of melagatran in blood is not accessible to locally generated thrombin and fibrin in the tubular cells e.g. outside the circulation. Since most other relevant coagulation proteins including factor $V^{31}$, and prothrombin (as wells as factor $X$ mRNA) ${ }^{32}$ have also been localized in kidney cells, a local and independent chain of renal coagulation reactions seems a realistic scenario.

Several limitations may apply to our study. First, the antibody used for fibrin staining, although generated against fibrin, may to some extent cross react with fibrinogen and we cannot exclude the possibility that the staining reflects in part fibrinogen accretion due to leakage from blood. Taking this consideration into account, this does not diminish the finding that thrombin inhibition did not reduce the other histological features of diabetic nephropathy, suggesting that also at the level of thrombin- PAR-1 interaction, ximelagatran was ineffective in preventing nephropathy.

A second limitation is that we did not quantify urinary microalbumin excretion as a functional marker of nephropathy, so that we are confined to interpretation of histological changes. Although the observed nephropathy was less outspoken as in previous studies ${ }^{16}$ the findings were quite consistent among diabetic mice, treated or untreated with ximelagatran and not present in control mice.

Given these limitations, the present experiment does rule out a major protective effect of the anticoagulant drug ximelagatran on diabetic nephropathy in C57BIJ6 mice. Since the clinical and experimental programme with ximelagatran has been terminated by the manufacturer, there will be no further studies performed with this agent. However, although other irreversible thrombin inhibitors such as hirudin, which have a stronger affinity for thrombin, may theoretically give different outcomes, it seems unlikely that thrombin inhibition will be a suitable target for preventing clinical diabetic nephropathy. 


\section{Acknowledgements}

Ximelagatran was kindly provided by Dr. Stefan C. Karlsson, MD, Astra Zeneca R\&D, Mölndall, Sweden. Hjalmar Hansen was supported by a grant from the Netherlands Heart Foundation (2000B062) 


\section{References}

1. Molitch ME, Defronzo RA, Franz MJ, Keane WF, Mogensen CE, Parving HH. Diabetic nephropathy. Diabetes Care. 2003;26 Suppl 1:594-98.

2. Jones CA, Francis ME, Eberhardt MS, et al. Microalbuminuria in the US population: third National Health and Nutrition Examination Survey. Am J Kidney Dis. 2002;39:445-459.

3. Harris Ml, Flegal KM, Cowie CC, et al. Prevalence of diabetes, impaired fasting glucose, and impaired glucose tolerance in U.S. adults. The Third National Health and Nutrition Examination Survey, 1988-1994. Diabetes Care. 1998;21:518-524.

4. Kamenetzky SA, Bennett PH, Dippe SE, Miller M, LeCompte PM. A clinical and histologic study of diabetic nephropathy in the Pima Indians. Diabetes. 1974;23:61-68.

5. Deckert T, Kofoed-Enevoldsen A, Norgaard K, Borch-Johnsen K, Feldt-Rasmussen B, Jensen T. Microalbuminuria. Implications for micro- and macrovascular disease. Diabetes Care. 1992;15:1181-1191.

6. Parving HH, Nielsen FS, Bang LE, et al. Macro-microangiopathy and endothelial dysfunction in NIDDM patients with and without diabetic nephropathy. Diabetologia. 1996;39:1590-1597.

7. Adler Al, Stevens RJ, Manley SE, Bilous RW, Cull CA, Holman RR, Development and progression of nephropathy in type 2 diabetes: the United Kingdom Prospective Diabetes Study (UKPDS 64). Kidney Int. 2003;63:225-232.

8. Sowers JR, Epstein M. Diabetes mellitus and associated hypertension, vascular disease, and nephropathy. An update. Hypertension. 1995;26:869-879.

9. Bakris GL, Bhandaru S, Akerstrom V, Re RN. ACE inhibitor-mediated attenuation of mesangial cell growth. A role for endothelin. Am J Hypertens. 1994;7:583-590.

10. Farquhar A, MacDonald MK, Ireland JT. The role of fibrin deposition in diabetic glomerulosclerosis: a light, electron and immunofluorescence microscopy study. J Clin Pathol. 1972;25:657-667.

11. Herlihy WG, Nordquist JA, Mandal AK, Llach F. Diabetic nephropathy associated with fibrin formation. Hum Pathol. 1981;12:658-660.

12. Vesey DA, Cheung CW, Kruger WA, Poronnik P, Gobe G, Johnson DW. Thrombin stimulates proinflammatory and proliferative responses in primary cultures of human proximal tubule cells. Kidney Int. 2005;67:1315-1329.

13. Hewitson TD, Martic M, Kelynack KJ, Pagel CN, Mackie EJ, Becker GJ. Thrombin is a profibrotic factor for rat renal fibroblasts in vitro. Nephron Exp Nephrol. 2005;101:e42-49.

14. Hertig $A$, Rondeau $E$. Role of the coagulation/fibrinolysis system in fibrin-associated glomerular injury. J Am Soc Nephrol. 2004;15:844-853.

15. Kawano K, Mori S, Hirashima T, Man ZW, Natori T. Examination of the pathogenesis of diabetic nephropathy in OLETF rats. J Vet Med Sci. 1999;61:1219-1228.

16. Sommeijer DW, Florquin S, Hoedemaker I, Timmerman JJ, Reitsma PH, Ten Cate H. Renal tissue factor expression is increased in streptozotocin-induced diabetic mice. Nephron Exp Nephrol. 2005;101:e86-94.

17. Kam PC, Kaur N, Thong CL. Direct thrombin inhibitors: pharmacology and clinical relevance. Anaesthesia. 2005;60:565-574.

18. Zumbach $M$, Hofmann $M$, Borcea $V$, et al. Tissue factor antigen is elevated in patients with microvascular complications of diabetes mellitus. Exp Clin Endocrinol Diabetes. 1997; 105:206-212. 
19. Song KS, Kim HK. Plasma levels of tissue factor antigen in patients with non-insulindependent diabetes mellitus. Yonsei Med J. 2004;45:38-42.

20. Sommeijer DW, Hansen HR, van Oerle R, et al. Soluble tissue factor is a candidate marker for progression of microvascular disease in patients with Type 2 diabetes. $J$ Thromb Haemost. 2006;4:574-580.

21. Ichikawa $K$, Yoshinari $M$, Iwase $M$, et al. Advanced glycosylation end products induced tissue factor expression in human monocyte-like U937 cells and increased tissue factor expression in monocytes from diabetic patients. Atherosclerosis. 1998;136:281-287.

22. Diamant M, Nieuwland R, Pablo RF, Sturk A, Smit JW, Radder JK. Elevated numbers of tissue-factor exposing microparticles correlate with components of the metabolic syndrome in uncomplicated type 2 diabetes mellitus. Circulation. 2002;106:2442-2447.

23. Asakawa $\mathrm{H}$, Tokunaga $\mathrm{K}$, Kawakami F. Elevation of fibrinogen and thrombin-antithrombin III complex levels of type 2 diabetes mellitus patients with retinopathy and nephropathy. $J$ Diabetes Complications. 2000;14:121-126.

24. Myrup B, de Maat $M$, Rossing P, Gram J, Kluft C, Jespersen J. Elevated fibrinogen and the relation to acute phase response in diabetic nephropathy. Thromb Res. 1996;81:485-490.

25. Dunn EJ, Ariens RA, Grant PJ. The influence of type 2 diabetes on fibrin structure and function. Diabetologia. 2005;48:1198-1206.

26. Carmassi $F$, Morale $M$, Puccetti $R$, et al. Coagulation and fibrinolytic system impairment in insulin dependent diabetes mellitus. Thromb Res. 1992;67:643-654.

27. Takahashi H, Tsuda A, Tatewaki W, Wada K, Niwano H, Shibata A. Activation of blood coagulation and fibrinolysis in diabetes mellitus: evaluation by plasma levels of thrombinantithrombin III complex and plasmin-alpha 2-plasmin inhibitor complex. Thromb Res. 1989;55:727-735.

28. Shimizu H, Ohtani $K$, Tanaka $Y$, et al. Increased plasma thrombin-antithrombin III complex levels in non-insulin dependent diabetic patients with albuminuria are reduced by ethyl icosapentatenoate. Thromb Haemost. 1995;74:1231-1234.

29. Samad F, Pandey M, Loskutoff DJ. Regulation of tissue factor gene expression in obesity. Blood. 2001;98:3353-3358.

30. de Waard V, Hansen HR, Spronk $\mathrm{HH}$, et al. Differential expression of tissue factor mRNA and protein expression in murine sepsis. The role of the granulocyte revisited. Thromb Haemost. 2006; $95: 348-353$.

31. Liu N, Ono $T$, Suyama $K$, et al. Mesangial factor $V$ expression colocalized with fibrin deposition in IgA nephropathy. Kidney Int. 2000;58:598-606.

32. Stenberg $L M$, Brown MA, Nilsson $E$, Ljungberg 0 , Stenflo J. A functional prothrombin gene product is synthesized by human kidney cells. Biochem Biophys Res Commun.

2001;280:1036-1041. 
Chapter 10

General discussion, summary and conclusions 


\section{The impact of blood coagulation proteases in (diabetic) vascular disease}

Diabetes mellitus is a widely expanding health (care) problem of worldwide proportions. Predominantly type 2 diabetes (DM2) occurs much more often than a century ago, due to the current epidemic of obesity. DM2 (and also DM1) is characterized by cardiovascular morbidity, including an increased risk of myocardial infarction, ischemic stroke and vascular death. In addition, microvascular complications including nephropathy and retinopathy are forms of serious and chronic morbidity.

Although the medical management of DM2 and its complications is improving in many ways, the incidence of new cases of DM2 and the associated vascular morbidity are not likely to disappear on the short term, because the most important risk factor for DM2, the "western" way of living including all elements that promote atherosclerosis, is not likely to be modified substantially, certainly not in the large populations with a low economic status.

This rather pessimistic scenario makes it necessary to carefully consider causes and consequences of vascular disease in DM2; in fact, understanding its pathophysiology is one of the keys to a better medical management.

The main focus of the studies described in this thesis is on blood coagulation. The central hypothesis is that hypercoagulability (non physiologically activated blood coagulation) contributes to atherosclerosis and atherothrombosis in patients with DM2 and that it also enhances microvascular complications, due to perturbation of vascular endothelium under influence of chronic inflammatory stimuli. The basis for this hypothesis can be summarized as the "bidirectional" communication between coagulation proteases and cellular receptors 1 . Whereas about 10 years ago, the blood coagulation system and particularly the coagulation proteins comprising the coagulation cascade, were thought to mainly contribute to fibrin generation, it is currently believed that several coagulation proteases including factor VIla-tissue factor (TF), factor $\mathrm{Xa}$ and thrombin are involved in multiple cellular pathways. The identification of the receptor for thrombin, being a protease activated receptor $(P A R)^{2}$, led to a series of studies establishing the mode of action of protease-PAR interactions and downstream signaling events. Presently, factor VIIa-TF (PAR-2) ${ }^{3}$, factor Xa (PAR-2) ${ }^{4}$ and thrombin (PAR-1 and PAR-4) 5 have been linked to specific cellular functions that have potential impact on diverse complex diseases including sepsis, atherosclerosis and cancer ${ }^{6}$. In general, it appears that these protease-PAR interactions exert profound control over complex biology that upon derangement by chronic inflammatory stimuli (oxidized LDL, C reactive protein, advanced glycated endproducts (AGEs) and so on) can translate into complex pathophysiology. The factors that regulate PAR activity and determine whether they signal in a "good" or "bad" direction are still poorly understood. Recent work on TF points to a novel regulatory mechanism which involves the cleavage of a disulfide bridge in the extracellular domain which acts like a molecular switch to 
convert $\mathrm{TF}$ from a procoagulant into a signaling molecule. The enzyme involved in this switching, protein disulfide isomerase, is active under conditions of oxidation and is dependent on nitrous oxide ${ }^{3}$. This finding adds to the available data on the regulation of the factor VIIa-TF complex, of which the intracellular domain is known to be an important regulator in connection to PAR-2 mediated cell proliferation and migration as a part of angiogenesis 7 . Deletion of the intracellular domain of TF abolishes the normal inhibitory action of TF on the PAR-2 mediated angiogenic response and increased cell proliferation is a consequence 6 . With the availability of specific antibodies 3 it now becomes possible to selectively target the cell signaling cascade of the factor VIIa- TF complex, without impairing the normal coagulation function in hemostasis. Ultimately, these applications may lead to agents that can control specific features of complex disease like cancer and diabetes in controlling the level of angiogenesis. This link to complex disease is still a long route to go, but it illustrates the potential impact that intervention in blood coagulation proteasereceptor interactions may have beyond acting as anticoagulants.

At the start of the experiments that led to this thesis, not all of the above interactions had been established. However, it was known that thrombin, via similar PAR interactions, would act as an agonist to inflammation and cell migration processes, in addition to its ability to activate PAR-4 on platelets causing platelet activation 8 . Thrombin is a multifunctional enzyme in the coagulation cascade ${ }^{9}$. It is the main procoagulant molecule, activating each of the factors XI, V, VIII and XIII, as well as converting fibrinogen into fibrin, at least under thrombogenic conditions. Physiologically, most free thrombin will be "scavenged" by the endothelial cell receptor thrombomodulin (TM) and this complex catalyzes the conversion of protein $C$ to its activated form activated protein $C(A P C)^{10}$. Under specific conditions, such as the inflammatory response to sepsis, thrombomodulin may be negatively regulated with reduced thrombin cofactor activity as a consequence, resulting in a relatively larger fraction of thrombin remaining available for other purposes, including procoagulant activity. In patients with sepsis, but also in those with marked atherosclerosis, there is diminished thrombomodulin detectable in the vessel wall 11 and one may speculate that this is one of the factors that tip the balance from an antithrombotic into a prothrombotic direction. In addition, more thrombin becomes available for activating PAR-1 that triggers inflammatory responses. This interaction has been demonstrated to be relevant in a model of crescentic glomerulonephritis, where thrombin, in a PAR-1 dependent manner, contributes to renal pathology ${ }^{12}$. Another model of disease is ischemic injury to the heart in which inhibition of thrombin by hirudin is able to diminish myocardial infarction (similar as intervention in the factor VIIa-tissue factor complex), probably also in a PAR-2 and PAR-1 dependent way (both by factor VIIa-TF and thrombin induced signaling) ${ }^{13}$. Also in models of sepsis, PARs (at least 
PAR-2) appear to be involved in regulating inflammatory pathways and thrombin is likely to drive part of these effects ${ }^{14}$, although the role of the different PARs in a mouse model of endotoxemia was not demonstrable in subsequent studies ${ }^{15}$.

To control the coagulation protease-PAR interactions, the same molecules that are involved in protecting against thrombosis (natural anticoagulants) are of importance. Thus, APC, by inhibiting thrombin generation, is a natural line of defense against uncontrolled thrombin production and PAR activation. In addition, antithrombin, tissue factor pathway inhibitor (TFPI) and protein $\mathrm{S}$ dampen thrombin generation and/or activity each in a different manner. For sepsis the importance of natural anticoagulants has been most clearly delineated by showing that APC, antithrombin and TFPI are all able to reduce sepsis associated inflammation and mortality and this protective effect has at least for APC been confirmed in clinical studies 16.

The clinical consequences of the above indicated mechanistic models are mostly unknown. Atherosclerosis is associated with evidence of increased coagulation activity in blood, being most pronounced in patients with most extensive generalized vascular disease (reviewed in ${ }^{17}$. There are also indications from clinical studies that elevated markers of coagulation, such as D-dimer fragments as split products from fibrin, have a predictive value for specific thromboembolic complications comparable to the established risk marker CRP. Such data suggest that chronic inflammation and activated coagulation may also be linked in a bidirectional way in atherosclerosis, although this issue remains controversial in that opponents would claim that markers of activated coagulation in systemic vascular disease merely reflect the consequences rather than the causes of atherosclerotic vascular damage 17.

It is unknown whether specific interventions in the coagulation system with anticoagulants would have clinical impact on the vascular disease burden. Preliminar experimental studies suggest that inhibition of thrombin with melagatran reduces atherosclerosis in mice and also attenuates the risk of plaque rupture 18. There are no clinical studies that have addressed this issue yet. Experimental studies with warfarin suggested a small reduction in extent of atherosclerosis, but clinical studies do not report this; in fact, the use of warfarin or other vitamin $\mathrm{K}$ antagonists is associated with increased calcification in arteries and heart valves, due to impaired carboxylation of the vitamin $\mathrm{K}$ dependent matrix Gla protein ${ }^{19}$. Thus, the possible favorable effects of thrombin inhibition by vitamin $\mathrm{K}$ antagonists may have been obscured or overcome by the unfavorable effects on matrix Gla protein. 


\section{Blood coagulation in diabetes; clinical studies}

Many cross sectional studies have explored blood coagulation in patients with diabetes mellitus. In general, such studies appear to indicate a "hypercoagulable state" that may be summarized as altered concentrations of coagulation proteins, increased reactivity of blood platelets towards subthreshold concentrations of agonists and impaired fibrinolysis mainly due to elevated plasminogen activator inhibitor 1 (PAI-1). Considering this evidence critically, one could conclude the following:

There are studies 20 including our own (Chapter 2) showing that in patients with diabetes there is no clear indication of increased coagulation activity as measured by activation markers. Overall, the evidence for a "hypercoagulable state" in terms of activated coagulation proteins seems controversial.

There is reasonable evidence for hyperreactivity of platelets in patients with DM 21 and also an indication that hyperglycemia is causally related to platelet activity measured by tromboxane B2 production ${ }^{22}$;

There is consistent evidence of elevated PAI- 1 in DM2, associated with body fat mass as well as liver fat deposition ${ }^{23}$, but there is still little evidence from clinical studies to support a major role of PAI- 1 in atherothrombotic disease ${ }^{24}$ although its involvement in mechanisms such as cell proliferation may be relevant to atherosclerosis 25 .

In Chapter 2 we have studied a number of coagulation proteins and activation markers. As indicated, this yielded no indication of hypercoagulability. We did, however, observe an association between soluble TF levels and microvascular disease. Soluble TF is still an obscure entity. With commercial assays, such as the one we used, TF can be measured in a plasma sample, but it is unknown which fraction of $\mathrm{TF}$ is exactly determined. Tissue factor is a membrane bound protein expressed constitutively in a number of cells not immediately in contact with circulating blood. There is also an inducible TF fraction, regulated by LPS sensitive domains in the TF promoter (AP-1 and NFKB) that may emerge upon stimulation of monocytes in blood ${ }^{26}$. This occurs for instance after endotoxin challenge of humans 27. In patients with diabetes membrane bound TF is merely detected in the form of microparticles, derived from mononuclear cells, granulocytes and mainly platelets 20,28. To what extent commercial $T F$ assays also detect microparticle-bound $T F$ is unknown and extraction methods have been tried to dissolve TF from its phospholipids binding, however without significant increase in soluble TF in plasma 29. Possibly, due to crossreaction with the commercial antibodies, another fraction of TF is (also) measured in available assays being the alternatively spliced form of tissue factor (asTF) that lacks the membrane domain of the molecule due to splicing of exon 5 30. Animal studies show that asTF is also induced upon inflammatory 
stimulation and detectable in a thrombus upon induction of clotting in a mouse carotid artery ${ }^{31}$.

The observed association between soluble "TF" (intact membrane-bound TF and/or asTF) and microvascular damage in DM2 suggests that inflammation and/or direct endothelial activation, leads to increased NFKB transactivated TF production. Although intact TF is cell bound and should not appear in the circulation (unless cleaved by proteases, but there is no evidence to support this), the soluble fraction may well represent asTF secreted by specific cells also involved in normal TF production. This may also include organs such as the kidney, which were shown to generate tubular epithelial cell- derived TF under conditions of hyperglycemia 32.

In diabetes, diverse inflammatory stimuli such as AGEs, C-reactive protein (CRP), oxidized LDL and hyperglycemia itself may activate leukocytes to interact with platelets, which may induce endothelial cell activation in a P-selectin dependent mechanism ${ }^{33,34}$. The inflammatory stimuli associated with diabetes may drive the formation and liberation of "soluble" TF. This way, increased endothelial activity, as well as altered activity of other vascular cells (monocytes-macrophages or smooth muscle cells), may be reflected by increased plasma concentrations of soluble TF. Other membrane proteins such as TM can also be detected as soluble proteins; in the absence of alternative spliced molecules, the assumption is that TM is being cleaved by proteolytic enzymes such as elastase from neutrophils or reactive oxygen species ${ }^{35}$.

\section{Characteristics of a diabetes cohort and the complications}

In order to address the role of blood coagulation in greater detail we assembled a prospective cohort of patients with DM2 attending the diabetes outpatient clinic of the Slotervaart hospital, Amsterdam, The Netherlands. This cohort forms the basis for the clinical studies described in Chapters 2-5. The cohort comprised patients referred to the hospital for diagnostic and/or therapeutic workup. The baseline characteristics as depicted in Table 1 (Chapter 2) indicate that the patients were in majority males with an average age of 59 years. Of note, the individuals had been known with diabetes already for a long time period (average 7.2 years) and showed typical features of DM2, including moderate hypertension, dyslipidemia, and increased glycosylated hemoglobin levels $\left(\mathrm{HbA}_{1 \mathrm{c}}\right)$, although on average this group was not extremely poor controlled (average $\mathrm{HbA}_{1 \mathrm{c}}$ of $7.5 \%$ ).

The baseline assessment of the patients from this cohort revealed the typical, rather extensive vascular damage, illustrated by the fact that $40 \%$ were known with any type of macrovascular complication, while $29 \%$ had any type of microvascular complication (retinopathy or nephropathy) and $23 \%$ had neurogenic complications (neuropathy and/or neuropathic ulcer) (Chapter 2). Hence, cardiovascular disease 
was highly prevalent in this diabetes cohort. Also impressive is the high rate of new complications during the short follow up period of one year during which 41 patients had one or more new vascular complication. This latter figure may be somewhat exaggerated by the more extensive screening in hospital in comparison with general practitioners' practice, but it remains substantial, illustrating that DM2 is a severe vascular disease.

In this patient population the availability of a diagnostic marker that predicts vascular complications may be of considerable benefit in determining the optimal management on a short term. The observed association between soluble $\mathrm{TF}$ and microvascular disease (Chapter 2) may offer benefit on top of typical markers like microalbuminuria or the presence of retinopathy, because it can be easily determined with a commercial assay on blood taken by a routine bloodsampling procedure at a cost of 15 euro per determination.

One of the routine screening procedures performed on patients with DM2 that attend the clinic is a standard ECG recording (Chapter 3). The usual analysis includes screening for abnormalities in conducting system and signs of ischemia, which may reveal "silent" myocardial ischemia. The main outcome of ECG analysis in this DM2 cohort is that the procedure gives relevant information with regard to the (risk of) vascular complications. QTc intervals were associated with prevalent neurogenic disease in that the intervals were longer than in patients without this finding (Chapter 3). In patients with new macrovascular complications during follow up the QRS interval at baseline was prolonged compared to patients that remained free of macrovascular complications. These findings illustrate that a routine ECG recording should be evaluated with care with regard to QT and QRS intervals, which could provide arguments for referral to a vascular specialist in case of increased risk of macrovascular complications. Obviously, in the individual patient cutoff levels for QT and QRS intervals should be established to guide the practicing physician and this information cannot be retrieved from this rather small cohort.

With regard to blood coagulation we undertook a regression analysis assuming that conduction disturbances in the heart may reflect either microvascular impairment or chronic ischemia. In accordance with the analysis described in Chapter 2, soluble TF showed up as associated marker. In fact, of all tested risk factors soluble TF was the only determinant showing a statistically significant relationship with QRS duration (Chapter 3, Table 2). While in the present analysis QRS duration was a marker of macrovascular complications and soluble TF a marker of microvascular complications in the same cohort, how do these findings match? Although coincidence may play a role in either of the statistical findings one might postulate that the conduction defect itself is a product of microvascular disease of the heart. The latter is also thought to be a critical factor in determining the poorer outcome of 
patients with DM2 as compared to those without diabetes, after a myocardial infarction 36,37

We examined two more types of plasma candidate determinants of vascular disease in the diabetes cohort. The AGE products $N^{6}$-(carboxymethyl)lysine (CML) and $\mathrm{N}^{\kappa_{-}}$ (carboxyethyl)lysine (CEL) are known products of oxidative modification of glycated proteins that can be detected in serum and have been implicated in diabetic vascular disease ${ }^{38,39}$. In Chapter 4 , a serum and urine determination of CML and CEL were studied and correlated with vascular complications in the diabetic cohort. Somewhat surprising, no correlations between CML and CEL on the one hand and complications on the other hand, were found. In addition, no significant correlation between the serum and blood assay of the two AGEs was found suggesting that the urine fraction is not a simple reflection of the blood concentration. The statistically significant correlation with soluble TF supports a role of AGEs in microvascular complications and may also point to a link between AGEs and TF synthesis ${ }^{40}$, as described above.

As a final and novel marker we studied the vitamin $\mathrm{K}$ dependent protein matrix Gla protein (MGP) in the diabetes cohort. The assumption was that the blood concentration of this protein would be associated with vascular disease, particularly with large vessel disease, because of the demonstrated relation between MGP and arterial calcification ${ }^{19}$. Since there is reasonable evidence pointing to a risk association between arterial calcification and cardiovascular complications, it was postulated that MGP would indirectly reflect cardiovascular risk profile. Measured with a novel immunoassay, MGP related antigen and incompletely carboxylated MGP were both measured in plasma samples from the same diabetes cohort (Chapter 5). The results provide an indication of risk association albeit that macrovascular risk only emerged by a significant negative correlation between lower Glu MGP plasma levels and arterial stiffness (estimated on the basis of pulse pressure). Surprisingly, lower Glu MGP levels were associated with microvascular complications and specifically with nephropathy. Glu MGP levels in plasma were negatively correlated with age and soluble $T F$, but the pathophysiological significance of these associations are still unknown.

\section{Mouse models of arterial thrombosis and the effects of diabetes (hyperglycemia)}

In Chapter 6 we give an overview of studies with mouse models of arterial thrombosis in which the role of blood coagulation determinants of thrombosis was studied. Mouse models of thrombosis are of significant importance for gaining a better understanding of the contribution of single proteins to the complex process of thrombosis. The studies we summarize yield the following important conclusions. 
With regard to platelet receptors and ligands VWF and fibrinogen appear to be important for thrombus stability, while the GPIIb/IIla complex is essential for thrombus formation. This means that in the absence of vWF or fibrinogen thrombi may still develop, provided that the trigger is sufficiently strong, while thrombi do not form in the complete absence of the GPIIb/IIIa complex.

With regard to the coagulation cascade initial experiments focused on the regulatory role of TFPI as inhibitor of the starting point in coagulation, assembly of the factor VIIa/TF complex. Experiments by Eitzman and colleagues showed that in mice with a heterozygous TFPI deficiency intercrossed in an apoE- $/$ - background the time to thrombus formation was reduced in comparison with apoE- $\%$ mice with a normal TFPI level (wildtypes) in photochemically induced arterial thrombosis experiments ${ }^{41}$ (Chapter 6). These experiments illustrated the involvement of $\mathrm{TF}$ in the initiation of arterial thrombosis. Subsequent studies published after completion of our review paper (Chapter 6) have extensively characterized the role of TF in thrombus formation. In experiments employing intravital imaging it was established that $T F$ recruited from different sources is involved in thrombus formation in which the vessel wall and circulating microparticles participate. The latter are formed due to inflammatory stimulation, involving platelet activation and platelet-leukocyteendothelium interactions through a P-selectin based mechanism ${ }^{33,34}$. The complete absence of TF is not compatible with life (TF- mice die in utero; ${ }^{42-44}$ ) and the minimal level of TF required to induce thrombosis is not known. The availability of mice with a low level of human TF ( 1\% functional TF) have been useful to establish the relative contribution of the different pools of TF to thrombosis 45 .

Of the other coagulation proteins, deficiency in any of the intrinsic factors (VIII, IX, $\mathrm{V}, \mathrm{X}$, prothrombin) is thought to reduce thrombin generation and impair thrombus formation, although this has not been systematically investigated with in vivo models ${ }^{33}$. In contrast, the role of factors XI and XII has gained extensive attention in recent years. In normal hemostasis, factor XII and the other factors from the prekallikrein-kallikrein- system (PKKS) do not appear to play any role. This means that even a severe deficiency of factor XII does not cause bleeding complications in man. Factor XI deficiency is associated with a bleeding diathesis secondary to trauma. The role of factor XI has been explored in in vivo models, showing that this intrinsic protein is important for amplifying the rate of thrombin generation, contributing to additional activation of the thrombin activated fibrinolytic inhibitor (TAFI), such that thrombus dissolution by fibrinolysis is reduced ${ }^{46}$. This property has been primarily established for venous thrombosis. A recent clinical study suggests that an elevated factor XI contributes to the risk of myocardial infarction in man, supporting also a link with arterial thrombosis 47 .

Factor XII has gained unexpected attention due to the finding that it is a relevant protein in arterial thrombus formation in mice, such that mice that have a complete absence (FXII- - ) are viable and have a normal life expectancy, but show a 
diminished thrombus stability in carotid artery thrombosis 48 . Furthermore, the absence of factor XII also protected against ischemic stroke in mice, corroborating a role in thrombosis and ischemia reperfusion injury 48.

What is the effect of diabetes on thrombus formation in vivo?

This effect should be distinguished in at least two components: first the factor hyperglycemia and second the factors that are associated with "metabolic syndrome". With regard to the factor hyperglycemia there is abundant literature showing increased platelet reactivity induced by hyperglycemia, based on several distinct mechanisms of platelet activation (reviewed in 49 ). We studied the in vivo effect of hyperglycemia on arterial thrombus formation (Chapter 7) and showed that thrombus formation time (time to occlusion) is not influenced, but the actual closure time is accelerated. While we did not detect any obvious thrombogenic changes in the vessel wall (similar level of TF mRNA and immunohistochemical TF signal), thrombin production in plasma was enhanced (increased thrombinantithrombin complexes) and platelet mediated thrombin generation was also significantly increased as compared to non-diabetic platelets. These data are in agreement with the observed positive relationship between plasma glucose regulation in diabetic patients and platelet activity, measured by thromboxane B2 production 22. As indicated earlier, we did not find evidence of substantial alterations in coagulation activity at least in patients with DM2 and there are no animal models that show an influence of diabetes on thrombin generation due to changes in coagulation protein concentrations or activity.

Two factors have emerged as determinants of thrombosis in relation to metabolic factors associated with obesity, insulin resistance and possibly diabetes. First, it was shown that leptin, the product of the $O B$ gene and an important regulator of fat and energy storage in humans, is ale to activate platelets through binding to a leptin receptor $50 ; 51$. Given that obesity is associated with increased leptin levels in blood, a prothrombotic effect of this adipocyte may be postulated in DM2. Second, it was shown that mice deficient in leptin or in the leptin receptor had a prolonged time to occlusion in a carotid artery thrombosis model (Konstantinides 2001). Infusion of recombinant leptin could overcome this delayed thrombus formation, but only in $\mathrm{Ob} / \mathrm{Ob}$ mice, demonstrating an important contribution of leptin and its receptor in platelets and maybe in other cells as well.

Another factor of which an important contribution to thrombosis would be expected based on its function as a key regulator of fibrinolysis is PAI- 1 and indeed in studies in murine arterial thrombosis the deficiency of PAI-1 caused a prolonged time to vessel occlusion as well as accelerated clot lysis times (reviewed in Chapter 6).

How do these data help to interpret clinical findings in patients with diabetes? 
In patients with DM2, the most obvious abnormalities in blood coagulation comprise of increased reactivity in platelet function, possibly increased reactivity of the coagulation factors that drive thrombin generation (although clinical data are inconsistent) and reduced fibrinolysis due to increased PAI-1 levels.

The mouse studies contribute to a better understanding of platelet involvement in thrombosis, also in diabetic conditions, and provide a basis for therapeutic intervention in patients at highest risk of arterial thrombosis. The contributing role of coagulation factors or their natural anticoagulant inhibitors has not been determined yet, but the available data do not support substantial differences between diabetic and non-diabetic individuals (or animals) in terms of TF dependent thrombin generation. Whether specific proteins such as factor XII have distinct properties under diabetic conditions is not known. Fibrinolysis remains intriguing in that clinical studies do not show a clear association between elevated PAI- 1 concentrations in blood and cardiovascular risk in the population ${ }^{24}$, in spite of the clear association between insulin resistance-adipocyte and liver derived PAI-1 production and circulating PAI-I levels ${ }^{23}$. One additional element has gained attention; in patients with diabetes fibrin clot structure appears to be more resistant to lysis than clots from non-diabetic individuals 52 and it may be that effects of hyperglycemia on fibrin structural components is a relevant factor in thrombosis.

\section{Blood coagulation: direct involvement in inflammatory organ damage?}

As indicated in the above sections, blood coagulation proteases are involved in a range of cellular processes unrelated to fibrin formation, via activation of PARs. In this context, the activation of the coagulation system second to inflammatory activation should be regarded as a defense mechanism that is part of innate immunity and protects against infectious invasion of the organisms as well as against bleeding from trauma.

In sepsis, the coagulation response has been well characterized and the experiments described in Chapter 8 further expand on this issue in showing organ specific responses to endotoxin challenge of mice. Employing in situ hybridization in conjunction with protein staining we analyzed the expression of $\mathrm{TF}$ in mouse organs. Distinct patterns of expression are encountered in which TF expression is increased in the kidney and lungs at 6 hours after endotoxin challenge. In the kidney particularly the region of tubular epithelial cells was involved in TF production, while glomeruli remained free from $\mathrm{TF}$ expression. This pattern was confirmed in subsequent experiments also showing that hyperglycemia induces TF production in renal tubular cells. The function of TF in these cells remains unknown, but its inducible character supports a role in inflammatory defense. In this context, the local generation of $\mathrm{TF}$ may also contribute to a procoagulant 
phenotype and the finding of fibrin deposits in the vascular bed of the kidney suggests that this may be an associated phenomenon. Fibrin may be indicative of (chronic) inflammation in the kidney and is in animal models a feature of diabetic nephropathy (Chapter 9 and ${ }^{32}$ ).

In order to demonstrate the pathophysiological significance of thrombin and fibrin generation in the kidney we undertook a study in which hyperglycemic mice were treated or not treated with the selective thrombin inhibitor ximelagatran (Chapter 9). In spite of effective anticoagulation, monitored by clotting times, we did not observe any measurable effect on histologically scored nephropathy, which although mild was readily discernible in these mice. Surprisingly, also no detectable effect on fibrin deposits in the kidney was observed suggesting that locally generated fibrin was not inhibited by systemically administered ximelagatran. Although the mechanism remains unclear, the lack of effect of thrombin inhibition suggests that there may be little options for pharmacological inhibition of renal coagulation processes, which may be driven by locally expressed $\mathrm{TF}$ and subsequent thrombin generation not accessible to blood anticoagulants. Alternatively, in spite of proper systemic levels of anticoagulation, the reversibility of this thrombin inhibitor may be less sufficient to block local (high?) concentrations of thrombin, whereas irreversible inhibitors like hirudin may be more effective as demonstrated in the glomerulonephritis model in mice ${ }^{12}$.

\section{Concluding remarks on blood coagulation and its relevance for patients with diabetes anno 2006}

Our clinical studies illustrate that DM2 is a severe condition in showing a high rate of prevalent cardiovascular complications in a cohort of patients with an average duration of known disease of about 7 years. In addition, on a short term there is a significant occurrence of new complications, showing that caution is required in the workup of these patients. What can be done to limit further cardiovascular complications? First, all those involved in the care of patients with this disease must be convinced that DM2 is a serious disease that requires strict attention in terms of information to patients regarding health care and risk factors. Relatively simple diagnostic tools such as ECG recording and urine analysis for microalbuminuria should be included in risk factor analysis. Multidisciplinary guidance from the initial diagnosis onwards is needed including advice by a dietician, proper foot care, analysis of all relevant risk factors by the general practitioner and training of patients in proper use of medication. Specific known cardiovascular risk factors such as obesity, hypertension and dyslipidemia should be addressed without delay and current guidelines should clearly be implemented by all involved. In the vast majority of patients this will include the prescription of a "statin" to lower cholesterol levels and blood pressure medication, on top of specific 
medication for diabetes. With regard to blood coagulation, medication recommendations are still very limited. The recent $\mathrm{CBO}$ consensus on Cardiovascular Riskmanagement does not recommend the use of aspirin in each patient with diabetes, while its use for secondary prevention is accepted both in diabetic and non-diabetic patients. In contrast, the American Diabetes Association supports the use of aspirin 75-162 $\mathrm{mg}$ /day in DM with history of CVD, but also as primary prevention in DM 1 or $2>40$ yrs with additional CV risk factors 53 . The high rate of cardiovascular complications and the small risk of complications with the use of low dose aspirin supports in our view the American recommendations.

Whether combined antiplatelet therapy is effective is questionable. The only dual therapy that has been analyzed is the combination of aspirin and clopidogrel, and although this combination has not been specifically studied in diabetics, the subgroup analysis from the Charisma study, does not support a benefit of the combination in the diabetes subgroup 54 .

Interestingly, the application of platelet GPIIb/IIIa inhibitors during percutaneous coronary interventions ( $\mathrm{PCI}$ ) has been shown to be more effective in patients with diabetes than in those without the disease 55. Theoretically, intervention in this platelet receptor complex would be more effective than aspirin alone, however all trials with oral GPIIb/IIa inhibitors have been disappointing and no drugs are being developed aimed at this target.

With regard to coagulation and fibrinolysis there are no pharmacological agents that have demonstrated specific benefit for patients with diabetes. Given the lack of firm evidence for a specific contribution of coagulation and impaired fibrinolysis to the risk of atherothrombosis in diabetes, the focus of drug targeting remains aimed on platelets rather than the other components. The link between obesity and blood coagulation (PAI-1 levels) is of great interest, but its pathophysiological significance remains to be proven.

Other and new indications may eventually emerge such as the opportunity to modulate inflammation or angiogenesis through (longterm) treatment with selective anticoagulant agents that target the factor VIIa/TF complex or thrombin- PAR interactions. The generation of specific antibodies towards extracellular domains of TF involved in the switch between coagulation and signaling opens ways for highly selective immune modulation. Processes involving excessive angiogenesis in patients with diabetes, including retinopathy, may be inhibited by (local?) blockade of factor VIIa/TF. Nephropathy is apparently not simply attenuated with a reversible thrombin inhibitor, but the observed beneficial effects of PAR-1\% in experimental glomerulonephritis indicates that certain nephropathies are in fact attenuated by disengaging the thrombin-PAR- 1 interaction. 
With the developing insights in the interactions that blood coagulation proteins and cells display in direction of non-coagulant processes involved in complex diseases, blood coagulation research may become of notable impact on diabetes research as well. 


\section{References}

1. Levi $M$, van der Poll T, Buller HR. Bidirectional relation between inflammation and coagulation. Circulation. 2004; 109:2698-2704.

2. Coughlin SR. Protease-activated receptors in hemostasis, thrombosis and vascular biology. J Thromb Haemost. 2005;3:1800-1814.

3. Ahamed J, Versteeg $\mathrm{HH}$, Kerver $M$, et al. Disulfide isomerization switches tissue factor from coagulation to cell signaling. Proc Natl Acad Sci U S A. 2006;103:13932-13937.

4. Riewald $M$, Ruf $W$. Mechanistic coupling of protease signaling and initiation of coagulation by tissue factor. Proc Natl Acad Sci U S A. 2001;98:7742-7747.

5. Coughlin SR. Thrombin signalting and protease-activated receptors. Nature. 2000;407:258264.

6. Belting $M$, Ahamed J, Ruf $W$. Signaling of the tissue factor coagulation pathway in angiogenesis and cancer. Arterioscler Thromb Vasc Biol. 2005;25:1545-1550.

7. Belting $M$, Dorrell Ml, Sandgren 5 , et al. Regulation of angiogenesis by tissue factor cytoplasmic domain signaling. Nat Med. 2004;10:502-509.

8. Hamilton JR, Cornelissen I, Coughlin SR. Impaired hemostasis and protection against thrombosis in protease-activated receptor 4-deficient mice is due to lack of thrombin signaling in platelets. $J$ Thromb Haemost. 2004;2:1429-1435.

9. Spronk HM, Govers-Riemslag JW, ten Cate H. The blood coagulation system as a molecular machine. Bioessays. 2003;25:1220-1228.

10. Esmon CT. The protein C pathway. Chest. 2003;124:26S-32S

11. Laszik ZG, Zhou XJ, Ferrell GL, Silva FG, Esmon CT. Down-regulation of endothelial expression of endothelial cell protein $C$ receptor and thrombomodulin in coronary atherosclerosis. Am J Pathol. 2001;159:797-802.

12. Cunningham MA, Rondeau E, Chen X, Coughlin SR, Holdsworth SR, Tipping PG. Proteaseactivated receptor 1 mediates thrombin-dependent, cell-mediated renal inflammation in crescentic glomerulonephritis. J Exp Med. 2000;191:455-462.

13. Erlich JH, Boyle EM, Labriola J, et al. Inhibition of the tissue factor-thrombin pathway limits infarct size after myocardial ischemia-reperfusion injury by reducing inflammation. Am J Pathol. 2000;157:1849-1862.

14. Pawlinski R, Pedersen B, Schabbauer G, et al. Role of tissue factor and protease-activated receptors in a mouse model of endotoxemia. Blood. 2004;103:1342-1347.

15. Camerer E, Duong DN, Hamilton JR, Coughlin SR. Combined deficiency of protease-activated receptor-4 and fibrinogen recapitulates the hemostatic defect but not the embryonic lethality of prothrombin deficiency. Blood. 2004;103:152-154.

16. Manns BJ, Lee H, Doig CJ, Johnson D, Donaldson C. An economic evaluation of activated protein $C$ treatment for severe sepsis. N Engl J Med. 2002;347:993-1000.

17. Spronk $\mathrm{HM}$, van der Voort $\mathrm{D}$, Ten $\mathrm{Cate} H$. Blood coagulation and the risk of atherothrombosis: a complex relationship. Thromb J. 2004;2:12.

18. Karanam $S$, Fritsche-Danielson $R$, Jackson $C$. Thrombin inhibition with melagatran prevents plaque rupture in apolipoprotein $E$ knockout mice. $X X$ th Congress of the International Society on Thrombosis and Haemostasis 2005 Sydney, Australia. 2005. 
19. Spronk HM, Soute BA, Schurgers $L J$, et al. Matrix Gla protein accumulates at the border of regions of calcification and normal tissue in the media of the arterial vessel wall. Biochem Biophys Res Commun. 2001;289:485-490.

20. Diamant M, Nieuwland R, Pablo RF, Sturk A, Smit JW, Radder JK. Elevated numbers of tissue-factor exposing microparticles correlate with components of the metabolic syndrome in uncomplicated type 2 diabetes mellitus. Circulation. 2002;106:2442-2447.

21. Sobol $A B$, Watala $C$. The role of platelets in diabetes-related vascular complications. Diabetes Res Clin Pract. 2000;50:1-16.

22. Ferroni P, Basili 5, Falco A, Davi G. Platelet activation in type 2 diabetes mellitus. J Thromb Haemost. 2004;2:1282-1291.

23. Alessi MC, Juhan-Vague I. PAI-1 and the metabolic syndrome: links, causes, and consequences. Arterioscler Thromb Vasc Biol. 2006;26:2200-2207.

24. Lowe GD. Can haematological tests predict cardiovascular risk? The 2005 Kettle Lecture. $\mathrm{Br}$ $J$ Haematol. 2006;133:232-250.

25. Lijnen HR, Alessi MC, Van Hoef B, Collen D, Juhan-Vague I. On the role of plasminogen activator inhibitor- 1 in adipose tissue development and insulin resistance in mice. $J$ Thromb Haemost. 2005;3:1174-1179.

26. Eilertsen KE, Osterud B. Tissue factor: (patho)physiology and cellular biology. Blood Coagul Fibrinolysis, 2004;15:521-538.

27. Franco RF, de Jonge $E$, Dekkers PE, et al. The in vivo kinetics of tissue factor messenger RNA expression during human endotoxemia: relationship with activation of coagulation. Blood. 2000;96:554-559.

28. Sommeijer DW, Hansen HR, van Oerle R, et al. Soluble tissue factor is a candidate marker for progression of microvascular disease in patients with Type 2 diabetes. $J$ Thromb Haemost. 2006;4:574-580.

29. van der Putten RF, te Velthuis H, Aarden LA, ten Cate H, Glatz JF, Hermens WT. Highaffinity antibodies in a new immunoassay for plasma tissue factor: reduction in apparent intra-individual variation. Clin Chem Lab Med. 2005;43:1386-1391.

30. Bogdanov VY, Balasubramanian V, Hathcock J, Vele O, Lieb M, Nemerson Y. Alternatively spliced human tissue factor: a circulating, soluble, thrombogenic protein. Nat Med. 2003;9:458-462.

31. Bruggemann LW, Drijfhout JW, Reitsma PH, Spek CA. Alternatively spliced tissue factor in mice: induction by Streptococcus pneumoniae. J Thromb Haemost. 2006;4:918-920.

32. Sommeijer DW, Florquin S, Hoedemaker I, Timmerman JJ, Reitsma PH, Ten Cate H. Renal tissue factor expression is increased in streptozotocin-induced diabetic mice. Nephron Exp Nephrol. 2005;101:e86-94.

33. Furie B, Furie BC. Thrombus formation in vivo. J Clin Invest. 2005;115:3355-3362.

34. Wagner DD, Burger PC. Platelets in inflammation and thrombosis. Arterioscler Thromb Vasc Biol. 2003;23:2131-2137.

35. Boehme $M W$, Galle $P$, Stremmel $W$. Kinetics of thrombomodulin release and endothelial cell injury by neutrophit-derived proteases and oxygen radicals. Immunology. 2002;107:340-349.

36. Hillege $\mathrm{HL}$, Fidler V, Diercks GF, et at. Urinary albumin excretion predicts cardiovascular and noncardiovascular mortality in general population. Circulation. 2002;106:1777-1782.

37. Karalliedde J, Viberti G. Microalbuminuria and cardiovascular risk. Am J Hypertens. 2004;17:986-993. 
38. Vlassara H, Palace MR. Diabetes and advanced glycation endproducts. J Intern Med. 2002;251:87-101.

39. Lieuw AFML, van Hinsbergh VW, Teerlink $T$, et al. Increased levels of N(epsilon)(carboxymethyl)lysine and $N$ (epsilon)-(carboxyethyl)lysine in type 1 diabetic patients with impaired renal function: correlation with markers of endothelial dysfunction. Nephrol Dial Transplant. 2004;19:631-636.

40. Bierhaus A, Illmer T, Kasper M, et al. Advanced glycation end product (AGE)-mediated induction of tissue factor in cultured endothelial cells is dependent on RAGE. Circulation. 1997;96:2262-2271.

41. Westrick RJ, Bodary PF, Xu Z, Shen YC, Broze GJ, Eitzman DT. Deficiency of tissue factor pathway inhibitor promotes atherosclerosis and thrombosis in mice. Circulation. 2001;103:3044-3046.

42. Carmeliet $P$, Mackman N, Moons $L$, et al. Role of tissue factor in embryonic blood vessel development. Nature. 1996;383:73-75.

43. Toomey JR, Kratzer KE, Lasky NM, Stanton JJ, Broze GJ, Jr. Targeted disruption of the murine tissue factor gene results in embryonic lethality. Blood. 1996;88:1583-1587.

44. Bugge $\mathrm{TH}$, Xiao Q, Kombrinck $\mathrm{KW}$, et al. Fatal embryonic bleeding events in mice lacking tissue factor, the cell-associated initiator of blood coagulation. Proc Natl Acad Sci U S A. $1996 ; 93 ; 6258-6263$.

45. Mackman N. Role of tissue factor in hemostasis, thrombosis, and vascular development. Arterioscler Thromb Vasc Biol. 2004;24:1015-1022.

46. Minnema MC, Friederich PW, Levi M, et al. Enhancement of rabbit jugular vein thrombolysis by neutralization of factor $X I$. In vivo evidence for a role of factor $X I$ as an anti-fibrinolytic factor. J Clin Invest. 1998;101:10-14.

47. Doggen CJ, Rosendaal FR, Meijers JC. Levels of intrinsic coagulation factors and the risk of myocardial infarction among men. Opposite and synergistic effects of factors XI and XII. Blood. 2006.

48. Kleinschnitz $C$, Stoll $G$, Bendszus $M$, et al. Targeting coagulation factor XII provides protection from pathological thrombosis in cerebral ischemia without interfering with hemostasis. J Exp Med. 2006.

49. Wolfs JL, Comfurius P, Rasmussen JT, et al. Activated scramblase and inhibited aminophospholipid translocase cause phosphatidylserine exposure in a distinct platelet fraction. Cell Mol Life Sci. 2005;62:1514-1525.

50. Giandomenico G, Dellas C, Czekay RP, Koschnick S, Loskutoff DJ. The leptin receptor system of human platelets. J Thromb Haemost. 2005;3:1042-1049.

51. Konstantinides S, Schafer K, Koschnick S, Loskutoff DJ. Leptin-dependent platelet aggregation and arterial thrombosis suggests a mechanism for atherothrombotic disease in obesity. J Clin Invest. 2001;108:1533-1540.

52. Dunn EJ, Ariens RA, Grant PJ. The influence of type 2 diabetes on fibrin structure and function. Diabetologia. 2005;48:1198-1206.

53. Standards of medical care in diabetes--2006. Diabetes Care. 2006;29 Suppl 1:54-42.

54. Bhatt DL, Fox KA, Hacke W, et al. Clopidogrel and aspirin versus aspirin alone for the prevention of atherothrombotic events. N Engl J Med. 2006;354:1706-1717.

55. Huber $\mathrm{K}$. The role of glycoprotein Ilb/llla-receptor antagonists in diabetics. J Thromb Thrombolysis. 2003;15:99-103. 
Algemene samenvatting 


\section{De impact van bloedstollingseiwitten in (diabetes gerelateerde) vaatziekte}

Diabetes mellitus is een snel groeiend gezondheidsprobleem van wereldwijde omvang. Vooral diabetes type 2 (DM-2) komt in toenemende mate voor ten opzichte van 10 jaar geleden, mede ten gevolge van de huidige epidemie van overgewicht. DM-2 (en dit geldt ten dele ook voor DM-1) wordt gekenmerkt door cardiovasculaire morbiditeit, waaronder een toegenomen risico op hartinfarcten, herseninfarcten en vasculaire dood. Daarenboven is er een verhoogd risico op chronische ziekte ten gevolge van microvasculaire complicaties, zoals aantasting van de nieren (nefropathie) en ogen (retinopathie).

Hoewel de behandelmogelijkheden van DM-2 en de complicaties zijn verbeterd in veel opzichten, zal de toegenomen incidentie van DM-2 en de daaraan verbonden vasculaire morbiditeit niet op korte termijn een daling laten zien. De belangrijkste risicofactor voor het ontstaan van DM-2, de "westerse" manier van leven, inclusief alle elementen daarvan die het ontstaan van atherosclerose bevorderen, zal waarschijnijik niet op korte termijn die verandering laten zien die nodig is om de toename in DM-2 alsmede hart- en vaatziekten te verminderen of te stoppen.

Dit tamelijk pessimistische scenario benadrukt het belang van het goed kunnen onderscheiden van oorzaak en gevolg van hart en vaat ziekten in DM-2. Het begrijpen van de pathofysiologie is de route naar een betere, want meer gerichte, behandeling met als doel een vermindering van complicaties.

De nadruk van de in dit proefschrift beschreven studies ligt op de relatie tussen bloedstolling en diabetes- gerelateerde complicaties. De centrale hypothese is dat hypercoagulabiliteit (pathologisch geactiveerde bloedstolling) bijdraagt aan (verergering van) atherosclerose en atherotrombose in patiënten met DM-2 en dat hypercoagulabiliteit ook in de microvasculaire complicaties een rol speelt door verandering van de endotheelfunctie. De basis van deze hypothese kan samengevat worden als de "tweerichting" communicatie tussen bloedstollingsfactoren en cellulaire receptoren.

Hoewel tot recent verondersteld werd dat de bloedstolling uitsluitend bedoeld is om fibrinevorming te bevorderen ingeval van verwonding van de bloedvaten, geeft onderzoek van de laatste jaren steeds duidelijker aan dat specifieke enzymen uit het stollingssysteem, zoals trombine, celspecifieke functies beïnvloeden door binding aan cellulaire receptoren. De ontdekking van deze protease geactiveerde receptoren (PARs) heeft geleid tot een serie van studies naar mechanismen van deze interacties en de voortvloeiende signalen in de cel. Hierdoor is het mogelijk om de activiteiten van factor Vlla-tissue factor (TF) (PAR2), factor Xa (PAR2) en trombine (PAR1 en PAR4) te koppelen aan specifieke cellulaire functies welke een potentiële invloed hebben op de pathofysiologie van uiteenlopende ziekten zoals sepsis, atherosclerose en kanker. De factoren die PAR activiteit reguleren en bepalen of een signaal resulteert in een "goede" of "slechte" uitkomst zijn nog steeds onduidelijk. Recent onderzoek aan de functies van het cellulaire eiwit TF wijst in de richting van nieuwe 
regulatiemechanismen, waarbij de splitsing van een disulfide brug in het extracellulaire domein van TF er toe leidt dat de activiteit van het TF molecuul van "procoagulant" naar "signaaloverdracht" verschuift. Het enzym dat verantwoordelijk is voor deze verandering (protein disulfide isomerase) is actief onder omstandigheden van oxidatie en is afhankelijk van stikstof oxide (NO). Deze bevindingen werpen meer licht op het regulatie mechanisme van het factor VIIa-TF complex, waarvan bekend is dat het intracellulaire domein een belangrijke regulerende functie heeft (samen met PAR-2) bij gereguleerde celproliferatie en migratie in normale angiogenese. Deletie van het intracellulaire domein van TF voorkomt de normale remmende werking van TF op de PAR-2 bepaalde angiogenese, resulterend in een toegenomen celproliferatie. Door de beschikbaarheid van specifieke antilichamen is het nu mogelijk om selectief het factor VIIa-TF complex te remmen zonder de functie van activatie van bloedstolling te verstoren. Uiteindelijk kunnen dit soort antilichamen aanleiding geven tot de ontwikkeling van medicijnen die selectief angiogenese beïnvloeden in ziekten zoals diabetes of kanker. De toepassing bij complexe ziekten is nog ver weg, maar illustreert wel het mogelijke potentieel dat interventies op het niveau van de bloedstolling consequenties kunnen hebben op andere processen in het lichaam.

Aan het begin van de experimenten die hebben geleid tot dit proefschrift waren de hierboven genoemde interacties nog niet duidelijk. Het was wel bekend dat trombine, naast zijn functie om via PAR-4 bloedplaatjes te activeren, via vergelijkbare PAR interacties stimulerend op ontsteking en celmigratie werkt. Trombine is bekend als een veelzijdig enzym in de stollingscascade. Het wordt gezien als het belangrijkste molecuul in de bloedstolling, dat zowel factoren XI, V, en XIII kan activeren, maar ook fibrinogeen omzet in fibrine (onder thrombogene omstandigheden). In fysiologische situaties zal het meeste vrije trombine weggevangen worden door de endotheelreceptor trombomoduline (TM) en dit complex verzorgt op zijn beurt de omzetting van proteïne $C$ naar de geactiveerde vorm (APC). Onder omstandigheden zoals de gegeneraliseerde ontstekingsreactie bij sepsis kan trombomoduline negatief gereguleerd worden wat tot gevolg heeft dat minder trombomoduline-trombine complexen worden gevormd en er meer vrij trombine beschikbaar is, resulterend in een procoagulante status. De verminderde aanwezigheid van trombomoduline op de vaatwand is, behalve bij patiënten met sepsis, ook aanwezig bij patiënten met atherosclerose, wat er toe zou kunnen bijdragen dat de balans van anti- naar prothrombotisch overhelt. Daamaast veroorzaakt de toegenomen beschikbaarheid van trombine ontstekingsreacties via PAR-1, zoals is aangetoond in een model van "crescending" glomerulonefritis. In een model van ischemische hartziekte zorgt de inhibitie van trombine door hirudine voor een vermindering van de infarctomvang (vergelijkbaar met de afname waargenomen na remming van het factor VIIa-TF complex in dit model). De afname 
in infarctgrootte is zeer waarschijnlijk het gevolg van signaal overdracht door het factor VIIa-TF complex en trombine via respectievelijk PAR-2 en PAR-1. In modellen van sepsis lijkt het erop dat trombine deels verantwoordelijk is voor de regulatie van de verschillende ontstekingsreacties via PAR's, maar een duidelijke rol van de verschillende onderlinge PAR's is nog niet aangetoond.

Om de interacties tussen stollingsfactoren en PAR's te beïnvloeden zijn dezelfde moleculen van belang die in het lichaam zorgen voor remming van de bloedstolling. Hierbij is APC, door inhibitie van trombine generatie, een natuurlijke barrière tegen ongecontroleerde trombine productie en dientengevolge PAR activatie. Daarnaast remmen antitrombine, tissue factor pathway inhibitor (TFPI) en proteine $S$ de trombine generatie en/of activiteit elk op een andere manier. Dit is het meest duidelijk bij sepsis waarbij is aangetoond dat TFPI, APC en antitrombine elk de aan sepsis gerelateerde ontstekingsreactie kunnen verminderen, althans in dierexperimentele studies. Voor APC is een reductie van de mortaliteit als gevolg van sepsis aangetoond in een fase 3 klinisch onderzoek, de PROWESS studie.

De klinische consequenties van de hierboven beschreven mechanismen zijn grotendeels onbekend. Atherosclerose is geassocieerd met een toegenomen stollingsactiviteit in bloed. Dit is het meest uitgesproken in patiënten met gegeneraliseerd arterieel vaatlijden. Uit klinische studies zijn er aanwijzingen dat verhoging van specifieke stollingsmarkers, zoals D-dimeer fragmenten (een splitsingsproduct van fibrine), een voorspellende waarde hebben voor specifieke tromboembolische complicaties. Een vergelijkbare associatie is aangetoond voor CRP suggererend dat een situatie van chronische ontsteking en geactiveerde stolling een vergelijkbaar effect hebben op (progressie van) atherosclerose. Tegenstanders van deze theorie voeren aan dat verandering van markers van stolling eerder een afspiegeling zijn van een (toegenomen) atherosclerotische toestand dan een causale factor.

Een manier om deze kwestie op te helderen zou zijn door middel van gerichte interventie in de stolling teneinde vast te stellen of dit effect heeft op atherosclerose en op die manier zou kunnen leiden tot het verminderen van hart- en vaatziekte. Remming van trombine met melagatran laat in dierexperimentele studies een vermindering van atherosclerose zien en een afname op het risico dat een atherosclerotische plaque scheurt. Er zijn echter nog geen klinische studies die deze bevindingen ondersteunen. Experimentele studies geven aanwijzingen dat warfarine de hoeveelheid atherosclerose vermindert. Er zijn echter nog geen klinische bewijzen voor dit effect. Het is zelfs zo dat warfarine gebruik (of andere vitamine $\mathrm{K}$ antagonisten) geassocieerd is met een toegenomen verkalking (calcificatie) van arteriën en hartkleppen, ten gevolge van afgenomen carboxylatic van het vitamine $K$ afhankelijke matrix Gla eiwit. De mogelijke positieve effecten van warfarine in de vroege fase van atherosclerose lijken dus in een later stadium teniet gedaan te worden ten gevolge van de ongunstige effecten op het matrix Gla eiwit. 


\section{Bloedstolling in diabetes; Klinische studies}

De betrokkenheid van de bloedstolling in diabetes is in vele crossectionele studies onderzocht. In het algemeen laten deze studies een toestand van verhoogde stollingsactiviteit zien, gepaard gaande met veranderingen in concentraties aan stollingseiwitten, toegenomen (re)activiteit van bloedplaatjes en verminderde activiteit van fibrinolyse (onder andere het gevolg van toegenomen hoeveelheid plasminogeen activator inhibitor 1 (PAI-1)). Deze studies in acht genomen kan het volgende geconcludeerd worden:

a. De mate waarin bloedstolling aantoonbaar veranderd is wisselt per onderzoek; er is geen consistent beeld. In de door ons beschreven studie in hoofdstuk 2 vinden we geen duidelijke indicatie van een verhoogde algemene stollingsstatus bij diabetes, zoals gemeten met stollingsactivatie markers.

b. Er zijn wel sterke aanwijzingen voor hyperreactiviteit van bloedplaatjes bij patiënten met DM. Tevens lijkt hyperglycemie bij deze patiënten een causaal verband te hebben met plaatjesactiviteit, zoals gemeten door tromboxane B2 productie.

c. Er is duidelijk bewijs van verhoogde concentratie van PAI-1 plasma van patienten met DM-2, geassocieerd met lichaamsvetmassa en levervet depositie, echter een causaal verband tussen PAI-1 en atherotrombotische problematiek is nog niet aangetoond.

In hoofdstuk 2 hebben we een aantal stollingseiwitten en stollingsactivatie markers bestudeerd. Zoals eerder aangegeven zagen we geen bewijs voor een verhoogde stollingstoestand in onze populatie met DM-2. Hiervoor bestaat geen goede verklaring. Een factor zou kunnen zijn de beperkte mate van ontregeling van diabetes; in onze populatie was de bloedsuikerregulatie vrij redelijk (gemiddeld $\mathrm{HbA}_{1 \mathrm{c}} 7 \%$ ).

Wel hebben we een relatie kunnen aantonen tussen oplosbare TF concentraties en microvasculaire schade in dit patiëntencohort. De exacte waarde en oorsprong van het middels een commerciële bepaling gemeten oplosbaar TF is nog onduidelijk. Tissue factor is een membraamgebonden eiwit dat tot expressie word gebracht in verschillende celtypen die niet in direct contact staan met het bloed. Daarnaast is er een induceerbare fractie van TF welke vrij kan komen uit gestimuleerde monocyten in het bloed en welke wordt gereguleerd door endotoxine (LPS) gevoelige domeinen in de $\mathrm{TF}$ promotor (AP-1 en $\mathrm{NFkB}$ ). In patiënten met DM2 wordt het membraangebonden TF alleen gezien in micropartikels welke afkomstig zijn van mononucleaire cellen, granulocyten en voornamelijk bloedplaatjes. Het is nog onduidelijk in hoeverre de commercieel verkrijgbare $T F$ bepalingen ook TF dat aan micropartikels is gebonden meten of ook andere vormen zoals het alternatief gesplitste TF. 
Een van de routine procedures op een diabetes polikliniek in Nederland is het maken van een standaard electrocardiogram (ECG). Dit wordt gewoonlijk gebruikt om te beoordelen of er afwijkingen zijn in het geleidingsysteem van het hart en of er aanwijzingen zijn voor zogenaamde "stille" ischemie. In Hoofdstuk 3 laten wij zijn dat dit standaard ECG mogelijk meer informatie geeft met betrekking op verschillende cardiovasculaire complicaties van DM-2. De belangrijkste twee uitkomsten zijn dat in dit cohort het ECG relevante informatie geeft met betrekking tot de aanwezigheid van diabetische neurologische complicaties, hetgeen zich uit in een verlenging van het zogenaamde QTC interval, en dat bij patiënten die in verloop van een jaar na het afnemen van het ECG een macrovasculaire complicatie kregen het basale QRS interval verlengd was vergeleken met?? Deze bevindingen laten zien dat een routine ECG ook beoordeeld zal moeten worden met betrekking tot QTc en QRS intervallen, zodat patiënten bijvoorbeeld eerder verwezen kunnen worden naar een cardioloog vanwege hun verhoogd risico op macrovasculaire complicaties. Natuurlijk is hiervoor wel nodig dat er duidelijke cut-off waarden worden. geïdentificeerd welke helaas uit dit kleine cohort niet kunnen worden afgeleid. Met betrekking tot de bloedstolling was de verwachting dat eventuele geleidingsstoornissen van het hart mogelijk mede zouden kunnen worden veroorzaakt door microvasculaire schade of door chronische ischemie. In deze studie bleek dat van de geteste factoren soluble TF de enige determinant was die een statistisch significante relatie had met de QRS duur (hoofdstuk 3, tabel 2).

Terwijl in deze analyse QRS duur een marker was van macrovasculaire complicaties en soluble TF een marker van microvasculaire complicaties moeten we ons afvragen hoe deze resultaten met elkaar in overeenstemming zijn.

Natuurlijk kan toeval een rol spelen in statistische analyses, maar men zou ook kunnen zeggen dat het geleidingseffect dat leidt tot QRS duur verlenging een uiting is van microvasculaire ziekte van het hart. Dit laatste zou dan ook een reden kunnen zijn voor de slechtere prognose voor patiënten met DM-2 na een myocardinfarct.

In dit diabetes cohort hebben we nog twee potentiële markers voor vasculaire schade onderzocht. De AGE's $N$-(carboxymethyl)lysine (CML) en N (carboxyethyl)lysine (CEL) zijn bekende producten van de zogenaamde oxidatieve modificatie van versuikerde eiwitten. Deze kunnen worden aangetoond in het serum en zijn geassocieerd met door diabetes veroorzaakte hart- en vaatziekten. In hoofdstuk 4 zijn serum en urine concentraties van CML en CEL bestudeerd in ons diabetes cohort. We vonden geen significante relaties tussen urine en plasma concentraties van deze twee AGE's, hetgeen suggereerd dat de urine fractie niet een simpele afspiegeling is van de plasma fractie. Wel bestond er een statistisch significante verband met soluble TF hetgeen een rol van AGE's bij microvasculaire complicaties ondersteunt. 
Als laatste "nieuwe" marker hebben we de rol van het vitamine $\mathrm{K}$ afhankelijke matrix Gla-eiwit (MGP) bestudeerd. Onze hypothese was dat de bloed concentraties van dit eiwit gerelateerd zouden kunnen zijn met vasculaire ziekte, daar er relaties zijn aangetoond tussen MGP en arteriële calcificatie. Hierbij komt dat er voldoende aanwijzingen zijn dat arteriële calcificatie, of vaatstijfheid, geassocieerd zijn met een verhoogd risico op cardiovasculaire ziekten. Hoofdstuk 5 laat zien dat de plasma Glu MGP concentraties een significante relatie hebben met vaatstijfheid (zoals geschat door de pols-druk). Lagere Glu MGP niveaus in het bloed blijken geassocieerd te zijn met de aanwezigheid van microvasculaire complicaties en vooral met diabetische nefropathie. Verder bleken de niveaus van Glu MGP ook negatief geassocieerd met leeftijd en soluble $\mathrm{TF}$, maar de pathofysiologische waarde van deze associaties blijft onduidelijk.

\section{Muizen modellen van bloedstolling en de effecten van diabetes (hyperglycemie)}

In hoofdstuk 6 wordt een kort overzicht gegeven van verschillende muizen modellen van arteriële trombose dat laat zien dat deze verschillende muizen modellen fundamentele kennis hebben bijgedragen over de rol van individuele eiwitten in het ontstaan van arteriële thrombi.

Als we ons afvragen wat het effect is van diabetes op het ontstaan van arteriële trombose moeten ten minste twee belangrijke kenmerken worden onderscheiden: de factor hyperglycemie en factoren geassocieerd met het metabole syndroom. De effecten van hyperglycemie op thrombus vorming hebben we bestudeerd in hoofdstuk 7, waarin we laten we zien dat de tijd waarna een thrombus ontstaat na initiële vaatwandbeschadiging niet beïnvloed wordt door hyperglycemie, maar de snelheid waarmee een afsluitende thrombus groeit na initiatie wel toegenomen is in een hyperglycemische omgeving. $\operatorname{Er}$ was geen verschil aantoonbaar in thrombogeniciteit van de vaatwanden van de verschillende muizen (dwz. vergelijkbare hoeveelheden TF mRNA en immunohistochemisch TF signaal), maar de trombine productie in plasma zoals gemeten door de aanwezigheid van trombineantitrombine complexen was wel verhoogd onder hyperglycemische omstandigheden. Ook de door bloedplaatjes gemedieerde trombine generatie was aanzienlijk verhoogd in vergelijking met de niet hyperglycemische bloedplaatjes. Deze data zijn in overeenstemming met de beschreven relaties tussen bloed glucoseregulatie in patiënten met diabetes en hun bloedplaatjes activiteit zoals gemeten door thromboxane B2 productie. Zoals eerder gezegd hebben we geen aanwijzingen gevonden van substantiële veranderingen in stollingsactivatie in patiënten met DM-2 and er zijn geen diermodellen die een invloed van diabetes op trombine generatie laten zien ten gevolge van veranderingen in stollingseiwit concentraties of activiteit. 
Hoe helpen deze data de verschillende klinische bevindingen bij patiënten met diabetes helpen te verklaren?

In patiënten met DM-2 zijn de meest duidelijke afwijkingen in de bloedstolling de verhoogde reactiviteit van de bloedplaatjes functie, mogelijk verhoogde reactiviteit van de stolingsfactoren die de trombinegeneratie aansturen (hoewel de data met betrekking hierop niet consistent zijn) en verminderde fibrinolyse ten gevolge van verhoogde PAI-1 concentraties.

De muizen studies dragen bij tot een beter inzicht in de rol van bloedplaatjes bij het ontstaan van trombose, ook in hyperglycemische condities en vormen een basis voor eventuele therapeutische interventies in die patiënten met het hoogste risico op arteriële trombose. De rol van stollingsfactoren en/of hun natuurlijke remmers is nog niet duidelijk, maar de beschikbare data laten niet een duidelijk verschil zien tussen diabeten en niet-diabeten in termen van TF afhankelijke trombine generatie. Of specieke stollingseiwitten zoals factor XII een veranderde rol hebben bij diabetes is nog onduidelijk.

Wat betreft de fibrinolyse laten klinische studies geen duidelijk verband zien tussen de verhoogde PAI-1 concentraties in het bloed en veranderingen in het cardiovasculaire risico in de populatie. Dit ondanks duidelijke relaties tussen insuline-resistentie en PAI-1 geproduceerd in adipocyten en lever enerzijds en PAI-1 concentraties in de circulatie anderzijds. Een extra aandachtspunt is verder dat bij patiënten met diabetes de fibrinestolsel structuur beter bestand lijkt tegen afbraak dan van stolsels bij niet- diabeten, hetgeen mogelijk veroorzaakt zou kunnen worden door directe invloed van hyperglycemie op de fibrine structuur (polymerisatie).

\section{Bloedstolling: een directe rol in orgaanschade?}

Zoals hierboven aangegeven zijn bloedstollingseiwitten via de activatie van PARs betrokken bij een reeks van processen die niet gerelateerd zijn met de fibrinevorming. In dit licht moet de activiteit van het stollingssysteem naast regulator van onstekingsmechanismen gezien worden als een afweermechanisme dat onderdeel is van de aangeboren immuniteit. Bij sepsis is de betrokkenheid van de bloedstolling duidelijk beschreven en de experimenten zoals beschreven in hoofdstuk 8 laten hierbij verschillende orgaan specifieke reacties zien al gevolg van endotoxine toediening aan muizen.

Doormiddel van in situ hybridisatie in combinatie met eiwit kleuringen hebben we de expressie van TF in muizen organen bestudeerd. TF expressie was maximaal in de nieren en longen 6 uur na endotoxine toediening. In de nieren was met name de regio van de tubulus epitheelcellen betrokken bij TF productie, terwijl in de glomeruli geen $\mathrm{TF}$ productie werd gezien. Dit patroon van TF productie werd ook 
gezien in verdere experimenten waarbij naar de rol van hyperglycemie op TF productie in de nieren werd gekeken. De functie van dit lokaal geproduceerde TF is nog onduidelijk, maar het zou mogelijk een rol kunnen hebben in ontstekingsreacties. De lokale productie van TF zou ook kunnen bijdragen aan een procoagulant fenotype en de vondst van fibrine deposities in het vaatbed van de nier is een mogelijke consequentie hiervan. Fibrine zou een indicatie kunnen zijn van een toestand van (chronische) ontsteking van de nier en is in proefdier modellen een onderdeel van diabetische nefropatie (hoofdstuk 9).

Om de pathofysiologische rol van trombine en fibrine in de nieren te bestuderen hebben we de rol van selectieve trombine inhibitie ( $\mathrm{dmv}$ ximelagatran) bestudeerd in een hyperglycemisch muizen model (hoofdstuk 9). Ondanks effectieve antistolling (zoals gemeten met stoltijden) hebben we helaas geen effect gezien op de histologische score van nefropatie in de verschillende muizen groepen. Verassend genoeg was er ook geen verschil waarneembaar in de hoeveelheden fibrine depositie in de nier, mogelijk verklaard doordat lokaal gegenereerd fibrine niet goed geremd wordt door systemisch toegediende ximelagatran.

\section{Conclusies met betrekking tot de afwijkingen in de bloedstolling bij diabetes en de relevantie hiervan voor patiënten met diabetes anno 2006}

Onze klinische studies laten zien dat DM-2 een ernstige aandoening is welke gekenmerkt word door een belangrijke mate van cardiovasculaire complicaties in een cohort van patiënten met een gemiddelde diabetes duur van 7 jaar. Tevens is er een relatief groot aantal nieuwe complicaties na 1 jaar, hetgeen het belang van een goede risico inventarisatie en aanpassing van therapie in deze groep ondersteunt. Als we ons afvragen wat gedaan kan worden om de hoeveelheid cardiovasculaire compilaties te verminderen moeten we ten eerste een ieder die betrokken is bij de zorg van diabeten ervan doordringen dat DM-2 een serieuze ziekte is, welke strikte aandacht behoeft op het gebied van voorlichting aan patiënten met betrekking tot behandeling en risicofactor reductie. Relatief simpele diagnostische instrumenten zoals een standaard ECG afleiding en urine analyse op microalbumine zouden moeten worden toegevoegd in de risico factor analyse. Multidisciplinaire ondersteuning vanaf het moment van de initiële diagnose is noodzakelijk, inclusief begeleiding door een diëtist, goede voetverzorging, analyse van alle relevante risicofactoren door de huisarts en training van patiënten in het juiste gebruik van medicatie. Specifieke bekende cardiovasculaire risicofactoren zoals overgewicht, hoge bloeddruk of dyslipidemie moeten worden behandeld zonder vertraging. In het grootse deel van de patiënten zal dit betekenen dat er een "statine" en bloeddruk verlagende medicatie zal worden voorgeschreven bovenop de medicijnen die nodig zijn voor de behandeling van de diabetes. Met betrekking tot de bloedstolling zijn de medicatie adviezen nog erg beperkt. De recente CBO consensus voor 
cardiovasculair risicomanagement adviseert niet tot primaire preventie middels aspirine in patiënten met diabetes, terwijl het gebruik van aspirine bij secondaire preventie bij zowel diabetes als niet-diabetes patiënten gemeengoed is. De American Diabetes Association adviseert het gebruik van aspirine bij patiënten met diabetes en een geschiedenis van cardiovasculaire ziekten, maar ook als primaire preventie bij diabetes type 1 of 2 met additionele cardiovasculaire risicofactoren. De grote hoeveelheid cardiovasculaire complicaties bij DM-2 en het relatief lage risico van het gebruik van een lage dosis aspirine is volgens ons een reden om het advies van de American Diabetes Association te onderschrijven.

Of preventieve therapie met aspirine gecombineerd moet worden met andere bloedplaatjes remmers zoals clopidogrel is onduidelijk. De enige combinatie therapie die onderzocht is, is die van aspirine en clopidogrel. Ondanks dat deze niet specifiek is onderzocht in een diabetes populatie, heeft de subgroep analyse van de Charisma studie geen toegevoegd effect laten zien van de combinatie in de diabetes subgroep.

Het is interessant te zien dat de remming van glycoproteine IIb/IIIa op bloedplaatjes gedurende percutane coronaire interventies meer effectief is bij patiënten met diabetes dan bij individuen zonder diabetes. De volgende zin moet je verduidelijken, snap ik niet. Theoretisch zou interventie in combinatie met GPIIb/IIIa remmers meer effectief zijn dan met aspirine alleen, maar alle trials tot op heden met GPIIb/IIla remmers zijn zonder resultaat, en er worden dan ook op dit moment geen medicijnen ontwikkeld met dit target.

Met betrekking tot de stolling en de fibrinolyse zijn er geen specifieke medicijnen die hun effectiviteit hebben bewezen in de preventie van cardiovasculaire complicaties in diabetes. Gegeven het ontbreken van een duidelijke rol van verstoorde bloedstolling of fibrinolyse op de atherothrombose in diabetes, zal de focus van medicamenteuze interventies vooral gericht blijven op bloedplaatjes.

Wel zullen er in de toekomst nieuwe mogelijkheden komen om ontsteking- en angiogenese afhankelijke orgaanpathologie te beïnvloeden met gebruik van selectieve remmers van het factor VIIa/TF complex, of trombine-PAR interacties. De ontwikkeling van specifieke antilichamen tegen de extracellulaire domeinen van TF die betrokken zijn in de switch tussen stolling en signaaltransductie opent ook een weg naar zeer selectieve beïnvloeding van het imuumsysteem.

Complicaties veroorzaakt door overmatige angiogenese bij patiënten met DM-2, zoals retinopathie, zouden verminderd kunnen worden door (locale?) blokkade van factor VIla/TF. Nefropathie is, zoals we hebben laten zien, niet eenvoudig te verminderen door toediening van een reversibele trombineremmer, maar de waargenomen positieve effecten van PAR-1\% in experimentele glomerulonefritis laten zien dat sommige vormen van nefropathie wel gunstig beinvloed kunnen worden door modificatie van trombine-PAR-1 interacties. 
Terwijl de kennis met betrekking tot de interacties tussen bloedstollingseiwitten richting niet-stollings gerelateerde processen in complexe ziekten nog steeds toeneemt, zou men kunnen verwachten dat verder onderzoek naar de rol van de bloedstolling een belangrijke plaats zal innemen in diabetes onderzoek. 


\section{Curriculum vitae}

Hjalmar Hansen werd op 13 februari 1973 geboren te Amsterdam. In 1991 behaaide hij het VWO diploma aan het Rijksscholen Gemeenschap te Hoorn. Aansluitend werd gestart met de studie medische biologie aan de Universiteit van Amsterdam. In 1993 werd ook gestart met de studie geneeskunde aan de zelfde universiteit. Tijdens zijn studie is hij ruim 2 jaar in perioden betrokken geweest bij onderzoek van de vakgroep Experimentele Anestesiologie naar onder andere methoden om de toestand van de microvasculaire doorbloeding van organen te kunnen monitoren. Het doctoraal examen voor medische biologie werd in 1996 behaald en het doctoraal voor geneeskunde volgde in 1998, waarna in 2000 het artsen diploma werd behaald.

In 2001 is hij begonnen met zijn werk als artsonderzoeker aan het laboratorium voor Experimentele Inwendige Geneeskunde op het Academisch Medisch Centrum te Amsterdam onder leiding van Prof. Dr. H. ten Cate en Prof. Dr. P. Reitsma. Een groot deel van de werkzaamheden heeft zich uiteindelijk afgespeeld in Maastricht alwaar Prof. Dr. H. ten Cate een aanstelling kreeg. Gedurende deze periode heeft hij ook gewerkt als arts op de diabetespolikliniek in her Slotervaartziekenhuis. 


\section{Publications}

Meesters EW, Hansen HR, Spronk HM, Hamulyak K, Rosing J, Rowshani AT, ten Berge IJ, ten Cate $\mathrm{H}$. The inflammation and coagulation crosstalk in patients with Systemic Lupus Erythematosus. Blood Coagulation and Fibrinolysis. Blood. Coagulation and Fibrinolysis 2007, 18:21-28.

Hansen HR, Sommeijer DW, van Oerle R, Hamulyak K, van Zanten AP, Meesters E, Spronk HM, ten Cate H. Soluble tissue factor is a candidate marker for progression of microvascular disease in patients with Type 2 diabetes. $J$ Thromb Haemost. 2006; 4(3): 574-80.

de Waard V, Hansen HR, Spronk HM, Timmerman JJ, Pannekoek H, Florquin S, Reitsma PH, ten Cate H. Differential expression of tissue factor mRNA and protein expression in murine sepsis. The role of the granulocyte revisited. Thromb Haemost. 2006; 95(2): 348-53.

Hansen HR, ten Cate H. Lessons from mouse models for arterial thrombosis: does clotting make a difference in human cardiovascular disease? Chapter in The Physiological Genomics of the Critically Ill Mouse. Ed. Can Ince, Kluwer Academic Publishers, Norwell, MA (2004).

Hansen HR, ten Holt WL, Meesters EW, Spronk HM, Reitsma PH, ten Cate H. The prognostic significance of QRS and QTc interval prolongation in a Dutch type-2 diabetes population. Diabetic Medicine. Submitted 2007.

Hansen HR, Jef L. Wolfs JL, Sommeijer DW, Bevers E, Hauer AD, Kuiper J, Spronk HM, Reitsma PH, ten Cate H. Hyperglycemia accelerates arterial thrombus formation in vivo. J Thromb Haemost. Submitted 2006. 


\section{Dankwoord}

Ook mij rest nu niets anders dan een begin te maken aan het meest gelezen deel van het hier voor $u$ liggend boekwerkje.

Het is zoals velen voor mij reeds hebben opgemerkt, en even zo velen na mij dit ook zullen doen geen eenvoudige taak om een dankwoord te schrijven dat moet samenvatten wie je hoeveel dank verschuldigd bent in de lange weg die promoveren heet. $\mathrm{Na}$ besluit om het dank woord in een korte en bondige vorm te gieten ben ik al gelijk aangekomen op het probleem van wie als eerste te bedanken.

Natuurlijk denk ik dan gelijk aan Prof. Dr. Hugo ten Cate, door wiens voortdurend enthousiasme ik meer dan eens ben meegesleept. Alle ups en downs in mijn humeur die je maar te verwerken kreeg, het begeleiden op afstand en toen dat moeizaam bleek de knoop doorhakken en mij parttime naar Maastricht te halen. Hij moet dit eerste bedankje maar delen met Dr. Henri Spronk, zonder hem had ik dit proefschrift zeker nooit tot een daadwerkelijk einde gebracht. Het is nog steeds voor mij ontzettend bijzonder hoe ik in letterlijk en figuurlijk in een bedje van Limburgse gastvrijheid terecht ben gekomen. Jullie beiden hebben uit mij toch een onderzoeker te voorschijn kunnen halen. Ik ga er van uit dat ik jullie beide nog meer dan eens zal ontmoeten in de komende jaren, zowel in verband met gezamenlijke wetenschappelijke interesses als in het kader van de gedeelde liefde voor het goede leven.

Hierna wil ik graag alle vrienden bedanken die me de afgelopen jaren op verschillende momenten en in verschillende toestanden van bewustzijn hebben meegemaakt. Natuurlijk Mark Fidler, onze eeuwige student, je stond altijd voor mij klaar voor de broodnodige afleiding. Sander Dinant, ik ben blij dat ik in dit geval in je voetsporen mag treden. Stefan Hoskens, aangewaaid maatje om nooit meer kwijt te raken. Herrie Heckman, klimmaatje extra-ordinaire, we gaan spoedig weer ergens (tropisch?) klimmetjes doen. Groot voorstander van "happy-hours" op de mooiste onbereikbare locaties, Dick van Vegchelen; wat hebben we mooie avonturen beleefd in de alpenl Radjin Steingröver, helaas door drukte momenteel wat weinig contact maar toch, dank je. En natuurlijk heb ik ook erg prettige herinneringen aan onze bootweekendjes en borrelavondjes met Glen, Ronne, Boris en natuurlijk Johan (mooie tijd als huisgenoot).

A short part in English to say thanks to my brother from different parents, Leigh we both know it was a strange coincidence to meet in a bar in Bangkok ("you must be Dutch, you smoke small cigars") and that after that I never left your life. In the time we spent together you have become an inspiration and a very dear friend. 
En als de vrienden bedankt worden wil ik natuurlijk ook Lek bedanken voor de wonderlijke tijd die we samen hebben doorgebracht. Ik heb je ontvoerd uit een ver warm land, we hebben een explosieve relatie gehad en nu een zeer hechte vriendschap, ik weet zeker dat je nog een lange tijd een speciale plek in mijn hart zult hebben.

Nu ontkom ik ook niet aan een opsomming van bedankjes aan mensen die op de een of andere manier hebben bijgedragen aan dit proefschrift.

In Amsterdam:

Prof. Dr. P.H. Reitsma, promotor en stille kracht van afstand, bedankt voor de nuttige commentaren op stukjes.

Dirkje en Martijn, mijn twee meest directe collega's en partners in crime in de carotis proeven, ik heb een leuke tijd met jullie gehad.

Hella en Angelique, bedankt voor jullie hulp bij de HAVANA studie en de rustige uitleg op mijn vragen. Joost en Ingvild, ik wil jullie bedanken bij de begeleiding van de muizenexperimenten en de mogelijkheden om altijd te mogen oefenen.

Natuurlijk als ik aan mijn AMC tijd denk moet ik ook aan Arnold Spek denken, eeuwige rust uitstralend, altijd klaar met een luisterend oor, en ook aan de bar een gezellige collega.

De rest van de collega's uit het AMC wil ik ook graag via deze manier bedanken, als we elkaar tegenkomen op congres mag je mopperen dat je niet persoonlijk genoemd bent, maar bij deze toch ontzettend bedankt.

In het Slotervaartziekenhuis heb ik voor het verzamelen van data voor de HAVANA veel hulp gehad aan Yvonne van der Heide voor het verwerken van de bloedsamples en van Olga en Monique voor jullie hulp bij de gegevensverzameling.

Als arts diabetespolikliniek ben ik met veel knuffels begeleid door Eelco Meesters, en heb ook met veel plezier samengewerkt met de diabetes verpleegkundigen Fatima en Wilma. Natuurlijk had ik nooit zo lekker poli kunnen draaien zonder de ondersteuning van alle polisecretaresses.

In het kader van de HAVANA studie zijn handmatig enkele honderden ECG's beoordeeld door cardioloog Wik ten Holt, waardoor we samen een leuk stukje hebben kunnen schrijven, nu nog weten te publiceren.

De collega's van de klinische chemie in het VU ziekenhuis (o.a. Rob Barto) hebben ons geholpen met bepalingen van AGE's in de urine van diabetes patiënten.

In Maastricht:

Henri en Hugo, ik had jullie al gehad, maar een tweede keer kan geen kwaad. Nogmaals bedankt voor de leuke, niet altijd even makkelijke, leerzame en inspirerende tijd.

Kim, bijzonder leuke tijd met je gehad, samen het bed gedeeld waarvoor nog mijn dank, en hopelijk ben jij de volgende in het rijtje van promovendi. 
Machiel en Arne, twee arts onderzoekers van het "die-hard" formaat, heb ook bij jullie een goede tijd op de kamer gehad, en erg veel plezier op de verschillende congressen, heel veel succes met jullie studies. Sara, niet bij je op de kamer gezeten, maar wel veel gezelligheid, zowel op de werkvloer als op onze buitenlandse trips. Karly Hamulyak ook jij bedankt voor de input tijdens de werkbesprekingen en je visie op de verschillende onderzoekjes.

Natuurlijk wil ik ook José bedanken voor haar laboratorium ondersteuning, maar zeker zonder René van Oerle en Diane Fens had dit project ook niet tot een geslaagd einde gebracht kunnen worden. Nog meer samples doormeten is voor René zelden een probleem gebleken.

Bij de muizenexperimenten in Maastricht werden we kundig ondersteund door Agnieska en Peter. Voor de MGP metingen heb ik dankbaar gebruik kunnen maken van de expertise van Leon Schürgers. Verder heb ik met plezier ook samengewerkt met Sjef Wolfs en Eduard Bevers gedurende de bloedplaatjes experimenten. Voor het beoordelen van de coupes van muizen niertjes wil ik Carina Peutz bedanken.

Het Maastrichtse deel afsluiten zonder een groot compliment voor Jessica Duckers kan niet, ik wil je dan ook ontzettend bedanken voor je gastvrijheid, nog erg veel geluk toegewenst de komende jaren met je 2 mannen Henri en Max.

$\mathrm{Nu}$ is het dankwoord bijna tot een einde gekomen, maar als laatste wil ik nog mijn ouders Hans en Loes bedanken, jullie hebben echt geen idee hoe goed onvoorwaardelijke steun aanvoelt en dat jullie daarbij ook nog een rol als echte vrienden kunnen vervullen. Ondanks al mijn wonderlijke avonturen uit het verleden (en de vele die gegarandeerd nog zullen volgen) blijven jullie vertrouwen hebben in een goede afloop, wat deze afloop ook zal zijn. Ik hoop dat onze vriendschap op deze manier nog jaren mag blijven bestaan.

So long, and thanks for the fish. 